\author{
UNiversidade de SÃo PaUlo \\ ESCOLA DE ENGENHARIA DE SÃo CARLOS \\ DEPARTAMENTO DE ENGENHARIA ELÉTRICA
}

\title{
Esforço do Ombro na Locomoção de Pacientes \\ Paraplégicos: Avaliação Cinética e ELETROMIOGRÁFICA.
}

Rodrigo Lício Ortolan 


\section{RODRIGO LÍCIO ORTOLAN}

\section{ESFORÇO dO OMBRO NA LOCOMOÇÃo de PACIENTES \\ Paraplégicos: Avaliação Cinética e \\ ELETROMIOGRÁFICA.}

Tese apresentada à Escola de Engenharia de São Carlos da Universidade de São Paulo, como parte dos requisitos para obtenção do título de Doutor em Engenharia Elétrica.

Área de Concentração: Eng. de Reabilitação Orientador: Prof. Dr. Alberto Cliquet Jr. 
AUTORIZO A REPRODUÇÃO E DIVULGAÇÃO TOTAL OU PARCIAL DESTE TRABALHO, POR QUALQUER MEIO CONVENCIONAL OU ELETRÔNICO, PARA FINS DE ESTUDO E PESQUISA, DESDE QUE CITADA A FONTE.

Ficha catalográfica preparada pela Seção de Tratamento da Informação do Serviço de Biblioteca - EESC/USP

Ortelan, Rodrigo Lício
Esforço do ombro na locomoção de pacientes
paraplégicos: avaliação cinética e eletromiográfica /
Rodrigo Lício Ortolan ; orientador Alberto
Cliquet Jr. -- São Carlos, 2007.
Tese (Doutorado-Programa de Pós-Graduação em
Engenharia Elétrica e Área de Concentraça em Engenharia
de Reabilitaça) -- Escola de Engenharia de São Carlos da
Universidade de São Paulo, 2007.
1. Medula espinhal - lesões. 2. Marcha. 3. Cinética.
4. Eletromiografia (EMG). 5. Engenharia de reabilitação.
6. Articulação do ombro. 7. Estimulação elétrica neuro-
muscular (EENM). 8. Andador. I. Título.


Candidato: Engenheiro RODRIGO LÍCIO ORTOLAN

Tese defendida e julgada em 05/07/2007 perante a Comissão Julgadora:

$\frac{2 C G \& \text { Chjel }}{\text { Prof. Titular ALBERTO CLIQUET JUNIOR (Orientador) }}$

apswodo

(Escola de Engenharia de São Carlos/USP)

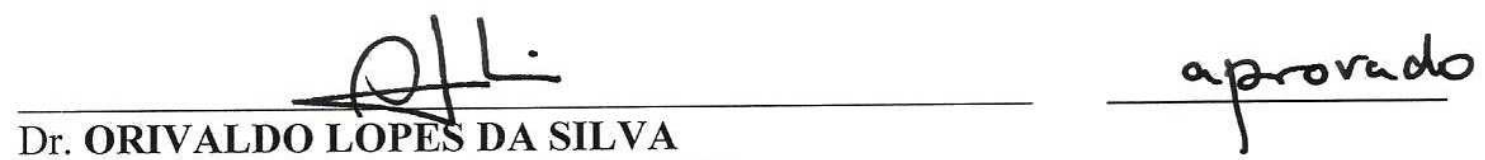

(Escola de Engenharia de São Carlos/USP)

Paule therde cole aprovedo Prof ${ }^{\mathrm{a}}$. Dr ${ }^{\mathrm{a}}$. PAULA HENTSCHEL LOBO DA COSTA

(Universidade Federal de São Carlos/UFSCar)

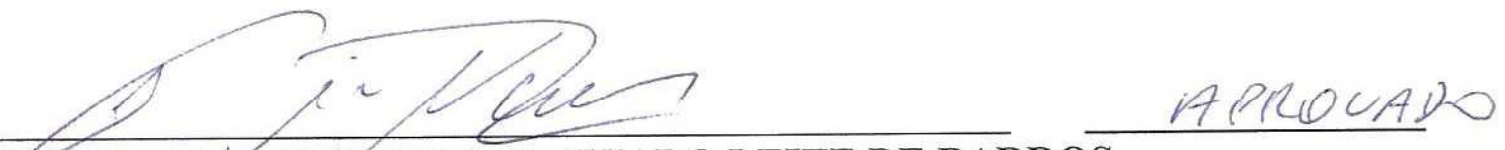

Prof. Associado RICARDO MACHADO LEITE DE BARROS

(Universidade Estadual de Campinas/UNICAMP)

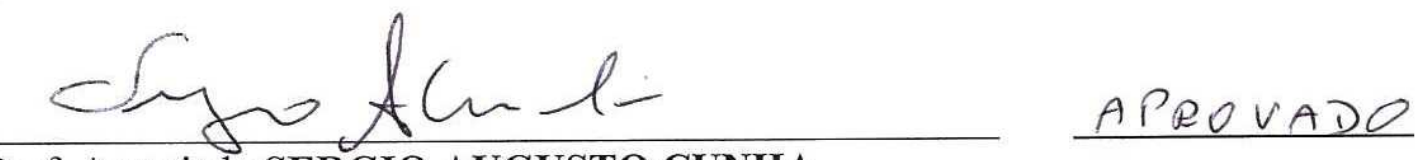

Prof. Associado SERGIO AUGUSTO CUNHA

(Universidade Estadual de Campinas/UNICAMP)

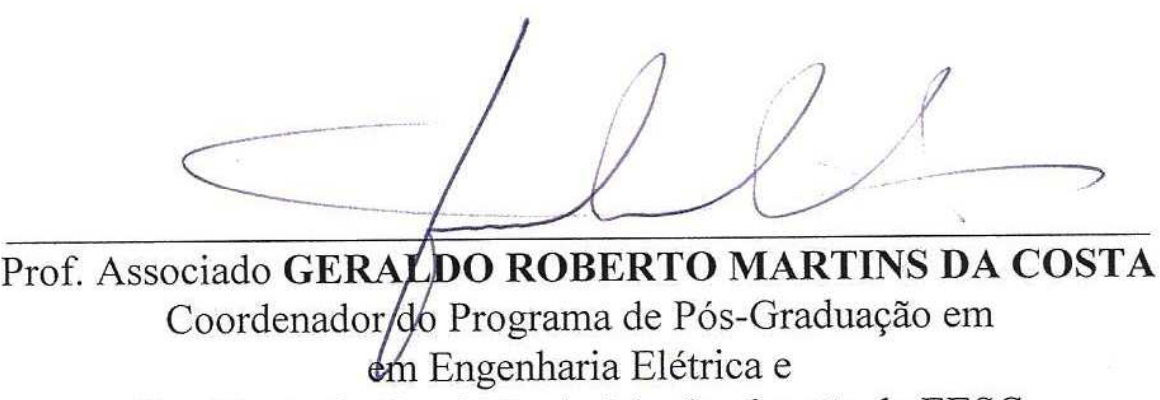

Presidente da Comissão de Pós-Graduação da EESC 


\section{DEDICATÓRIA}

"Nunca se vence uma guerra lutando sozinho, você sabe que a gente precisa entrar em contato. Com toda essa força contida que vive guardada, o eco de suas palavras não repercute em nada.

É sempre mais fácil achar que a culpa é do outro, evita o aperto de mão de um possível aliado. Convence as paredes do quarto e dorme tranquilo, sabendo no fundo do peito que não era nada daquilo.

Coragem... coragem... se o que você quer é aquilo que pensa e faz.

Coragem... coragem... eu sei que você pode mais...”

Raul Santos Seixas Por quem os sinos dobram (1979)

Dedico aos meus pais que sempre me incentivaram a estudar e trabalhar honestamente, e a Beatriz por todo carinho e pelo incondicional apoio e compreensão. 


\section{Agradecimentos}

Este trabalho não seria possível sem a valiosa contribuição de várias pessoas, às quais expresso minha sincera gratidão:

Aos meus pais, Roberto e Suzana pela incansável tarefa de transmitir os bons valores aos seus filhos, além da oportunidade de estudar e do total apoio e incentivo. Aos meus irmãos Carolina e Danilo pela contagiante alegria, pela convivência e todo carinho. Mesmo de longe a lembrança de vocês me fortalece.

À Beatriz pelo sorriso, carinho, força e compreensão sempre presentes, pela sua incansável ajuda, e também por estar sempre ao meu lado me apoiando e incentivando em minhas investidas. Essa mulher guerreira (mãe dos filhos que ainda vou ter) consegue cativar a todos com sua alegria, humildade e simpatia.

Ao professor Dr. Alberto Cliquet Jr. pela orientação durante a elaboração deste trabalho e principalmente pela experiência (tanto pessoal quanto profissional) que tive oportunidade de adquirir durante este período.

Ao professor Dr. Orivaldo Lopes da Silva, da Bioengenharia (Interunidades/USP) pelas incansáveis conversas e pelas valiosas contribuições nas dúvidas esclarecidas, além da sua boa vontade e atenção sempre presente.

Aos companheiros do LABCIBER, principalmente ao Renato Varoto pela convivência diária, pelas conversas e companheirismo. Aos fisioterapeutas do Laboratório de Biomecânica e Reabilitação do Aparelho Locomotor (HC/UNICAMP), especialmente aos amigos Ênio Walker A. Cacho e Roberta Oliveira pelo auxílio nas coletas, pela oportunidade da troca de informações e os trabalhos realizados em conjunto, espero que possamos continuar com este intercâmbio.

Aos funcionários do Departamento de Engenharia Elétrica da EESC/USP em especial à Marisa, Denise, Xaraba, Zé Carlos e Jussara pela atenção, organização e eficiência nos serviços prestados. Aos técnicos Alex, Alessandro, Rui Bertho, Gerson e Roseli pelo companheirismo, manutenção dos equipamentos e auxílios prestados.

Aos grandes amigos, ex-integrantes da República dos "Cachassauros Largados", (Engenheiros: Maru, Bicudo, Spin, Fernandinho, Velinho, Tonho, Sardinha e Verô), pelos momentos (etílicos ou não) de companhia, descontração e cumplicidade. 
Aos amigos da graduação pelas lembranças e a amizade revigorada a cada ano.

Aos amigos Mineiro, Buda, Velinho, Prof. Dennis, e demais integrantes do BECCC (Bando de Expressão Cômico Cultural do CAASO) pela investidas realizadas tanto na "dramaturgia" quanto com a banda de paródias; estes momentos serão inesquecíveis.

Ao Mestre Benigno Alonso Gomez pelo companheirismo e a constante disposição em me ajudar.

Aos Profs. Drs. Américo Zoppi Filho, Orivaldo Lopes da Silva, Paula Hentschel Lobo da Costa, Sergio Augusto Cunha e Ricardo Machado Leite de Barros por aceitarem o convite para participar das bancas de qualificação e defesa, pelos comentários e sugestões a este trabalho.

Aos pacientes do HC da UNICAMP, que participaram voluntariamente da fase experimental do trabalho, pela disposição, paciência e exemplo de vida. À minha avó Carmem que me recebeu de braços abertos em sua casa em Campinas durante os meses de coleta no HC da UNICAMP e sempre carinhosamente preocupada. Aos parentes e amigos que participaram nos testes preliminares (Beatriz, Velinho, Ana, Bicudo, Karina, Danilo e Felipe).

À família Gatti pela calorosa acolhida e constante apoio e confiança.

Aos parentes mais distantes, que nem sempre podem se fazer presentes, mas sempre torcem por mim; lembro frequentemente com muito carinho de todos vocês.

Às Faculdades Integradas de Araraquara (Logatti) e aos seus alunos de engenharia elétrica do $4^{\circ}$ e $5^{\circ}$ anos pela oportunidade de aplicar na prática a recompensante tarefa da docência durante o ano de 2007.

À Fundação Coordenação de Aperfeiçoamento de Pessoal de Nível Superior (CAPES), pela bolsa concedida e à Fundação de Amparo à Pesquisa do Estado de São Paulo (FAPESP) pelo financiamento do projeto 96/12198-2. Agradeço ainda à Bolsa PAI e Bolsa ESPOSA concedidas durante o último ano do doutorado.

A Deus por todas as oportunidades que me foram apresentadas até hoje. Ao Raul Seixas e ao Pink Floyd que, com suas obras imortais, sempre me fizeram companhia, mesmo nas longas madrugadas atravessadas dentro do laboratório. Fato este que me levou a usar textos do Raul Seixas nas epígrafes dos capítulos da tese.

Enfim sou imensamente grato a minha família, amigos e todos aqueles que contribuíram anonimamente na realização deste trabalho. 


\section{SUMÁRIO}

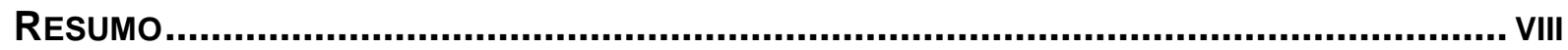

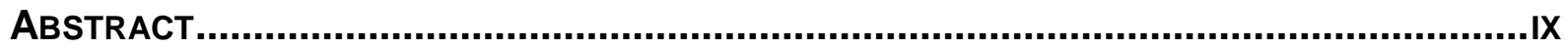

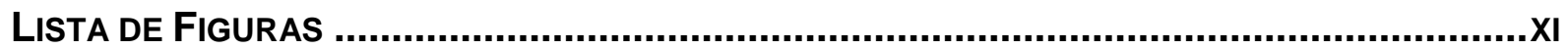

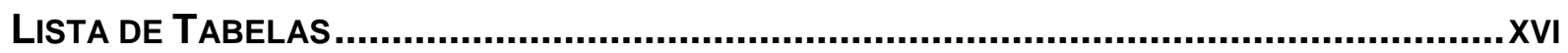

ABREVIAÇÕES, SigLAS E TERMOS TÉCNICOS.......................................................... XVIII

\begin{tabular}{lr} 
PREFÁCIO & 19 \\
\hline INTRODUCAO
\end{tabular}

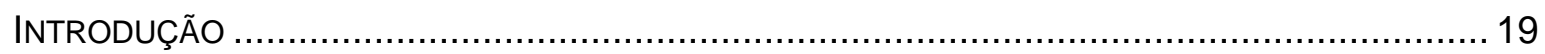

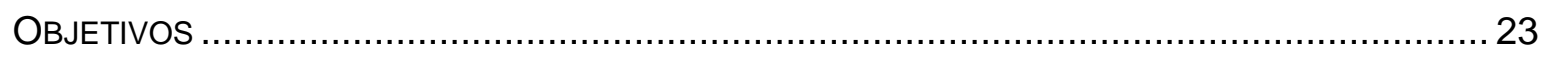

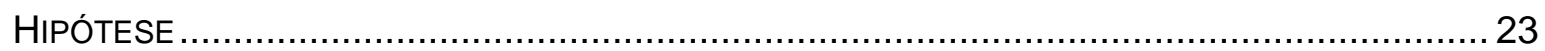

CAPÍTULO1 25

REVISÃo BIBLIOGRÁFICA

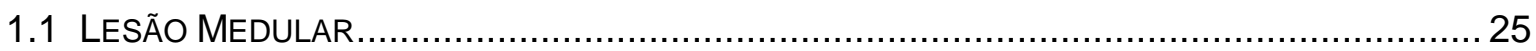

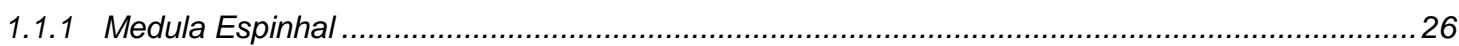

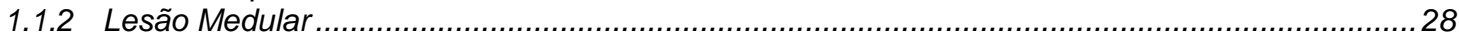

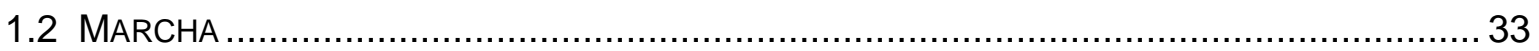

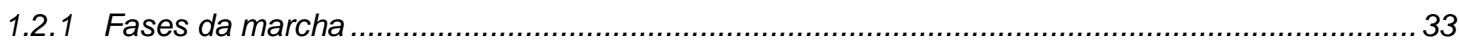

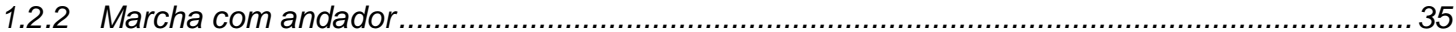

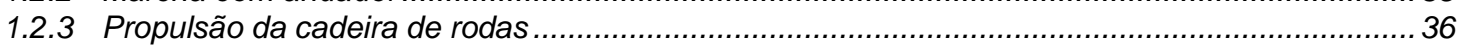

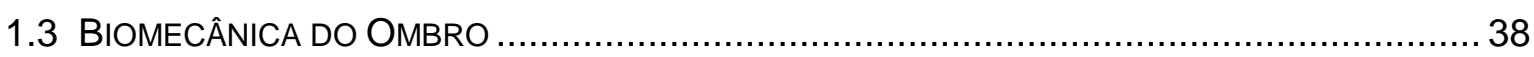

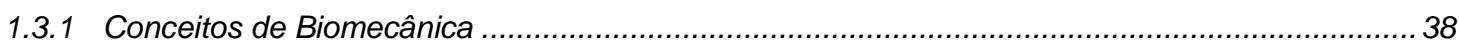

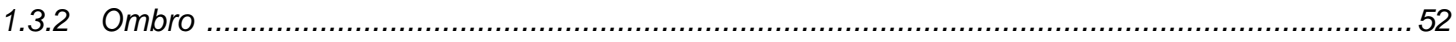

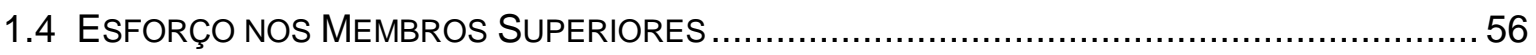

CAPÍTULO 2

63

MATERIAIS E MÉTODOS

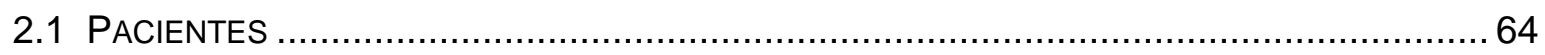

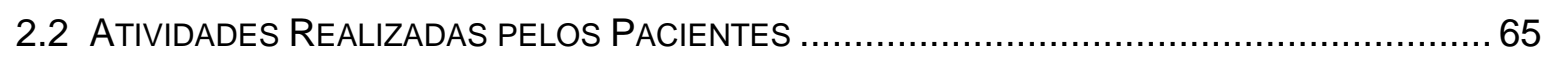

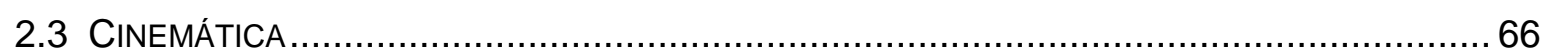

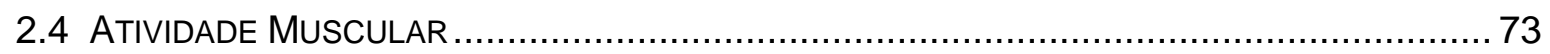

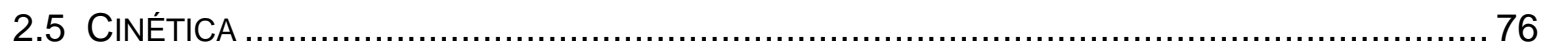

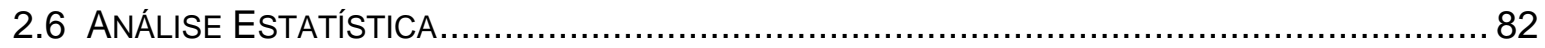




\section{RESULTADOS}

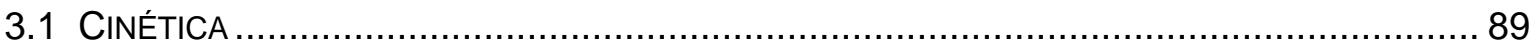

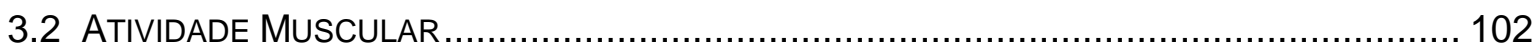

CapítulO 4

\section{DISCUSSÃo}

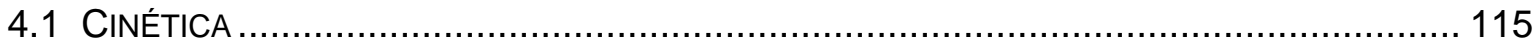

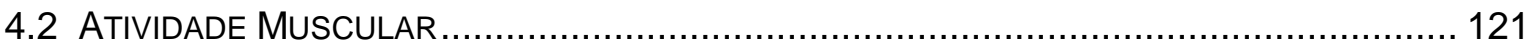

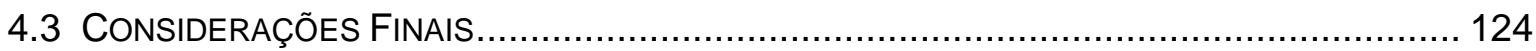

CAPÍTULO 5

\section{CONCLUSÕES}

REFERÊNCIAS

APÊNDICE - PACIENTES

\section{ReSULTADOS INDIVIDUAIS dOS PACIENTES ANALISADOS}

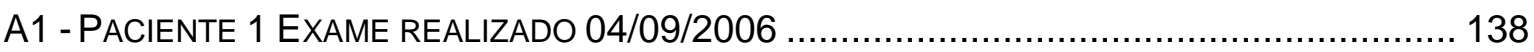

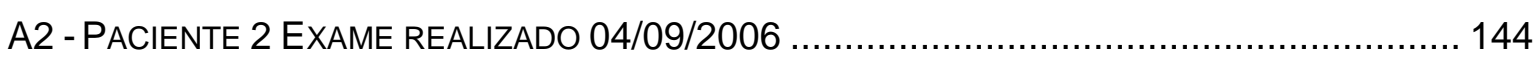

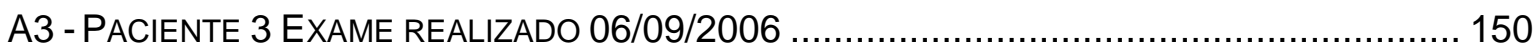

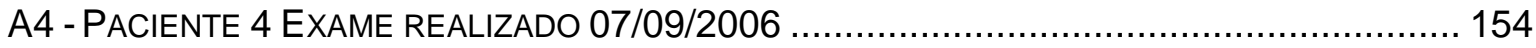

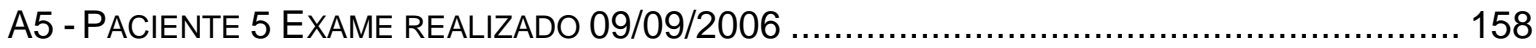

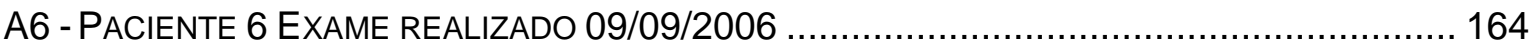

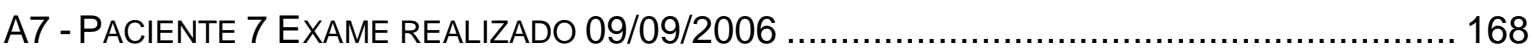

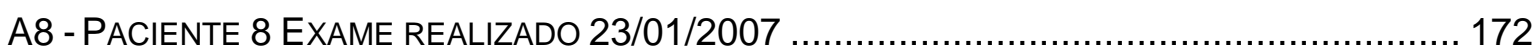

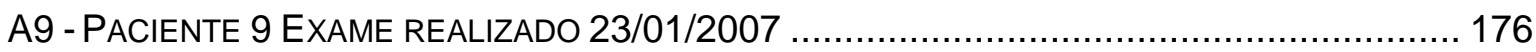

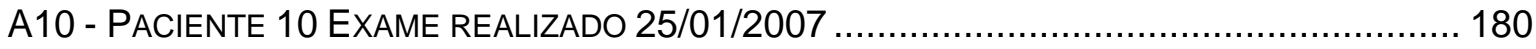

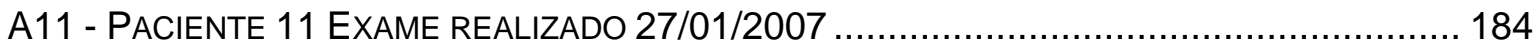

A12 - PACIENTE 12 EXAME REALIZADO 27/01/2007 ………........................................ 190

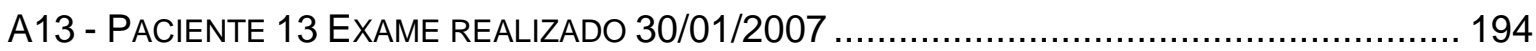

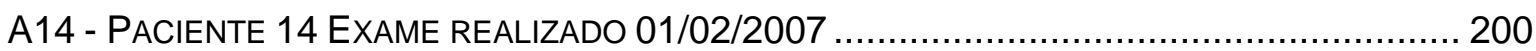

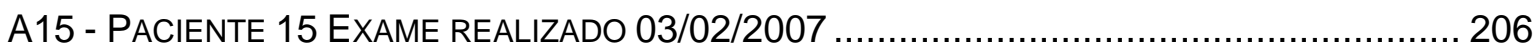




\section{RESUMO}

ORTOLAN, R.L. (2007): "Esforço do ombro na locomoção de pacientes paraplégicos: avaliação cinética e eletromiográfica". São Carlos, 2007. 211p. Tese (Doutorado) Depto. de Eng. Elétrica da Escola de Engenharia de São Carlos, Univ. de São Paulo.

Pacientes lesados medulares frequentemente mencionam dores nos ombros, devido à elevada demanda dos membros superiores. Estes pacientes se submetem a diferentes tipos de reabilitação, no entanto é importante avaliar os métodos utilizados em tais programas para evitar possíveis prejuízos. O objetivo deste trabalho é avaliar o esforço e a atividade muscular dos ombros em pacientes paraplégicos caminhando com Estimulação Elétrica Neuro Muscular (EENM) e um andador em seções de reabilitação e comparar com duas atividades diárias executadas por estes indivíduos: propulsão da cadeira de rodas e elevação para alívio da pressão. Quinze homens adultos com paraplegia foram avaliados. Os movimentos em 3 dimensões foram obtidos com um sistema de 6 câmeras de infravermelho, e a atividade mioelétrica de 6 músculos dos ombros foi obtida bilateralmente por eletrodos de superfície ativos. Um andador instrumentalizado capturou a força durante a marcha, e a força nas outras duas atividades foi obtida por dinâmica inversa utilizando os dados cinemáticos e antropométricos. Os dados cinéticos e da atividade muscular foram avaliados estatisticamente utilizando análise de variância (ANOVA) e o teste das diferenças menos significativas de Tukey com nível de significância $p<0,05$. Foram obtidos picos de força quatro vezes maiores durante a marcha comparando-se à propulsão da cadeira de rodas. O esforço do ombro durante a marcha e a elevação foi equivalente, porém o lado direito durante a marcha apresentou maiores valores. O músculo mais ativo durante a marcha foi o tríceps, seguido pelo peitoral maior, deltóide anterior e trapézio inferior. A ação geral dos músculos durante a marcha também foi maior comparada aos outros exercícios executados. A marcha com EENM e andador, realizada por lesados medulares durante as seções de reabilitação, requer esforços significativos dos membros superiores, podendo gerar complicações nas articulações do ombro. Lesados medulares submetidos a seções de reabilitação que executam esforços significativos devem ser frequentemente monitorados, por métodos de ultra-som ou ressonância magnética, para evitar o comprometimento dos membros superiores e a consequente perda das funções de independência remanescentes.

Palavras-chave: Lesão Medular, Marcha, Cinética, Eletromiografia (EMG), Reabilitação, Articulação do Ombro, Estimulação Elétrica Neuromuscular (EENM), Andador. 


\section{Abstract}

ORTOLAN, R. L. (2007): "Shoulder effort in paraplegic locomotion: kinetics and EMG assessment”. São Carlos, 2007. 211p. Thesis (PhD) - Depto. de Engenharia Elétrica da Escola de Engenharia de São Carlos, Universidade de São Paulo.

Spinal Cord Injured subjects often refer pain in their shoulders, due to the increased demand of the upper limbs. These subjects usually go through different rehabilitation strategies. Therefore, it becomes rather important to assess those methods in order to avoid further injuries to the patients. The goal of this work was to evaluate the shoulder effort and muscular activity in paraplegic subjects during gait with Neuromuscular Electrical Stimulation (NMES) with the aid of a walker and to compare it with two daily activities: wheelchair start up and weight relief raise. Fifteen adult male paraplegics were part of this study. The three-dimensional motions were acquired with six infrared cameras, and surface-active electrodes recorded the electromyography activity of 6 shoulder muscles, bilaterally. The vertical reaction force during walking was measured with a strain gauge instrumented walker, and the horizontal (wheelchair start-up) and vertical (weight relief raise) forces were obtained by inverse dynamics from kinematics and anthropometric data. The statistics of kinetic and electromyography data were done by analysis of variance (ANOVA) and the Tukey least significant differences post hoc test with significance level of $p<0,05$. Results have shown NMES gait force peaks being about four times higher than the values obtained for wheelchair start-up. The shoulder effort (force and torque) during walking and weight relief was similar, although the right side during NMES gait presented greater values. The triceps was the most active muscle during NMES walking, followed by pectoralis major, anterior deltoid and lower trapezius. The overall muscular activity during NMES walking was again higher than the other tasks executed. The NMES walking, when performed by spinal cord injured subjects can lead to injuries to the shoulder girdle. Due to the results obtained, continuous supervision of paraplegic upper limb effort should therefore be part of any rehabilitation center and for that ultrasound or magnetic resonance imaging may be recommended.

Keywords: Spinal Cord Injury, Gait, Kinetics, Electromyography (EMG), Rehabilitation, Shoulder Joint, Neuromuscular Electrical Stimulation (NMES), Walker. 


\section{LISTA DE FIGURAS}

Fig. 1 - Distribuição das áreas na pele inervadas por axônios sensitivos dentro de cada nervo segmentar (modificado de ASIA, 1992).

Fig. 2 - Posição da medula espinhal no canal vertebral. (modificado de Sarah, 2007).

Fig. 3 - Fases da Marcha (modificado de Franca, 2003).

Fig. 4 - Divisões das fases da Marcha proposto por Perry (1992). (modificado de Franca, 2003).

Fig. 5 - Parâmetros da passada durante a marcha (Hamill e Knutzen, 1999). .......35

Fig. 6 - Fases da marcha com andador (Valores obtidos de Franca, 2003) ...........36

Fig. 7 - Fases da Propulsão da cadeira de rodas (Hamill e Knutzen, 1999). 37

Fig. 8 - Posição anatômica nos três planos de movimento. Os sentidos dos movimentos em cada plano também estão indicados (Franca, 2003 baseado em Rash, 1999).

Fig. 9 - Terminologia dos movimentos (Franca, 2003 baseado em Rash, 1999).

Fig. 10 - Representação dos segmentos geométricos do corpo utilizado por Hanavan (1964). (obtido de Hamill e Knutzen, 1999)....

Fig. 11 - Ossos e articulações do ombro (modificado de Calais-Germain, 1991).

Fig. 12 - Movimentos realizados pela escápula (Hamill e Knutzen, 1999).

Fig. 13 - Músculos do complexo do ombro. Parte anterior.

(Hamill e Knutzen, 1999).

Fig. 14 - Músculos do complexo do ombro. Parte posterior.

(Hamill e Knutzen, 1999).

Fig. 15 - Padrões de propulsão da cadeira de rodas observados por Boninger et al. (2002). As barras ao lado direito de cada padrão representam o início da propulsão e as barras a esquerda representam fim da propulsão e início do retorno. a) Semicircular, b) Laço Simples, c) Laço Duplo, d) Arqueado. (Modificado de Boninger et al., 2002). 
Fig. 16 - Esquema representando a marcha pendular (swing-through). Diferentes fases da marcha em um ciclo completo. $\mathrm{O}$ ciclo inicia quando a muleta toca o chão e existe um pequeno período de suporte duplo (pés e muletas) seguido pela fase de suporte simples das muletas (onde o corpo é levantado e propagado para frente). O contato do calcanhar inicia a segunda fase de suporte duplo (apoio das pernas) seguido pela fase de balanço da muleta. (Modificado de Noreau et al., 1995).

Fig. 17 - Câmera de infravermelho integrante do sistema de aquisição de movimento da empresa Qualysis (Qualisys Inc., Glatonbury, CT, USA). 66

Fig. 18 - Marcador reflexivo utilizado 66

Fig. 19 - Paciente com marcadores durante atividades na cadeira de rodas. 67

Fig. 20 - Paciente com marcadores durante a marcha. 67

Fig. 21 - Localização dos marcadores nos pacientes 68

Fig. 22 - Vistas Lateral e Frontal dos marcadores de uma coleta durante a marcha de um paciente com EENM e andador.

Fig. 23 - Volume da aquisição cinemática no laboratório 69

Fig. 24 - Planta da disposição das câmeras e do volume de aquisição no laboratório.

Fig. 25 - Centros das articulações e centos de massa referentes à coleta da figura 22

Fig. 26 - Localização dos eletrodos de EMG de acordo com Perotto (1994). (Figuras modificadas de SENIAM, 2007)

Fig. 27 - Eletrodos Ativos de Superfície Diferenciais Utilizados. 75

Fig. 28 - Dispositivo com LEDs infravermelho confeccionado para sincronia. 76

Fig. 29 - Detalhe da montagem dos extensômetros na perna do andador 77

Fig. 30 - Detalhe da montagem do amplificador de instrumentação 77

Fig. 31 - Andador Instrumentalizado. 78

Fig. 32 - Esquema para calibração do andador 78

Fig. 33 - Curva de calibração do andador para o lado direito. Coeficiente angular: $-60,9205$.

Fig. 34 - Curva de calibração do andador para o lado esquerdo. Coeficiente angular: $-69,8392$. 
Fig. 35 - Resultados de uma repetição para um paciente durante o intervalo de propulsão da cadeira de rodas. Linha sólida: Lado direito. Linha tracejada: Lado esquerdo. Torque1: Plano Sagital (XZ). Torque2: Plano Transversal (XY). O Torque2 do lado direito é apresentado com sinal invertido. As atividades musculares são apresentadas como porcentagem da MCV. Músculos: Bi: Bíceps, Tr: Tríceps, DA: Deltóide Anterior, DP: Deltóide Posterior, PM: Peitoral Maior, TI: Trapézio Inferior.

Fig. 36 - Resultados de uma repetição para um paciente durante a elevação para alívio da pressão. Linha sólida: Lado direito. Linha tracejada: Lado esquerdo. Torque1: Plano Sagital (XZ). Torque2: Plano Frontal (YZ). O Torque2 do lado direito é apresentado com sinal invertido. As atividades musculares são apresentadas como porcentagem da MCV. Músculos: Bi: Bíceps, Tr: Tríceps, DA: Deltóide Anterior, DP: Deltóide Posterior, PM: Peitoral Maior, TI: Trapézio Inferior.

Fig. 37 - Resultados de uma repetição para um paciente durante a marcha com andador e EENM. Linha sólida: Lado direito. Linha tracejada: Lado esquerdo. Torque1: Plano Sagital (XZ). Torque2: Plano Frontal (YZ). O Torque2 do lado direito é apresentado com sinal invertido. As atividades musculares são apresentadas como porcentagem da MCV. Músculos: Bi: Bíceps, Tr: Tríceps, DA: Deltóide Anterior, DP: Deltóide Posterior, PM: Peitoral Maior, TI: Trapézio Inferior.

Fig. 38 - Médias dos Picos da Força de cada paciente. As médias (barras) e seus respectivos erros padrões para cada exercício estão representados em cores diferentes em ambos os lados. As diferentes letras representam diferenças significativas entre os exercícios.

Fig. 39 - Médias dos Picos do Torque no plano Sagital (XZ) de cada paciente. As médias (barras) e seus respectivos erros padrões para cada um dos exercícios executados estão representados em cores diferentes para ambos os lados. As diferentes letras para cada parâmetro representam diferenças significativas entre os exercícios com $\mathrm{p}<0,05$.

Fig. 40 - Médias dos Picos do 2ํㅜ Torque de cada paciente. As médias (barras) e seus respectivos erros padrões para cada um dos exercícios executados estão representados em cores diferentes para ambos os lados. Para a propulsão da cadeira de rodas o torque é referente ao plano Transversal $(X Y)$ e para a elevação para alívio da pressão e a marcha com andador e EENM é referente ao plano Frontal $(Y Z)$. As diferentes letras para cada parâmetro representam diferenças significativas entre os exercícios com $\mathrm{p}<0,05$ 
Fig. 41 - Médias das Integrais das Forças de cada paciente. As médias (barras) e seus respectivos erros padrões para cada exercício estão representados em cores diferentes em ambos os lados. As diferentes letras representam diferenças significativas entre os exercícios.

Fig. 42 - Médias das Integrais do Torque no plano Sagital (XZ) de cada paciente. As médias (barras) e seus respectivos erros padrões para cada um dos exercícios executados estão representados em cores diferentes para ambos os lados. As diferentes letras para cada parâmetro representam diferenças significativas entre os exercícios com $p<0,05$.

Fig. 43 - Médias das Integrais do $2^{\circ}$ Torque de cada paciente. As médias (barras) e seus respectivos erros padrões para cada um dos exercícios executados estão representados em cores diferentes para ambos os lados. Para a propulsão da cadeira de rodas 0 torque é referente ao plano Transversal $(X Y)$ e para a elevação para alívio da pressão e a marcha com andador e EENM é referente ao plano Frontal (YZ). As diferentes letras para cada parâmetro representam diferenças significativas entre os exercícios com $\mathrm{p}<0,05$.

Fig. 44 - Médias do Pico das Forças de todos pacientes. As médias (barras) e seus respectivos erros padrões para cada um dos 3 exercícios executados estão representados em cores diferentes em ambos os lados. As diferentes letras representam diferenças significativas entre os exercícios com $\mathrm{p}<0,05$ para cada lado. 96

Fig. 45 - Médias dos Picos dos Torques de todos pacientes. As médias (barras) e seus respectivos erros padrões para cada um dos 3 exercícios executados estão representados em cores diferentes para ambos os lados. O Torque 1 é referente ao plano sagital $(X Z)$. O Torque 2 é referente ao plano Transversal $(X Y)$ para a propulsão da cadeira de rodas e ao plano Frontal (YZ) para a elevação para alívio da pressão e a marcha com andador e EENM. As diferentes letras em cada parâmetro representam diferenças significativas entre os exercícios com $p<0,05$.

Fig. 46 - Médias da Integral das Forças de todos pacientes. As médias (barras) e seus respectivos erros padrões para cada um dos 3 exercícios executados estão representados em cores diferentes em ambos os lados. As diferentes letras representam diferenças significativas entre os exercícios com $\mathrm{p}<0,05$ para cada lado. 
Fig. 47 - Médias da Integral dos Torques de todos pacientes. As médias (barras) e seus respectivos erros padrões para cada um dos 3 exercícios executados estão representados em cores diferentes para ambos os lados. O Torque 1 é referente ao plano sagital $(X Z)$. O Torque 2 é referente ao plano Transversal (XY) para a propulsão da cadeira de rodas e ao plano Frontal (YZ) para a elevação para alívio da pressão e a marcha com andador e EENM. As diferentes letras para cada parâmetro representam diferenças significativas entre os exercícios com $p<0,05$.

Fig. 48 - Médias das atividades musculares dos pacientes 1, 2, 3 e 4. Cada letra indica diferentes faixas com nível de significância $p<0,05$.

Fig. 49 - Médias das atividades musculares dos pacientes 5, 6, 7 e 8. Cada letra indica diferentes faixas com nível de significância $p<0,05$.

Fig. 50 - Médias das atividades musculares dos pacientes 9, 10, 11 e 12. Cada letra indica faixa diferente com nível de significância $p<0,05$.

Fig. 51 - Médias das atividades musculares dos pacientes 13, 14, e 15. Cada letra indica diferentes faixas com nível de significância $p<0,05$.

Fig. 52 - Médias das atividades musculares entre todos paciente analisados para os 3 exercícios executados. As atividades musculares são apresentadas como uma porcentagem da MCV. As médias de cada músculo são representadas pelas barras e seus respectivos erros padrões. Cada letra indica diferentes faixas com nível de significância $p<0,05$. As letras maiúsculas representam diferentes atividades musculares entre os músculos do mesmo lado para um mesmo exercício. As letras minúsculas, entre parênteses, representam diferentes atividades musculares de um mesmo músculo entre os 3 exercícios executados. 


\section{LISTA DE TABELAS}

Tab. 1 - Escala de deficiência ASIA. Modificado de ASIA (1992)............................ 31

Tab. 2 - Distribuição dos músculos na cintura escapula classificados quanto a sua origem e inserção e localização (profundo ou superficial)................ 54

Tab. 3 - Dados dos pacientes paraplégicos participantes do estudo ...................... 65

Tab. 4 - Dados antropométricos obtidos por Dempster (1959). (Adaptado de Miller e Nelson, 1973)

Tab. 5 - Médias das características de todos os pacientes que executaram os 3 ciclos iniciais de propulsão da cadeira de rodas.

Tab. 6 - Médias das características de todos os pacientes que executaram a elevação para alívio da pressão.

Tab. 7 - Médias das características de todos os pacientes que executaram a marcha com andador e EENM.

Tab. 8 - Médias e Desvios Padrões dos Picos e Integrais da Força, Torque no Plano Sagital (XZ) e 2o Torque no Lado Direito

Tab. 9 - Médias e Desvios Padrões dos Picos e Integrais da Força, Torque no Plano Sagital (XZ) e $2^{\circ}$ Torque no Lado Esquerdo.

Tab. 10 -Médias e Desvios Padrões das atividades musculares médias no lado Direito durante os exercícios realizados.

Tab. 11 - Médias e Desvios Padrões das atividades musculares médias no lado Esquerdo durante os exercícios realizados. 
TABELAS APÊNDICE - Resultados Individuais dos Pacientes.

Tab. A1.1 - Características dos 3 ciclos iniciais de propulsão da cadeira de rodas 138

Tab. A1.2 - Características da elevação para alívio da pressão ......................................... 140

Tab. A1.3 - Características da passada com andador e EENM …................................. 142

Tab. A2.1 - Características dos 3 ciclos iniciais de propulsão da cadeira de rodas............ 144

Tab. A2.2 - Características da elevação para alívio da pressão ...................................... 146

Tab. A2.3 - Características da passada com andador e EENM ….................................. 148

Tab. A3.1 - Características dos 3 ciclos iniciais de propulsão da cadeira de rodas............ 150

Tab. A3.2 - Características da elevação para alívio da pressão ....................................... 152

Tab. A4.1 - Características dos 3 ciclos iniciais de propulsão da cadeira de rodas............ 154

Tab. A4.2 - Características da elevação para alívio da pressão ...................................... 156

Tab. A5.1 - Características dos 3 ciclos iniciais de propulsão da cadeira de rodas............ 158

Tab. A5.2 - Características da elevação para alívio da pressão ...................................... 160

Tab. A5.3 - Características da passada com andador e EENM …..................................... 162

Tab. A6.1 - Características dos 3 ciclos iniciais de propulsão da cadeira de rodas............ 164

Tab. A6.2 - Características da elevação para alívio da pressão ...................................... 166

Tab. A7.1 - Características da elevação para alívio da pressão ...................................... 168

Tab. A7.2 - Características da passada com andador e EENM …..................................... 170

Tab. A8.1 - Características dos 3 ciclos iniciais de propulsão da cadeira de rodas............ 172

Tab. A8.2 - Características da elevação para alívio da pressão ..................................... 174

Tab. A9.1 - Características dos 3 ciclos iniciais de propulsão da cadeira de rodas............ 176

Tab. A9.2 - Características da elevação para alívio da pressão ...................................... 178

Tab. A10.1 - Características dos 3 ciclos iniciais de propulsão da cadeira de rodas .......... 180

Tab. A10.2 - Características da elevação para alívio da pressão ....................................... 182

Tab. A11.1 - Características dos 3 ciclos iniciais de propulsão da cadeira de rodas .......... 184

Tab. A11.2 - Características da elevação para alívio da pressão ...................................... 186

Tab. A11.3 - Características da passada com andador e EENM ..................................... 188

Tab. A12.1 - Características dos 3 ciclos iniciais de propulsão da cadeira de rodas .......... 190

Tab. A12.2 - Características da elevação para alívio da pressão .................................... 192

Tab. A13.1 - Características dos 3 ciclos iniciais de propulsão da cadeira de rodas .......... 194

Tab. A13.2 - Características da elevação para alívio da pressão ....................................... 196

Tab. A13.3 - Características da passada com andador e EENM ...................................... 198

Tab. A14.1 - Características dos 3 ciclos iniciais de propulsão da cadeira de rodas .......... 200

Tab. A14.2 - Características da elevação para alívio da pressão ....................................... 202

Tab. A14.3 - Características da passada com andador e EENM .................................... 204

Tab. A15.1 - Características dos 3 ciclos iniciais de propulsão da cadeira de rodas ..........206

Tab. A15.2 - Características da elevação para alívio da pressão ..................................... 208 


\section{AbreviaÇões, Siglas e Termos TéCnicos}

Além das abreviações e siglas, são apresentadas também algumas expressões técnicas que normalmente são mencionadas em inglês.

A/D: Conversor Analógico Digital

ASIA: American Spinal Injury

Association

DC: Direct Current. Corrente Contínua

D/A: Conversor Digital Analógico

Distal: Afastado do centro do corpo.

EENM: Estimulação Elétrica Neuromuscular.

EMG: Eletromiografia

FIR: Finite Inpulse Respost. Resposta Finita ao Impulso

GPL: Gerador de Padrões Locomotores

IIR: Infinite Inpulse Respost . Resposta Infinita ao Impulso
Lateral: Situado longe da linha mediana do corpo.

LED: Light Emitting Diode. Diodo Emissor de Luz.

Medial: Situado perto da linha mediana do corpo.

NMES: Neuromuscular Electrical Stimulation (sigla inglesa de EENM)

Offset : sintaxe relacionada com um nível de tensão indesejado adicionado ao sinal por um circuito elétrico

Proximal: Próximo do centro do corpo.

RMS: Root Mean Square. Raiz da média quadrática.

SME: Sinal Mioelétrico

Swing-Through: Marcha pendular realizada com a propulsão conjunta das duas pernas para frente. 


\section{PREFÁCIO}

“...Aprendi a ficar quieto e começar tudo de novo,

o que eu quero eu vou conseguir...".

R.S.S. /Rockixe (1973)

\section{Introdução}

A lesão medular e a consequente inatividade muscular são causas de muitos problemas nos sistemas musculoesquelético, circulatório e nervoso. Várias técnicas de reabilitação são utilizadas para reduzir prejuízos como osteoporose, úlceras de pressão e a redução de massa muscular nestes pacientes. A Estimulação Elétrica Neuromuscular (EENM) é uma técnica frequentemente usada e pode ser aplicada tanto para fins terapêuticos quanto funcionais (ORTOLAN et al., 2001; SIPSKI; RICHARDS, 2006).

A restauração das funções motoras, sensoras e autonômicas após lesões medulares tornou-se uma das principais atividades da comunidade neurocientífica durante a última década (FOUAD; PEARSON, 2004). A idéia é que praticando a marcha com EENM é possível "ensinar a medula a caminhar". Resultados positivos em experimentos com gatos e recentemente com humanos encorajaram o uso desta técnica de reabilitação (PEARSON, 2000).

Evidências de um Gerador de Padrões Locomotores (GPL), localizado na medula espinhal humana, foram obtidas baseadas nos movimentos involuntários semelhantes a passos depois de lesões medulares completas (CALANCIE et al., 1994). Movimentos locomotores também foram induzidos em pacientes portadores de 
paraplegia completa e incompleta utilizando um suporte para suspensão do corpo e uma esteira elétrica (DIETZ et al., 1995; WERNING et al., 1998). De acordo com Dietz (2002) a força de contato é a informação aferente mais importante para ativar o GPL.

Lamb e Yang (2000) obtiveram passos em bebês recém nascidos submetidos a uma esteira elétrica. Este fato fornece um suporte adicional à existência do GPL na medula espinhal humana, pois a via descendente (do cérebro à medula espinhal) em recém nascidos é imatura e não considerada funcional.

A EENM tem sido usada para auxiliar a execução de uma variedade de movimentos em pacientes lesados medulares inclusive movimentos para realização da marcha (BAJD et al., 1983; CLIQUET et al., 1989). A marcha com EENM aplicada aos membros inferiores (também chamada de neuroprótese de membros inferiores) tem se mostrado uma promissora forma de reabilitação. No entanto ainda não é possível utilizar a EENM na marcha como uma forma alternativa de locomoção em substituição a cadeira de rodas, principalmente devido à fadiga muscular e habituação nervosa (MUNIH; ICHIE, 2001).

Apesar da fadiga muscular e habituação nervosa a EENM vem sendo usada como modalidade terapêutica mesmo em estágios crônicos de lesão medular (BARBEAU et al., 2002). A característica mais importante dos trabalhos incluindo a marcha com EENM é o uso do reflexo de retirada para realizar a fase de balanço na marcha. Desta forma são necessários apenas dois canais de estimulação em cada perna, um para estimular o músculo quadríceps durante a fase de suporte, e outro canal estimulando o nervo fibular (realizando o reflexo de retirada) durante a fase de balanço. Este método é usado pelo sistema Parastep ${ }^{1}$ e a maioria dos sistemas

\footnotetext{
${ }^{1}$ Parastep é um sistema comercial de locomoção para paraplégicos aprovado pela Food and Drug Administration (FDA) norte americana.
} 
utilizados hoje em dia (MUNIH; ICHIE, 2001).

Dispositivos de auxílio à marcha (andadores, muletas etc.) são essenciais para os pacientes paraplégicos realizarem a marcha com EENM, pois apesar do estímulo elétrico contrair os músculos das pernas, estes pacientes não têm propriocepção e precisam usar os membros superiores para uma melhor estabilização e assim poderem se manter em pé (CLIQUET et al., 1989; BATENI; MAKI, 2005).

Vários programas de reabilitação envolvendo a marcha induzida artificialmente são frequentados por pacientes lesados medulares, onde normalmente são analisados seus benefícios. No entanto, existem algumas desvantagens associadas a esta atividade que incluem o aumento do consumo energético comparado à marcha normal (WATERS; MULROY, 1999; ULKAR et al., 2003; CARVALHO et al., 2005) e o risco de induzir danos pelo sobreuso nas articulações dos membros superiores destes sujeitos.

Os membros superiores são apropriados à manipulação de objetos, porém a maioria dos pacientes com lesão medular apresenta dores nos ombros, devido excessiva carga aplicada diariamente nestas articulações (JENSEN et al., 2005; SALISBURY et al., 2003; BALLINGER et al., 2000). Desta forma torna-se importante avaliar o esforço produzido pelo ombro destes pacientes para evitar danos a esta articulação e o comprometimento das funções de independência remanescentes (HASTING; GOLDSTEIN, 2004; SAMUELSSON et al., 2004; NINOMYIA et al., 2007).

Poucos trabalhos mensuraram a carga em membros superiores de pacientes lesados medulares durante a marcha. Crosbie e Nicol (1990), Noreau et al. (1995), Melis et al. (1999), Requejo et al. (2005) e Haubert et al. (2006) avaliaram o esforço nos membros superiores de lesados medulares incompletos que andam diariamente com auxílio de bengalas ou muletas. No entanto, nenhum estudo ainda foi realizado 
com pacientes portadores de lesão completa, ou que necessitam de EENM para realizar a marcha com andador, durante seções de reabilitação, com o intuito de verificar se o tratamento poderia gerar algum prejuízo. 


\section{Objetivos}

O objetivo deste trabalho foi avaliar o esforço e a atividade muscular dos ombros em pacientes paraplégicos, durante seções de reabilitação realizadas por meio de marcha induzida artificialmente (estimulação elétrica) utilizando um andador.

A avaliação cinética e da atividade muscular durante a marcha foi realizada pela comparação com duas atividades executadas diariamente por estes sujeitos (propulsão da cadeira de rodas e elevação do corpo para alívio da pressão), com objetivo de verificar a possibilidade de prejuízos aos pacientes durante as seções de reabilitação.

\section{Hipótese}

O esforço do ombro em pacientes paraplégicos ao realizar a marcha (induzida artificialmente por EENM) com auxílio de um andador durante as seções de reabilitação é maior que outros esforços realizados diariamente por estes sujeitos. 


\section{Capítulo 1}

“...Essa lama que a gente engole e não faz nada...nada... mas esse caos de gente é sinal de que algo está para acontecer.

R.S.S. / Metamorfose Ambulante

\section{REVISÃo BIBLIOGRÁFICA}

Este capítulo apresenta uma breve revisão bibliográfica sobre: Lesão medular, Caracterização da marcha, Biomecânica do ombro e Pesquisas recentes sobre o esforço do ombro em lesados medulares.

\subsection{Lesão Medular}

A lesão medular caracteriza-se pela interrupção (total ou parcial) da comunicação na medula espinhal, comprometendo a transmissão de informações entre as partes acima da lesão (incluindo o cérebro) com as regiões abaixo da lesão. 


\subsubsection{Medula Espinhal}

A medula espinhal encontra-se envolvida e protegida pela coluna vertebral e consiste no principal condutor de informações sensitivas e motoras entre o cérebro e o restante do corpo.

A medula é composta por inúmeros neurônios aferentes (sensitivos) e eferentes (motores) sendo que os neurônios aferentes têm seus axônios entrando na medula e os eferentes têm seus axônios saindo da medula. Estes axônios são reunidos em nervos e são denominados e numerados de acordo com o forame vertebral em que entram ou saem da coluna. Desta forma a medula é dividida, como a coluna vertebral, em 4 partes principais: Cervical, Torácica, Lombar e Sacral. Os segmentos cervicais são oito ( $\mathrm{C} 1$ a C8) e controlam a sensibilidade e o movimento da região cervical e dos membros superiores. Os segmentos torácicos (T1 a T12) controlam o tórax, abdome e parte dos membros superiores. Os segmentos lombares (L1 a L5) estão relacionados com movimentos e sensibilidade dos membros inferiores. Os sacrais ( $\mathrm{S} 1$ a S5 mais o nervo Coccígeo) controlam parte dos membros inferiores, sensibilidade da região genital e funcionamento da bexiga e intestino (Sarah, 2007). A figura 1 apresenta as regiões da pele que são inervadas por axônios sensitivos de cada nervo segmentar.

Apesar da medula estar segmentada de acordo com o forame vertebral por onde sai o nervo, não existe correspondência entre a vértebra e o segmento medular subjacente. Isso se deve ao tamanho desigual entre a medula e a coluna vertebral. A medula espinhal adulta termina no nível vertebral L1-L2. Abaixo desses níveis na coluna vertebral, encontramos apenas raízes nervosas, que constituem a cauda eqüina. Na figura 2 é apresentado um esquema da distribuição da medula espinhal dentro do canal vertebral. 

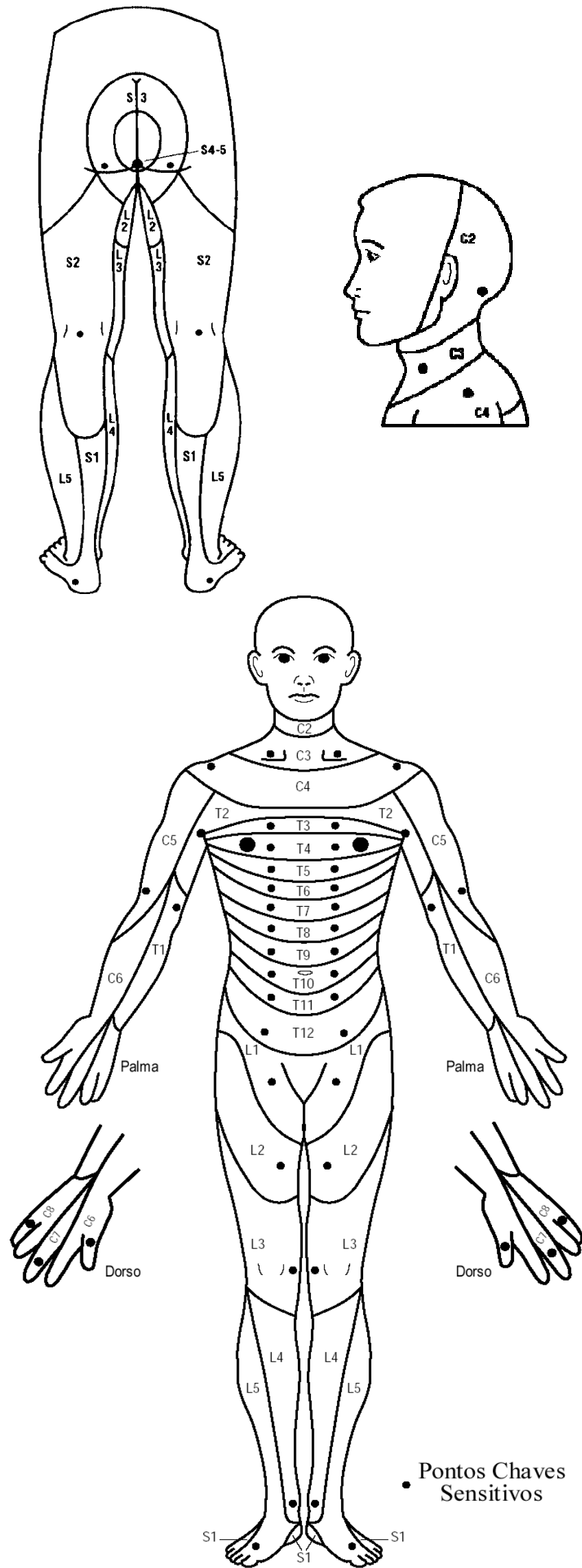

Fig. 1 - Distribuição das áreas na pele inervadas por axônios sensitivos dentro de cada nervo segmentar (modificado de ASIA, 1992).

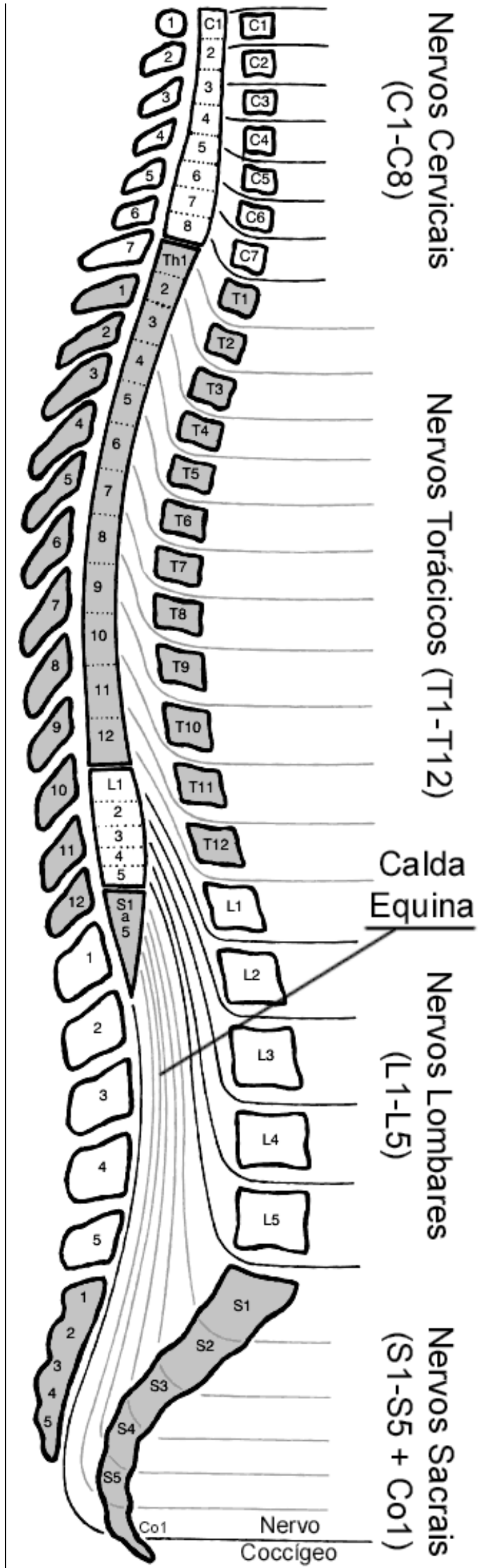

Fig. 2 - Posição da medula espinhal no canal vertebral. (modificado de Sarah, 2007). 
Além da sua função condutora de informação, a medula espinhal ainda contém interneurônios que compõem circuitos neurais locais, se tornando um centro regulador de inúmeras funções relacionadas com reflexos medulares. Tais reflexos podem ser motores (reflexo de retirada, da extensão cruzada, da locomoção, da postura, de coçar e que causam espasmos) ou autonômicos (pressão arterial, sudorese, evacuação da bexiga e do cólon e algumas funções motoras do trato digestivo).

\subsubsection{Lesão Medular}

A lesão medular caracteriza-se pela interrupção (total ou parcial) da comunicação na medula espinhal, podendo prejudicar a coordenação das funções motoras, sensitivas e autonômicas. A lesão medular pode ocorrer devido a um trauma (acidente automobilístico, armas de fogo, mergulho) ou doenças (infecção, tumor).

Estudos realizados pela National Spinal Cord Injury Statistical Center ${ }^{2}$ (NSCISC) estimam que no ano de 2006 haviam 253.000 pessoas portadoras de lesão medular vivendo nos Estados Unidos, e que a cada ano ocorrem 11.000 novos casos (desconsiderando aqueles que falecem no acidente). Estatísticas realizadas com os casos ocorridos a partir de 2000 mostram que a idade média na data da lesão é de 38 anos com prevalência masculina em $77,8 \%$ dos casos. (NSCISC, 2006)

\footnotetext{
${ }^{2}$ National Spinal Cord Injury Statistical Center é um centro norte-americano que mantêm uma extensa base de dados sobre lesão medular desde 1973.
} 
A lesão traumática é a mais frequente (84\%) sendo sua principal causa os acidentes automobilísticos (47\%), seguido por quedas (24\%), atos de violência (14\%), e lesões associadas a atividades esportivas (9\%) sendo a maioria mergulho em águas rasas. Entre 1990 e 1999 os atos de violência (associados principalmente com armas de fogo) tiveram uma maior representação na incidência de lesão medular, alcançando 25\% dos casos. (NSCISC, 2006).

No Brasil durante o ano 2000, na rede Sarah de Hospitais do Aparelho Locomotor $^{3}$, entre os pacientes comprometidos com traumatismo medular $31 \%$ dos casos teve como causa acidente de trânsito, seguido de agressão com arma de fogo (30\%), quedas (21\%) e mergulho (6,5\%). (SARAH, 2007).

A expectativa de vida para estes pacientes vêm aumentando significativamente com os avanços da ciência, mas ainda é menor comparada a sujeitos normais. A taxa de mortalidade é maior durante o primeiro ano após a lesão, e no passado estava relacionada principalmente com insuficiência renal, porém com os avanços na área urológica os problemas renais deixaram de ser a maior causa de morte para estes pacientes aumentando assim sua expectativa de vida. Hoje em dia as principais causas de falecimento em lesados medulares estão relacionadas à pneumonia, embolia pulmonar e septicemia. (NSCISC, 2006).

Quando a medula espinhal é subitamente lesionada todas as suas funções abaixo da lesão (inclusive os reflexos medulares) ficam imediatamente deprimidas a ponto de haver silêncio total, uma reação chamada de choque espinhal. Após um intervalo de tempo os neurônios espinhais reconquistam gradativamente sua excitabilidade. No ser humano este retorno costuma demorar alguns meses

\footnotetext{
${ }^{3}$ A rede Sarah de Hospitais do Aparelho Locomotor é uma rede pública brasileira composta por unidades situadas em seis capitais brasileiras denominadas Hospitais Sarah Kubitschek com a finalidade de atender vítimas de politraumatismo e problemas locomotores.
} 
chegando até 1 ano, e às vezes não é completo. Por outro lado, essa recuperação pode ser excessiva, causando hiperexcitabilidade de algumas ou de todas as funções medulares (GUYTON, 1997).

O nível da lesão é o ponto mais baixo preservado da medula espinhal, quanto mais baixo o nível de lesão mais funcionalidade o individuo apresentará. As lesões nos segmentos cervicais são caracterizadas como tetraplegia (paralisia dos quatro membros), as lesões cervicais altas (C1 e C2) normalmente são fatais devido à insuficiência respiratória pelo comprometimento do nervo frênico que comanda a contração do diafragma. Nas lesões cervicais baixas (C6, C7 e C8) observa-se paralisia dos membros inferiores e das mãos. As lesões nos segmentos torácicos, lombares e sacrais da medula espinhal se caracterizam como paraplegia (paralisia dos membros inferiores).

Nas lesões medulares completas ocorre a paralisia e a perda de todas as modalidades sensitivas (tátil, dolorosa, para temperatura, pressão e localização de partes do corpo no espaço) abaixo da lesão, além da alteração no controle esfincteriano (urinário e fecal). As sociedades American Spinal Injury Association (ASIA) e International Medical Society of Paraplegia (IMSOP) publicaram conjuntamente em 1992 os "Padrões Internacionais para Classificação Neurológica e Funcional das lesões Medulares Espinhais" (ASIA, 1992), estes padrões determinam 5 categorias dependendo do tipo de lesão: Completa (A), Incompleta (B, C e D) e Normal (E). A tabela 1 apresenta uma descrição detalhada de cada categoria na escala de deficiência ASIA.

Segundo o National Spinal Cord Injury Statistical Center a tetraplegia incompleta foi a classe de maior incidência de lesão medular desde o ano 2000 nos Estados Unidos, chegando a $34 \%$ dos casos, a paraplegia completa compreendeu 
$23 \%$ dos casos e a incompleta $19 \%$. A tetraplegia completa foi a lesão de menor incidência aparecendo em 18\% dos casos. (NSCISC, 2006).

Tab. 1 - Escala de deficiência ASIA. Modificado de ASIA (1992)

\begin{tabular}{|c|c|c|}
\hline Escala & $\begin{array}{l}\text { Nível de } \\
\text { Lesão }\end{array}$ & Descrição \\
\hline$A$ & Completa & $\begin{array}{l}\text { Não há função motora ou sensitiva preservada abaixo } \\
\text { do nível da lesão }\end{array}$ \\
\hline B & Incompleta & $\begin{array}{l}\text { Há função sensitiva, porém não há função motora } \\
\text { preservada abaixo do nível da lesão. }\end{array}$ \\
\hline C & Incompleta & $\begin{array}{l}\text { Há função motora preservada abaixo do nível da lesão, } \\
\text { e a maioria dos músculos abaixo do nível da lesão têm } \\
\text { força muscular inferior a } 3^{\star} \text {. }\end{array}$ \\
\hline D & Incompleta & $\begin{array}{l}\text { Há função motora preservada abaixo do nível da lesão, } \\
\text { e pelo menos a metade dos músculos abaixo do nível } \\
\text { da lesão têm força muscular maior ou igual a } 3^{\star} \text {. }\end{array}$ \\
\hline $\mathrm{E}$ & Normal & As funções sensitivas e motoras são preservadas. \\
\hline
\end{tabular}

*Força muscular = 3: Movimento ativo contra a gravidade. Detalhes no Anexo.

Além da perda das funções motoras e sensitivas a lesão medular ainda pode apresentar uma série de outros problemas como: úlceras por pressão, disfunção urinária, disfunção intestinal, disreflexia autonômica, trombose, hipotensão ortostática, embolia pulmonar, siringomielia e distúrbios do humor (SARAH, 2007).

Uma das complicações mais comuns encontrada em pacientes com lesão medular são as úlceras por pressão, que podem ser responsáveis por hospitalizações e longos períodos de imobilidade. As úlceras surgem quando a circulação local é interrompida por tempo prolongado, devido à pressão dos ossos contra a pele apoiada em uma superfície por longos períodos. A falta de mobilidade associada à falta de sensibilidade em lesados medulares representa um grande risco de ocorrência de úlceras por pressão. Tais úlceras requerem cuidados especiais para sua cura e para bloquear seu crescimento (tanto em extensão quanto em 
profundidade) caso contrário podem gerar outras complicações, inclusive fatais. As úlceras por pressão são mais fáceis de prevenir do que de ser tratadas, e uma das medidas mais importantes para evitar o aparecimento e crescimento dessas úlceras é o alívio da pressão sobre a pele periodicamente, quando o paciente se encontra na cama ou cadeira de rodas. Este alívio é realizado com a constante elevação do corpo ou a mudança de posição do paciente.

Siringomielia pós-traumática é uma complicação que pode acontecer meses ou anos após a ocorrência da lesão medular e pode aumentar a incapacidade funcional nos lesados medulares. No local do trauma, na medula espinhal, pode surgir um cisto e quando este cisto é preenchido por liquido céfalo-raquidiano ocorre a siringomielia (KIRSHBLUM, 2005). Quando este líquido se expande, comprime a medula espinhal gerando a morte de mais neurônios e consequentemente a elevação do nível neurológico da lesão, resultando em maior perda funcional. A entrada de líquido dentro do cisto pode ocorrer devido a um aumento na pressão venosa, proveniente da elevação da pressão intratorácica. Atividades com grande esforço como o levantamento de cargas pesadas que requeiram a execução da "manobra de Valsalva" aumentam a pressão intratorácica. A siringomielia foi considerada rara no passado, no entanto com o advento da ressonância magnética, sua prevalência em pacientes com lesão medular tem sido estimada em torno de $8 \%$ (SARAH, 2007).

\footnotetext{
${ }^{4}$ Manobra de Valsalva: Expiração forçada contra a glote fechada, aumentado a pressão intratorácica e impedindo o retorno venoso ao coração.
} 


\subsection{Marcha}

A marcha humana é um eficiente método de locomoção, podendo superar vários obstáculos e adquirir diferentes velocidades.

\subsubsection{Fases da marcha}

A marcha humana pode ser dividida em duas fases principais: suporte e balanço (figura 3). Estas fases estão relacionadas com um dos lados da pessoa que caminha, pois enquanto a perna direita está na fase de balanço a esquerda estará na fase de suporte.

A fase de suporte ocorre quando o membro inferior mantém contato com o chão sustentando o peso do corpo, neste período o suporte pode ser simples (a perna sustenta todo o peso do corpo), ou duplo (as duas pernas mantêm contato com o chão). A fase de balanço ocorre quando a perna é lançada para frente, neste intervalo todo o peso do corpo estará aplicado na outra perna.

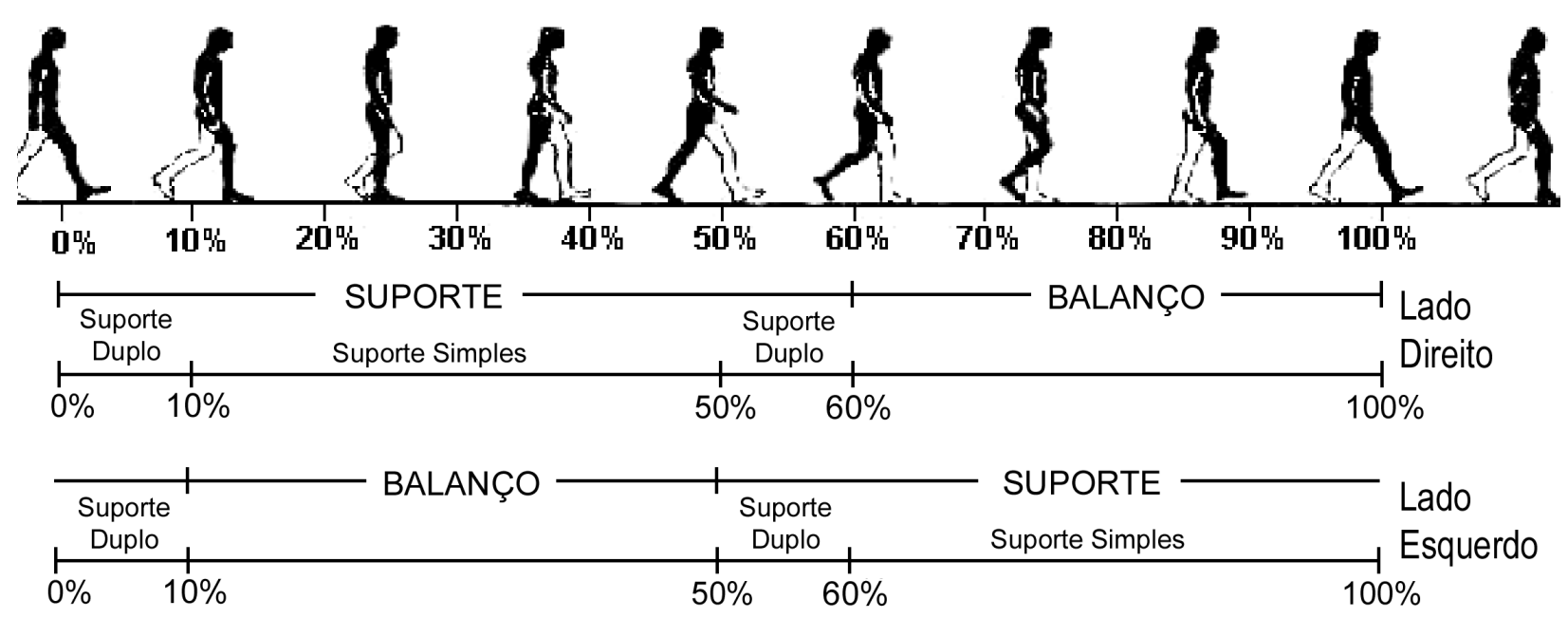

Fig. 3 - Fases da Marcha (modificado de Franca, 2003). 
Perry (1992) propôs subdivisões a estas duas fases principais obtendo 8 fases durante um ciclo da marcha. A fase de balanço foi subdividida em 3 fases (balanço inicial, meio da fase de balanço e final da fase de balanço), e a fase de suporte em 5 fases (contato inicial, resposta à carga, meio da fase de suporte, final da fase de suporte e pré-balanço). O contato inicial e a resposta à carga ocorrem no primeiro suporte duplo (após a fase de balanço); e o pré-balanço ocorre no segundo suporte duplo (antes da fase de balanço). O contato inicial se dá em um curto intervalo do ciclo da marcha (de $0 \%$ a $2 \%$ ), caracterizado pelo contato do pé com o chão iniciando a fase de apoio. Os outros intervalos de tempo são apresentados na figura 4.

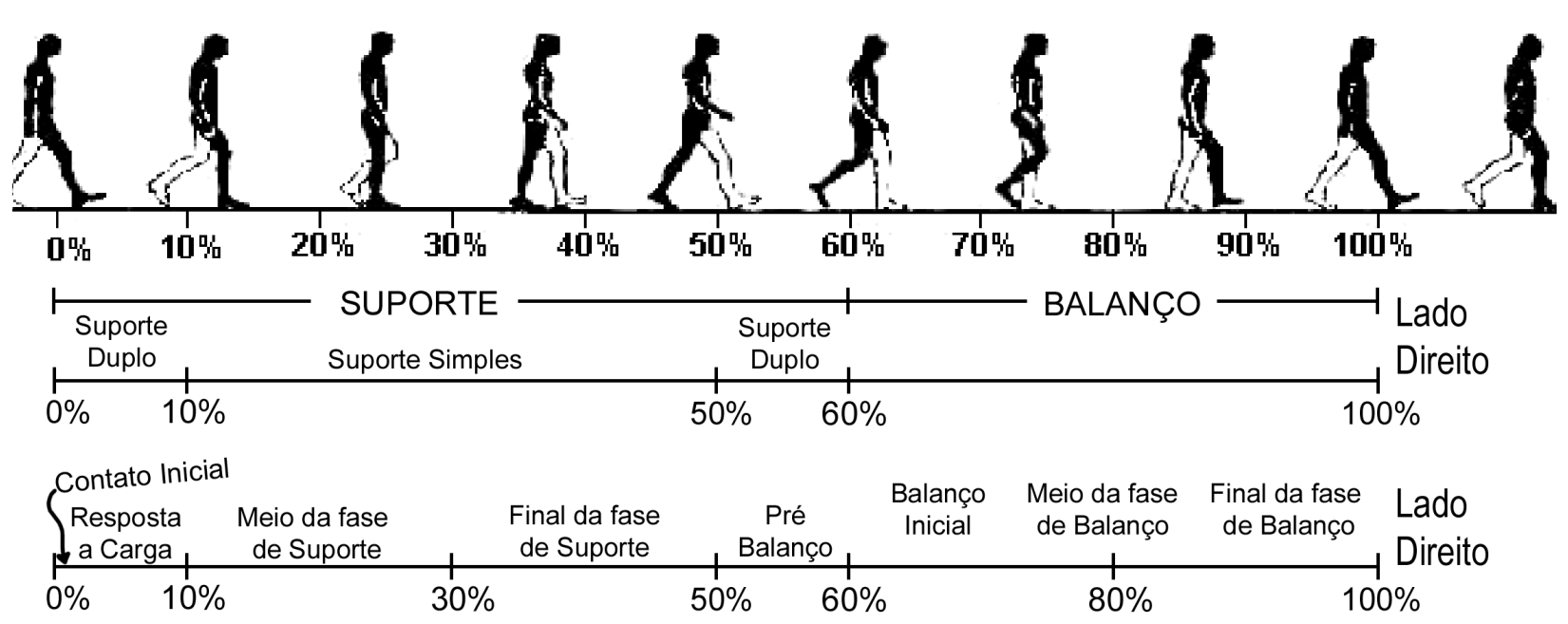

Fig. 4 - Divisões das fases da Marcha proposto por Perry (1992). (modificado de Franca, 2003).

A distância percorrida por um ciclo completo da marcha é denominada passada. Uma passada é definida dentro do intervalo de um evento sobre uma perna até uma nova ocorrência deste mesmo evento sobre a mesma perna. (figura 5). Um passo, no entanto, é definido dentro do intervalo de um mesmo evento entre pernas diferentes. 


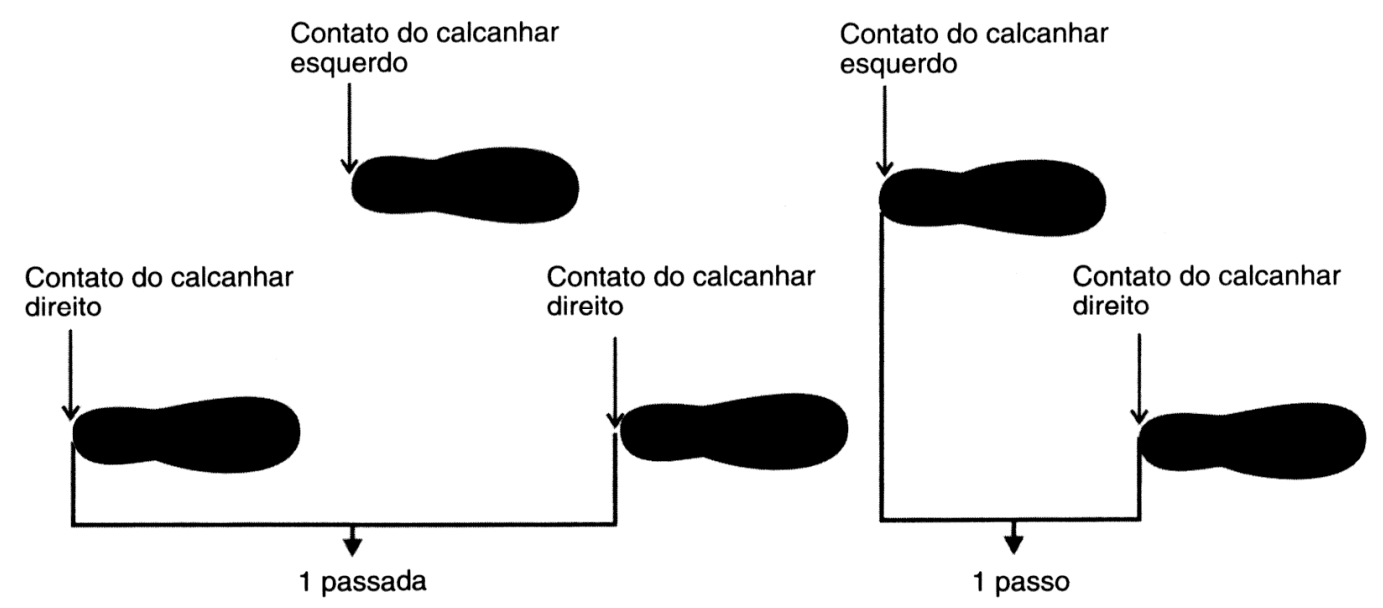

Fig. 5 - Parâmetros da passada durante a marcha (Hamill e Knutzen, 1999).

A marcha é caracterizada pelo comprimento da passada, frequência dos passos (cadência), tempo de um ciclo (uma passada) e a velocidade média. A velocidade média é calculada utilizando o comprimento da passada e a cadência (equação 1).

Veloc.Média $[\mathrm{m} / \mathrm{s}]=\frac{\text { Comp.Passada }[\mathrm{m}] \times \text { Cadência [passos } / \mathrm{min} \text { ] }}{120}$

\subsubsection{Marcha com andador}

A marcha com andador se diferencia da marcha normal principalmente pelo menor período da fase de balanço, já que o indivíduo gasta um tempo maior para realizar o avanço do andador e manter o corpo estabilizado. Nesta marcha a fase de suporte tem o acréscimo da fase de avanço do andador, situada entre a fase de resposta à carga de uma perna e o pré-balanço da outra perna. A fase de aceitação do peso inclui o contato inicial e a resposta à carga. Na figura 6 são apresentadas as fases da marcha com andador, obtidas por meio de um estudo com paraplégicos ao realizarem a marcha com andador e EENM. 

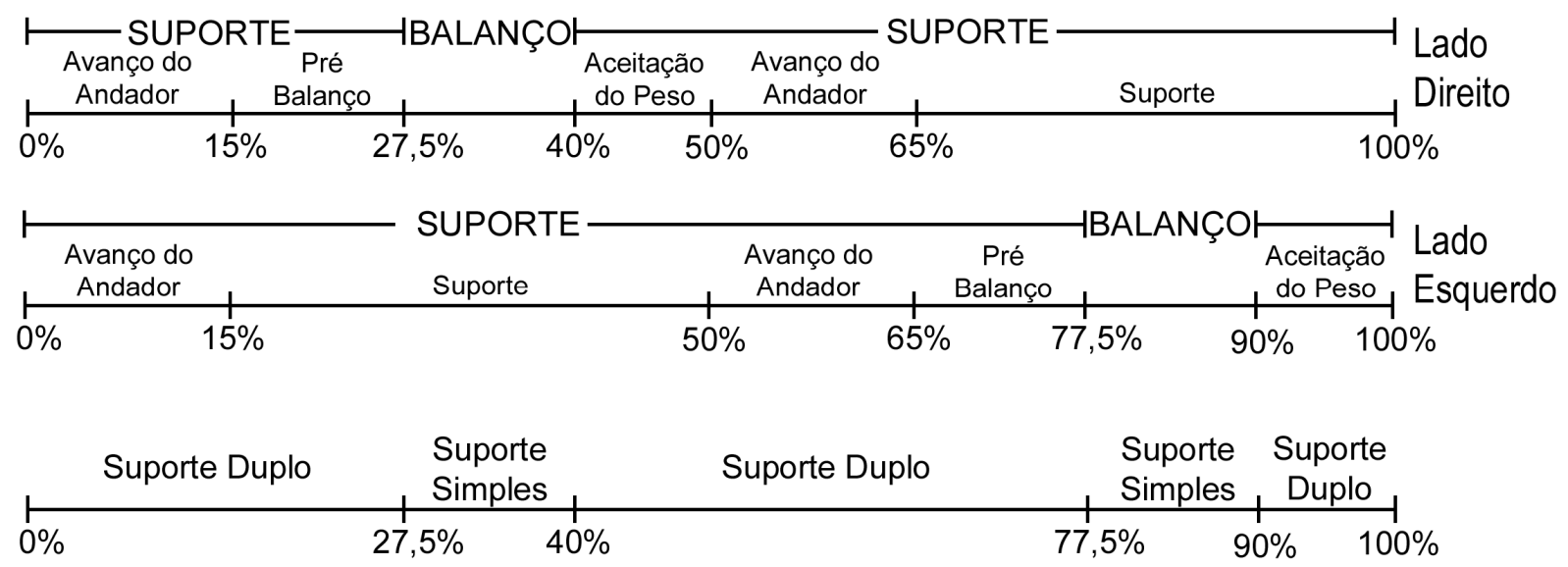

Fig. 6 - Fases da marcha com andador (Valores obtidos de Franca, 2003)

\subsubsection{Propulsão da cadeira de rodas}

Um dispositivo utilizado amplamente por pessoas incapacitadas de realizar a marcha é a cadeira de rodas.

As cadeiras de rodas podem ser tracionadas por motor ou manualmente. As cadeiras de rodas motorizadas normalmente utilizam motores elétricos de corrente contínua com potências próximas de $1 \mathrm{cv}$ (cavalo vapor). As cadeiras de rodas manuais são aquelas que requerem força humana para movimentação e podem ser propelidas por um assistente ou pelo próprio usuário.

As cadeiras de rodas tracionadas pelo próprio usuário apresentam rodas traseiras grandes (20 a 26 polegadas de diâmetro) que se assemelham a rodas de bicicleta. Junto a essas rodas são acoplados aros (com diâmetro ligeiramente menor ao das rodas) que permitem a propulsão da cadeira de rodas pelos membros superiores do ocupante.

A propulsão da cadeira de rodas pode ser dividida em duas fases: impulso e retorno. O impulso começa com os membros superiores posicionados para trás, com uma adução e elevação da cintura escapular, hiperextensão do ombro e flexão de 
cotovelo. O tronco também é flexionado contribuindo com a hiperextensão do ombro. A força da mão sobre o aro é aplicada por aproximadamente 90 graus (para corrida este angulo é maior chegando a 200 graus) e ao final da fase de impulso os membros superiores se aproximam da posição anatômica (figura 7). Durante a fase de retorno, o braço volta à posição inicial da fase de impulso, sem tocar no aro, e o tronco é estendido também voltando à posição inicial (HAMILL; KNUTZEN, 1999).

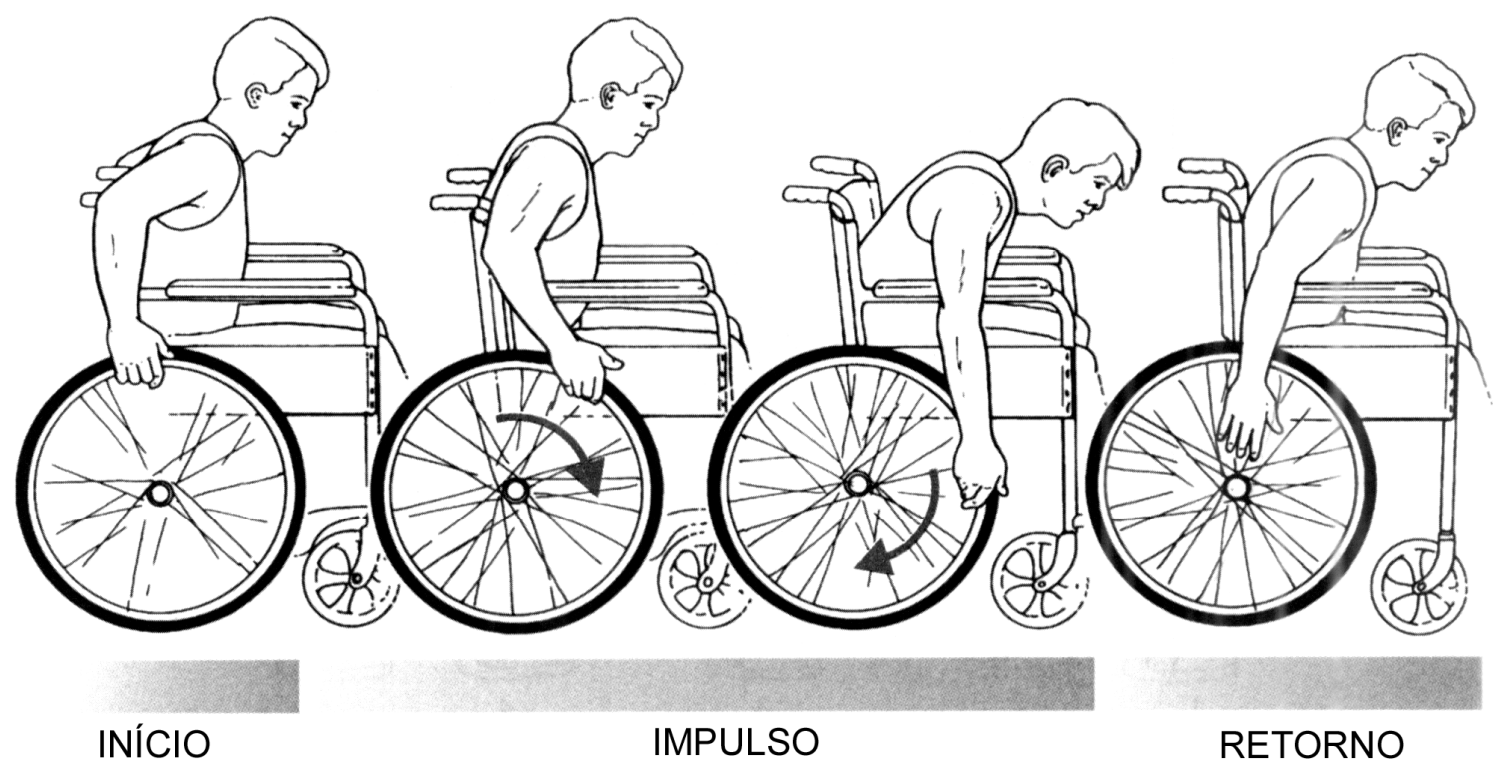

Fig. 7 - Fases da Propulsão da cadeira de rodas (Hamill e Knutzen, 1999). 


\subsection{Biomecânica do Ombro}

Neste item serão apresentados alguns conceitos e terminologias de biomecânica e também uma breve abordagem sobre anatomia funcional do ombro.

\subsubsection{Conceitos de Biomecânica}

A biomecânica pode ser definida como a aplicação dos conceitos da mecânica clássica em sistemas biológicos. O estudo da biomecânica envolve aplicações das Leis de Newton para modelar objetos biológicos com a finalidade de descrever seus comportamentos.

A descrição dos movimentos em biomecânica utiliza a terminologia apresentada a seguir.

\section{TERMINOLOGIA PARA MOVIMENTO EM BIOMECÂNICA}

A descrição dos movimentos é realizada a partir de uma posição de referência chamada posição anatômica, que mantêm o corpo ereto, pés juntos e paralelos, braços pendentes ao longo do corpo e palmas das mãos voltadas para frente (figura 8).

Os movimentos são analisados em 3 planos ortogonais que atravessam o corpo: sagital, transversal e frontal. O plano sagital é posicionado na direção ânteroposterior e divide o corpo em duas metades: direita e esquerda (neste plano são observados os movimentos visíveis de perfil). O plano transversal é um plano horizontal que divide o corpo em parte superior e inferior (sendo visíveis movimentos observados de cima para baixo). O plano frontal é posicionado na direção médio lateral e divide o corpo na parte anterior e posterior (neste plano são observados movimentos visíveis de frente). (figura 8). 


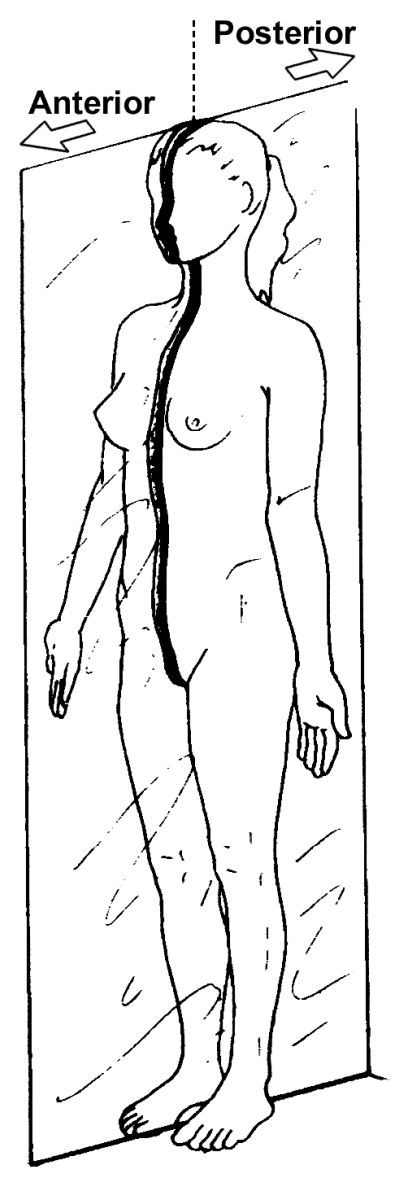

\section{Plano Sagital}

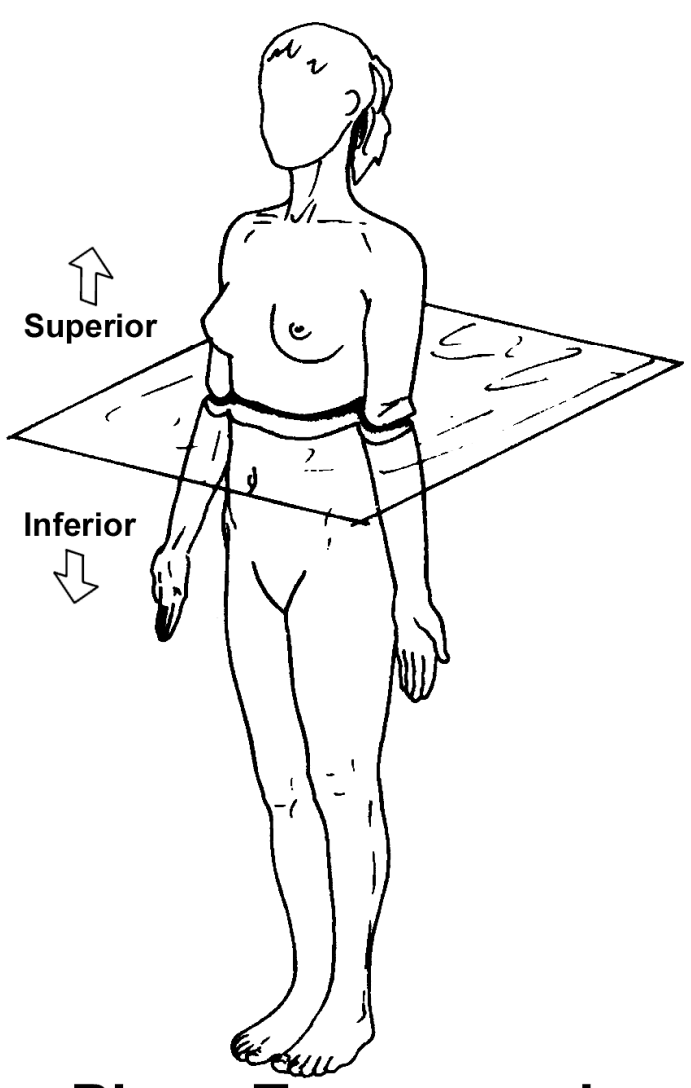

Plano Transversal

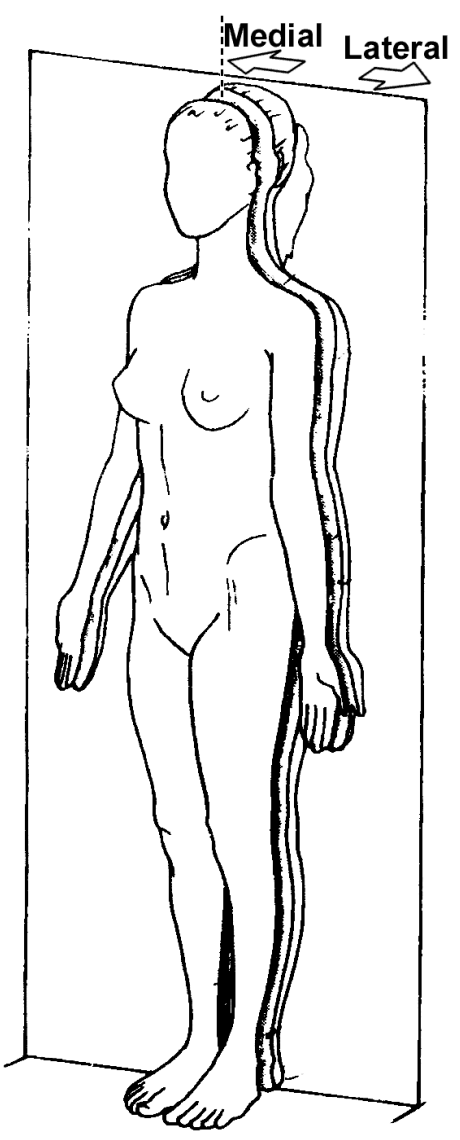

Plano Frontal

Fig. 8 - Posição anatômica nos três planos de movimento. Os sentidos dos movimentos em cada plano também estão indicados (modificado de Calais-Germain, 1991).

Existem seis movimentos básicos que podem ocorrer em diferentes combinações nas articulações do corpo: flexão, extensão, adução, abdução, rotação medial e lateral. Cada plano está associado a um par de movimentos. Os movimentos de extensão e flexão ocorrem no plano sagital. A flexão leva uma parte do corpo para frente da posição anatômica, e a extensão para trás. Os movimentos de adução e abdução são observados no plano frontal. Adução é o movimento de uma parte do corpo no sentido medial, e a abdução o movimento realizado no sentido lateral. Os movimentos de rotação são visíveis no plano transversal. A rotação interna leva uma parte do corpo no sentido medial e a rotação externa no sentido lateral (figura 9). 


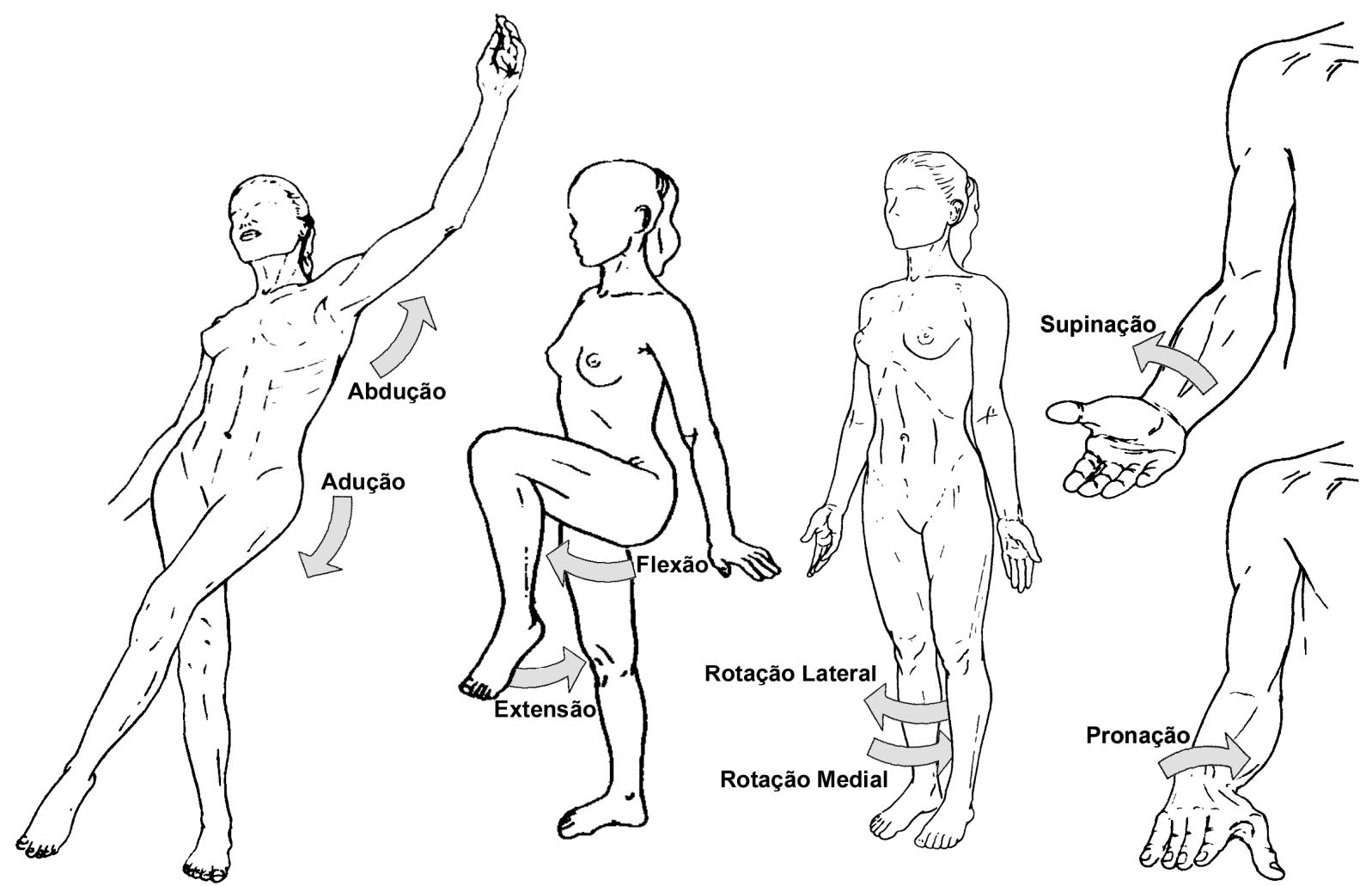

Fig. 9 - Terminologia dos movimentos (modificado de Calais-Germain, 1991).

As análises biomecânicas podem ser conduzidas a partir de duas perspectivas: cinemática e cinética.

\section{ANÁLISE CINEMÁTICA}

A análise cinemática está relacionada com as características do movimento, considerando variáveis temporais e espaciais, sem levar em conta as forças que causam o movimento. A cinemática descreve o movimento utilizando parâmetros como posição, velocidade e aceleração de um corpo.

Um movimento linear ocorre em uma trajetória que pode ser aproximada por uma linha reta. Todas as partes do objeto percorrem a mesma distância, na mesma direção e ao mesmo tempo. O movimento pode ser retilíneo ou curvilíneo dependendo da trajetória.

Quando um objeto se movimenta em torno de um ponto fixo o movimento é chamado de angular. Todas as partes do objeto se movem por um mesmo ângulo, na mesma direção, ao mesmo tempo, não percorrendo necessariamente a mesma 
distância. Os deslocamentos são mensurados em ângulos e utiliza-se velocidade e aceleração angular neste tipo de análise.

De modo geral, a maioria dos movimentos realizados pelo corpo é angular. No entanto, algumas exceções são encontradas, como por exemplo, o movimento linear da escápula durante elevação/depressão ou adução/abdução (figura 12).

Existem vários métodos para coleta de dados cinemáticos. Alguns exemplos de sensores utilizados em análises cinemáticas são: acelerômetros, eletrogoniômetros, e métodos cinemétricos. O processamento das imagens (cinemetria) é o método mais comum de obter dados cinemáticos. Esta técnica utiliza marcadores fixados sobre a pele em pontos de referência no corpo, e depois de coletados os dados são realizados cálculos matemáticos (baseados em dados antropométricos) para encontrar os centros das articulações e os centros de massa dos membros.

\section{ANÁLISE CINÉTICA}

A cinética é a área que estuda as forças que agem em um sistema causando movimento. Assim como a cinemática, a cinética pode ser dividida em cinética linear e angular. A cinética linear trata sobre forças que aplicadas aos objetos causam deslocamentos em trajetórias lineares e a cinética angular trata sobre forças que causam um movimento de giro nos objetos, gerando um torque ou momento de força.

As Leis do Movimento descritas por Isaac Newton em seu livro: Principia Mathematica de 1687 formam a base mecânica para o estudo da cinética.

\section{1.) Primeira Lei de Newton - Lei da Inércia}

“Um corpo continua em seu estado de repouso, ou de movimento uniforme em linha reta, a menos que seja compelido a mudar de estado por forças colocadas sobre ele" 
A lei da inércia afirma que um objeto permanece continuamente no estado em que se encontra (repouso ou movimento) até que sofra uma força externa, ou seja, esta lei é utilizada para descrever a resistência de um objeto ao movimento. Quanto maior a massa de um objeto, maior sua inércia, e assim maior a dificuldade de alterar sua velocidade.

\section{2.) Segunda Lei de Newton - Lei da Aceleração}

"A mudança de movimento é proporcional à força impressa e é feita na direção da linha reta na qual a força é impressa"

A segunda lei de Newton (da aceleração) descreve um objeto quando sai da inércia, ou seja, quando existe uma força externa agindo sobre ele que altera sua velocidade e aceleração em proporção direta a força aplicada. A massa continua contribuindo como resistência ao movimento. Desta maneira a aceleração é inversamente proporcional à massa. A equação 2 relaciona a força aplicada a um objeto com a sua aceleração em movimentos lineares (análise cinética linear).

$$
\overrightarrow{\mathrm{F}}=\mathrm{m} \cdot \overrightarrow{\mathrm{a}}
$$

\section{3.) Terceira Lei de Newton - Lei da Ação e Reação}

"A cada ação corresponde uma reação igual e oposta; ou, a ação mútua de dois corpos, um sobre o outro é sempre igual e dirigida a partes contrárias."

A terceira lei de Newton diz que para toda ação existe uma reação, ou seja, nenhuma força existe isoladamente, mas aos pares. As forças de ação e reação apresentam módulos iguais e sentidos opostos. Apesar das forças apresentarem 
módulos iguais terão respostas diferentes dependendo da massa dos corpos em questão.

A aplicação de uma força sobre um objeto pode originar um movimento de giro em torno de um ponto. Neste caso diz-se que a força gerou um torque ou momento de força. Como o corpo humano se move por uma série de articulações (que realizam em sua maioria deslocamentos angulares) o valor do torque que um músculo desenvolve é uma conveniente medida para avaliar o seu efeito.

O torque não é uma força, mas a efetividade de uma força para causar rotação em um eixo específico. Desta forma qualquer discussão sobre torque precisa ser com referência a um eixo específico. A distância perpendicular entre o eixo de rotação e o ponto de aplicação da força é conhecida como braço de alavanca da força. A magnitude do torque pode ser calculada pela multiplicação da força que o gerou $(\mathrm{F})$ com o braço de alavanca $(\mathrm{d})$. A equação 3 apresenta a equação do torque.

$$
/ \mathrm{T} /=/ \mathrm{F} / \cdot / \mathrm{d} /
$$

Como o braço de alavanca $(\mathrm{d})$ deve ser perpendicular à força $(\mathrm{F})$, e o torque (T) é um vetor é ortogonal a estes dois vetores, então o torque pode ser calculado pelo produto vetorial do braço de alavanca pela força.

$$
\overrightarrow{\mathrm{T}}=\overrightarrow{\mathrm{d}} \times \overrightarrow{\mathrm{F}}
$$

O conceito de torque pode ser utilizado para definir o centro de massa de um objeto. O centro de massa é o ponto onde a massa do objeto está uniformemente distribuída, constituindo-se o ponto de equilíbrio. Desta forma, no centro de massa a soma dos torques é nula. 


$$
\sum \overrightarrow{\mathrm{T}_{\mathrm{cm}}}=0
$$

A posição do centro de massa pode ser obtida adotando-se como ponto de giro uma posição diferente do centro de massa. Neste caso, o torque de cada parte do objeto será igual ao torque total deste objeto, conforme a equação 6 .

$$
\begin{gathered}
\overrightarrow{\mathrm{T}_{1}}+\overrightarrow{\mathrm{T}_{2}}+\ldots+\overrightarrow{\mathrm{T}_{\mathrm{N}}}=\overrightarrow{\mathrm{T}_{\text {Total }}} \\
\overrightarrow{\mathrm{F}_{1}} \times \overrightarrow{\mathrm{d}_{1}}+\overrightarrow{\mathrm{F}_{2}} \times \overrightarrow{\mathrm{d}_{2}}+\ldots+\overrightarrow{\mathrm{F}_{\mathrm{N}}} \times \overrightarrow{\mathrm{d}_{\mathrm{N}}}=\overrightarrow{\mathrm{F}_{\text {Total }}} \times \overrightarrow{\mathrm{d}_{\text {Total }}}
\end{gathered}
$$

Cada torque é gerado pela sua respectiva força, aplicada no correspondente braço de alavanca. A distância $\mathrm{d}_{\text {Total }}$ é o braço de alavanca da força $\mathrm{F}_{\text {Total }}$, ou seja é o ponto onde toda a força é aplicada ao objeto. Como a força total aplicada a um objeto é feita no centro de massa então $\mathrm{d}_{\text {Total }}$ é a distância do centro de massa. Desta forma, é possível obter o centro de massa de um objeto pela equação 7.

$$
\overrightarrow{\mathrm{d}_{\mathrm{CM}}}=\frac{\overrightarrow{\mathrm{F}_{1}} \times \overrightarrow{\mathrm{d}_{1}}+\overrightarrow{\mathrm{F}_{2}} \times \overrightarrow{\mathrm{d}_{2}}+\ldots+\overrightarrow{\mathrm{F}_{\mathrm{N}}} \times \overrightarrow{\mathrm{d}_{\mathrm{N}}}}{\overrightarrow{\mathrm{F}_{\text {Total }}}}
$$

Se um objeto não tiver influência de forças externas, ou seja, estiver submetido apenas à força peso originada pela ação da gravidade, pode-se representar a equação 7 pelas massas dos elementos que compõem o objeto (equação 8):

$$
\overrightarrow{\mathrm{d}_{\mathrm{CM}}}=\frac{\mathrm{m}_{1} \cdot \overrightarrow{\mathrm{d}_{1}}+\mathrm{m}_{2} \cdot \overrightarrow{\mathrm{d}_{2}}+\ldots+\mathrm{m}_{\mathrm{N}} \cdot \overrightarrow{\mathrm{d}_{\mathrm{N}}}}{\text { Massa }_{\text {Total }}}
$$

Desta forma, pode-se calcular a posição do centro de massa do corpo humano sabendo-se as massas e as posições de cada segmento do corpo. As posições são 
obtidas através da análise cinemática, porém as massas e centros de massa de cada segmento devem ser conhecidos previamente. Estas informações, chamadas de antropométricas, foram estudadas essencialmente por três métodos: 1) medidas baseadas em estudos de cadáveres, 2) modelos matemáticos, 3) exame de imagens médicas (raio-x ou similares). (HAMILL; KNUTZEN, 1999).

Dempster et al. (1959), Clauser et al. (1969) e Chandler et al. (1975) realizaram estudos com cadáveres e obtiveram equações para as massas e centros de massas de cada segmento do corpo em função do peso total corporal e extensão dos segmentos.

Hanavan (1964) e Hartze (1980) utilizaram modelos matemáticos para prever as massas e a localização dos centros de massa dos segmentos, nestes métodos os segmentos do corpo são aproximados por formas geométricas conhecidas (cones, cilindros, esferas, etc.). A figura 10 apresenta a representação geométrica do corpo utilizada por Hanavan (1964). O uso deste método requer medidas adicionais dos segmentos, como por exemplo, a circunferência superior e inferior da coxa, além da massa total e do comprimento do segmento.

Zatsiorsky e Seluyanov (1983) e de Leva (1996) obtiveram a massa por unidade de área dos segmentos do corpo humano, in vivo, utilizando imagens de raios-gama.

Estes três métodos têm sido utilizados em pesquisas para determinar as características e centros de massa dos segmentos do corpo humano, e apresentam estimativas razoáveis destes parâmetros (HAMILL; KNUTZEN, 1999). 


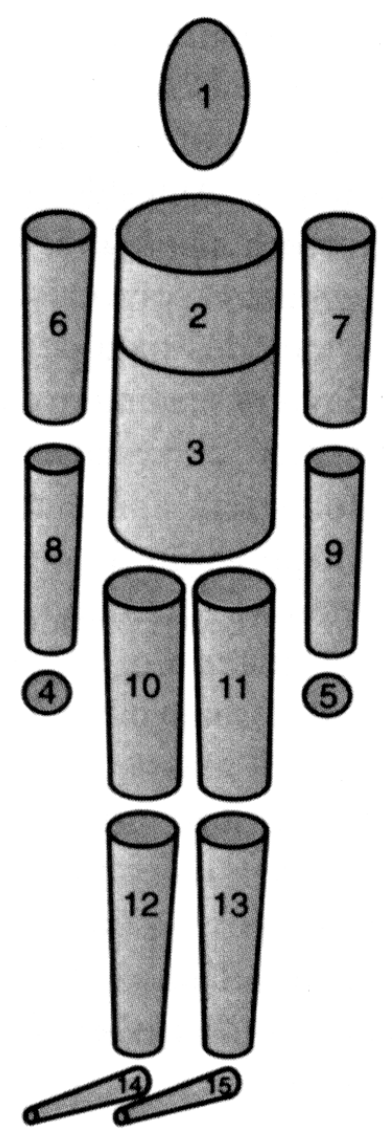

Fig. 10 - Representação dos segmentos geométricos do corpo utilizado por Hanavan (1964). (obtido de Hamill e Knutzen, 1999) 


\section{ATIVIDADE MUSCULAR}

A avaliação da atividade muscular é um método frequentemente utilizado em análises biomecânicas. A contração de um músculo ocorre quando um potencial de ação percorre as fibras musculares liberando cálcio e induzindo a aproximação das proteínas que compõe estas fibras (ORTOLAN, 2002). Um eletrodo localizado próximo destes potenciais de ação é capaz de detectar o potencial elétrico referente à contração muscular, este potencial é chamado de Sinal Mioelétrico (SME).

O SME pode ser obtido por meio de eletrodos monopolares ou bipolares. A configuração monopolar obtém diferenças de potenciais entre dois pontos, sendo um deles o ponto de referência. Na configuração bipolar são obtidos dois sinais em relação a uma referência, e posteriormente são subtraídos, neste caso são necessários três pontos de detecção. Para as duas configurações normalmente utilizam-se eletrodos confeccionados com prata revestida com cloreto de prata (Ag$\mathrm{AgCl}$ ), pois é um metal nobre não polarizável, evitando assim a oxidação e indução de um nível DC nos eletrodos de detecção.

Os eletrodos para captação do SME podem ser invasivos ou não invasivos. Os eletrodos invasivos são de fio ou de agulha. Pelo fato de estarem em contato com o fluído corpóreo, que possui baixa resistência, não necessitam de gel condutor. Estes eletrodos, comparados com eletrodos não invasivos, captam maiores amplitudes e espectro de potência mais amplo, com frequências até $10 \mathrm{kHz}$ (OLSON, 1998).

Eletrodos invasivos são utilizados principalmente em análises clínicas, pois são capazes de detectar até mesmo o potencial de ação de uma única unidade motora e explorar a atividade isolada de músculos profundos. Tais eletrodos embora permitam a aquisição de sinais que mostrem o comportamento da unidade motora em detalhes, possuem vários inconvenientes como a necessidade de excelente 
esterilização e o perigo da quebra dos fios dentro do músculo, além disso, ainda existe a questão do desconforto do paciente (BASMAJIAN; DeLUCA, 1985).

A aquisição não invasiva do SME, utilizando eletrodos de superfície, é um método conveniente para análise do movimento (apesar de produzir uma informação grosseira sobre as fibras musculares em investigações clinicas), pois capta a atividade de todo um músculo ou grupo muscular. Eletrodos de superfície são capazes de captar sinais até $500 \mathrm{~Hz}$ com amplitudes variando entre $50 \mu \mathrm{V}$ e $5 \mathrm{mV}$ dependendo do músculo analisado e da configuração do eletrodo utilizado. A densidade espectral de potência do SME é estimada para várias aplicações clínicas, como tremores patológicos e análise de fadiga muscular (ALMEIDA, 1997).

Eletrodos de superfície podem ser ativos ou passivos. O eletrodo passivo consiste de um disco de $\mathrm{Ag}-\mathrm{AgCl}$, que deve ser posicionado acima da pele. Em geral estes eletrodos são utilizados em conjunto com um gel ou pasta condutora contendo íons cloro, a fim de diminuir a impedância de contato entre o eletrodo e a pele. Para melhores resultados, pode-se remover a camada superficial da pele com o uso de um gel abrasivo, e normalmente é necessário realizar a raspagem dos pelos (tricotomia) na área onde o eletrodo será posicionado. Eletrodos passivos podem ser reutilizáveis ou descartáveis, sendo que os descartáveis normalmente vêm com gel condutor e adesivo, para manter-se em contato com a pele. Eletrodos não descartáveis são fixados com cintas ou fitas adesivas (ORTOLAN, 2002).

Eletrodos ativos possuem um circuito de amplificação encapsulado no próprio eletrodo. Normalmente estes eletrodos são bipolares, ou seja, o amplificador utilizado é diferencial. Tais eletrodos também são chamados de eletrodos secos, pois normalmente não necessitam o uso de gel condutor, pasta abrasiva ou a retirada dos pelos (DELSYS INC., 1996). 
O estudo e a captação da atividade muscular por meio do SME são definidos como EMG (eletromiografia). A EMG teve início com a finalidade estritamente clínica, e se desenvolveu fortemente como ferramenta diagnóstica durante a segunda guerra mundial. Hoje em dia o SME tem sido usado por profissionais nas áreas de Anatomia, Reabilitação, Fisioterapia, Esportes, Educação Física, Medicina, Odontologia, Fonoaudiologia, etc. (CLARYS; LEWILLIE, 1992; ORTOLAN et al., 2005).

Existem três formas básicas de contração muscular: isométrica, isotônica (concêntrica) e isotônica (excêntrica).

Contrações isométricas são realizadas quando um músculo se contrai, produzindo força, sem alterar seu comprimento. Desta forma o músculo se contrai, mas não gera nenhum movimento. O ângulo da articulação não muda.

Quando ocorre variação no angulo da articulação a contração muscular é chamada de isotônica. Uma contração isotônica concêntrica ocorre quando o músculo diminui de comprimento enquanto realiza o movimento do membro (a origem e a inserção do músculo se movem uma em direção à outra). Na contração isotônica excêntrica o movimento realizado é ao contrário, o músculo aumenta seu comprimento enquanto está sendo contraído (a origem e a inserção muscular se distanciam uma da outra).

Na análise biomecânica normalmente são extraídos parâmetros dos SME para efeitos de comparação. Parâmetros temporais e espectrais podem ser obtidos dos sinais mioelétricos para quantificar a contração muscular (ORTOLAN et al., 2004).

As equações de 9 a 12 são exemplos de cálculos de parâmetros temporais. Considerando que $x(i)$ é o valor do SME no instante $i$, com a equação 9 pode-se obter a área sob a curva em janelas de $N$ amostras (a área é equivalente à integral do sinal). O valor RMS (Root Mean Square) está relacionado com a quantidade de 
energia contida no sinal e é obtido pela raiz da média quadrática dentro de uma janela de $N$ amostras conforme descrito pela equação 10.

$$
\begin{gathered}
\text { Área }=\sum_{i=1}^{N} / x(i) / \\
\text { RMS }=\sqrt{\frac{1}{N} \cdot \sum_{i=1}^{N} x(i)^{2}}
\end{gathered}
$$

A equação 11 apresenta o valor da média retificada, também conhecida como MAV (Mean Absolute Value). O valor do MAV e da área estão fortemente correlacionados já que o que diferencia os dois é uma constante relativa ao tamanho da janela de análise $(N)$. A diferença entre as amostras (soma do valor absoluto da derivada, que está expressa na equação 12), está relacionada com a taxa de variação do sinal, desta forma altos valores indicam a presença de componentes frequenciais de alta ordem.

$$
\begin{aligned}
& \text { Média Retificada }=\frac{1}{N} \cdot \sum_{i=1}^{N} / x(i) / \\
& \underset{\text { Diferença entre }}{\text { amostras }}=\sum_{i=1}^{N-1} / x(i+1)-x(i) /
\end{aligned}
$$

Com relação aos parâmetros espectrais estes são obtidos a partir do espectro de densidade de potência (EDP), calculados a partir da transformada de Fourier (equação 13).

$$
\operatorname{EDP}(i)=\frac{|F F T[x(i)]|^{2}}{N}
$$


Com a obtenção do Espectro de Densidade de Potência (EDP) é possível obter os parâmetros espectrais. As equações 14, 15, 16 são exemplos de cálculos de parâmetros espectrais. A área sob o EDP (equação 15) indica a quantidade de energia contida no sinal. A frequência mediana (equação 16) é a frequência no espectro de potência que divide a área sob a curva do EDP em duas áreas iguais. Segundo Basmajian e DeLuca (1985) a frequência mediana é útil para identificar fadiga muscular (músculos que começam a fadigar tendem a apresentar valores menores de frequências medianas).

$$
\text { Máximo Valor no } \mathrm{EDP} \Rightarrow \max (E D P(i))
$$

$$
\text { Área sob o EDP }=\sum_{i=1}^{N} E D P(i)
$$

Frequência Mediana $=n_{F} \cdot F_{S} / N$ tal que:

$$
\sum_{i=1}^{n_{F}} \operatorname{EDP}(i)=\sum_{i=n_{F}}^{N} E D P(i)=\frac{1}{2} \cdot \sum_{i=1}^{N} E D P(i)
$$




\subsubsection{Ombro}

O ombro não é uma articulação única, mas um conjunto de articulações que permite o movimento do braço em relação ao tronco.

Estes movimentos normalmente ocorrem por meio de complexas interações entre os movimentos individuais das articulações acromioclavicular, glenoumeral, esternoclavicular e escapulotorácica.

\section{OSSOS DO OMBRO}

Os ossos que participam da articulação do ombro são: clavícula, escápula e úmero. A escápula é um osso achatado capaz de se deslocar linearmente nas costas, proporcionando assim uma maior amplitude no movimento do braço. O úmero é o osso do braço e a clavícula o osso que conecta a escápula ao tronco (figura 11)

O ponto de contato entre os ossos do ombro e o tronco é a articulação esternoclavicular (conexão entre clavícula e o esterno). Os movimentos da clavícula na articulação esternoclavicular ocorrem nas três direções (elevação/depressão, anterior/posterior e de rotação). A clavícula é conectada à escápula em sua extremidade distal pela articulação acromioclavicular, esta articulação possibilita movimentos da escápula em três direções (elevação/depressão, adução/abdução e rotação) (HAMILL; KNUTZEN, 1999). A figura 11 apresenta as articulações do ombro e a figura 12 os movimentos escapulares.

A escápula mantém contato com o tórax por meio da articulação escapulotorácica. Essa não é uma articulação verdadeira em termos anatômicos (osso com osso), pois entre a escápula e o tórax existem dois músculos que servem de apoio à escápula e a mantém separada dos ossos do tórax: serrátil anterior e subescapular. 
A articulação glenoumeral conecta a escápula ao úmero (figura 11). É uma articulação "bola e soquete" com diversos ligamentos e bursas, é formada pela grande cabeça do úmero e pela pequena fossa glenóide (a cavidade glenóide apresenta um quarto do tamanho da cabeça do úmero que poderia se encaixar nela) (HAMILL; KNUTZEN, 1999). Como o contato entre a cavidade glenóide e a cabeça do úmero é pequeno, a estabilização desta articulação é realizada por ligamentos e músculos, principalmente por quatro músculos mais profundo inseridos no úmero que formam um conjunto de ligamentos ativos denominado manguito rotador.

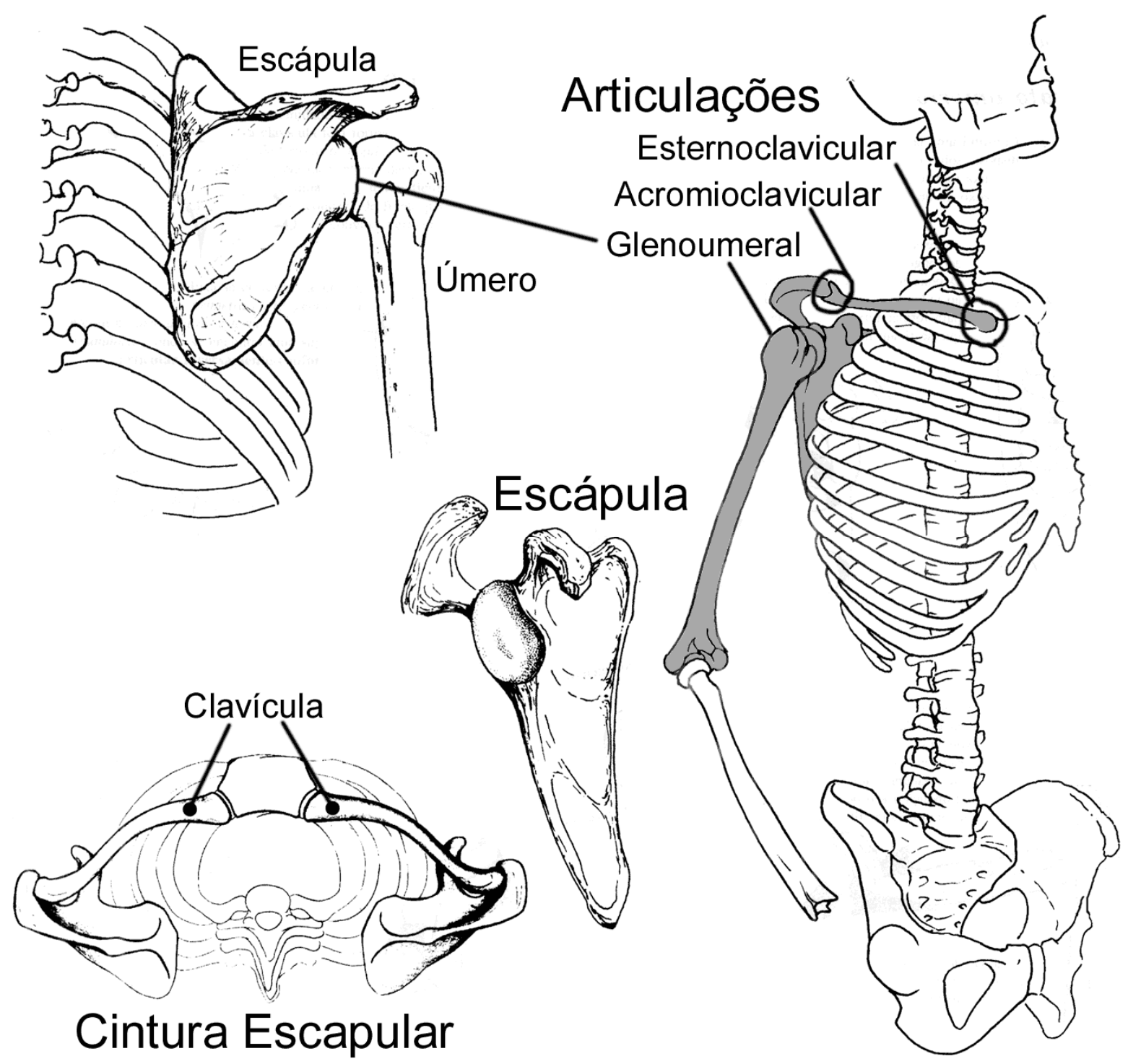

Fig. 11 - Ossos e articulações do ombro (modificado de Calais-Germain, 1991). 

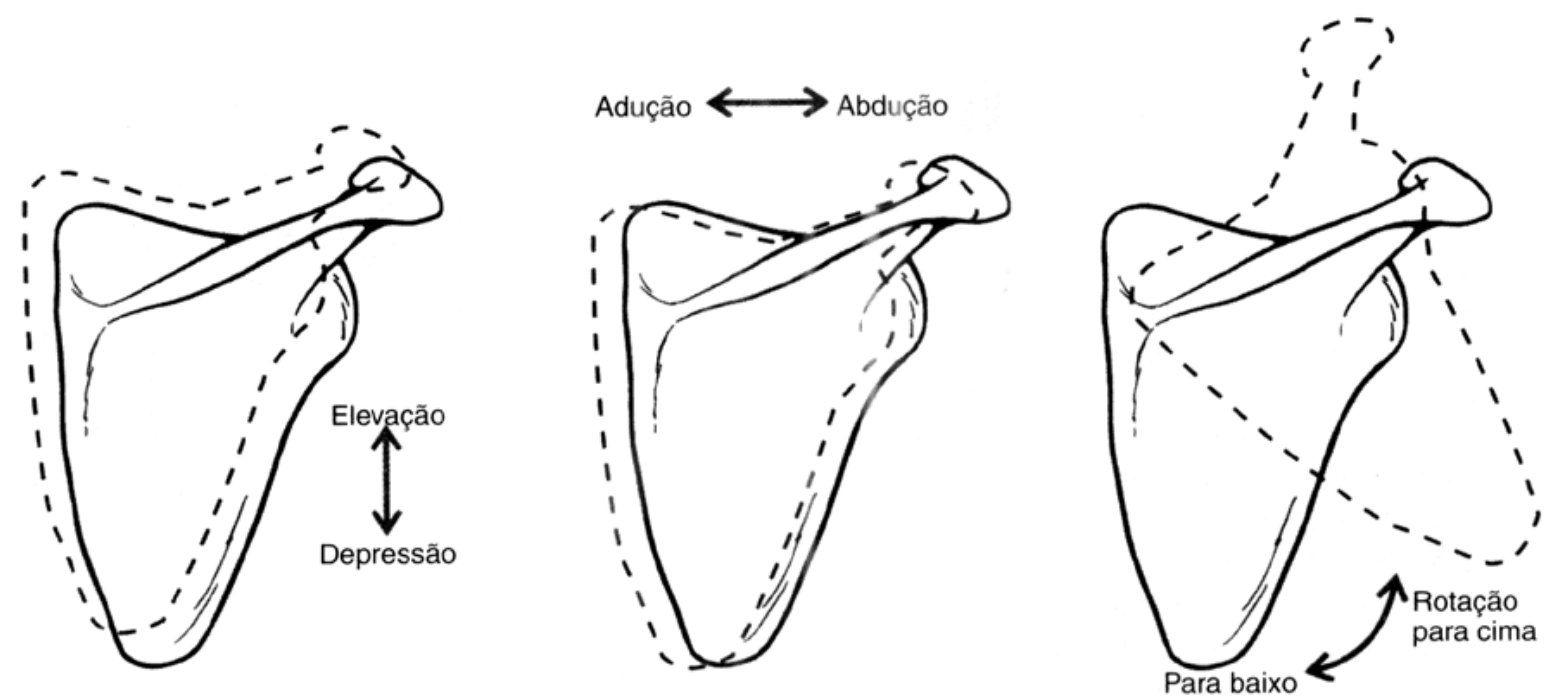

Fig. 12 - Movimentos realizados pela escápula (Hamill e Knutzen, 1999).

\section{MÚSCULOS DO OMBRO}

Vinte diferentes músculos agem sobre a cintura escapular, e alguns destes músculos ainda podem ser divididos de acordo com sua função, como o deltóide (3 partes), bíceps (2 partes), peitoral maior (2) e trapézio (3). Os músculos que compõem o complexo do ombro podem ser divididos em três classes de acordo com sua origem e inserção: escapuloumeral, escapulotorácica e toracoumeral. Os músculos escapuloumerais profundos compõem o manguito rotador (supraespinhal, infraespinhal, subescapular e redondo menor). A tabela 2 apresenta a distribuição dos músculos na cintura escapular.

Tab. 2 - Distribuição dos músculos na cintura escapular, classificados quanto a sua origem, inserção e localização (profundo ou superficial)

\begin{tabular}{|c|c|c|c|c|}
\hline \multirow{2}{*}{ Localização } & \multicolumn{4}{|c|}{ Classificação dos músculos do ombro quanto a sua origem e inserção } \\
\hline & Escapuloumeral & Escapulotorácica & Toracoumeral & Outros \\
\hline \multirow{4}{*}{$\begin{array}{l}\text { Músculos } \\
\text { profundos }\end{array}$} & Supraespinhal & Peitoral Menor & \multirow{4}{*}{-} & \\
\hline & Infraespinhal & Elevador da Escápula & & Subclávio \\
\hline & Subescapular & Rombóide Maior & & Omo-hioideo \\
\hline & Redondo Menor & Romboide Menor & & \\
\hline \multirow{5}{*}{$\begin{array}{l}\text { Músculos } \\
\text { superficiais }\end{array}$} & Redondo Maior & \multirow{5}{*}{$\begin{array}{l}\text { Trapézio ( } 3 \text { partes) } \\
\text { Serrátil Anterior }\end{array}$} & \multirow{5}{*}{$\begin{array}{l}\text { Peitoral Maior (esternocostal) } \\
\text { Grande Dorsal }\end{array}$} & \\
\hline & Coracobraquial & & & Esternocleidomastóideo \\
\hline & Bíceps (cabeça curta) & & & Peitoral Maior (clavicular) \\
\hline & Tríceps (cabeça longa) & & & Bíceps (cabeça longa) \\
\hline & Deltóide (3 porções) & & & \\
\hline
\end{tabular}


A disposição dos músculos do ombro é apresentada nas figuras 13 e 14 .

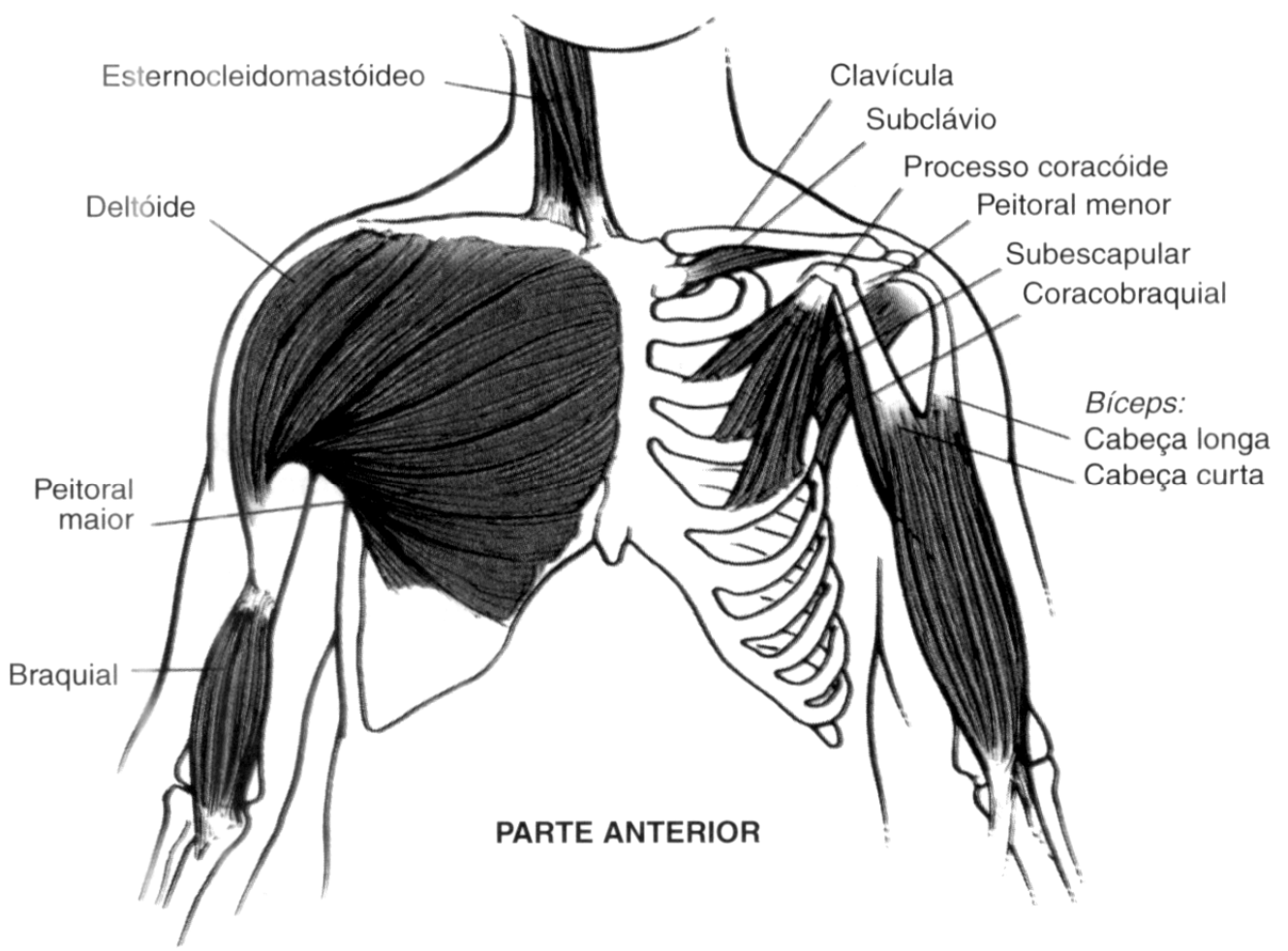

Fig. 13 - Músculos do complexo do ombro. Parte anterior. (Hamill e Knutzen, 1999).

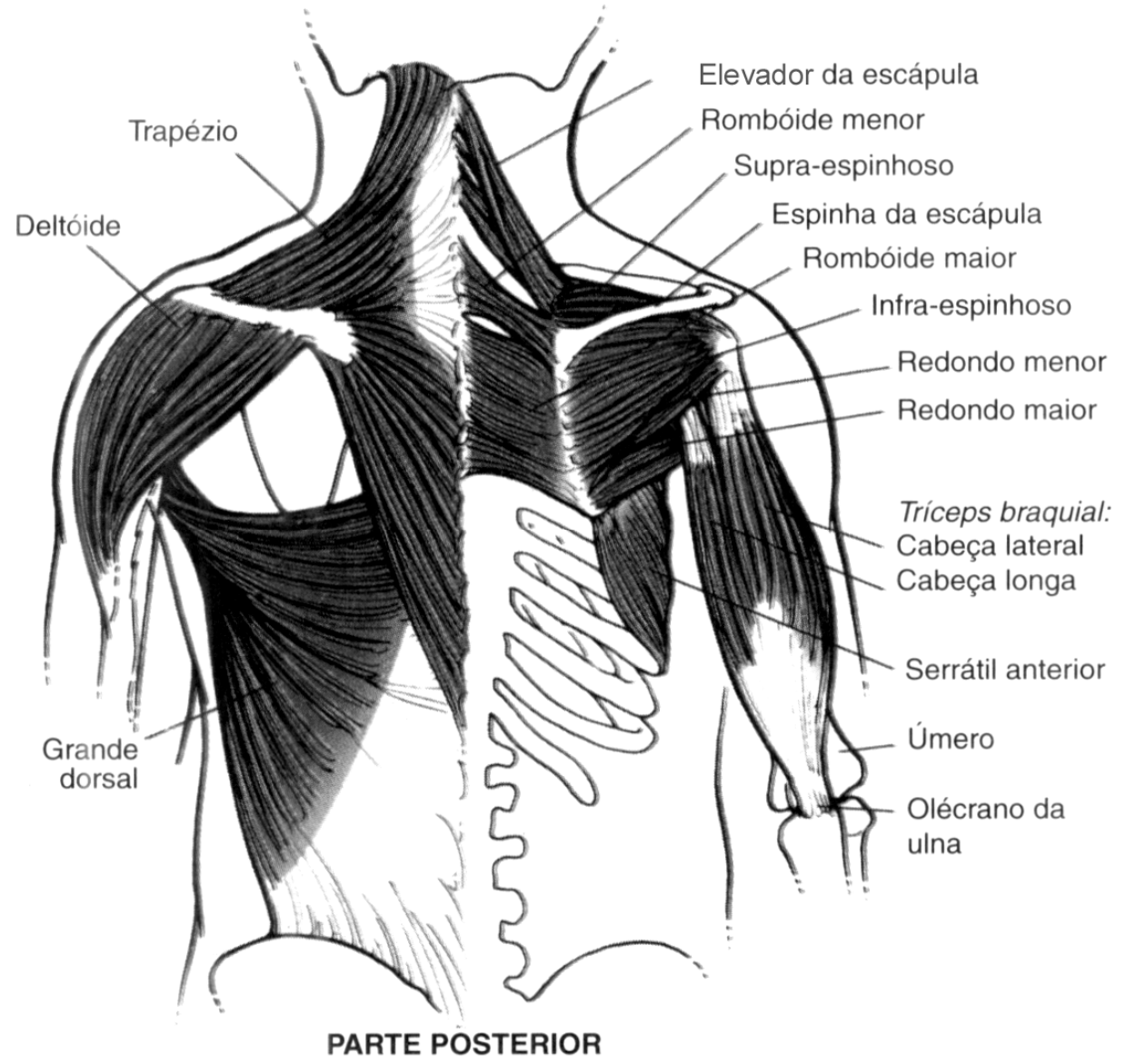

Fig. 14 - Músculos do complexo do ombro. Parte posterior. (Hamill e Knutzen, 1999). 


\subsection{Esforço nos Membros Superiores}

A maioria dos pacientes com lesão medular apresenta dores nos ombros, devido à excessiva carga aplicada nestas articulações durante as atividades diárias (GIANINI et al., 2006; JENSEN et al., 2005; SALISBURY et al., 2003; BALLINGER et al., 2000).

A propulsão manual da cadeira de rodas é uma importante forma de locomoção para pacientes com deficiência nos membros inferiores, e o ombro é um complexo conjunto de articulações que realiza uma importante função na propulsão da cadeira de rodas. Devido ao grande esforço realizado pelo ombro, durante esta atividade, vários usuários de cadeiras de rodas apresentam dores nestas articulações.

Finley e Rodgers (2004) realizando um estudo com 52 pacientes reportaram que $60 \%$ apresentam dores nos ombros desde que começaram a utilizar a cadeira de rodas.

Boninger et al. (2002) encontrou 4 padrões de propulsão da cadeira de rodas em estudo com pacientes paraplégicos (figura 15). A fase de impulso para os padrões semicircular (a), laço simples (b) e laço duplo (c) são praticamente iguais enquanto que para o padrão arqueado (d) a trajetória de impulso é menor. A fase de retorno é diferente para cada padrão. Os picos de força encontrados para cada padrão foram de $60,5 \mathrm{~N}$ para o Semicircular (a), 70,8N para o Laço Simples (b), 86,2N para o Laço Duplo (c) e 68,7N o para Arqueado (d) (BONINGER et al., 2002).

De acordo com Kulig et al. (2001) o esforço maior é durante a fase de impulso da cadeira de rodas, sendo que na fase de retorno o pico de força horizontal é de $50 \%$ a $70 \%$ menor comparado à fase de impulso, e para o torque é cerca de $60 \%$ a $90 \%$ menor. 

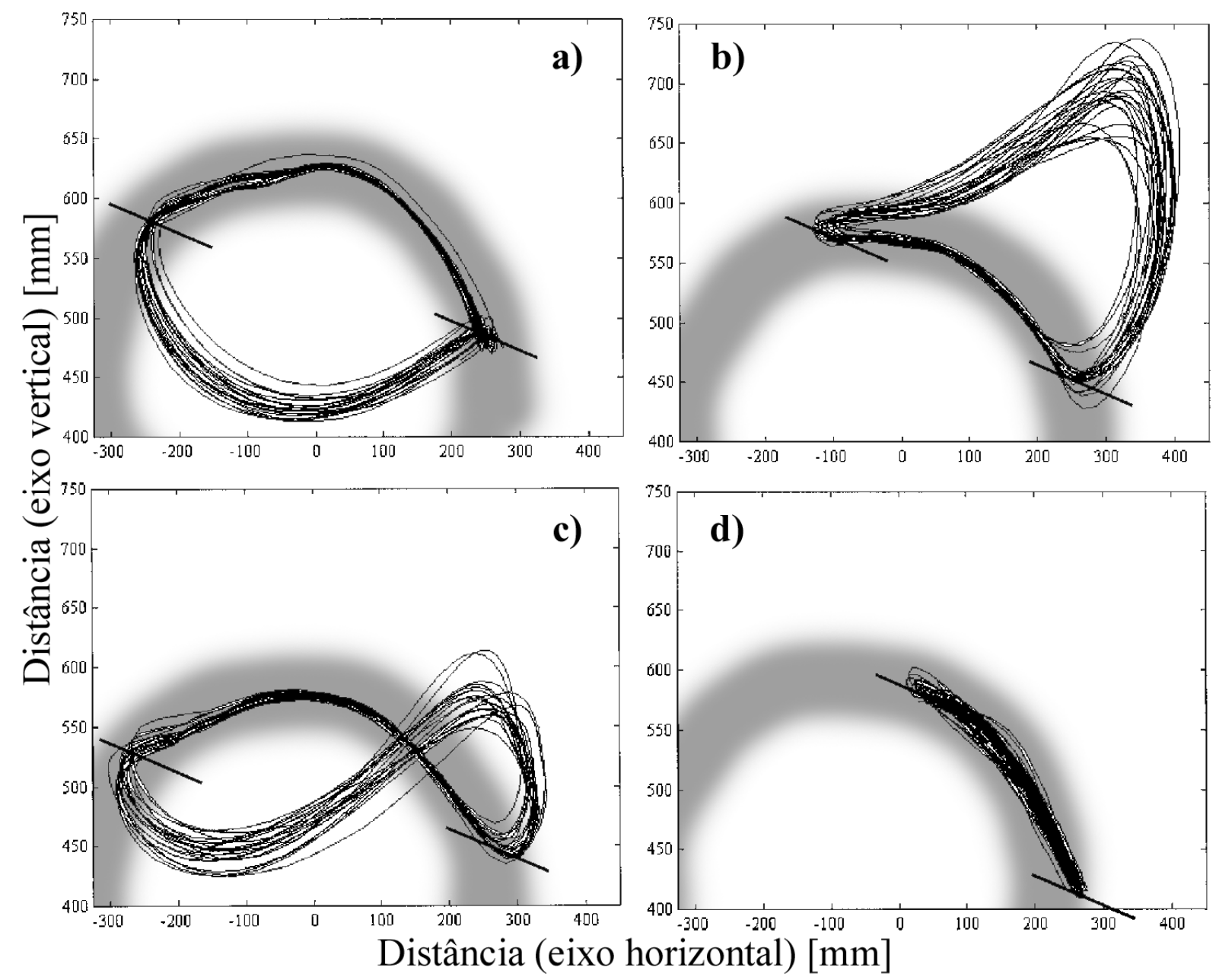

Fig. 15 - Padrões de propulsão da cadeira de rodas observados por Boninger et al. (2002). As barras ao lado direito de cada padrão representam o início da propulsão e as barras a esquerda representam o fim da propulsão e início do retorno. a) Semicircular, b) Laço Simples, c) Laço Duplo, d) Arqueado. (Modificado de Boninger et al., 2002).

Segundo Veeger et al. (2002) a propulsão da cadeira em baixa velocidade parece não levar a altas forças de contato na articulação glenoumeral, no entanto as forças musculares do manguito rotador (principalmente do músculo supraespinhal) são altas, indicando assim um possível risco de acometimento muscular e subseqüente desenvolvimento de complicações no ombro, assim como a ruptura do manguito rotador.

A alta demanda dos membros superiores em lesados medulares não está associada apenas à propulsão da cadeira, mas também a outras atividades diárias executadas por estes pacientes como: a elevação do corpo para alívio da pressão, 
elevação do corpo para transferência e manipulação de objetos. A manipulação de objetos, por usuários de cadeiras de rodas, requer frequentes movimentos e manutenções do braço elevado, devido à baixa estatura que é mantida sentada, sobrecarregando assim a articulação do ombro.

Van Drongelen et al. (2005a) encontraram uma força de contato na articulação glenoumeral duas vezes maior durante elevação para alívio da pressão comparado ao alcance e preensão de um objeto de 1,5kg, e quatro vezes maior se comparada à propulsão da cadeira de rodas. Porém de acordo com Reyes et al. (1995) a elevação do corpo é executada principalmente por grandes músculos que agem diretamente entre o tronco e o braço (peitoral maior e grande dorsal), diminuindo assim o risco de lesão dos pequenos músculos do manguito rotador (que funcionam como um ligamento dinâmico na articulação glenoumeral).

Movimentos de transferência do corpo que requerem tanto as funções de elevação quanto de movimento do tronco apresentam como principais músculos o tríceps, trapézio inferior e peitoral maior, assim como durante a elevação para alívio da pressão. Além destes músculos, durante a transferência do corpo é observada uma alta atividade do músculo deltóide anterior, devido à manutenção do corpo inclinado para frente em grande parte desta tarefa (PERRY et al., 1996; GAGNON et al., 2005).

Harvey e Crosbie (2000) estimaram o momento nos ombros e cotovelos para pacientes tetraplégicos durante a elevação para alívio da pressão $(45 \mathrm{~N} \cdot \mathrm{m}$ e $30 \mathrm{~N} \cdot \mathrm{m}$ respectivamente). Como estes pacientes não têm o controle do tríceps, o músculo deltóide anterior realiza a extensão do cotovelo através da flexão do ombro com as mãos fixadas (GEFEN et al., 1997; HARVEY; CROSBIE, 2000). 
Pacientes lesados medulares realizam a elevação para alívio da pressão várias vezes ao dia para evitar úlceras por pressão. Esta atividade, no entanto, solicita um grande esforço dos membros superiores sendo frequentemente identificada como possível fonte de patologias no ombro.

Fatores que têm sido mencionados como contribuintes para o desenvolvimento de complicações nos ombros estão relacionados com cargas aplicadas com grande frequência durante a propulsão da cadeira de rodas (VEEGER et al., 2002; BONINGER et al., 2002; KULIG et al., 2001). Além disso, e possivelmente mais importante, altas carga nos ombros durante outras atividades relacionadas aos usuários de cadeiras de rodas (transferência e elevação para alívio da pressão) também têm sido mencionado como fatores que contribuem com as complicações nos membros superiores (REYES et al., 1995; PERRY et al., 1996; HARVEY; CROSBIE, 2000; van DRONGELEN et al., 2005b).

Lesados medulares ao se manterem em pé utilizam os membros superiores para executar esta atividade, desta maneira cargas significativas são aplicando a estes membros. No entanto o esforço nos ombros de pacientes paraplégicos durante a marcha ainda foi pouco documentado (CROSBIE; NICOL, 1990; NOREAU et al., 1995; MELIS et al., 1999; BACHSCHMIDT et al., 2001; REQUEJO et al., 2005; HAUBERT et al., 2006).

Um dos primeiros trabalhos analisando o torque nos ombros de pacientes paraplégicos foi realizado por Crosbie e Nicol (1990). Neste trabalho foram obtidos picos de torque da ordem de $42 \mathrm{~N} \cdot \mathrm{m}$ durante a marcha recíproca (uma perna após a outra) com muletas canadenses. 
Noreau et al. (1995) avaliou pacientes paraplégicos com lesão baixa utilizando muletas canadenses durante a marcha pendular (avanço das duas pernas ao mesmo tempo conforme ilustrado na figura 16) e encontrou picos de torque nos ombros da ordem de $35 \mathrm{~N} \cdot \mathrm{m}$.

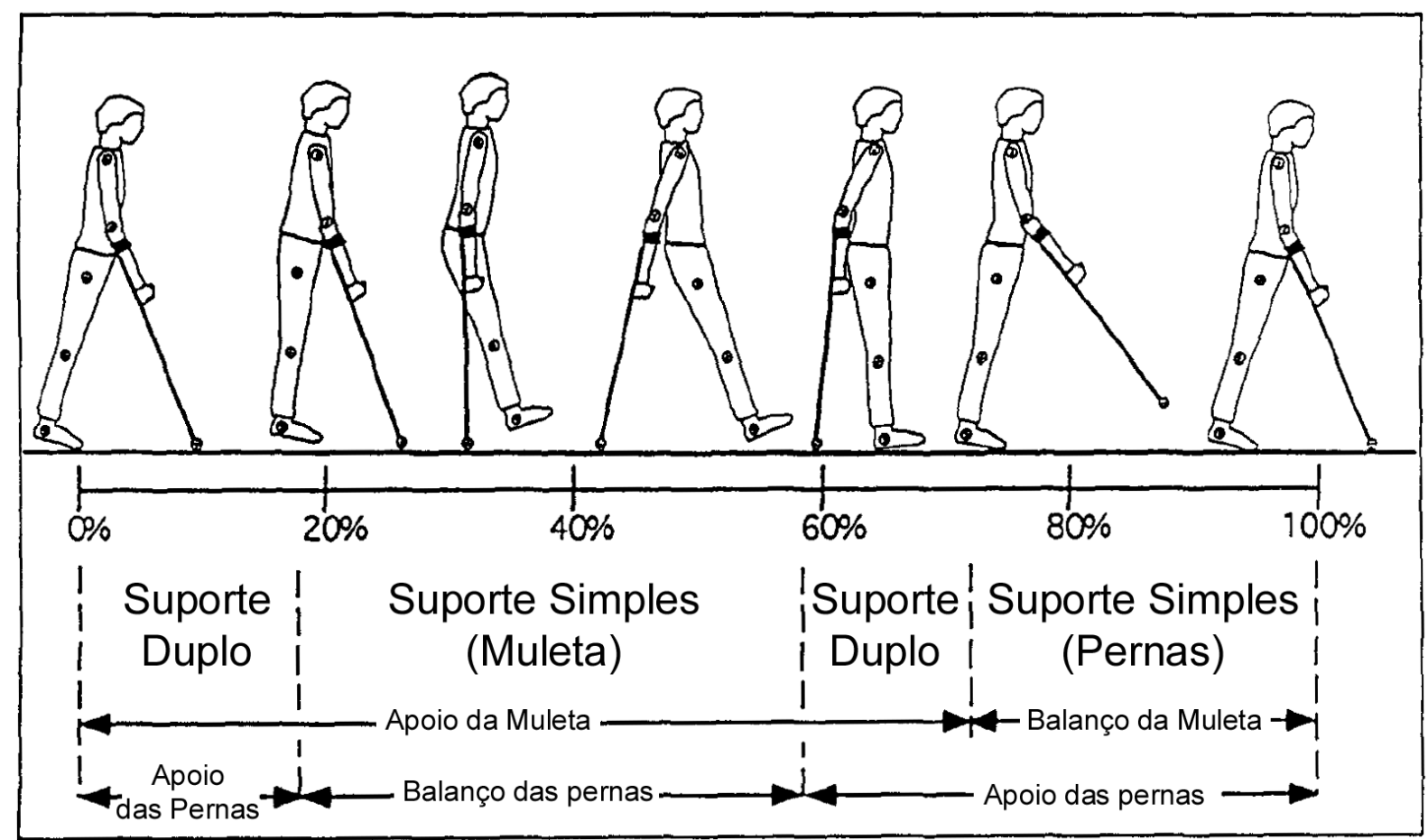

Fig. 16 - Esquema representando a marcha pendular (swing-through). Diferentes fases da marcha em um ciclo completo. $O$ ciclo inicia quando a muleta toca o chão e existe um pequeno período de suporte duplo (pés e muletas) seguido pela fase de suporte simples das muletas (onde o corpo é levantado e propagado para frente). 0 contato do calcanhar inicia a segunda fase de suporte duplo (apoio das pernas) seguido pela fase de balanço da muleta. (Modificado de Noreau et al., 1995).

Melis et al. (1999) realizaram estudo com pacientes paraplégicos incompletos que utilizam diariamente andador, muleta ou bengala e constatou que os pacientes que utilizam o andador aplicam uma carga maior aos membros superiores (até 100\% do peso corporal) comparado aos outros casos. Segundo Bateni e Maki (2005) a carga nos membros superiores em pacientes que utilizam o andador geralmente é maior (de 85 e 100\% do peso corporal) comparado a pacientes que usam outros dispositivos de auxílio à marcha. 
Pacientes que precisam utilizar o andador normalmente apresentam maior comprometimento motor comparado aos que utilizam muletas, por isso a carga em seus ombros foi maior nos estudos de Melis et al. (1999) e Bateni e Maki (2005). No entanto, pacientes aptos a utilizar os dois equipamentos apresentam maior carga nos ombros com o uso de muletas, pois o andador fornece uma melhor estabilidade (HAUBERT et al., 2006).

Apesar de Haubert et al. (2006) concluírem que a carga nos membros superiores é maior com muletas comparado ao andador, Ulkar et al. (2003) constataram que o consumo energético utilizando andador é maior comparado a muletas canadenses em testes com paraplégicos incompletos aptos a utilizar os dois tipos de equipamentos.

Em um estudo com sujeitos normais utilizando um andador Bachschmidt et al. (2001) encontraram picos de torque nos ombros maiores que os apresentados por Requejo et al. (2005) que analisou um paciente paraplégico incompleto com lesão baixa (T12) utilizando muletas.

Todos os trabalhos até o momento analisaram o esforço nos membros superiores durante marcha com pacientes normais ou lesados medulares incompletos, que andam diariamente com auxílio de bengalas ou muletas. No entanto, ainda não foi documentado nenhum estudo sobre o esforço nos ombros de pacientes incapazes de andar diariamente e que necessitam de EENM para realizar a marcha com andador durante as seções de reabilitação. 


\section{CAPÍtulo 2}

"Até que parece sério, mas é tudo armação, o problema é muita estrela, para pouca constelação..." R.S.S. / Muita estrela para pouca constelação (1983).

\section{MATERIAIS E MÉTODOS}

Quinze voluntários portadores de paraplegia foram avaliados durante três atividades: marcha com andador e Estimulação Elétrica Neuromuscular (EENM), propulsão da careira de rodas e elevação para alívio da pressão (atividade também conhecida como push-up). Os dados tridimensionais dos movimentos foram obtidos por um sistema de análise de movimento (Qualisys Inc., Glatonbury, CT, USA) com 6 câmeras de infravermelho e a atividade muscular de 6 músculos dos ombros foi obtida por eletrodos ativos de superfície dispostos bilateralmente. A força durante a marcha foi medida com um andador instrumentalizado com extensômetros (strain gauges), e a força nas outras duas tarefas foi obtida pela dinâmica inversa utilizando os dados cinemáticos e antropométricos. 


\subsection{Pacientes}

Foram avaliados quinze voluntários adultos portadores de paraplegia e participantes do programa de reabilitação no Laboratório de Biomecânica e Reabilitação do Aparelho Locomotor (HC/Unicamp) do Departamento de Ortopedia e Traumatologia da Faculdade de Ciências Médicas da Unicamp. A média das idades dos pacientes foi de $34,9( \pm 14,5)$ anos e o tempo de lesão médio de $95,1( \pm 57,9)$ meses (a tabela 3 apresenta os dados dos pacientes). A massa e altura média dos pacientes foram de $76,1( \pm 14,2) \mathrm{kg}$ e $175,6( \pm 9,0) \mathrm{cm}$ respectivamente. O nível de lesão variou de T1 a T12 sendo que a maioria dos casos apresenta lesão completa (Escala A no exame ASIA, (1992)), todos os pacientes utilizam a cadeira de rodas como principal meio de locomoção. Os pacientes 1, 2, 5, 7, 11, 13 e 14 realizam seções de reabilitação utilizando a marcha com andador e EENM durante 1,5 horas, duas vezes por semana, desde os tempos apresentados na tabela 3. Os demais pacientes $(3,4,6,8,9,10,12$ e 15) são estimulados na cadeira de rodas (m. quadríceps) durante 1,5 horas, duas vezes por semana e ainda não se encontram preparados para realizar a marcha com andador e EENM, ou começaram a andar recentemente (necessitam tutor).

O procedimento experimental foi aprovado pelo comitê de ética e pesquisa da Faculdade de Medicina da UNICAMP, e todos os pacientes leram e assinaram uma declaração de consentimento esclarecido antes da participação na avaliação deste trabalho. 
Tab. 3 - Dados dos pacientes paraplégicos participantes do estudo

\begin{tabular}{|c|c|c|c|c|c|c|c|c|c|c|}
\hline 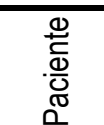 & Altura & Massa & $\begin{array}{c}\begin{array}{c}\text { Massa da } \\
\text { Cadeira }\end{array} \\
{[\mathrm{kq}]}\end{array}$ & Idade & $\begin{array}{c}\text { Mão } \\
\text { Dominante }\end{array}$ & $\begin{array}{l}\text { Nível } \\
\text { de } \\
\text { Lesão }\end{array}$ & $\mathrm{ASIA}^{*}$ & $\begin{array}{c}\text { Tempo } \\
\text { de Lesão } \\
\text { [meses] }\end{array}$ & $\begin{array}{l}\text { Tipo de } \\
\text { Reabilit. }\end{array}$ & $\begin{array}{c}\text { Tempo no } \\
\text { Prog. de Reab. } \\
\text { [meses] }\end{array}$ \\
\hline 1 & 182 & 89 & 17.1 & 31 & Direita & T6 & $A$ & 84 & Marcha & 70 \\
\hline 2 & 175 & 63 & 16.2 & 27 & Direita & T6 & $A$ & 92 & Marcha & 5 \\
\hline 3 & 180 & 101.3 & 14.8 & 55 & Direita & $\mathrm{T} 7$ & $A$ & 67 & Cadeira & 24 \\
\hline 4 & 168 & 76 & 13.5 & 41 & Direita & T10 & $A$ & 25 & Cadeira & 1 \\
\hline 5 & 175 & 74.7 & 15.5 & 59 & Direita & $\mathrm{T} 4$ & $A$ & 162 & Marcha & 42 \\
\hline 6 & 180 & 72.5 & 14.5 & 18 & Direita & T4 & A & 60 & Cadeira & 40 \\
\hline 7 & 190 & 68 & 15.5 & 24 & Direita & T9 & $A$ & 84 & Marcha & 24 \\
\hline 8 & 165 & 70.3 & 19.4 & 65 & Direita & $\mathrm{T} 1$ & A & 60 & Cadeira & 9 \\
\hline 9 & 153 & 68 & 14 & 19 & Direita & T12 & A & 204 & Cadeira & 36 \\
\hline 10 & 185 & 65.5 & 16.5 & 33 & Direita & T12 & A & 96 & Cadeira & 30 \\
\hline 11 & 180 & 109.1 & 19.6 & 35 & Direita & T5 & $B$ & 228 & Marcha & 84 \\
\hline 12 & 170 & 85.7 & 23 & 39 & Direita & T6 & A & 96 & Cadeira & 66 \\
\hline 13 & 180 & 66 & 16.5 & 27 & Direita & T8 & C & 56 & Marcha & 46 \\
\hline 14 & 173 & 72.6 & 15.7 & 22 & Direita & T9 & A & 58 & Marcha & 48 \\
\hline 15 & 178 & 59.5 & 16.2 & 28 & Esquerda & $\mathrm{T} 2$ & A & 54 & Cadeira & 12 \\
\hline Média & 175,6 & 76,1 & 16,5 & 34,9 & & & & 95,1 & & 35,8 \\
\hline Desvio & 9,0 & 14,2 & 2,5 & 14,5 & & & & 58,0 & & 24,6 \\
\hline
\end{tabular}

*American Spinal Cord Association (ASIA, 1992).

\subsection{Atividades Realizadas pelos Pacientes}

Os pacientes realizaram três diferentes atividades: marcha com andador e EENM, propulsão da cadeira de rodas e elevação do corpo para alívio da pressão. Todos os pacientes realizaram a propulsão da cadeira e o alívio da pressão pelo menos 5 vezes cada um.

A propulsão da cadeira foi realizada em uma distância de 6 metros e o período de análise conteve os 3 ciclos de propulsão iniciais com o paciente inicialmente em repouso. Também foi analisado o intervalo de 10\% antes do início do movimento (o $1^{\circ}$ ciclo iniciou no instante $10 \%$ do intervalo completo avaliado) para considerar as contrações musculares do início do exercício que ocorrem alguns instantes antes da realização do movimento.

Os pacientes realizaram a elevação para alívio da pressão por pelo menos 5 segundos e o início e final desta tarefa foram aplicados nos instantes $10 \%$ e $90 \%$, respectivamente, do intervalo completo analisado, para considerar as contrações 
musculares que ocorrem alguns instantes antes e depois da realização do movimento.

Sete pacientes foram capazes de realizar a marcha com andador e EENM (pacientes 1, 2, 5, 7, 11, 13 e 14) em um comprimento mínimo de 6 metros e pelo menos 5 vezes. Foi analisado um ciclo completo da marcha no meio da caminhada. Um ciclo completo consistiu das seguintes fases: Avanço do Andador, Pré-Balanço Esquerdo, Balanço Esquerdo, Aceitação do Peso Esquerdo, Avanço do Andador, Pré-Balanço Direito, Balanço Direito, e Aceitação do Peso Direito (figura 6)

Foi utilizado um estimulador elétrico modulado em $25 \mathrm{~Hz}$ com 4 canais, estimulando em cada perna o músculo quadríceps e o nervo fibular, durante a fase de apoio e balanço respectivamente.

\subsection{Cinemática}

Os dados tridimensionais dos movimentos durante as atividades foram obtidos por meio de 6 câmeras de infravermelho (figura 17) integrantes do sistema de aquisição de movimento da empresa Qualysis (Qualisys Inc., Glatonbury, CT, USA). Marcadores reflexivos com $20 \mathrm{~mm}$ de diâmetro (figura 18) foram aplicados ao corpo do paciente e também ao eixo da cadeira de rodas (figuras 19 e 20).

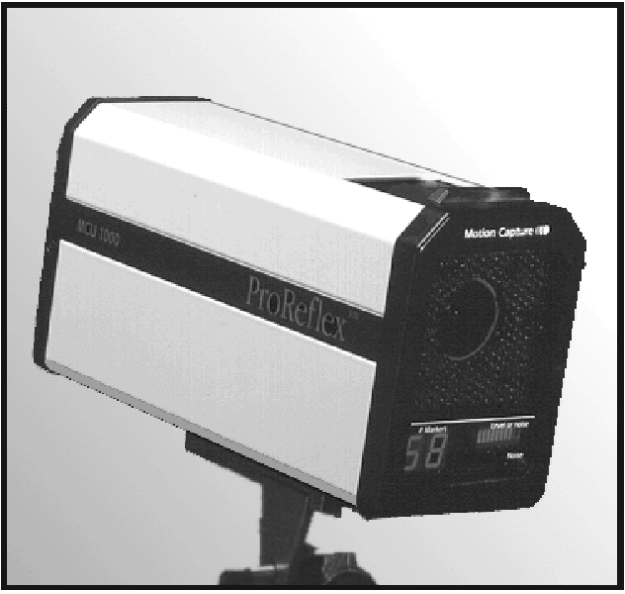

Fig. 17 - Câmera de infravermelho integrante do sistema de aquisição de movimento da empresa Qualysis (Qualisys Inc., Glatonbury, CT, USA).

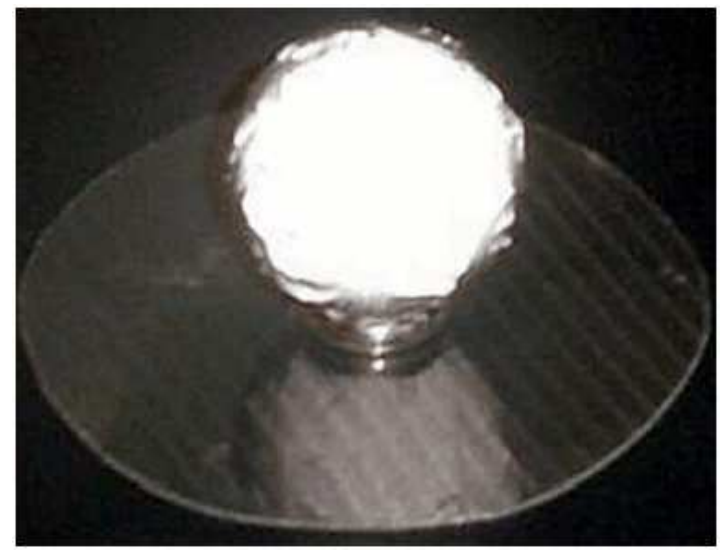

Fig. 18 - Marcador reflexivo utilizado 


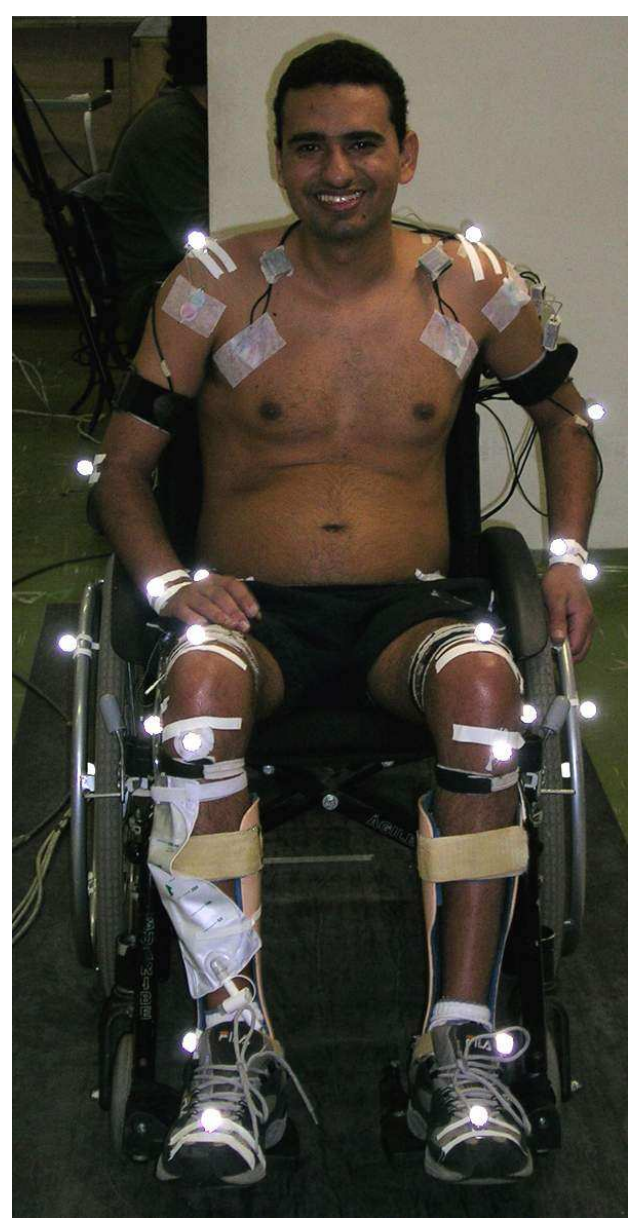

Fig. 19 - Paciente com marcadores durante atividades na cadeira de rodas.

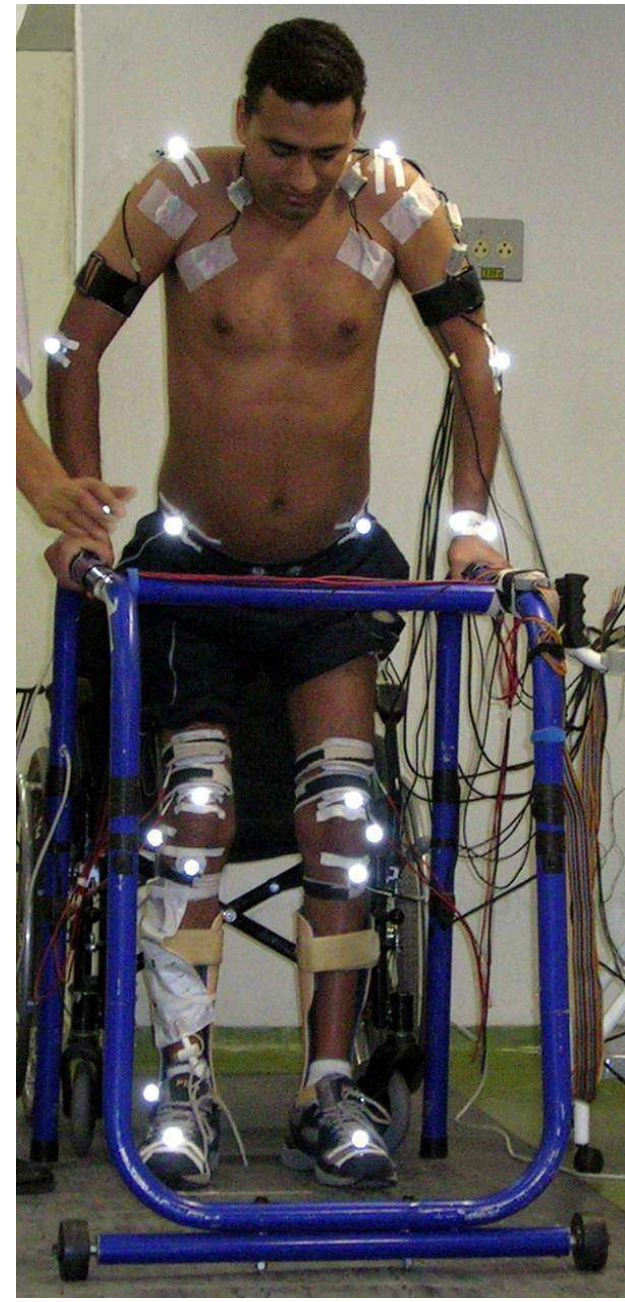

Fig. 20 - Paciente com marcadores durante a marcha.

Dois marcadores foram colocados nos centros das rodas direita e esquerda da cadeira de rodas. Os marcadores do paciente foram aplicados bilateralmente sobre pontos de referência anatômicos na extremidade superior e inferior do corpo. Os pontos de referência superiores usados foram: processos estilóides radial e ulnar, epicôndilos medial e lateral, processo acromial e processos espinhosos C7 e T12. Os pontos de referência inferiores utilizados foram: $1^{\underline{a}}$ vértebra sacral, espinha ilíaca ântero-superior, borda superior da patela, linha da articulação lateral do joelho, tuberosidade tibial, maléolo lateral, calcâneo e dorso do pé entre o $2^{\circ}$ e $3^{\circ}$ metatarso.

Na figura 21 é apresentada a localização dos marcadores e na figura 22 são apresentadas as vistas lateral e frontal dos marcadores em um exemplo de coleta durante a marcha com EENM e andador de um dos pacientes. 


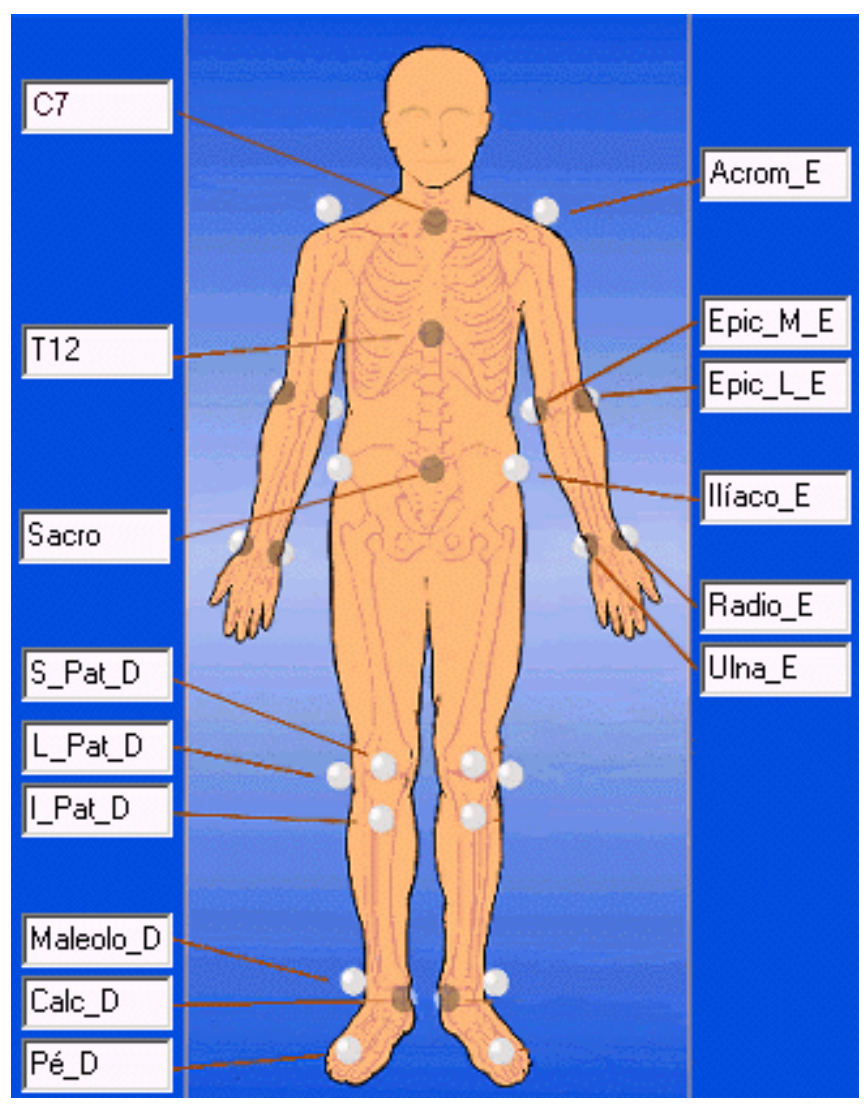

Fig. 21 - Localização dos marcadores nos pacientes

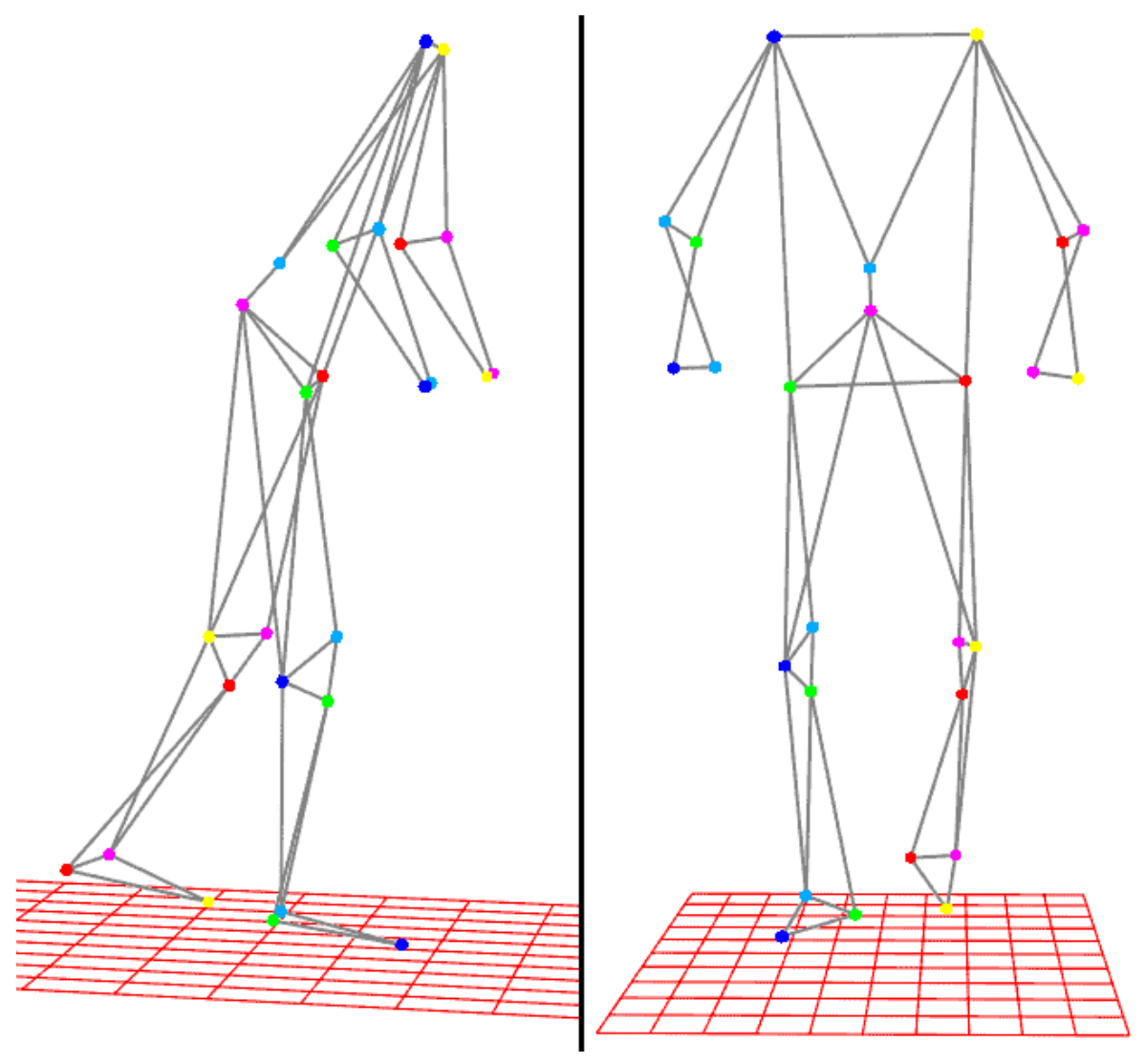

Fig. 22 - Vista Lateral e Frontal dos marcadores de uma coleta durante a marcha de um paciente com EENM e andador. 
O sistema de aquisição foi calibrado para captura em um volume de $3 \times 1 \times 1,7 \mathrm{~m}^{3}$ e os dados das imagens foram amostrados em 120Hz (figuras 23 e 24).

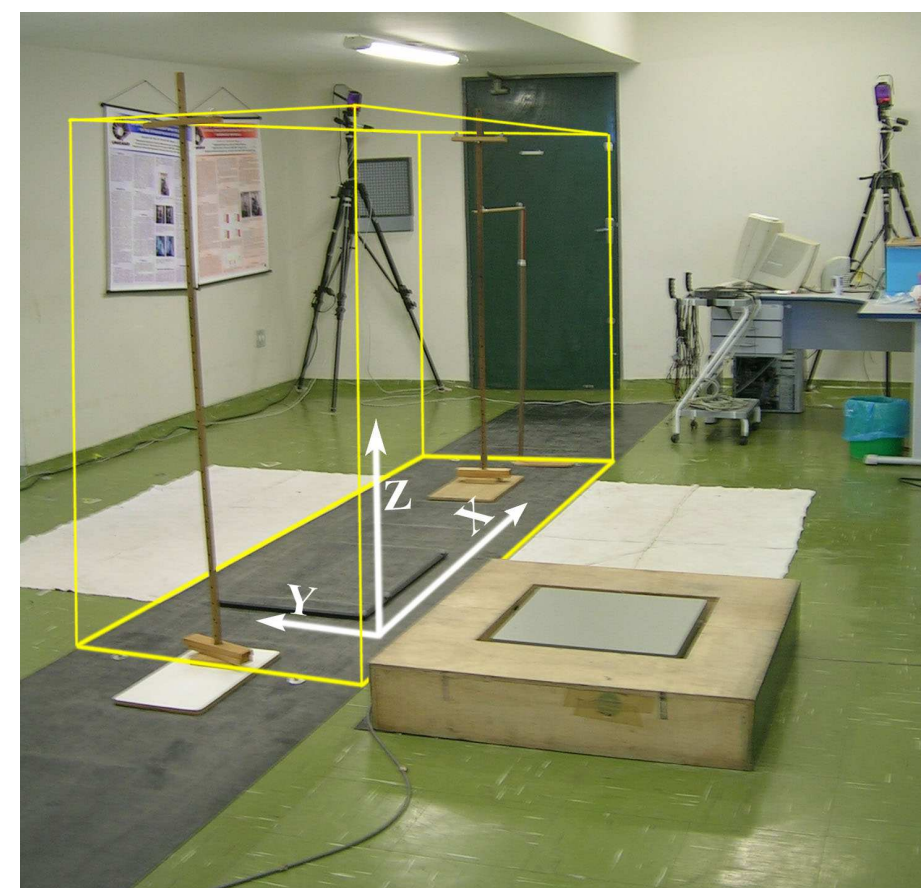

Fig. 23 - Volume da aquisição cinemática no laboratório

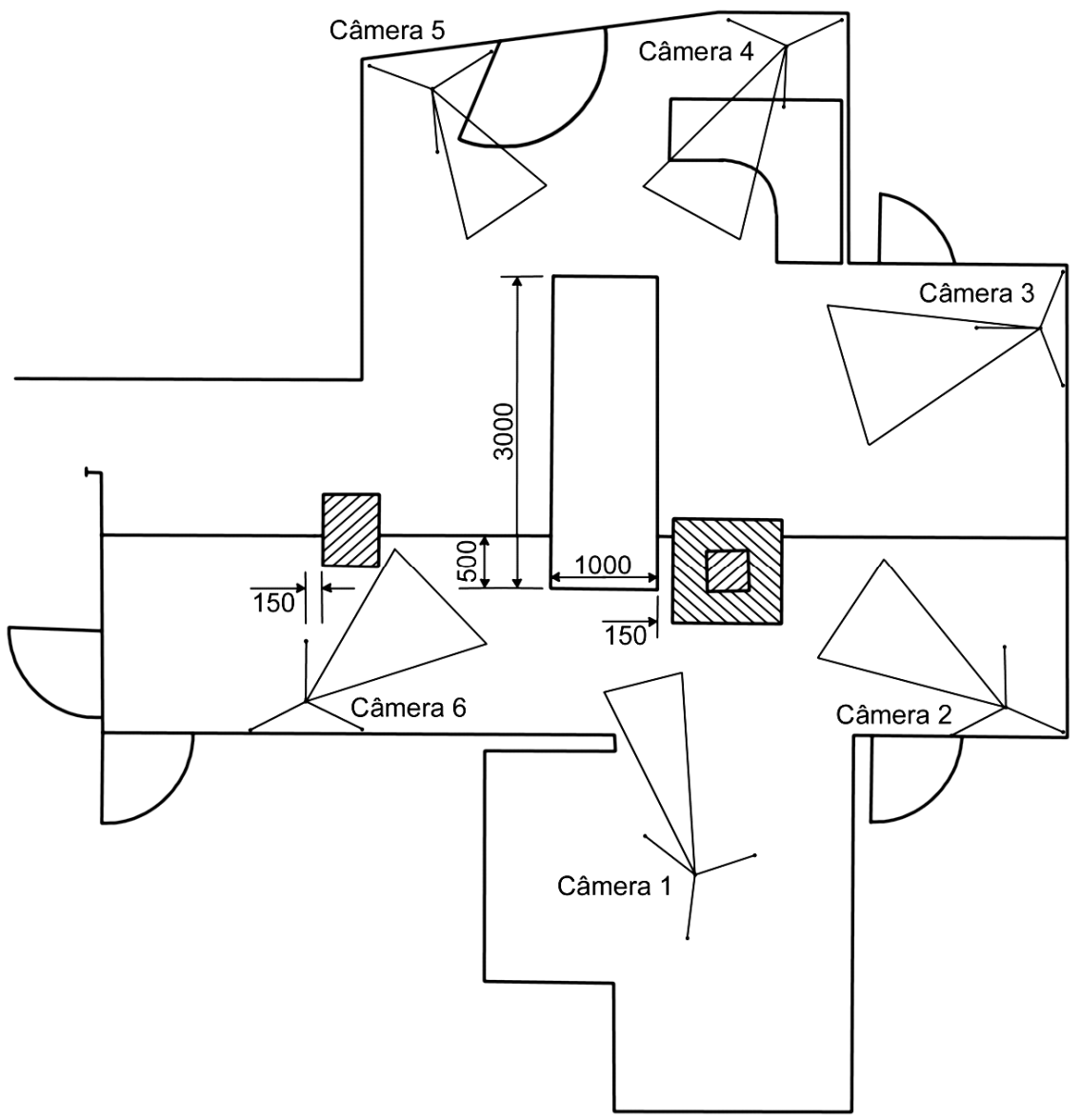

Fig. 24 - Planta da disposição das câmeras e do volume de aquisição no laboratório 
Os centros das articulações e centros de massa dos membros inferiores foram obtidos utilizando o programa Qgait (software fornecido pela Qualysis), e todos os dados da região superior (cabeça, tronco e membros superiores) foram calculados usando o programa MatLab (Mathworks Inc., Natick, MA, USA).

O centro das articulações dos punhos foi situado no ponto médio entre os processos estilóides radial e ulnar e o centro das articulações dos cotovelos no ponto médio entre epicôndilos medial e lateral (BACHSCHMIDT et al., 2001).

O centro da articulação glenoumeral foi calculado subtraindo $60 \mathrm{~mm}$ da posição do marcador do acrômio na direção do centro da articulação do quadril (NUSSBAUM; ZHANG, 2000).

Os centros de massa da região superior e a massa dos membros (braço, antebraço, mão, tronco e cabeça) foram calculados utilizando os dados antropométricos obtidos por Dempster (1959) reportados por Miller e Nelson (1973). A tabela 4 apresenta estes dados antropométricos. 
Tab. 4 - Dados antropométricos obtidos por Dempster (1959). (Adaptado de Miller e Nelson, 1973)

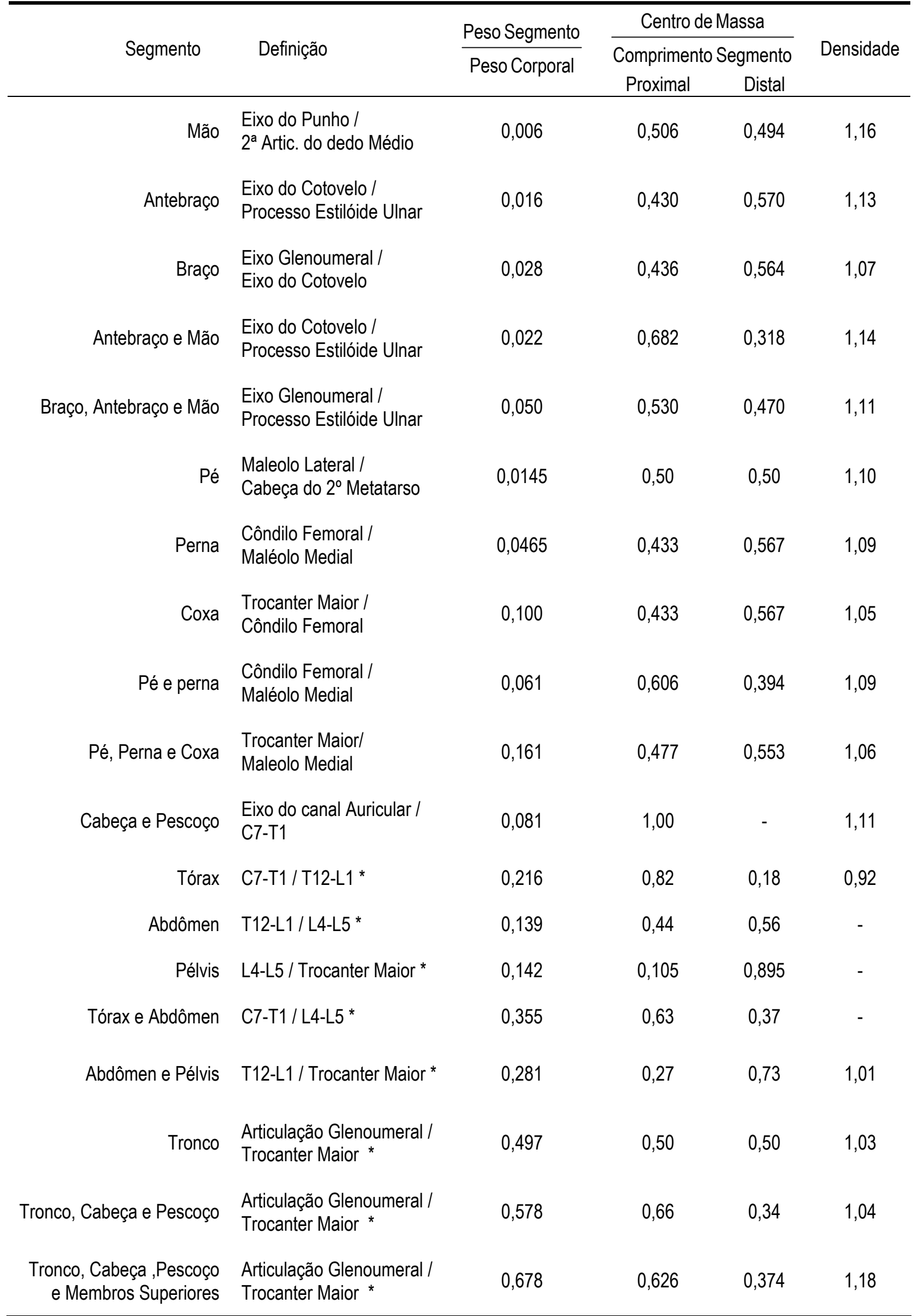

* $\bar{O}$ Centro de massa destes segmentos é calculado entre o ponto médio das Articulações Glenoumerais e o ponto médio dos Trocanteres Maiores. 
A figura 25 apresenta as vistas lateral e frontal dos centros das articulações e centros de massa, referentes aos dados coletados apresentados na figura 22.

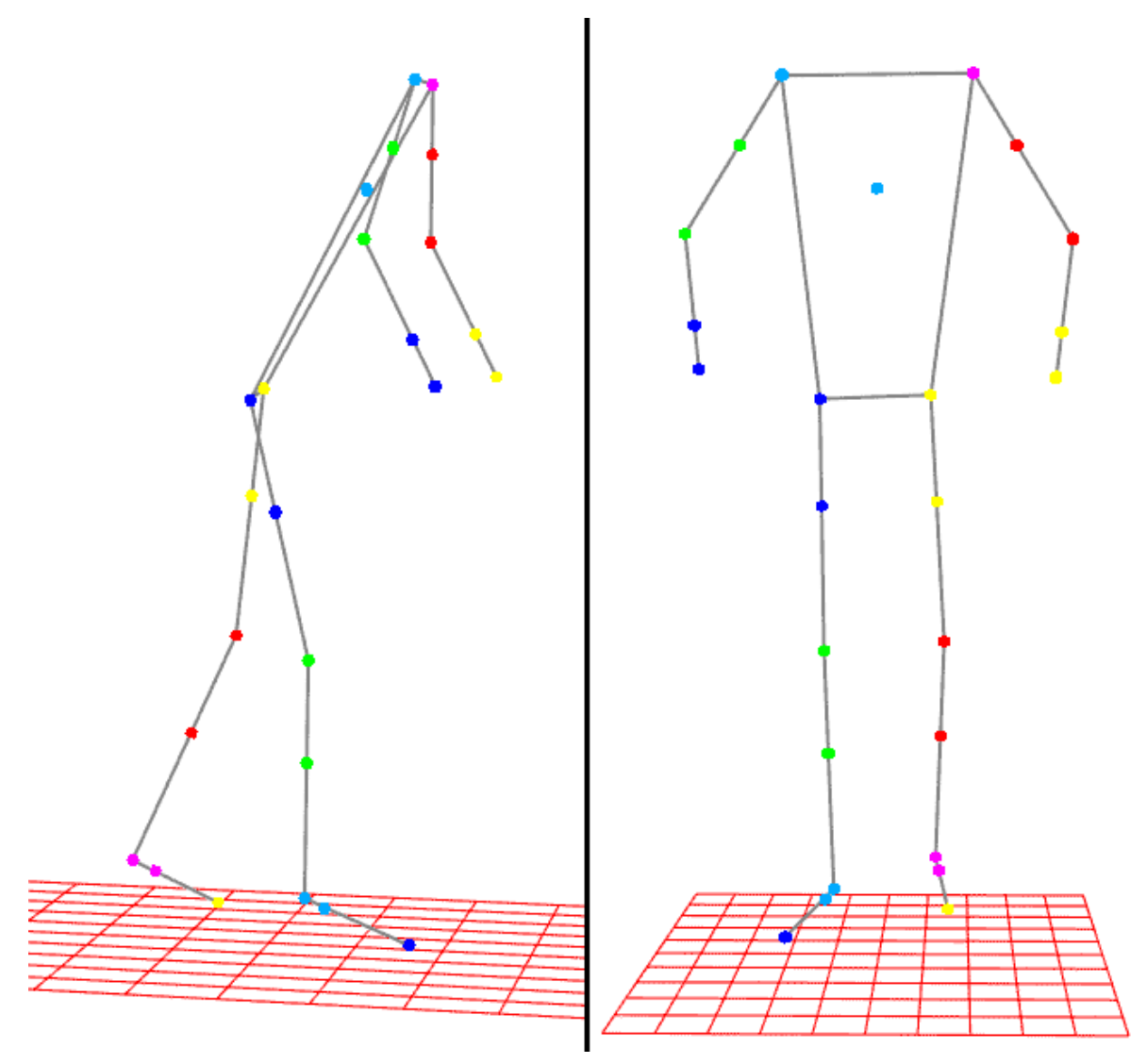

Fig. 25 - Centros das articulações e centos de massa referentes à coleta da figura 22

Os dados das coordenadas dos marcadores da cadeira, dos centros de massa e dos centros das articulações dos pacientes foram filtrados utilizando um filtro passa baixa, tipo FIR (Finite Impulse Respost), de $3 \mathrm{~Hz}$ com ordem 100.

Os dados foram normalizados no tempo para representar as respostas como porcentagem das tarefas executadas. 


\subsection{Atividade Muscular}

A atividade muscular de 6 músculos em ambos os lados dos ombros de cada paciente foi obtida através de eletromiografia (EMG) de superfície. Os músculos analisados foram: Bíceps Braquial (cabeça longa), Tríceps Braquial (cabeça longa), Deltóide Anterior, Deltóide Posterior, Peitoral Maior (parte esternocostal) e Trapézio Inferior. A localização dos eletrodos foi adotada de acordo com Perotto (1994) conforme indicado na figura 26.

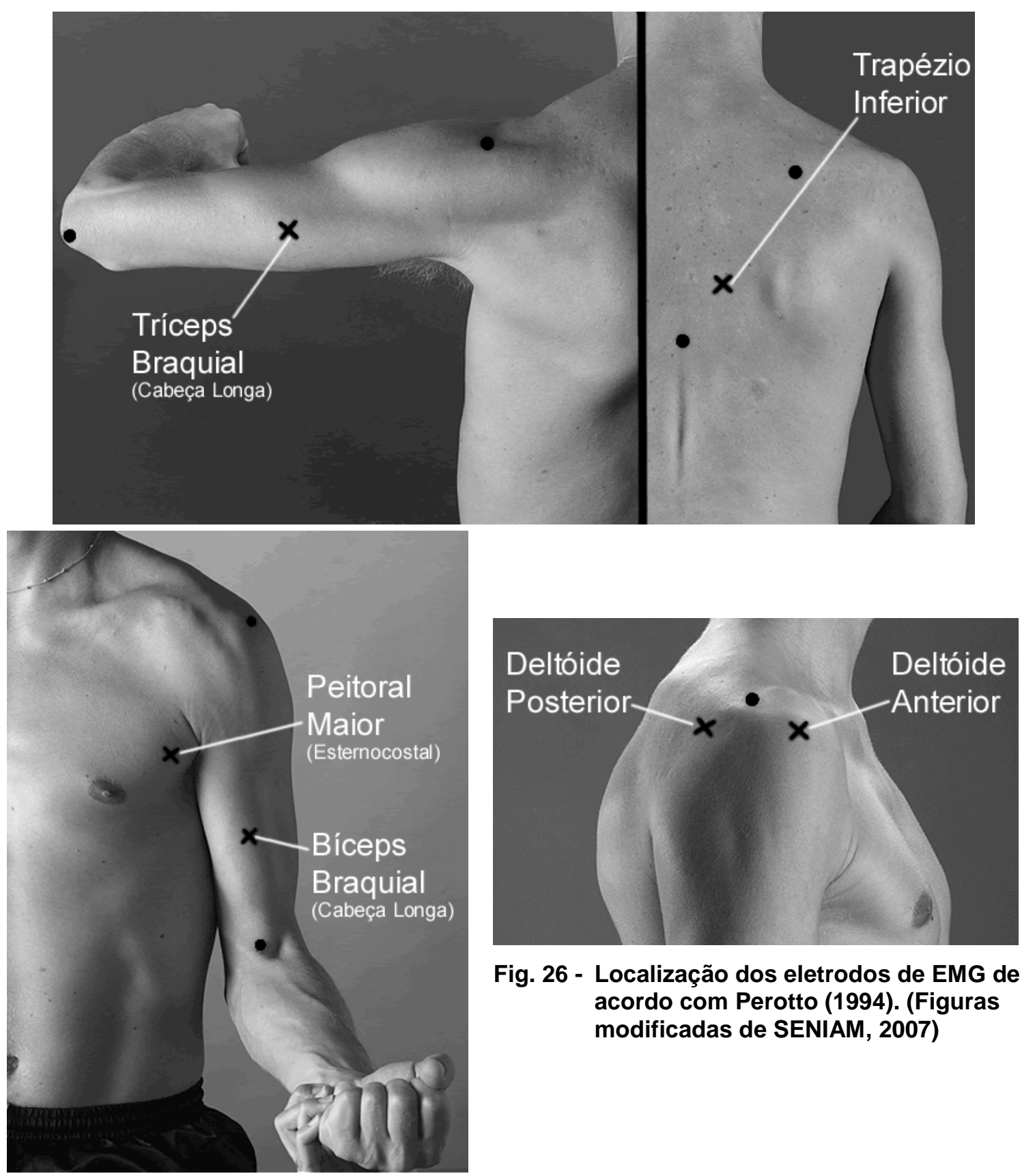


Além das 3 atividades executadas pelos pacientes (marcha, propulsão da cadeira e elevação para alívio da pressão) foi realizada também a máxima contração voluntária $(\mathrm{MCV})$ isométrica antes de cada seção para expressar o sinal mioelétrico como porcentagem da MCV. Estas contrações foram executadas três vezes, por pelo menos 5 segundos, para cada um dos 12 músculos analisados, com o paciente sentado na cadeira de rodas. O teste de MCV foi realizado utilizando as posições padrão para teste manual de músculos, de acordo com Kendal et al. (1993). Nos casos dos músculos normalmente testados na posição prono (trapézio inferior) e supino (tríceps e peitoral maior), a mesma posição dos membros superiores com relação ao tronco e direção de resistência foi aplicada na posição sentada.

O sinal mioelétrico (SME) foi obtido utilizando eletrodos ativos de superfície diferencial com ganho de 20 vezes. Foram utilizados eletrodos comerciais da empresa Lynx (Lynx Tecnologia Eletrônica LTDA, São Paulo, SP, Brasil) modelo (PA602) e também eletrodos descartáveis acoplados a circuitos amplificadores diferenciais confeccionados no Laboratório de Biocibernética e Engenharia de Reabilitação (LABCIBER/USP). Os eletrodos utilizados estão ilustrados na figura 27.

Os sinais mioelétricos captados pelos eletrodos ativos foram amplificados mais 50 vezes em uma placa condicionadora de sinais (MCS1000-V2 da Lynx), totalizando em um ganho de 1000 vezes. Na placa condicionadora os sinais também foram filtrados analogicamente por filtros ativos passa baixa de $2^{\underline{a}}$ ordem com frequência de corte em $510 \mathrm{~Hz}$ para evitar aliasing na digitalização do sinal e filtros passivos passa alta de $22,5 \mathrm{~Hz}$ para cancelar os artefatos de movimento. Estes sinais foram então amostrados com $2400 \mathrm{~Hz}$ por uma placa de conversão A/D de 12 bits (CAD12/56 da Lynx). 


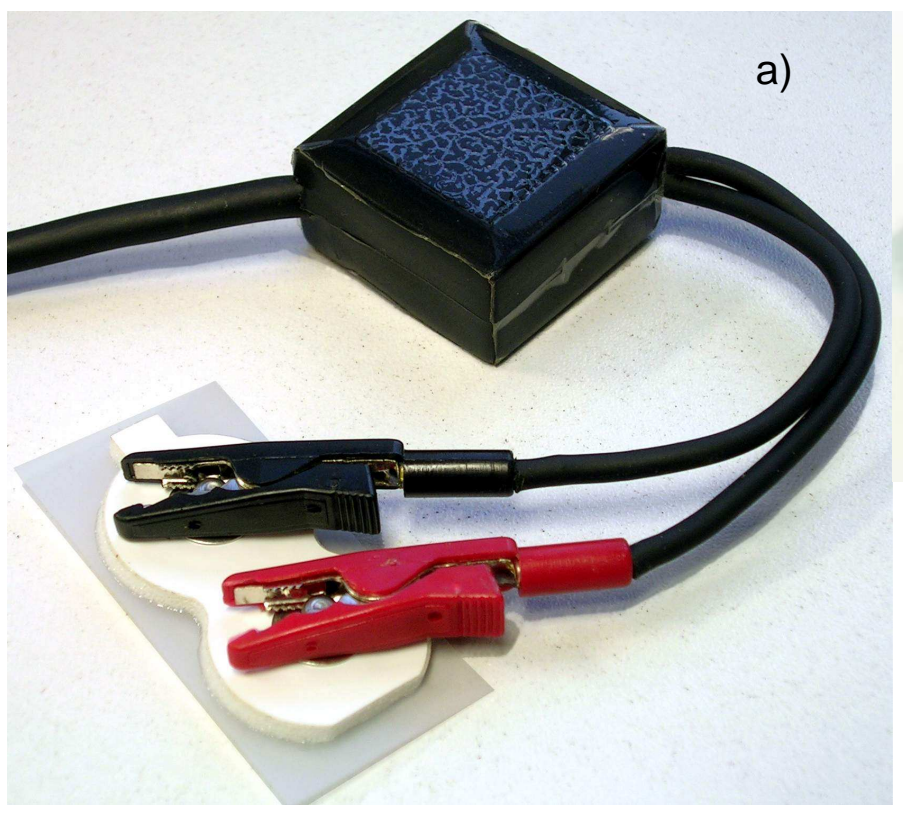

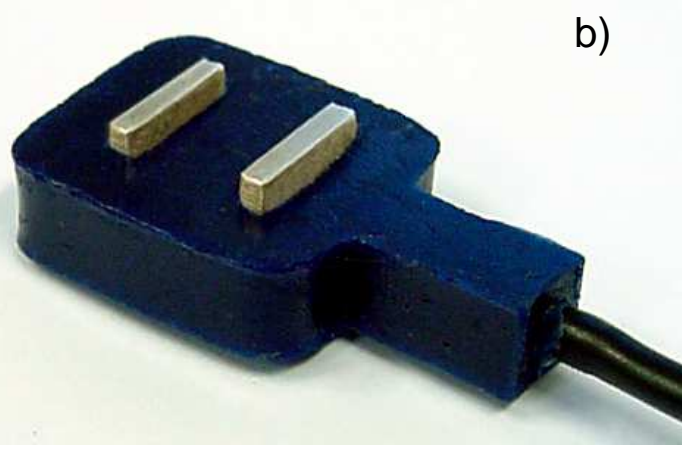

Fig. 27 - Eletrodos Ativos de Superfície Diferenciais Utilizados.

a) Eletrodo descartável com circuito ativo confeccionado no Laboratório.

b) Eletrodo comercial da empresa Lynx.

Todo processamento digital do SME foi realizado através de cálculos matemáticos utilizando o programa MatLab (Mathworks Inc., Natick, MA, USA). O sinal mioelétrico foi aplicado em um filtro digital passa baixa, tipo FIR, com frequência de corte em $495 \mathrm{~Hz}$ e ordem 200. E na sequência o sinal foi aplicado em um filtro passa alta de $10 \mathrm{~Hz}$ com ordem 400 para cancelar o offset gerado pelos competentes eletrônicos, o sinal em repouso foi utilizado para determinar a linha de base do ruído do sistema (ORTOLAN et al., 2003).

A partir do SME filtrado foi então calculado o valor RMS (equação 10) em sucessivas janelas contendo 40 amostras e meia janela de sobreposição, resultando em um sinal amostrado em $120 \mathrm{~Hz}$. O RMS do sinal foi filtrado para encontrar sua envoltória utilizando um filtro passa baixa, tipo FIR, de $5 \mathrm{~Hz}$ com ordem 100. As amplitudes dos sinais obtidos para cada músculo foram então normalizadas pela média dos máximos valores obtidos nas 3 repetições de MCV. 
O SME foi sincronizado com os dados cinemáticos através de um conjunto de 5 LEDs infravermelho com comprimento de onda $940 \mathrm{~nm}$ e potência de $200 \mathrm{~mW}$ cada um. O sinal deste grupo de LEDs foi aplicado em um canal da placa de aquisição de conversão $A / D$ e a sincronia foi realizada com o movimento do dispositivo dentro do volume de captura da cinemática.

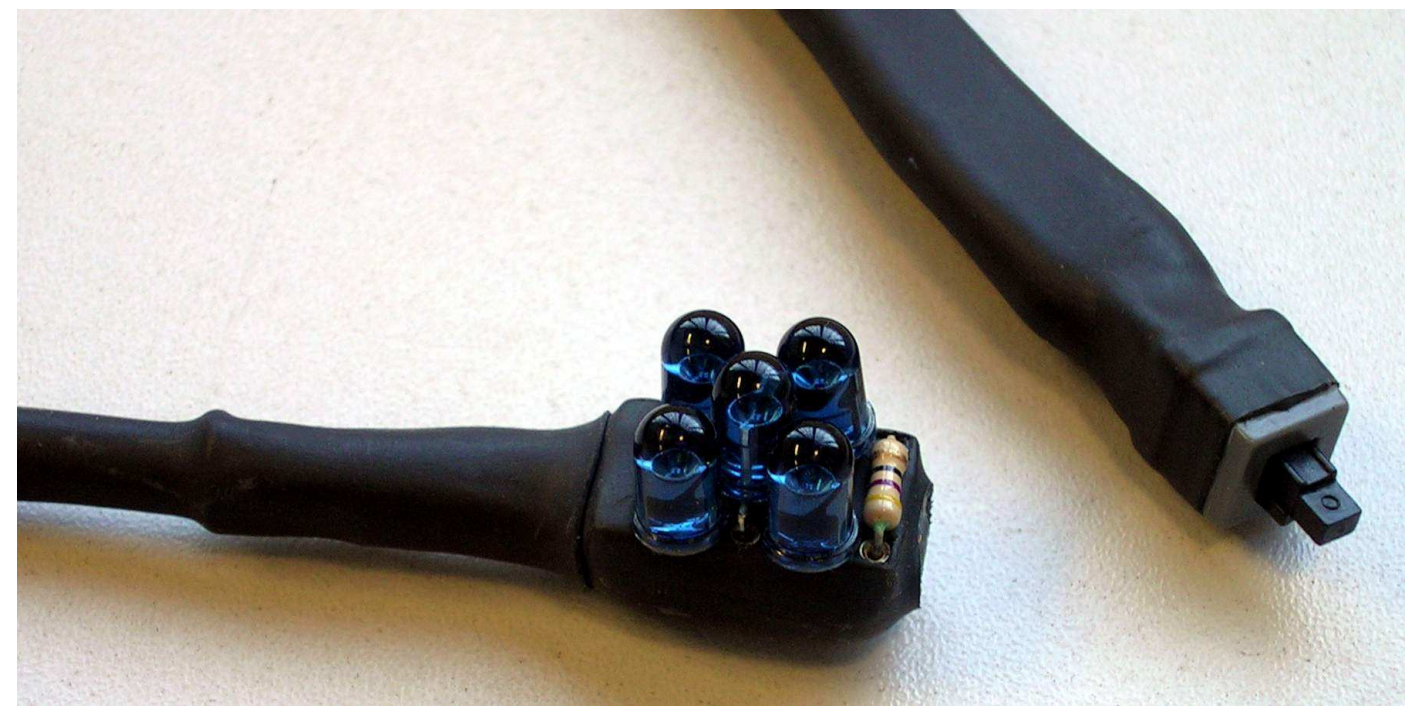

Fig. 28 - Dispositivo com LEDs infravermelho confeccionado para sincronia.

\subsection{Cinética}

Um andador normalmente utilizado pelos pacientes nas seções de reabilitação foi instrumentalizado com extensômetros (strain gauges) para estimar a carga aplicada nos ombros.

Quatro extensômetros (350 $\Omega$ ) dispostos em configuração de ponte completa de Wheatstone foram fixados em cada perna do andador com adesivo epóxi profissional. As pontes foram orientadas para obter a deformação axial (figura 29) 

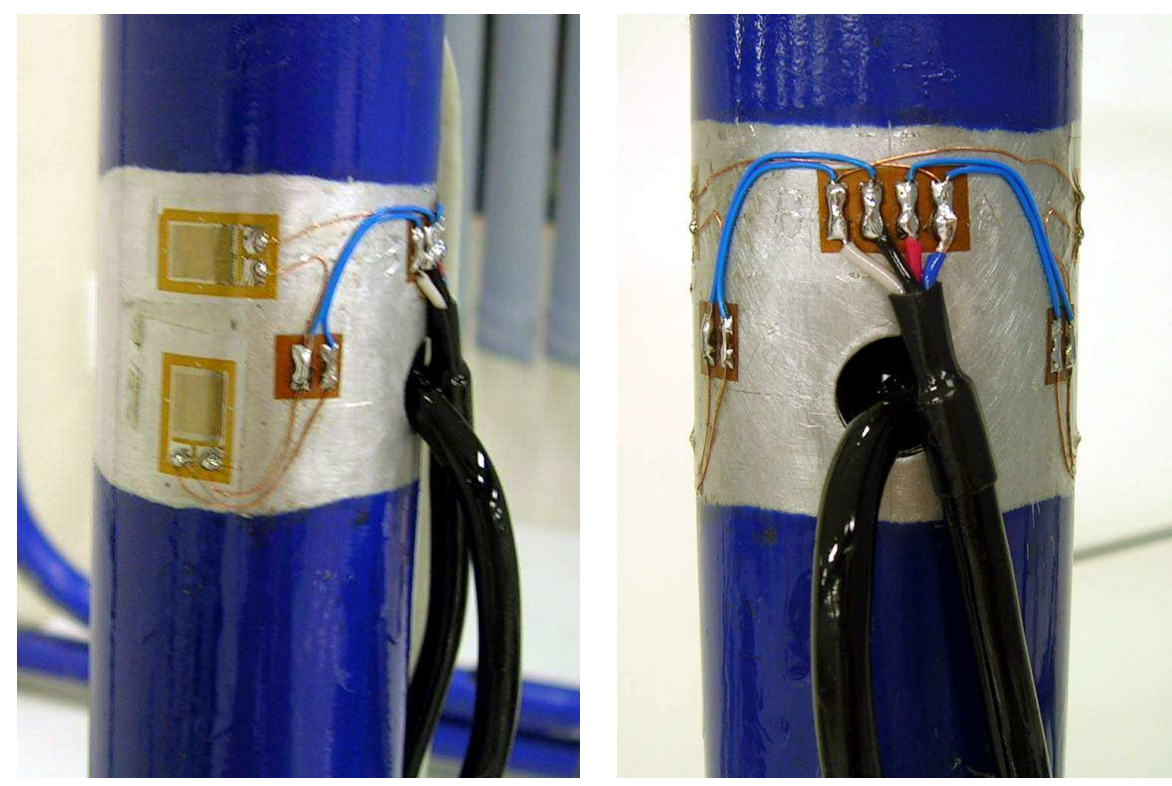

Fig. 29 - Detalhe da montagem dos extensômetros na perna do andador

O sinal de cada ponte foi amplificado 2000 vezes por amplificadores de instrumentação (figura 30) e filtrado por um filtro passa baixa ativo de $2^{\underline{a}}$ ordem com frequência de corte em $30 \mathrm{~Hz}$. Este sinal filtrado do andador foi amostrado em $2400 \mathrm{~Hz}$ utilizando os 4 canais remanescentes da placa de conversão A/D de 12 bits.
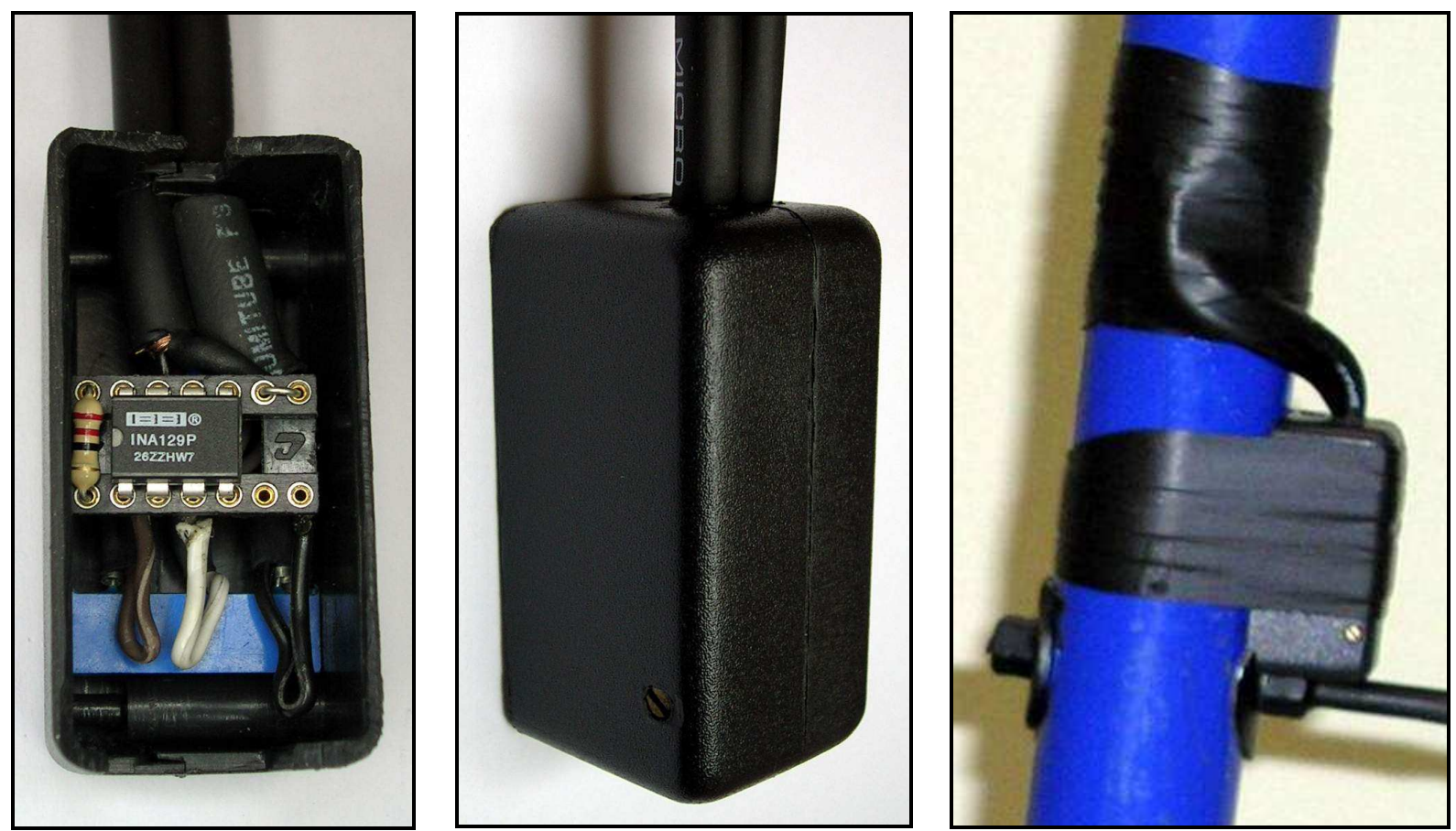

Fig. 30 - Detalhe da montagem do amplificador de instrumentação 


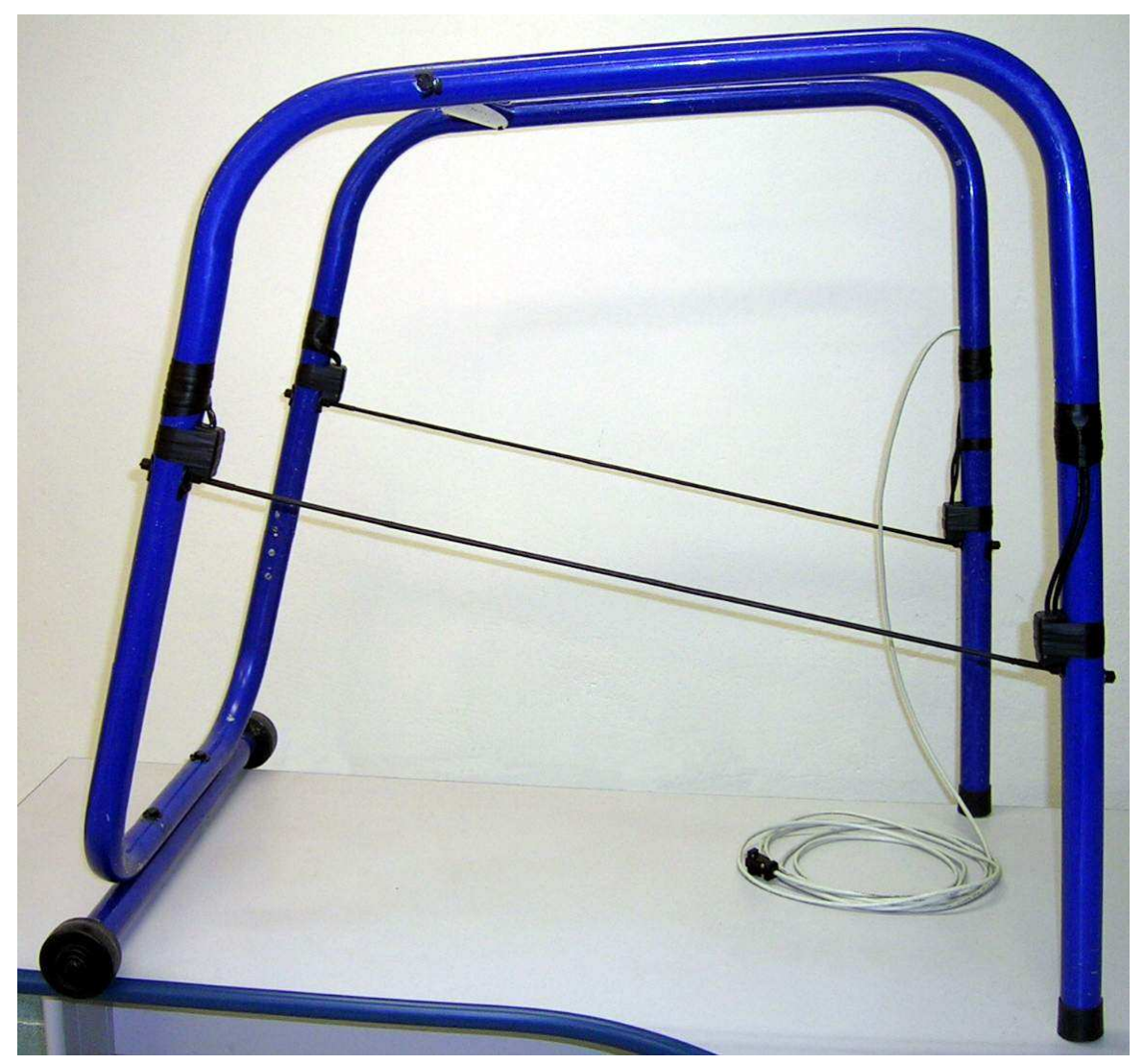

Fig. 31 - Andador Instrumentalizado.

Um dinamômetro da marca Shimpo

(Shimpo America Corp., Itasca, IL, USA) foi utilizado para calibrar o andador.

Foram aplicados verticalmente cargas de Okg a $25 \mathrm{~kg}$ (em intervalos de $5 \mathrm{~kg}$ ) sobre a manopla em cada lado do andador, com pelo menos 3 repetições para cada carga. A figura 32 apresenta o esquema utilizado para calibração do andador.

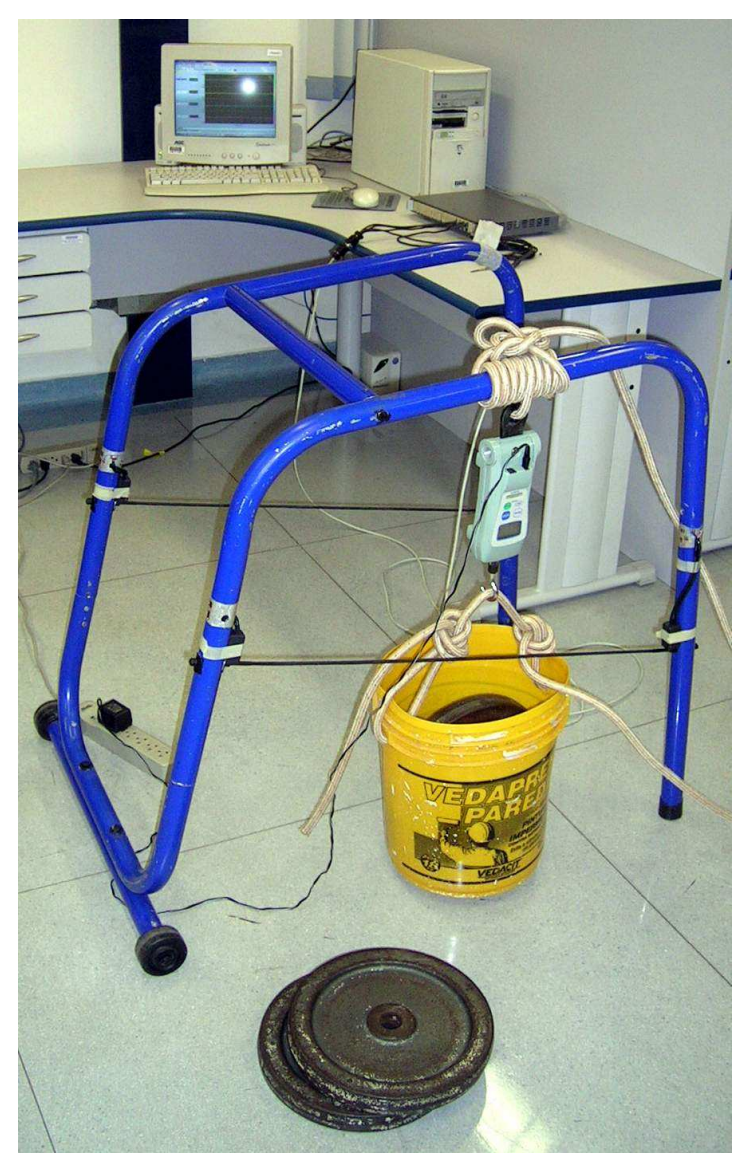

Fig. 32 - Esquema para calibração do andador 
Os dois sinais de cada lado do andador (dianteiro e traseiro) foram somados e foi obtida a curva de calibração aplicando regressão linear aos pontos obtidos. Para o lado direito foi obtido um coeficiente angular de $-60,9205$ e para o lado esquerdo de $-69,8392$. As figuras 33 e 34 apresentam os pontos e as curvas obtidas.

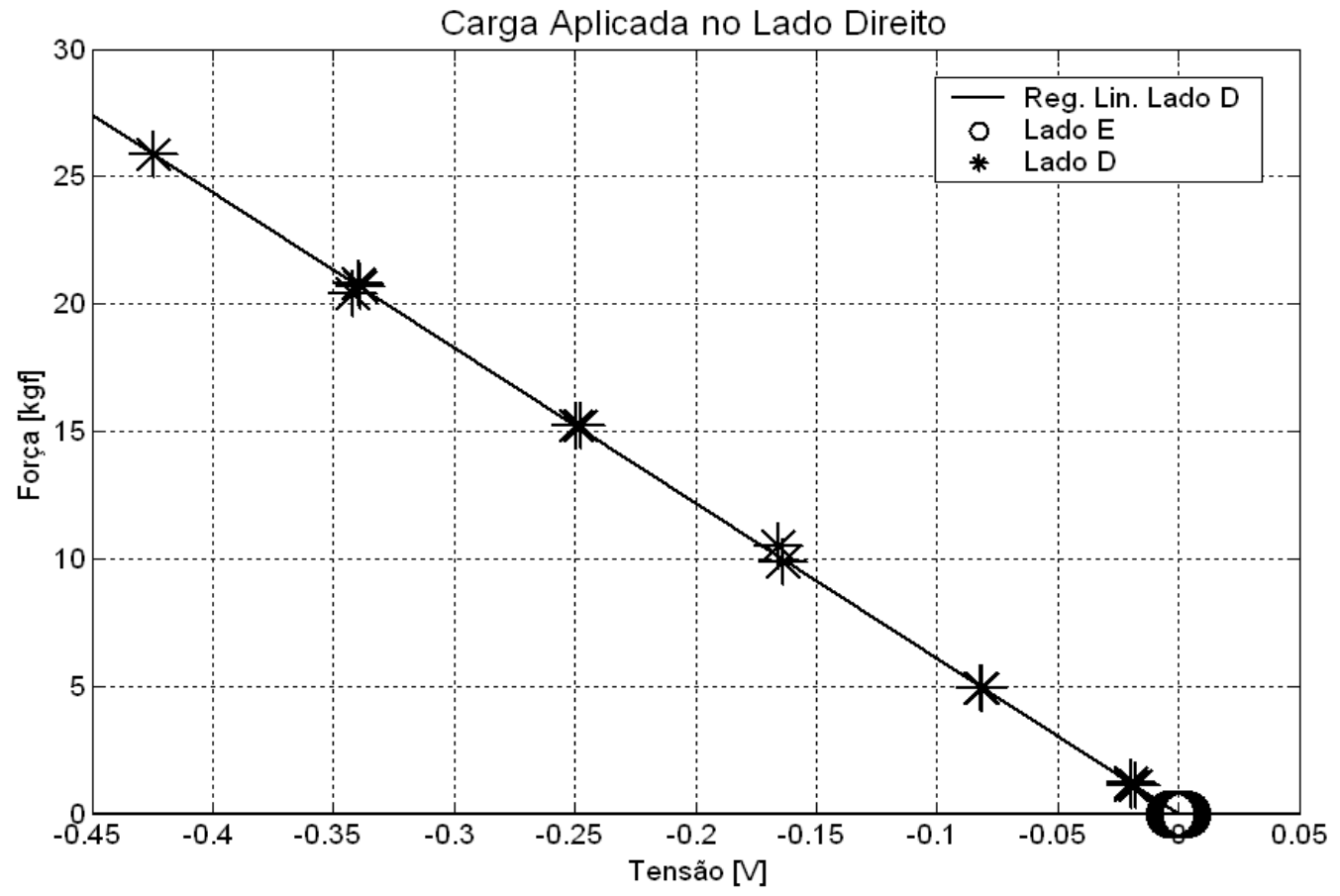

Fig. 33 - Curva de calibração do andador para o lado direito. Coeficiente angular: $-60,9205$

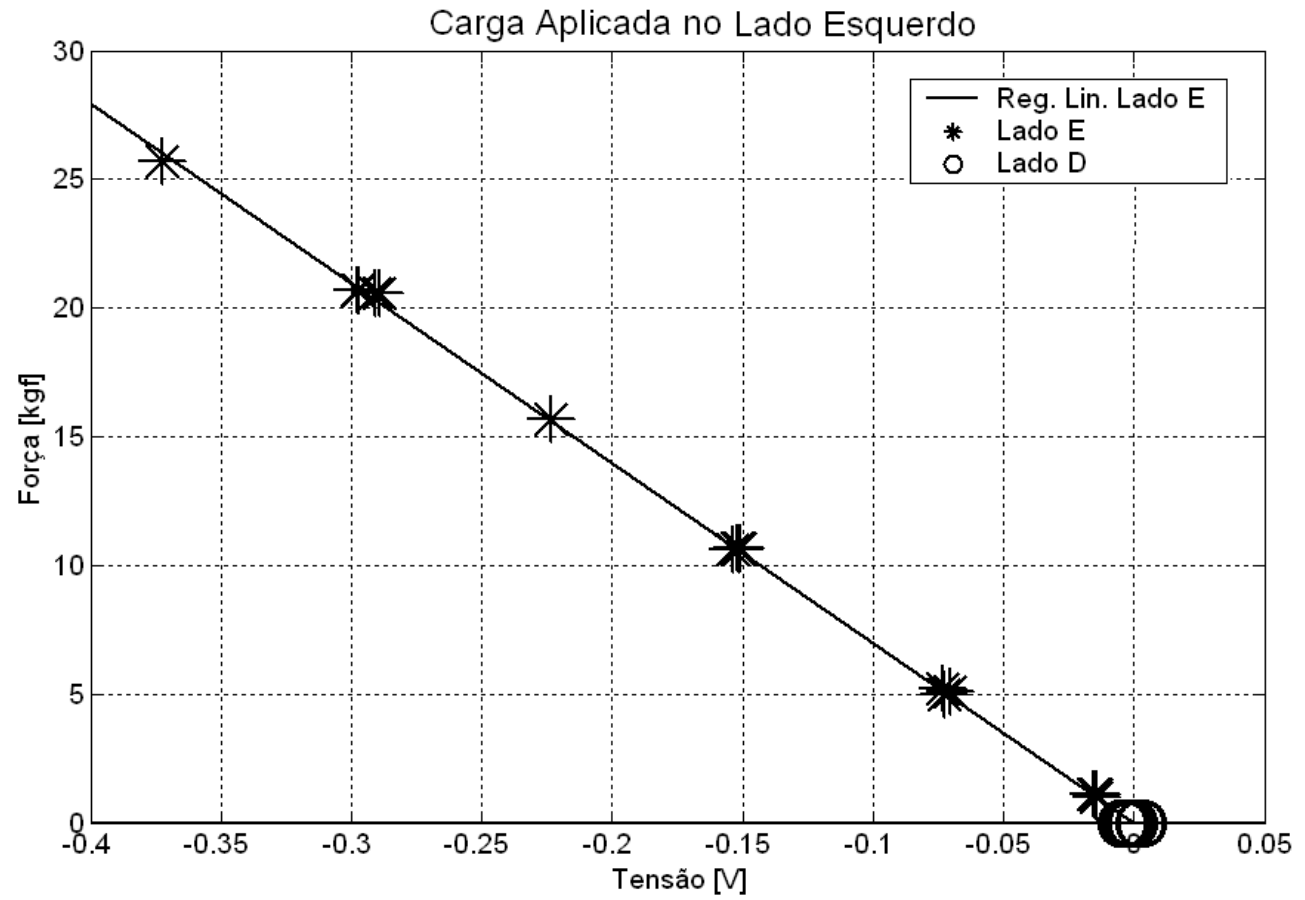

Fig. 34 - Curva de calibração do andador para o lado esquerdo. Coeficiente angular: $-69,8392$ 
O coeficiente linear não foi considerado na curva de calibração, pois os extensômetros são muito sensíveis, e mesmo sendo montados em ponte completa, podem sofrer influência da temperatura. Desta maneira 30 minutos antes de cada seção de coleta o andador foi ligado e ajustado ao nível zero para permitir a estabilização da temperatura do sistema. Ao final de cada marcha estendeu-se a coleta por mais 5 segundos com o andador em repouso (sem o apoio do paciente) e este valor foi considerado como força zero.

A força vertical em cada lado do andador durante a marcha do paciente com EENM foi calculada utilizando a curva de calibração e subtraindo o valor médio em cada intervalo de força zero. Depois disso foi calculada a média da força vertical em sucessivas janelas com 40 amostras com sobreposição de meia janela, resultando em um sinal amostrado em $120 \mathrm{~Hz}$. Este sinal reamostrado foi filtrado utilizando um filtro passa baixa, tipo FIR, de $5 \mathrm{~Hz}$ com ordem 100.

O torque no ombro durante a marcha foi calculado pelo produto vetorial da força vertical resultante aplicada nos punhos em ambos os lados e o centro de rotação da articulação glenoumeral obtido com os dados cinemáticos (equação 4). Desta forma o torque foi representado nos planos $\mathrm{XZ}$ e $\mathrm{YZ}$ (plano sagital e frontal).

A força e o torque nas outras duas atividades realizadas foram obtidos por dinâmica inversa utilizando os dados cinemáticos e antropométricos.

A força necessária para empurrar a cadeira de rodas foi calculada utilizando a aceleração linear, através da segunda derivada dos dados dos marcadores localizados nos centros das rodas. A força de atrito no eixo da roda foi desconsiderada e a força em cada lado foi calculada pela segunda lei de Newton (equação 2), considerando a massa de cada paciente mais a da sua cadeira de rodas como massa total do sistema (tabela 3). Neste caso a força resultante foi 
considerada no eixo $\mathrm{X}$, e o torque foi calculado pelo produto vetorial da força com os centros das articulações obtidos na cinemática (equação 4). Para esta atividade o torque foi representado nos planos $X Z$ e $X Y$ (plano sagital e transverso).

Para calcular a força durante a atividade de elevação para alívio da pressão foram utilizados os dados antropométricos obtidos por Dempster (1959) (apresentados na tabela 4) a fim de obter a massa de cada segmento superior do corpo dos pacientes (braço, antebraço, mão, tronco e cabeça). Com as massas de cada segmento e seus respectivos centros de massa foi obtido o centro de massa dos membros superiores a cada instante de tempo, utilizando a equação 8. Para esta atividade as pernas e os pés foram considerados estáticos e as coxas puxadas pelo tronco em uma extremidade e apoiadas nas pernas na outra extremidade.

Para cada amostra no tempo foi calculada a resultante do peso da coxa (que puxa o tronco para baixo) considerando o equilíbrio das forças e torques, e então obtida a força resultante suportada pelos membros superiores durante esta atividade (peso dos braços, antebraços, mãos, tronco, cabeça e resultante das coxas). Os valores de força entre $0-10 \%$ e entre $90-100 \%$ do ciclo foram ignorados, pois o paciente inicia a atividade em $10 \%$ do ciclo e retorna em $90 \%$ do ciclo total, desta maneira não teria sentido calcular a força e o torque quando o paciente se encontra sentado na cadeira. O torque foi calculado pelo produto vetorial da força aplicada nos punhos dos pacientes com os dados cinemáticos da articulação glenoumeral (equação 4). Neste caso o torque foi representado nos planos XZ e YZ (plano sagital e frontal). 


\subsection{Análise Estatística}

As análises estatísticas foram realizadas por rotinas desenvolvidas utilizando o programa MatLab (Mathworks Inc., Natick, MA, USA). Para determinar as diferenças de força e torque entre as três atividades executadas foi realizada a análise de variância (ANOVA) de uma variável. Para as atividades musculares foi utilizada ANOVA de duas variáveis a fim de analisar as respostas entre os músculos do mesmo lado durante um determinado exercício bem como a atividade de cada músculo em exercícios diferentes.

Foi executado o teste de comparação múltipla entre as médias, utilizando o processo das diferenças menos significantes de Tukey, para encontrar as diferenças significativas entre as amostras utilizando $\mathrm{p}<0,05$ em todo procedimento estatístico.

Os parâmetros cinéticos analisados estatisticamente foram os picos da força e do torque e também a integral no tempo destas grandezas. O parâmetro referente à atividade muscular foi o valor médio do RMS do sinal mioelétrico normalizado pela MCV. 


\section{CAPÍTULO3 \\ "Está em qualquer profecia que o mundo se acaba um dia..." \\ R.S.S / Profecias (1979).}

\section{RESULTADOS}

Os dados individuais dos 15 pacientes em cada atividade executada estão apresentados no Apêndice.

Neste capítulo serão apresentados exemplos das curvas obtidas para cada exercício executado os e parâmetros extraídos das curvas (picos, integrais e médias) analisados estatisticamente.

A figura 35 apresenta os resultados de uma repetição para um paciente durante o intervalo contendo os três primeiros ciclos de propulsão da cadeira de rodas. A linha contínua é relativa ao lado direito e a linha tracejada ao lado esquerdo. A máxima força encontrada neste caso (pico) foi em torno de $100 \mathrm{~N}$. Os torques da força são apresentados em dois planos, sagital (torque 1) e transversal (torque 2). Pode-se observar que o plano sagital apresentou valores maiores de torque em relação ao transversal (Sagital: pico de $30 \mathrm{~N} \cdot \mathrm{m}$. Transversal: pico de $15 \mathrm{~N} \cdot \mathrm{m}$ ).

As seis últimas curvas na figura 35 são relativas à atividade muscular. A atividade dos músculos analisados é apresentada pelo valor RMS do sinal mioelétrico normalizado pela MCV. Pode-se observar que o deltóide posterior apresentou maior valor e que todos os músculos tiveram atividade menor que $50 \%$ da MCV. 

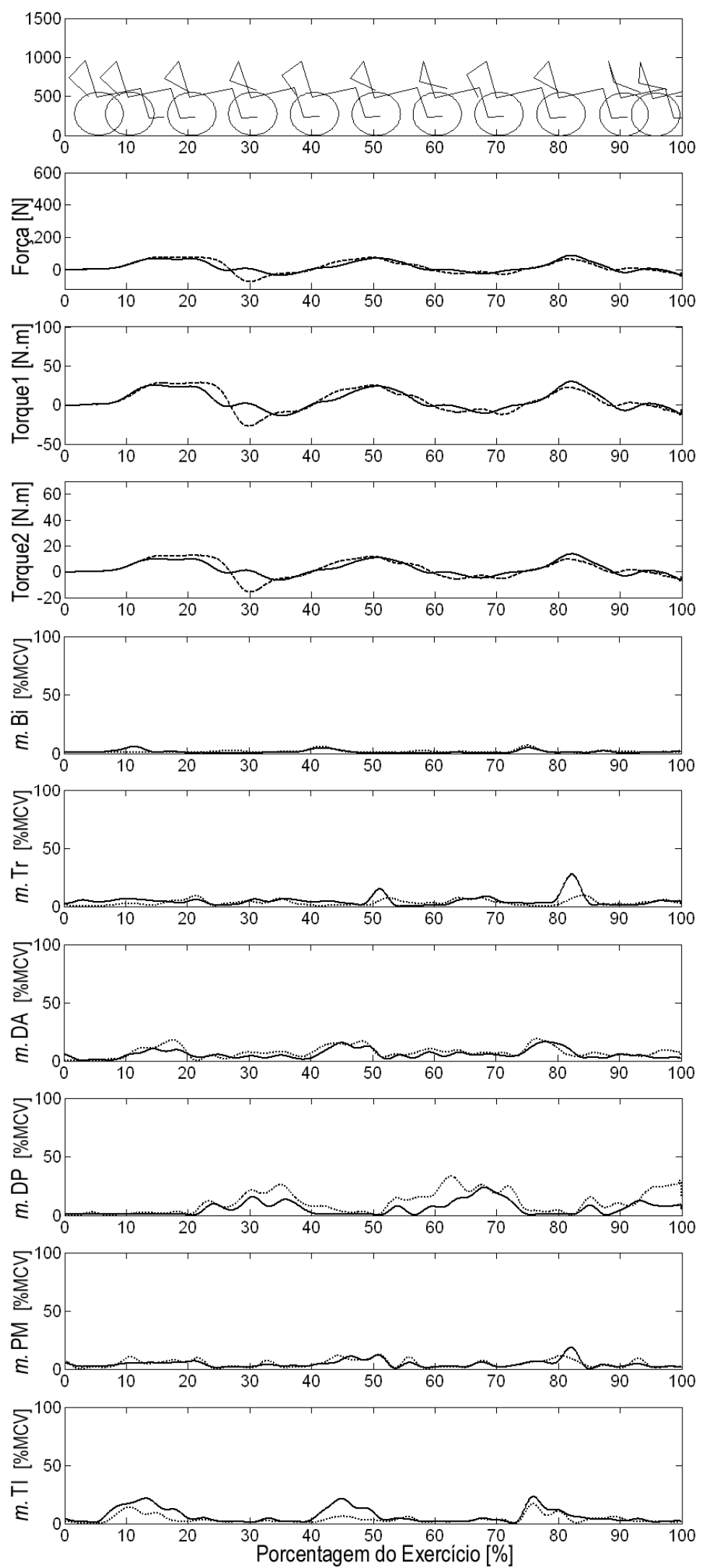

Fig. 35 - Resultados de uma repetição para um paciente durante o intervalo de propulsão da cadeira de rodas. Linha sólida: Lado direito. Linha tracejada: Lado esquerdo. Torque1: Plano Sagital (XZ). Torque2: Plano Transversal (XY). 0 Torque2 do lado direito é apresentado com sinal invertido. As atividades musculares são apresentadas como porcentagem da MCV. Músculos: Bi: Bíceps, Tr: Tríceps, DA: Deltóide Anterior, DP: Deltóide Posterior, PM: Peitoral Maior, TI: Trapézio Inferior. 
Os resultados de uma repetição da elevação para o alívio da pressão de um paciente são apresentados na figura 36. Pode-se observar que a máxima força foi em torno de $300 \mathrm{~N}$ e que os valores de torque no plano sagital (torque 1) e frontal (torque 2) são próximos, em torno de $30 \mathrm{~N} \cdot \mathrm{m}$. Neste caso, os picos de torque no plano sagital ocorreram no início do exercício, entre 10 e $20 \%$ da atividade, e os picos de torque no plano frontal ocorrem no início da atividade para o lado direito e no final para o lado esquerdo (próximo de 90\% da execução do exercício). Com relação às curvas do sinal mioelétrico pode-se observar maior atividade no músculo tríceps braquial, seguido pelo deltóide anterior e trapézio inferior. Neste caso os sinais mioelétricos chegaram a alcançar $100 \%$ da MCV.

A figura 37 apresenta os resultados de uma repetição para um paciente durante a marcha com andador e EENM. Esta atividade exibiu máxima força, próxima a $500 \mathrm{~N}$ na fase de balanço da perna contra lateral. Na curva de força ainda é possível observar 2 grupos contendo 2 vales cada um (no início e no meio da marcha), estes vales são referentes ao deslocamento para frente do andador durante a fase de avanço do andador. Com relação ao torque no plano sagital podese observar que os picos são da ordem de $70 \mathrm{~N} \cdot \mathrm{m}$ e $90 \mathrm{~N} \cdot \mathrm{m}$ nos lados direito e esquerdo respectivamente. No entanto, o plano frontal apresentou picos em torno de $40 \mathrm{~N} \cdot \mathrm{m}$ e $60 \mathrm{~N} \cdot \mathrm{m}$ para os lados direito e esquerdo respectivamente.

A atividade muscular (apresentada nas 6 últimas curvas da figura 37) indica altos valores para o músculo tríceps, seguido do trapézio inferior e peitoral maior. 0 músculo bíceps apresentou valores relevantes apenas durante a fase de avanço do andador. 

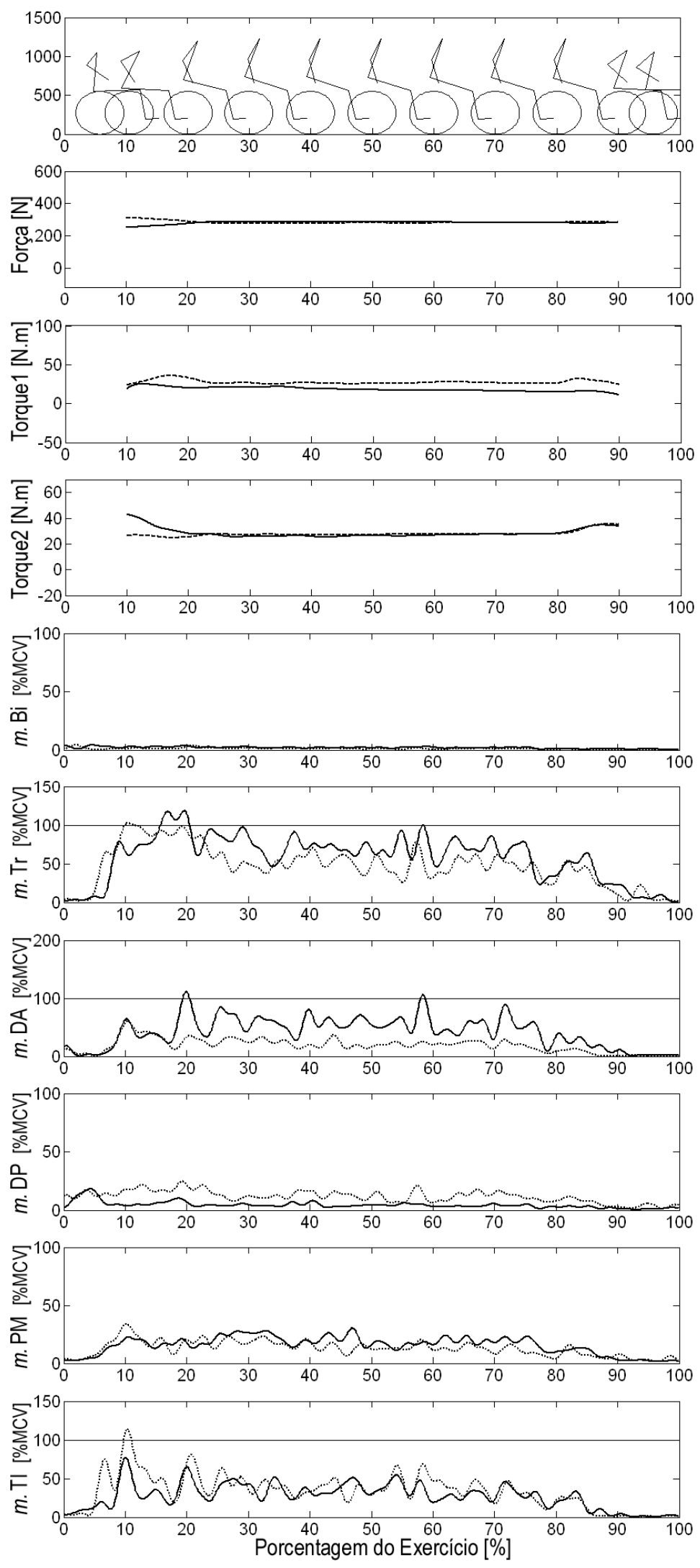

Fig. 36 - Resultados de uma repetição para um paciente durante a elevação para alívio da pressão. Linha sólida: Lado direito. Linha tracejada: Lado esquerdo. Torque1: Plano Sagital (XZ). Torque2: Plano Frontal (YZ). O Torque2 do lado direito é apresentado com sinal invertido. As atividades musculares são apresentadas como porcentagem da MCV. Músculos: Bi: Bíceps, Tr: Tríceps, DA: Deltóide Anterior, DP: Deltóide Posterior, PM: Peitoral Maior, TI: Trapézio Inferior. 

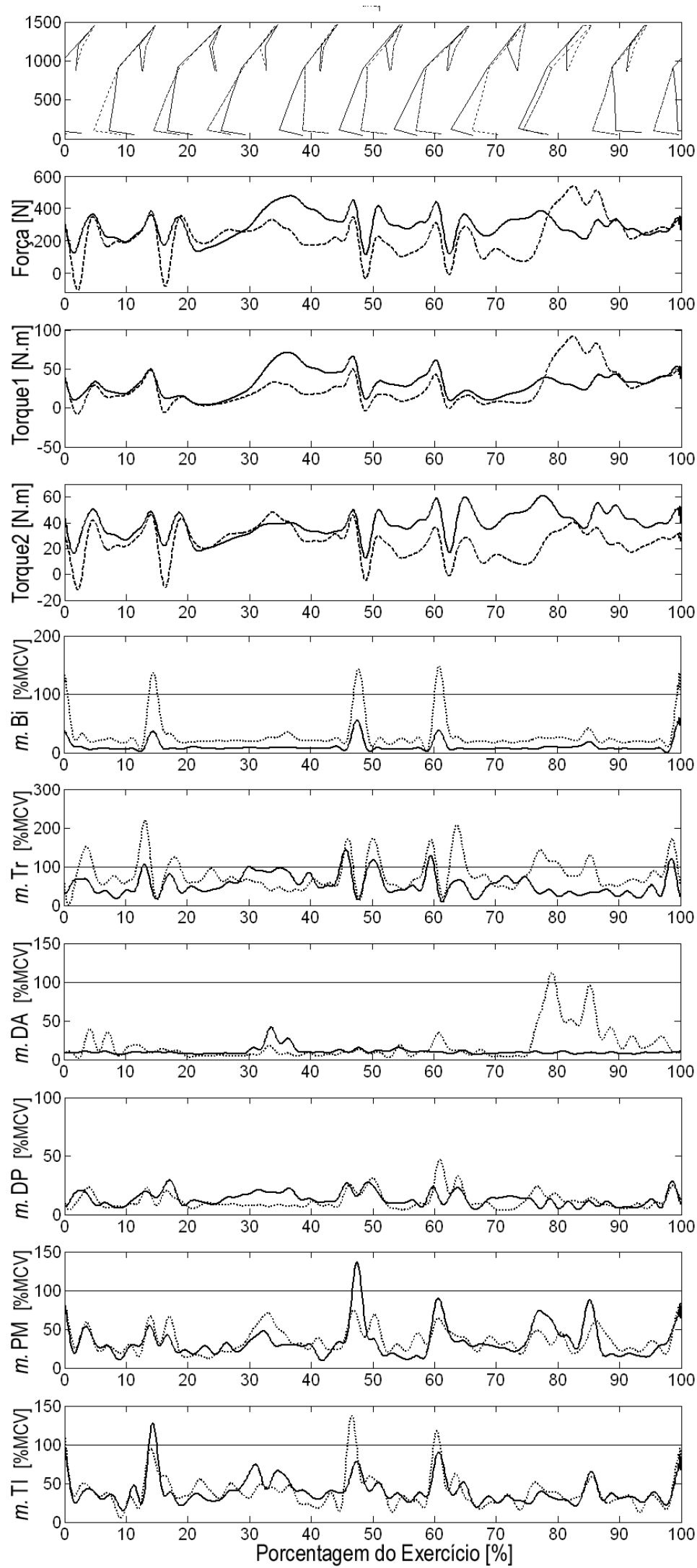

Fig. 37 - Resultados de uma repetição para um paciente durante a marcha com andador e EENM. Linha sólida: Lado direito. Linha tracejada: Lado esquerdo. Torque1: Plano Sagital (XZ). Torque2: Plano Frontal (YZ). O Torque2 do lado direito é apresentado com sinal invertido. As atividades musculares são apresentadas como porcentagem da MCV. Músculos: Bi: Bíceps, Tr: Tríceps, DA: Deltóide Anterior, DP: Deltóide Posterior, PM: Peitoral Maior, TI: Trapézio Inferior. 
As características médias das atividades realizadas pelos 15 pacientes são apresentadas nas tabelas 5, 6 e 7. Dentre as características apresentadas estão o tempo de execução da tarefa, a distância percorrida, a velocidade média, a altura que o paciente se elevou durante a elevação para alívio da pressão, o comprimento da passada e a cadência durante a marcha. A tabela 5 apresenta as características médias para a propulsão da cadeira de rodas. Na tabela 6 são apresentadas as características médias da elevação para alívio da pressão e na tabela 7 as características da marcha com andador e EENM.

Tab. 5 - Médias das características de todos os pacientes que executaram os 3 ciclos iniciais de propulsão da cadeira de rodas.

\begin{tabular}{lccc}
\hline & $\begin{array}{c}\text { Tempo } \\
{[\mathrm{s}]}\end{array}$ & $\begin{array}{c}\text { Distância } \\
{[\mathrm{cm}]}\end{array}$ & $\begin{array}{c}\text { Velocidade } \\
{[\mathrm{cm} / \mathrm{s}]}\end{array}$ \\
\hline Média & 3,61 & 152,86 & 41,99 \\
Desvio Padrão & 0,50 & 55,97 & 13,45 \\
\hline
\end{tabular}

Tab. 6 - Médias das características de todos os pacientes que executaram a elevação para alívio da pressão.

\begin{tabular}{lcc}
\hline & $\begin{array}{c}\text { Tempo } \\
{[\mathrm{s}]}\end{array}$ & $\begin{array}{c}\text { Elevação } \\
{[\mathrm{cm}]}\end{array}$ \\
\hline Média & 6,47 & 21,49 \\
Desvio Padrão & 0,80 & 5,96 \\
\hline
\end{tabular}

Tab. 7 - Médias das características de todos os pacientes que executaram a marcha com andador e EENM.

\begin{tabular}{lcccc}
\hline & $\begin{array}{c}\text { Tempo } \\
{[\mathrm{s}]}\end{array}$ & $\begin{array}{c}\text { Passada } \\
\text { [cm] }\end{array}$ & $\begin{array}{c}\text { Velocidade } \\
\text { [cm/s] }\end{array}$ & $\begin{array}{c}\text { Cadência } \\
\text { [passos/min] }\end{array}$ \\
\hline Média & 6,33 & 62,65 & 10,45 & 19,98 \\
Desvio Padrão & 1,38 & 9,73 & 2,98 & 4,97 \\
\hline
\end{tabular}

Analisando todos os pacientes observou-se que os picos da força e torque ocorreram nos instantes relativos a $20 \%, 50 \%$ e $80 \%$ da execução do exercício para a propulsão da cadeira de rodas. Durante a elevação para alívio da pressão a força e o torque se mantiveram praticamente constantes durante todo intervalo, no entanto os maiores valores de torque ocorreram próximos a 10\% e 90\% (início e fim desta atividade, pois sem a extensão completa do cotovelo o torque tende a ser maior). 
Durante a marcha com andador e EENM os picos de força e torque foram próximos a $35 \%$ e $85 \%$ dos ciclos analisados (final das fases de balanço).

A seguir são apresentados os resultados estatísticos obtidos por meio de parâmetros extraídos da análise Cinética e da Atividade Muscular.

\subsection{Cinética}

Foram obtidos os valores de pico da força e dos torques para todas as repetições das atividades realizadas por todos pacientes. Além disso, obteve-se também a integral no tempo destas grandezas. Estes parâmetros foram analisados estatisticamente a fim de encontrar diferenças significativas entre os exercícios executados.

Na figura 38 são apresentados os valores médios dos picos de força em cada uma das atividades executadas para cada paciente em ambos os lados. As barras representam as médias com seus respectivos erros padrões, obtidos pela análise estatística. Cada cor representa um exercício diferente e cada letra representa uma faixa estatisticamente diferente entre os exercícios realizados por um mesmo paciente com nível de significância menor que 5\%.

Pode-se observar que os picos de força para a propulsão da cadeira de rodas apresentaram, em todos os casos, valores significativamente menores que os picos de força nas outras duas atividades em ambos os lados.

Entre a marcha com EENM e a elevação para alívio da pressão pode-se notar que para o lado direito os picos de força durante a marcha foram maiores, ou pelo menos iguais, à elevação estatisticamente (figura 38). Para o lado esquerdo apenas o paciente 1 apresentou pico de força superior durante a marcha, comparado com a elevação, dois outros pacientes (2 e 7) apresentaram valores significativamente 
iguais entre estas atividades, e outros quatro pacientes (5, 11, 13 e 14) apresentaram valores de pico inferiores durante a marcha comparado com a elevação para alívio da pressão.

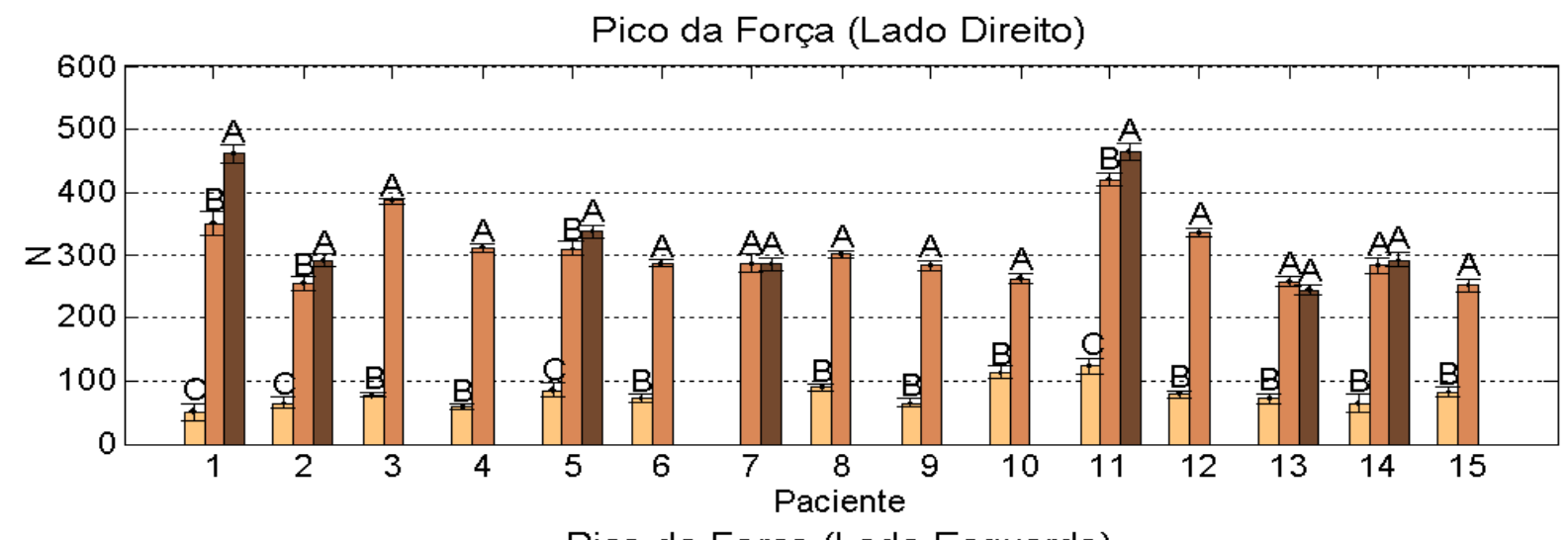

Pico da Força (Lado Esquerdo)

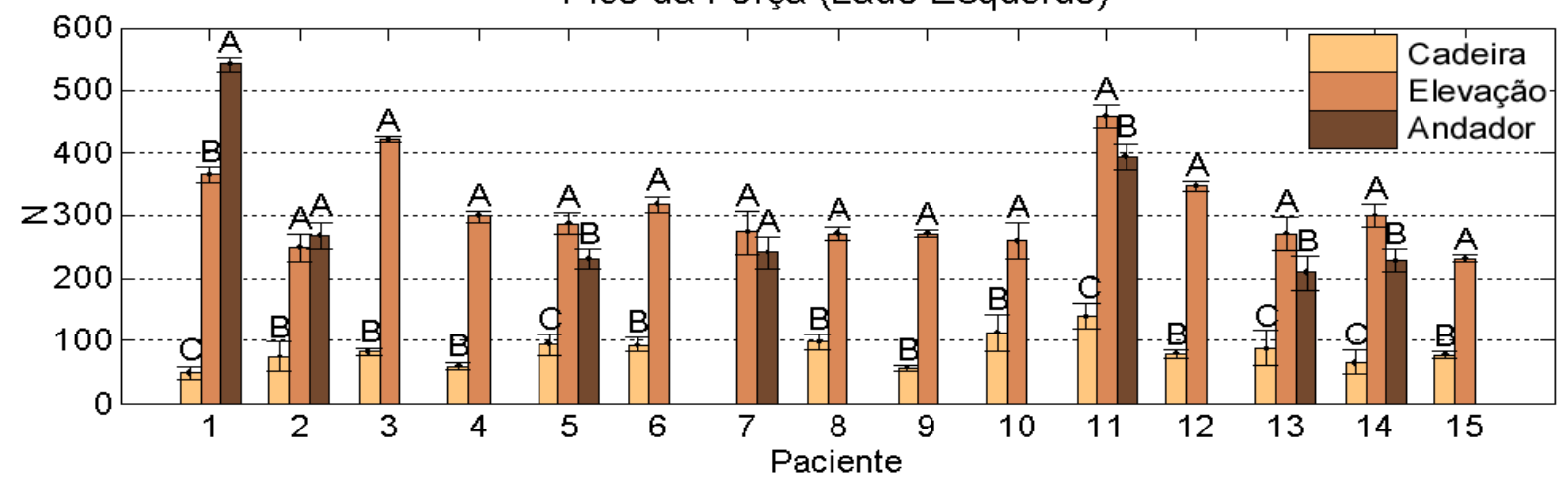

Fig. 38 - Médias dos Picos da Força de cada paciente. As médias (barras) e seus respectivos erros padrões para cada exercício estão representados em cores diferentes em ambos os lados. As diferentes letras representam diferenças significativas entre os exercícios.

As médias entre os picos do torque no plano sagital (XZ) para cada paciente são apresentadas na figura 39. Com relação à propulsão da cadeira de rodas podese observar que os pacientes 5, 8 e 10 apresentaram picos de torque maiores que os picos na elevação para alívio da pressão. Para outros seis pacientes $(2,6,11,13$, $14,15)$ não houve diferença significativa nos valores de pico entre estas duas atividades e para os pacientes 1, 3, 4, 9 e 12 a elevação apresentou picos maiores comparado à propulsão da cadeira. Relativo aos picos de torque durante a marcha pode-se observar que o paciente 13 apresentou valores menores comparado às outras duas atividades bilateralmente, no entanto os pacientes 1,5 e 7 apresentaram valores maiores (exceto apenas o lado esquerdo do paciente 5 
durante a propulsão da cadeira de rodas, que não apresentou diferenças significativas). Os picos de torque durante a marcha para os demais pacientes que realizaram esta atividade $(2,11$ e 14) foram significativamente iguais aos picos das outras duas atividades para o lado direito, porém para o lado esquerdo os pacientes 2 e 11 apresentaram valores menores e o paciente 14 apresentou valores maiores.
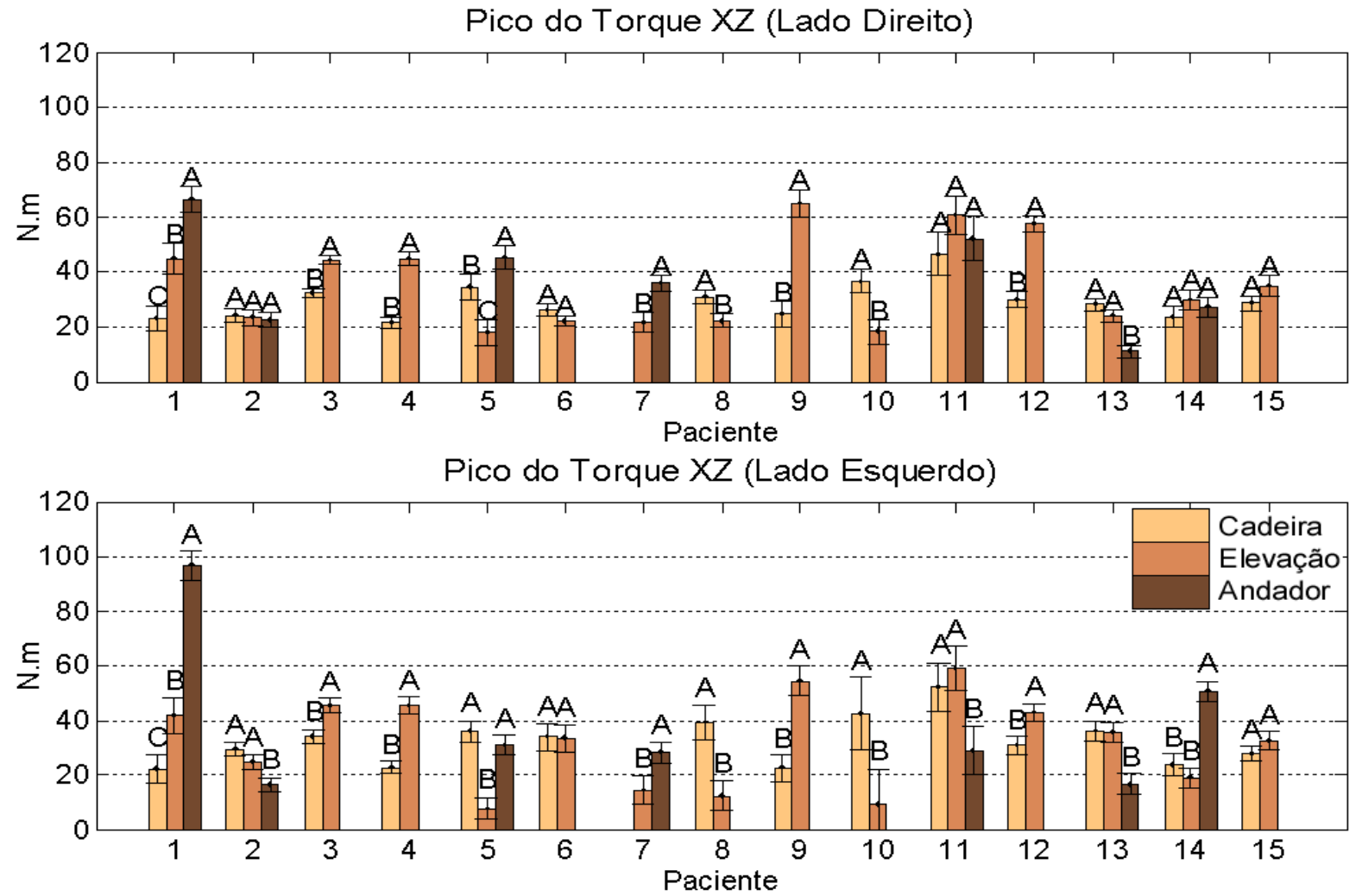

Fig. 39 - Médias dos Picos do Torque no plano Sagital (XZ) de cada paciente. As médias (barras) e seus respectivos erros padrões para cada um dos exercícios executados estão representados em cores diferentes para ambos os lados. As diferentes letras para cada parâmetro representam diferenças significativas entre os exercícios com $p<0,05$.

A figura 40 apresenta os picos de torque no segundo plano para as três atividades executadas. O torque no segundo plano para a propulsão da cadeira de rodas é referente ao plano transversal $(X Y)$ e para as outras duas atividades ao plano frontal (YZ). Apesar do torque na propulsão da cadeira de rodas estar em plano diferente das outras duas atividades, pode-se observar que os valores de pico durante a propulsão foram menores (exceto para o paciente 13 que apresentou valor significativamente igual no lado esquerdo durante a marcha). Comparando os picos 
de torque durante a marcha com os picos da elevação para alívio da pressão podese observar que não houve diferenças significativas para o paciente 2 , no entanto para os pacientes 1 e 14 a marcha apresentou maiores valores. Para o restante dos pacientes que realizou a marcha $(5,7,11,13)$ pode-se observar que os picos de torque no lado direito foram maiores durante a marcha, comparados com a elevação, porém para lado esquerdo os picos da marcha foram menores, exceto o paciente 7 que apresentou resultados estatisticamente iguais neste lado.

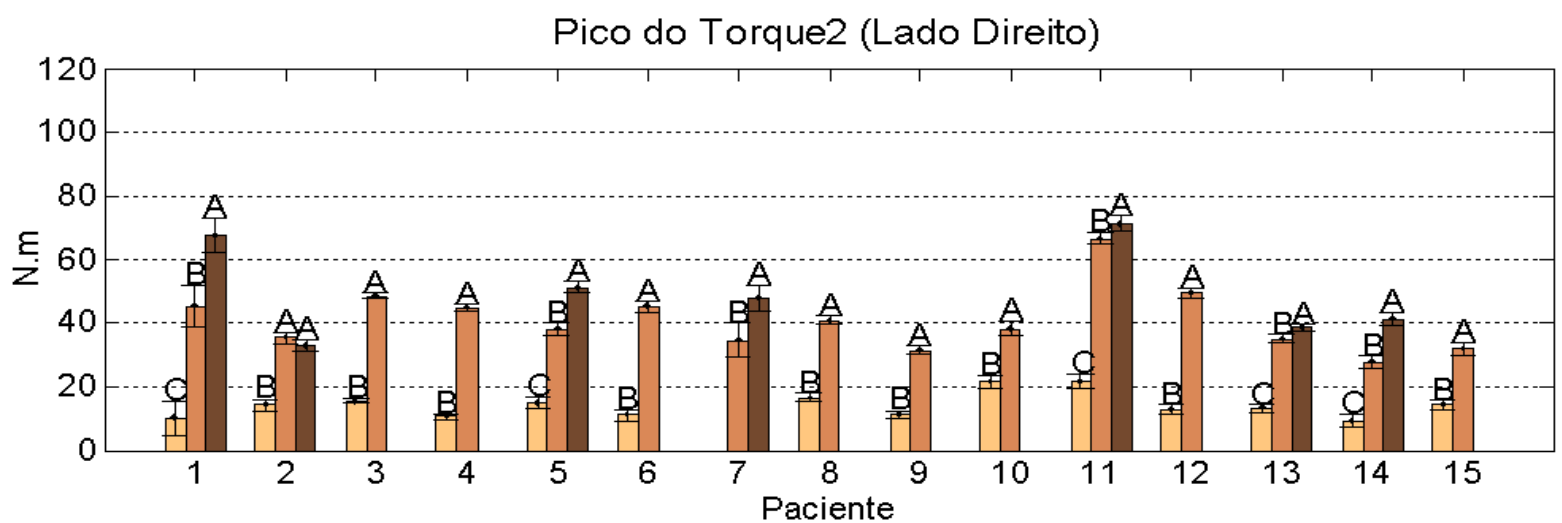

Pico do Torque2 (Lado Esquerdo)

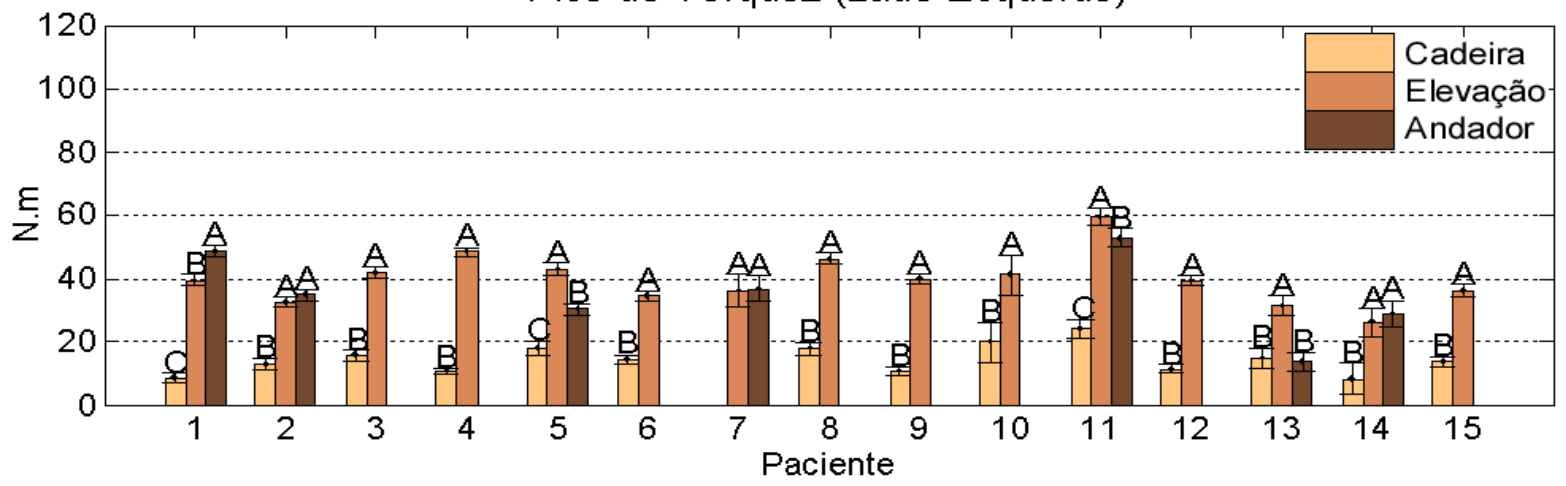

Fig. 40 - Médias dos Picos do $2^{\circ}$ Torque de cada paciente. As médias (barras) e seus respectivos erros padrões para cada um dos exercícios executados estão representados em cores diferentes para ambos os lados. Para a propulsão da cadeira de rodas o torque é referente ao plano Transversal $(X Y)$ e para a elevação para alívio da pressão e a marcha com andador e EENM é referente ao plano Frontal (YZ). As diferentes letras para cada parâmetro representam diferenças significativas entre os exercícios com $\mathrm{p}<0,05$.

Os valores médios das integrais da força em cada uma das atividades executadas para cada paciente em ambos os lados são apresentados na figura 41. As integrais de força para a propulsão da cadeira de rodas apresentaram, em todos os casos, valores significativamente menores comparados às outras duas atividades. 
Os valores da integral de força durante a marcha para o paciente 1 não diferiram estatisticamente dos valores obtidos na elevação para alívio da pressão. No entanto para todos os outros pacientes que realizaram a marcha a integral da força durante a elevação foi significativamente maior que durante as outras atividades em ambos os lados.
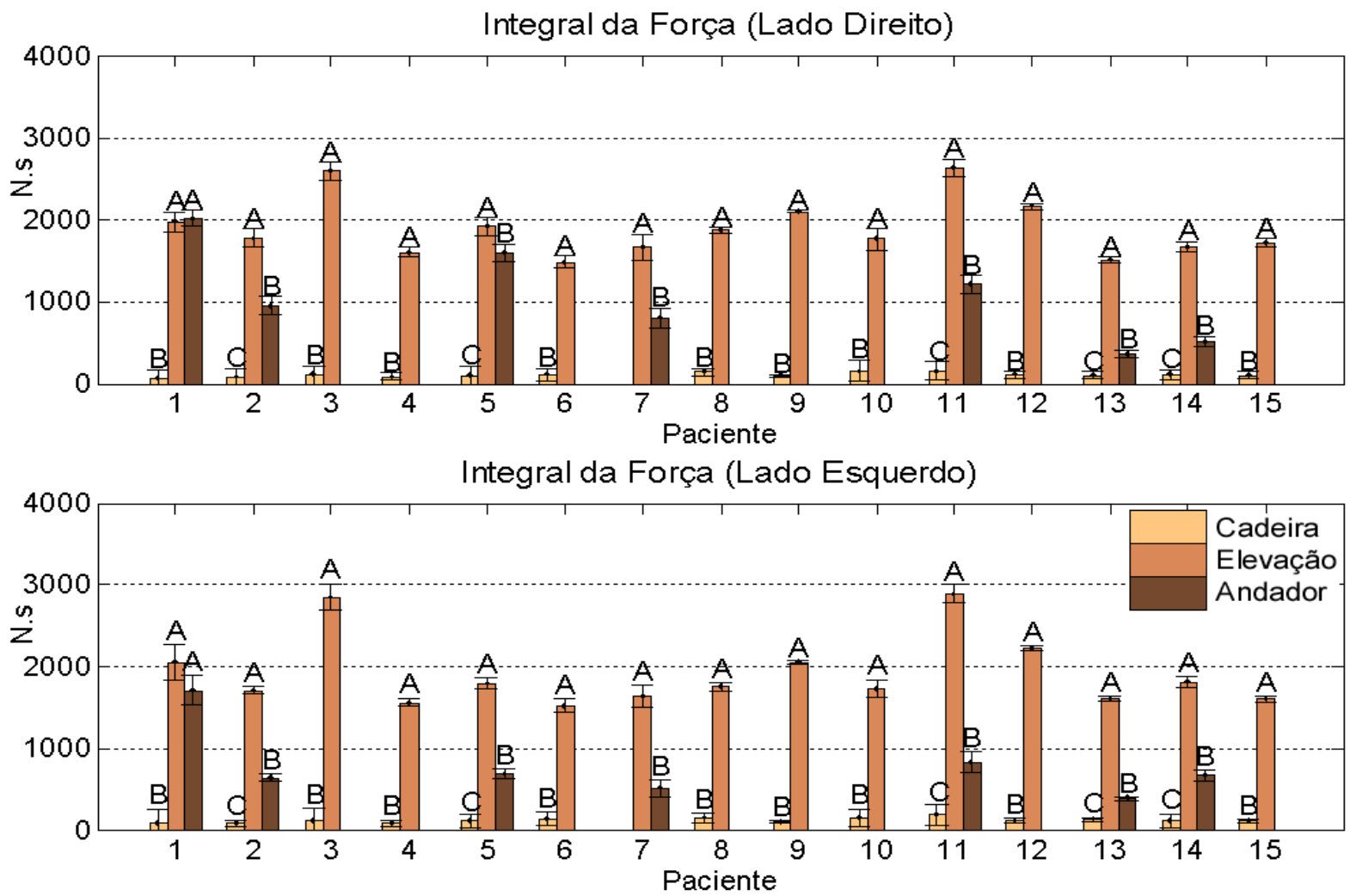

Fig. 41 - Médias das Integrais das Forças de cada paciente. As médias (barras) e seus respectivos erros padrões para cada exercício estão representados em cores diferentes em ambos os lados. As diferentes letras representam diferenças significativas entre os exercícios.

A figura 42 apresenta as médias das integrais no tempo do torque no plano sagital (XZ). Para o lado direito observa-se que as médias da propulsão da cadeira de rodas apresentam valores estatisticamente menores ou iguais às outras duas atividades, com exceção do paciente 13 , onde a média da propulsão da cadeira apresentou valor maior que da marcha. Para o lado esquerdo (além do paciente 13) ainda outros dois pacientes (8 e 10) apresentaram médias significativamente maiores durante a propulsão da cadeira. 
Com relação à marcha com andador e EENM pode-se observar que a integral do torque sagital no lado direito apresentou médias maiores às outras duas atividades para os pacientes 1 e 5 , e no lado esquerdo foram observadas médias significantemente maiores nos pacientes 5, 7 e 14 .

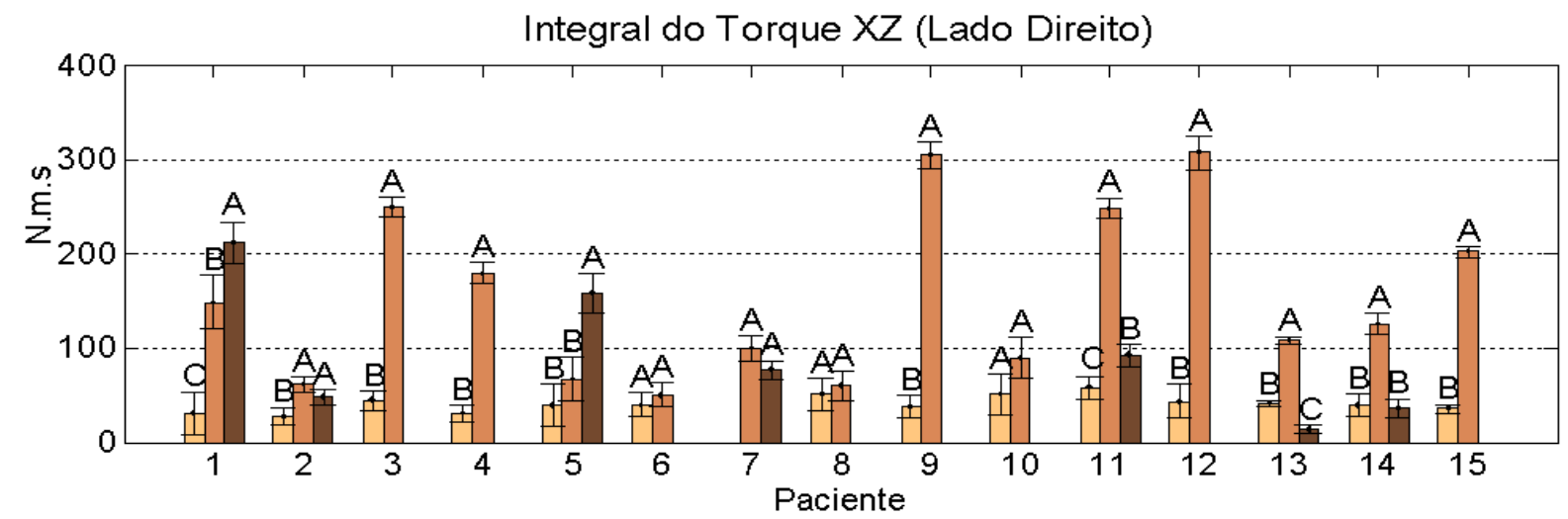

Integral do Torque XZ (Lado Esquerdo)

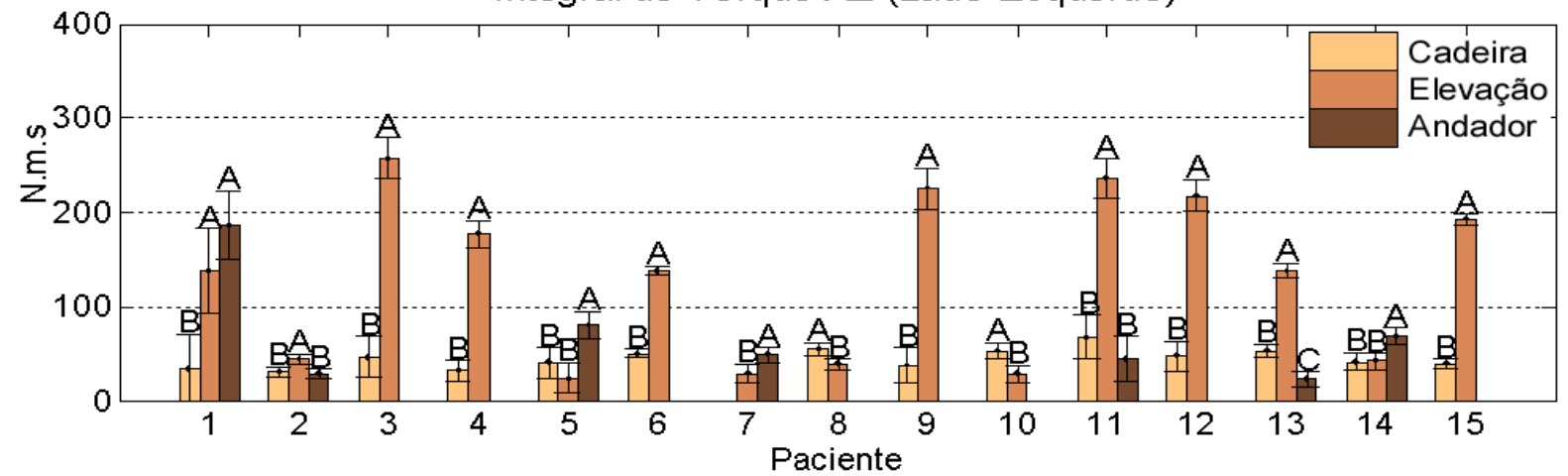

Fig. 42 - Médias das Integrais do Torque no plano Sagital (XZ) de cada paciente. As médias (barras) e seus respectivos erros padrões para cada um dos exercícios executados estão representados em cores diferentes para ambos os lados. As diferentes letras para cada parâmetro representam diferenças significativas entre os exercícios com $p<0,05$.

Na figura 43 são apresentadas as média das integrais de torque no segundo plano para as três atividades executadas. Apesar do torque durante a propulsão da cadeira de rodas estar em plano diferente às outras duas atividades, pode-se observar que as integrais do torque durante a propulsão apresentaram valores menores.

Pode-se observar que em nenhum caso a marcha apresentou integral do segundo torque significativamente superior aos valores obtidos durante a elevação, inclusive para os pacientes 2, 7, 11, 13 e 14 as integrais de torque na marcha foram significativamente menores comparados com a elevação. 

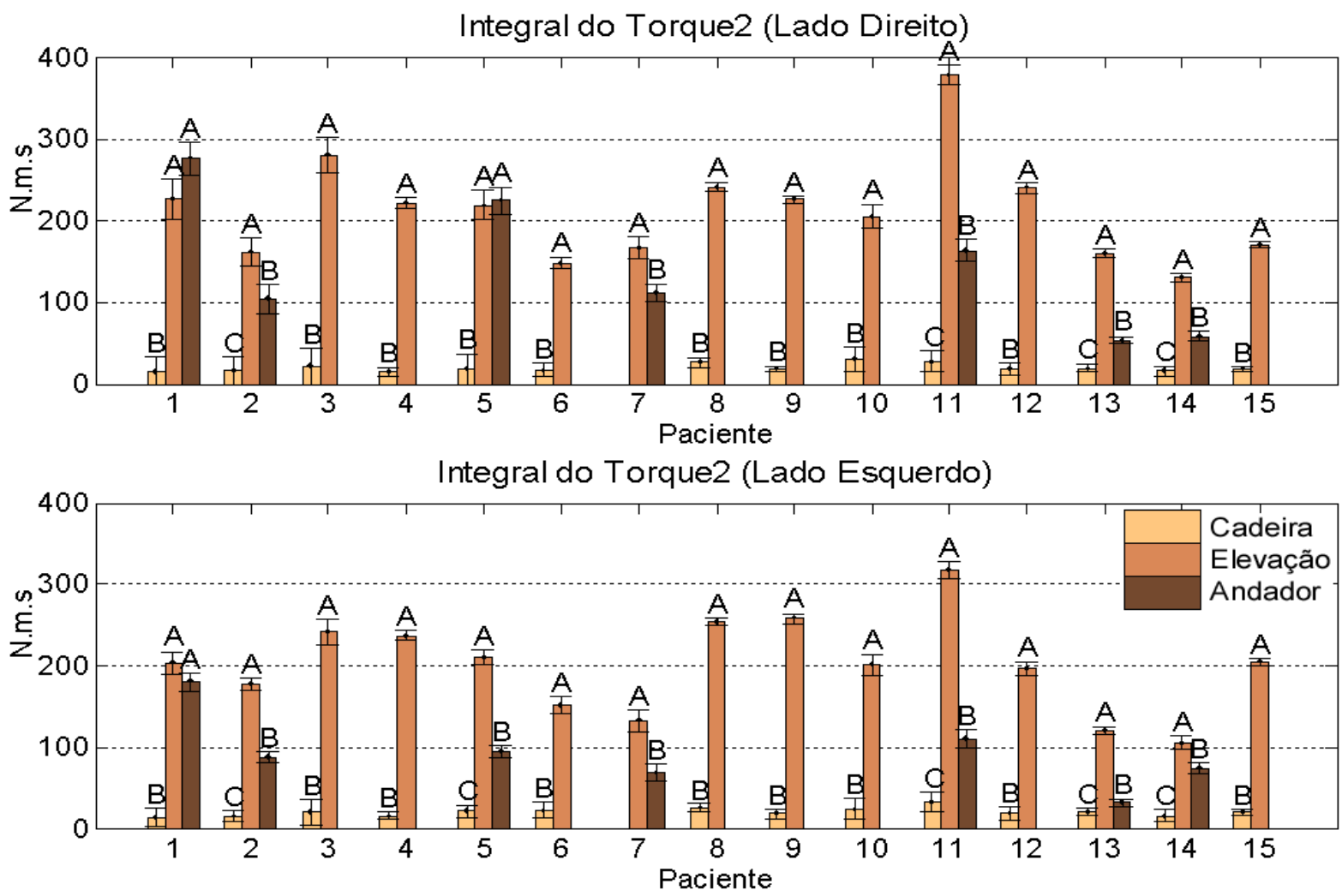

Fig. 43 - Médias das Integrais do 20 Torque de cada paciente. As médias (barras) e seus respectivos erros padrões para cada um dos exercícios executados estão representados em cores diferentes para ambos os lados. Para a propulsão da cadeira de rodas o torque é referente ao plano Transversal (XY) e para a elevação para alívio da pressão e a marcha com andador e EENM é referente ao plano Frontal (YZ). As diferentes letras para cada parâmetro representam diferenças significativas entre os exercícios com $\mathrm{p}<0,05$.

A figura 44 indica as médias dos picos de força entre todos os pacientes, durante as três atividades executadas. Cada letra representa uma faixa estatisticamente diferente entre os exercícios realizados por todos os pacientes. Pode-se observar que as médias dos picos de força durante a propulsão da cadeira de rodas foram significativamente menores que as outras duas atividades para ambos os lados.

Com relação à marcha com andador e EENM pode se observar que as médias dos picos de força foram significativamente maiores comparadas com as médias obtidas durante a elevação no lado direito, porém para o lado esquerdo estes valores não diferiram estatisticamente. 


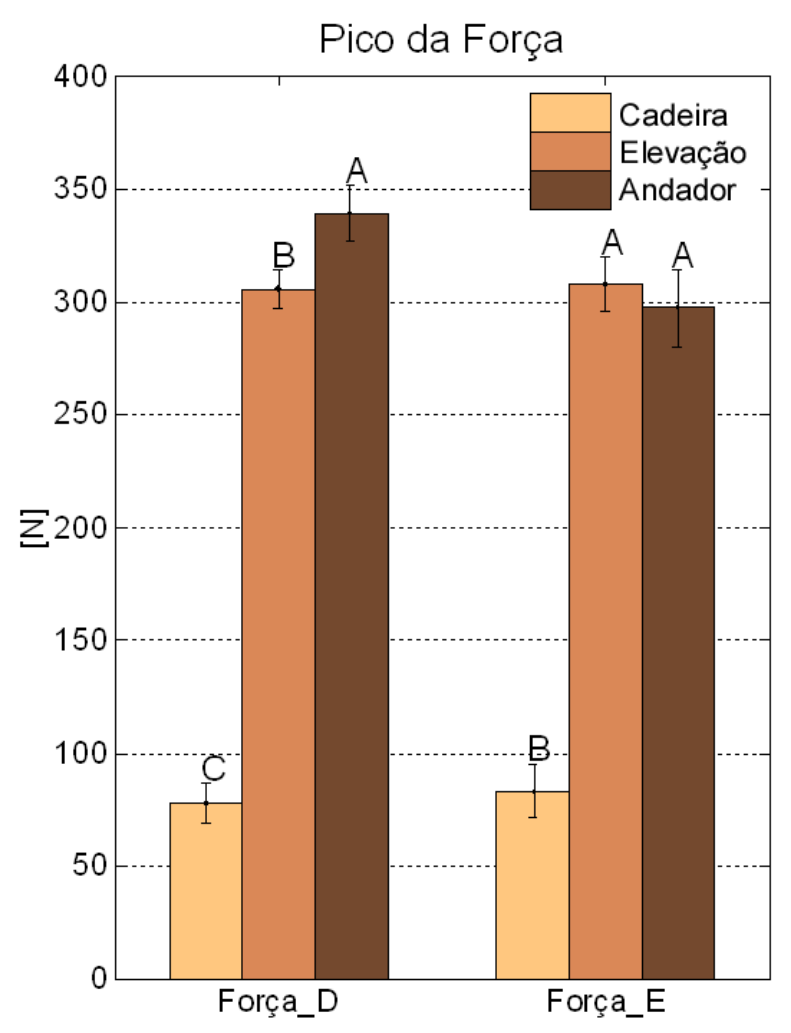

Fig. 44 - Médias do Pico das Forças de todos pacientes. As médias (barras) e seus respectivos erros padrões para cada um dos 3 exercícios executados estão representados em cores diferentes em ambos os lados. As diferentes letras representam diferenças significativas entre os exercícios com $\mathrm{p}<0,05$ para cada lado.

Na figura 45 são apresentadas as médias dos picos dos torques para todos os pacientes. $O$ torque 1 é referente ao plano sagital $(X Z)$. $O$ torque 2 é referente ao plano transversal $(\mathrm{XY})$ para a propulsão da cadeira de rodas e ao plano frontal $(\mathrm{YZ})$ para a elevação e para a marcha. Pode-se observar que as médias dos picos de torque nos dois planos durante a propulsão da cadeira de rodas foram significativamente menores comparadas às outras duas atividades, exceto para o torque no lado esquerdo do plano sagital (torque 1), onde não houve diferenças significativas entre as três atividades executadas.

Comparando a marcha com a elevação para alívio da pressão, pode-se observar que as médias no plano sagital não diferiram significativamente para 
ambos os lados, porém no plano frontal (torque 2) as médias da marcha foram superiores às médias da elevação no lado direito e inferiores no lado esquerdo.

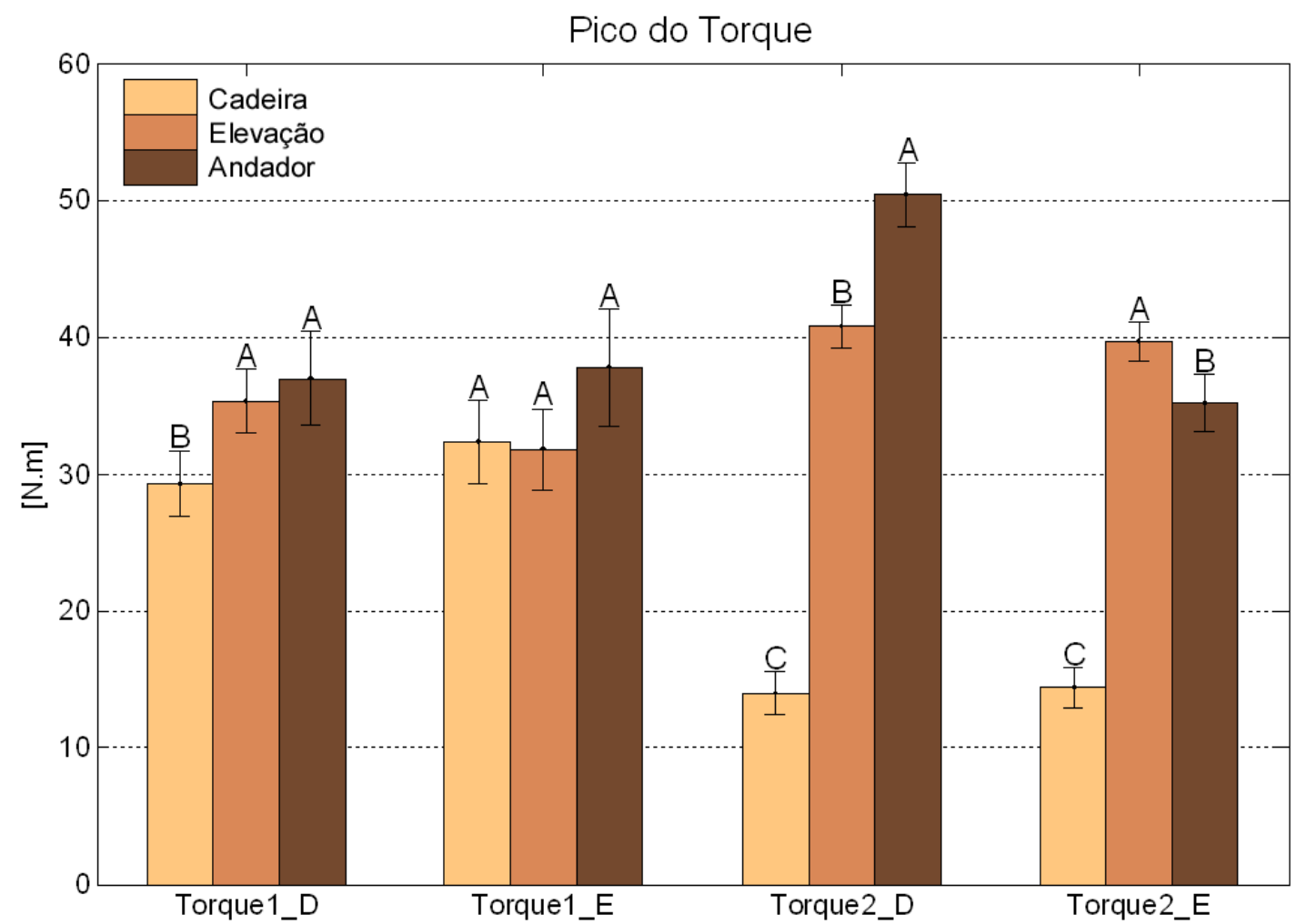

Fig. 45 - Médias dos Picos dos Torques de todos pacientes. As médias (barras) e seus respectivos erros padrões para cada um dos 3 exercícios executados estão representados em cores diferentes para ambos os lados. 0 Torque 1 é referente ao plano sagital (XZ). O Torque 2 é referente ao plano Transversal (XY) para a propulsão da cadeira de rodas e ao plano Frontal (YZ) para a elevação para alívio da pressão e a marcha com andador e EENM. As diferentes letras em cada parâmetro representam diferenças significativas entre os exercícios com $p<0,05$.

Os valores médios das integrais da força para todos pacientes em cada uma das atividades executadas são apresentados na figura 46. Pode-se observar que as médias das integrais de força para a propulsão da cadeira de rodas foram significativamente menores, e para a elevação foram significativamente maiores, comparadas às outras duas atividades em ambos os lados. 


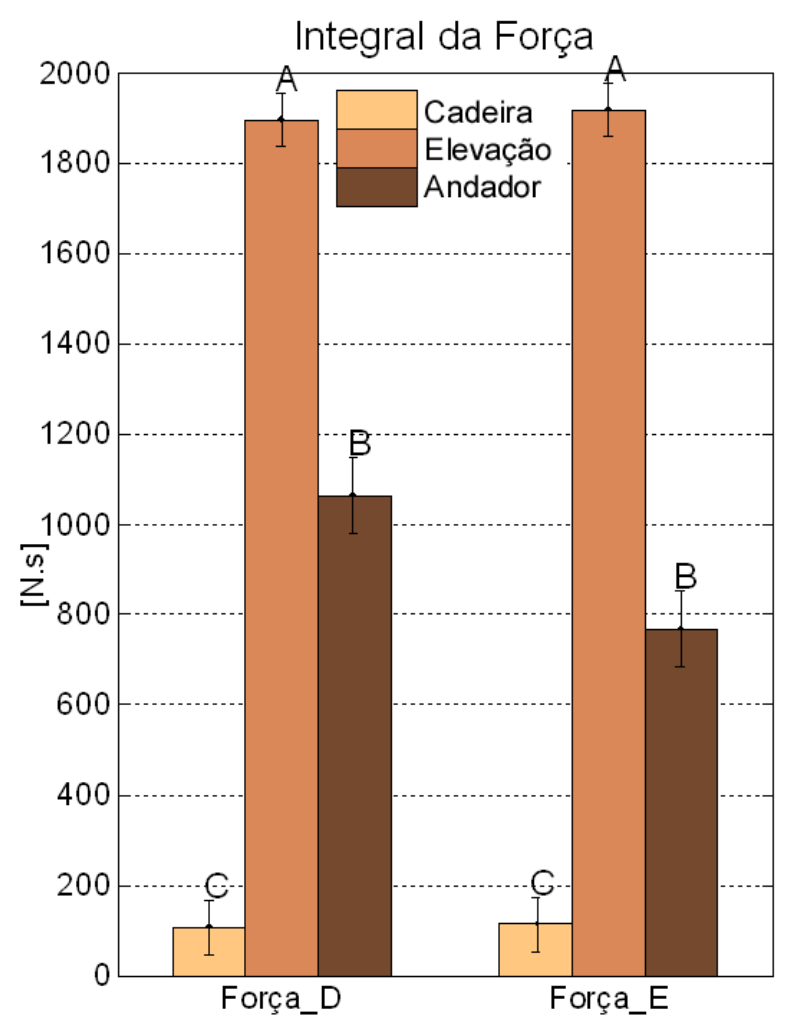

Fig. 46 - Médias da Integral das Forças de todos pacientes. As médias (barras) e seus respectivos erros padrões para cada um dos 3 exercícios executados estão representados em cores diferentes em ambos os lados. As diferentes letras representam diferenças significativas entre os exercícios com $p<0,05$ para cada lado.

A figura 47 apresenta as médias das integrais dos torques para todos os pacientes. $O$ torque 1 é referente ao plano sagital $(X Z)$. $O$ torque 2 é referente ao plano transversal $(\mathrm{XY})$ para a propulsão da cadeira de rodas, e ao plano frontal $(\mathrm{YZ})$ para a elevação e para a marcha.

Pode-se observar pela figura 47 que as médias das integrais de torque nos dois planos durante a propulsão da cadeira de rodas foram significativamente menores, exceto no plano sagital do lado esquerdo, onde não diferiu estatisticamente da marcha, apesar das médias da propulsão serem sempre menores.

Comparando a marcha com a elevação para alívio da pressão pode-se observar que as médias da marcha foram inferiores em ambos os lado nos dois planos analisados. 


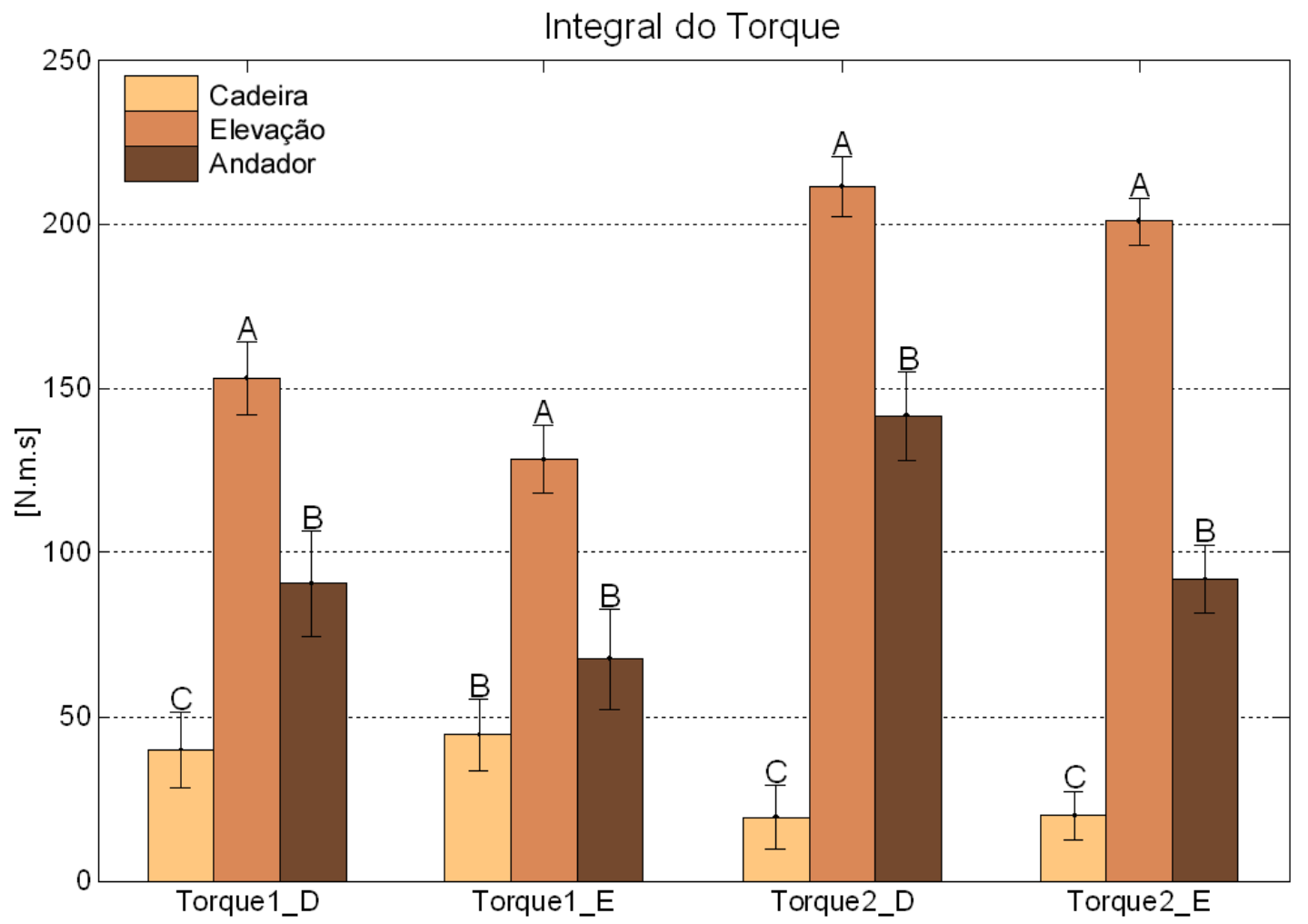

Fig. 47 - Médias da Integral dos Torques de todos pacientes. As médias (barras) e seus respectivos erros padrões para cada um dos 3 exercícios executados estão representados em cores diferentes para ambos os lados. 0 Torque 1 é referente ao plano sagital $(X Z)$. O Torque 2 é referente ao plano Transversal $(X Y)$ para a propulsão da cadeira de rodas e ao plano Frontal (YZ) para a elevação para alívio da pressão e a marcha com andador e EENM. As diferentes letras para cada parâmetro representam diferenças significativas entre os exercícios com $p<0,05$.

$\mathrm{Na}$ tabela 8 são apresentadas as médias e desvios padrões dos picos e integrais da força e dos torques para o lado direito durante as atividades realizadas por cada paciente, e na tabela 9 as médias e desvios padrões dos picos e integrais da força e dos torques no lado esquerdo. 
Tab. 8 - Médias e Desvios Padrões dos Picos e Integrais da Força, do Torque no Plano Sagital (XZ) e do 2 o Torque no Lado Direito.

\begin{tabular}{|c|c|c|c|c|c|c|c|}
\hline \multirow{3}{*}{$\begin{array}{l}\frac{0}{0} \\
\frac{\pi}{0} \\
. \\
\end{array}$} & \multirow{3}{*}{ 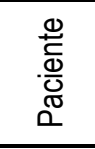 } & \multicolumn{2}{|c|}{ FORÇA } & \multicolumn{2}{|c|}{ TORQUE XZ } & \multicolumn{2}{|c|}{ TORQUE 2} \\
\hline & & Pico & Integral & Pico & Integral & Pico & Integral \\
\hline & & {$[\mathrm{N}]$} & {$[\mathrm{N} \cdot \mathrm{s}]$} & {$[\mathrm{N} \cdot \mathrm{m}]$} & {$[\mathrm{N} \cdot \mathrm{m} \cdot \mathrm{s}]$} & {$[\mathrm{N} \cdot \mathrm{m}]$} & {$[\mathrm{N} \cdot \mathrm{m} \cdot \mathrm{s}]$} \\
\hline \multirow{15}{*}{ 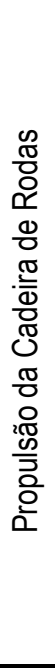 } & 1 & $49,5 \pm 16,2$ & $66,6 \pm 21,5$ & $22,9 \pm 6,7$ & $30,5 \pm 9,8$ & $-10,1 \pm 3,4$ & $14,1 \pm 4,6$ \\
\hline & 2 & $64,0 \pm 4,5$ & $72,1 \pm 6,6$ & $24,1 \pm 2,0$ & $27,3 \pm 2,0$ & $-14,2 \pm 1,9$ & $16,1 \pm 1,9$ \\
\hline & 3 & $77,0 \pm 5,3$ & $105,5 \pm 11,6$ & $32,4 \pm 1,9$ & $44,1 \pm 4,6$ & $-15,4 \pm 1,5$ & $21,8 \pm 4,1$ \\
\hline & 4 & $57,6 \pm 7,4$ & $81,1 \pm 22,9$ & $21,6 \pm 3,3$ & $30,0 \pm 8,9$ & $-10,5 \pm 1,4$ & $15,5 \pm 3,9$ \\
\hline & 5 & $85,2 \pm 11,2$ & $98,7 \pm 5,8$ & $34,3 \pm 5,8$ & $38,7 \pm 2,3$ & $-14,9 \pm 3,1$ & $17,3 \pm 1,4$ \\
\hline & 6 & $72,2 \pm 11,2$ & $107,9 \pm 7,6$ & $26,1 \pm 3,5$ & $39,6 \pm 2,9$ & $-10,9 \pm 1,9$ & $16,9 \pm 1,4$ \\
\hline & 8 & $88,4 \pm 9,1$ & $145,4 \pm 8,7$ & $30,9 \pm 2,7$ & $50,7 \pm 2,9$ & $-16,5 \pm 1,5$ & $26,2 \pm 1,3$ \\
\hline & 9 & $64,5 \pm 13,0$ & $97,2 \pm 8,7$ & $24,6 \pm 4,8$ & $36,6 \pm 3,2$ & $-11,2 \pm 2,2$ & $18,2 \pm 2,0$ \\
\hline & 10 & $113,8 \pm 16,4$ & $153,3 \pm 12,7$ & $36,6 \pm 5,5$ & $50,4 \pm 4,4$ & $-21,4 \pm 2,6$ & $29,6 \pm 2,1$ \\
\hline & 11 & $123,3 \pm 13,6$ & $149,5 \pm 17,8$ & $46,5 \pm 2,6$ & $57,9 \pm 6,2$ & $-21,7 \pm 1,7$ & $27,2 \pm 3,3$ \\
\hline & 12 & $77,6 \pm 14,0$ & $109,1 \pm 12,1$ & $29,9 \pm 5,2$ & $43,1 \pm 4,5$ & $-12,8 \pm 2,3$ & $18,1 \pm 1,9$ \\
\hline & 13 & $71,3 \pm 12,6$ & $100,5 \pm 14,6$ & $28,1 \pm 4,9$ & $40,5 \pm 5,8$ & $-13,0 \pm 2,3$ & $18,7 \pm 2,9$ \\
\hline & 14 & $64,0 \pm 19,0$ & $104,3 \pm 10,8$ & $23,8 \pm 7,2$ & $39,1 \pm 4,6$ & $-9,1 \pm 2,8$ & $15,9 \pm 1,9$ \\
\hline & 15 & $82,3 \pm 11,4$ & $101,9 \pm 13,6$ & $28,5 \pm 4,2$ & $35,0 \pm 4,5$ & $-14,1 \pm 2,1$ & $17,7 \pm 2,8$ \\
\hline & Média & $77,9 \pm 22,3$ & $106,0 \pm 28,6$ & $29,3 \pm 7,5$ & $40,0 \pm 9,6$ & $-14,0 \pm 4,2$ & $19,4 \pm 5,3$ \\
\hline \multirow{16}{*}{ 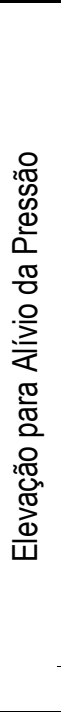 } & 1 & $349,8 \pm 2,9$ & $1975 \pm 223$ & $44,8 \pm 3,3$ & $147,9 \pm 46,7$ & $-45,1 \pm 3,4$ & $225,9 \pm 44,3$ \\
\hline & 2 & $255,1 \pm 6,9$ & $1772 \pm 35$ & $23,4 \pm 4,2$ & $60,6 \pm 13,9$ & $-35,2 \pm 1,9$ & $161,4 \pm 9,3$ \\
\hline & 3 & $385,9 \pm 6,8$ & $2593 \pm 231$ & $44,2 \pm 2,4$ & $248,5 \pm 20,6$ & $-48,6 \pm 0,3$ & $280,5 \pm 45,7$ \\
\hline & 4 & $311,2 \pm 9,2$ & $1603 \pm 134$ & $44,8 \pm 3,9$ & $179,0 \pm 20,4$ & $-44,8 \pm 1,8$ & $221,9 \pm 14,3$ \\
\hline & 5 & $310,2 \pm 4,2$ & $1916 \pm 90$ & $17,7 \pm 4,7$ & $67,2 \pm 17,1$ & $-38,0 \pm 0,4$ & $218,5 \pm 6,4$ \\
\hline & 6 & $287,0 \pm 4,0$ & $1480 \pm 152$ & $22,1 \pm 1,8$ & $49,6 \pm 25,5$ & $-45,0 \pm 2,8$ & $147,8 \pm 15,1$ \\
\hline & 7 & $286,4 \pm 6,8$ & $1668 \pm 311$ & $21,4 \pm 1,8$ & $99,2 \pm 23,9$ & $-34,6 \pm 0,9$ & $166,7 \pm 27,4$ \\
\hline & 8 & $301,4 \pm 3,5$ & $1874 \pm 72$ & $22,2 \pm 3,5$ & $59,6 \pm 30,1$ & $-40,8 \pm 2,0$ & $240,6 \pm 11,3$ \\
\hline & 9 & $282,6 \pm 4,9$ & $2102 \pm 22$ & $64,9 \pm 8,8$ & $304,5 \pm 26,8$ & $-31,5 \pm 0,5$ & $225,9 \pm 8,6$ \\
\hline & 10 & $262,3 \pm 3,2$ & $1760 \pm 254$ & $18,2 \pm 7,0$ & $89,0 \pm 43,7$ & $-38,2 \pm 3,6$ & $205,1 \pm 31,6$ \\
\hline & 11 & $419,8 \pm 7,9$ & $2628 \pm 119$ & $60,7 \pm 11,2$ & $247,4 \pm 20,3$ & $-66,6 \pm 3,5$ & $378,5 \pm 11,9$ \\
\hline & 12 & $336,1 \pm 4,2$ & $2157 \pm 89$ & $57,5 \pm 2,5$ & $307,3 \pm 36,5$ & $-49,3 \pm 2,0$ & $239,8 \pm 12,3$ \\
\hline & 13 & $257,6 \pm 4,0$ & $1509 \pm 81$ & $23,8 \pm 1,7$ & $107,8 \pm 7,5$ & $-35,1 \pm 1,5$ & $159,7 \pm 6,8$ \\
\hline & 14 & $283,3 \pm 2,0$ & $1670 \pm 124$ & $29,6 \pm 5,7$ & $125,8 \pm 24,7$ & $-27,7 \pm 1,7$ & $130,0 \pm 11,0$ \\
\hline & 15 & $253,1 \pm 11,4$ & $1720 \pm 105$ & $34,7 \pm 3,6$ & $201,7 \pm 8,7$ & $-31,6 \pm 2,8$ & $170,0 \pm 7,6$ \\
\hline & Média & $305,5 \pm 47,9$ & $1895 \pm 364$ & $35,3 \pm 16,4$ & $153,0 \pm 90,0$ & $-40,8 \pm 9,6$ & $211,5 \pm 63,0$ \\
\hline \multirow{8}{*}{ 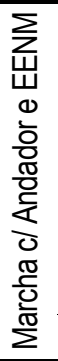 } & 1 & $460,9 \pm 19,8$ & $2012 \pm 51$ & $66,4 \pm 4,0$ & $211,3 \pm 21,5$ & $-67,7 \pm 8,7$ & $276,1 \pm 15,5$ \\
\hline & 2 & $290,7 \pm 19,5$ & $945 \pm 259$ & $22,6 \pm 4,0$ & $46,8 \pm 13,7$ & $-32,9 \pm 3,1$ & $103,5 \pm 37,9$ \\
\hline & 5 & $338,2 \pm 20,0$ & $1590 \pm 229$ & $45,2 \pm 7,1$ & $157,7 \pm 44,1$ & $-51,1 \pm 3,0$ & $224,4 \pm 37,4$ \\
\hline & 7 & $286,3 \pm 21,2$ & $806 \pm 125$ & $35,8 \pm 5,8$ & $76,0 \pm 13,1$ & $-47,7 \pm 8,7$ & $111,5 \pm 10,4$ \\
\hline & 11 & $464,7 \pm 24,4$ & $1209 \pm 221$ & $52,2 \pm 13,3$ & $91,7 \pm 16,6$ & $-71,4 \pm 2,5$ & $163,4 \pm 27,5$ \\
\hline & 13 & $244,3 \pm 12,8$ & $360 \pm 57$ & $11,0 \pm 2,0$ & $13,3 \pm 3,4$ & $-38,5 \pm 1,1$ & $53,3 \pm 9,9$ \\
\hline & 14 & $292,0 \pm 25,6$ & $515 \pm 67$ & $27,1 \pm 2,1$ & $35,7 \pm 5,0$ & $-41,3 \pm 4,0$ & $58,5 \pm 8,0$ \\
\hline & Média & $339,2 \pm 85,0$ & $1064 \pm 569$ & $37,0 \pm 18,6$ & $90,5 \pm 68,9$ & $-50,4 \pm 14,4$ & $141,5 \pm 81,6$ \\
\hline
\end{tabular}


Tab. 9 - Médias e Desvios Padrões dos Picos e Integrais da Força, do Torque no Plano Sagital (XZ) e do 20 Torque no Lado Esquerdo.

\begin{tabular}{|c|c|c|c|c|c|c|c|}
\hline \multirow{2}{*}{ 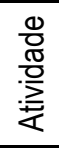 } & \multirow{2}{*}{ 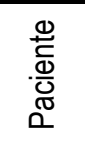 } & \multicolumn{2}{|c|}{ FORÇA } & \multicolumn{2}{|c|}{ TORQUE XZ } & \multicolumn{2}{|c|}{ TORQUE 2} \\
\hline & & $\begin{array}{l}\text { Pico } \\
{[N]}\end{array}$ & $\begin{array}{c}\text { Integral } \\
{[\mathrm{N} \cdot \mathrm{s}]}\end{array}$ & $\begin{array}{l}\text { Pico } \\
{[\mathrm{N} \cdot \mathrm{m}]}\end{array}$ & $\begin{array}{l}\text { Integral } \\
{[\mathrm{N} \cdot \mathrm{m} \cdot \mathrm{s}]}\end{array}$ & $\begin{array}{l}\text { Pico } \\
{[\mathrm{N} \cdot \mathrm{m}]}\end{array}$ & $\begin{array}{l}\text { Integral } \\
{[\mathrm{N} \cdot \mathrm{m} \cdot \mathrm{s}]}\end{array}$ \\
\hline \multirow{15}{*}{ 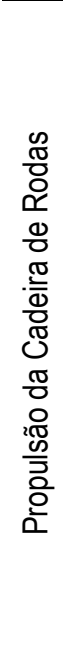 } & 1 & $48,2 \pm 14,5$ & $73,5 \pm 21,7$ & $22,0 \pm 6,4$ & $33,3 \pm 9,7$ & $8,4 \pm 2,6$ & $13,7 \pm 3,5$ \\
\hline & 2 & $73,2 \pm 6,5$ & $77,5 \pm 2,1$ & $29,4 \pm 3,3$ & $30,7 \pm 1,4$ & $12,9 \pm 1,7$ & $14,5 \pm 1,5$ \\
\hline & 3 & $82,8 \pm 9,4$ & $110,3 \pm 19,7$ & $34,2 \pm 3,4$ & $46,6 \pm 8,3$ & $15,7 \pm 2,7$ & $20,1 \pm 4,4$ \\
\hline & 4 & $58,5 \pm 10,9$ & $82,2 \pm 20,3$ & $22,7 \pm 4,5$ & $31,4 \pm 7,8$ & $10,5 \pm 2,0$ & $15,4 \pm 3,8$ \\
\hline & 5 & $93,9 \pm 9,0$ & $104,7 \pm 6,5$ & $36,0 \pm 3,5$ & $40,3 \pm 2,8$ & $18,1 \pm 1,8$ & $21,5 \pm 1,2$ \\
\hline & 6 & $92,9 \pm 21,8$ & $134,4 \pm 16,5$ & $33,9 \pm 8,0$ & $49,7 \pm 5,8$ & $14,4 \pm 3,2$ & $22,3 \pm 3,4$ \\
\hline & 8 & $97,3 \pm 26,1$ & $138,5 \pm 9,4$ & $39,3 \pm 11,4$ & $54,4 \pm 4,4$ & $17,7 \pm 3,9$ & $25,4 \pm 1,5$ \\
\hline & 9 & $56,4 \pm 8,5$ & $94,0 \pm 11,6$ & $22,4 \pm 3,2$ & $37,2 \pm 4,7$ & $10,6 \pm 1,5$ & $17,8 \pm 2,1$ \\
\hline & 10 & $112,5 \pm 60,9$ & $148,2 \pm 23,9$ & $42,5 \pm 26,7$ & $52,8 \pm 7,3$ & $19,8 \pm 12,9$ & $24,2 \pm 4,2$ \\
\hline & 11 & $138,4 \pm 34,5$ & $177,2 \pm 37,2$ & $52,1 \pm 12,1$ & $67,1 \pm 13,7$ & $24,1 \pm 4,9$ & $32,2 \pm 6,6$ \\
\hline & 12 & $77,9 \pm 14,3$ & $116,3 \pm 16,3$ & $30,7 \pm 5,6$ & $46,8 \pm 6,4$ & $11,4 \pm 2,4$ & $17,8 \pm 2,5$ \\
\hline & 13 & $88,1 \pm 12,7$ & $125,2 \pm 11,2$ & $36,1 \pm 6,1$ & $52,8 \pm 4,7$ & $14,8 \pm 3,0$ & $20,7 \pm 1,8$ \\
\hline & 14 & $64,7 \pm 21,2$ & $111,2 \pm 8,9$ & $23,5 \pm 7,7$ & $41,4 \pm 3,4$ & $8,2 \pm 2,6$ & $15,2 \pm 1,3$ \\
\hline & 15 & $76,0 \pm 8,9$ & $104,8 \pm 18,9$ & $27,6 \pm 3,6$ & $38,9 \pm 6,9$ & $13,9 \pm 2,2$ & $19,4 \pm 3,5$ \\
\hline & Média & $83,1 \pm 30,4$ & $114,1 \pm 32,1$ & $32,4 \pm 11,8$ & $44,5 \pm 11,6$ & $14,4 \pm 5,8$ & $20,0 \pm 5,6$ \\
\hline \multirow{16}{*}{ 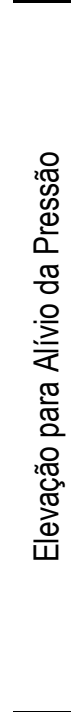 } & 1 & $364,4 \pm 1,3$ & $2045 \pm 326$ & $41,7 \pm 2,6$ & $137,3 \pm 60,1$ & $39,4 \pm 0,2$ & $204,2 \pm 17,7$ \\
\hline & 2 & $248,1 \pm 1,5$ & $1712 \pm 18$ & $24,7 \pm 3,4$ & $44,5 \pm 8,5$ & $32,4 \pm 2,1$ & $177,3 \pm 5,1$ \\
\hline & 3 & $421,2 \pm 6,0$ & $2852 \pm 323$ & $45,4 \pm 4,1$ & $257,6 \pm 44,1$ & $42,1 \pm 2,2$ & $241,0 \pm 32,2$ \\
\hline & 4 & $298,8 \pm 8,9$ & $1558 \pm 107$ & $45,4 \pm 2,9$ & $177,2 \pm 31,3$ & $48,4 \pm 1,8$ & $236,9 \pm 13,4$ \\
\hline & 5 & $288,1 \pm 2,1$ & $1791 \pm 69$ & $7,7 \pm 1,1$ & $23,8 \pm 11,2$ & $42,7 \pm 1,4$ & $210,3 \pm 9,0$ \\
\hline & 6 & $317,8 \pm 11,4$ & $1519 \pm 166$ & $33,4 \pm 6,0$ & $138,0 \pm 6,9$ & $34,5 \pm 0,9$ & $152,1 \pm 20,5$ \\
\hline & 7 & $273,5 \pm 13,1$ & $1635 \pm 249$ & $14,2 \pm 2,0$ & $29,2 \pm 11,0$ & $36,1 \pm 1,0$ & $132,3 \pm 27,8$ \\
\hline & 8 & $270,4 \pm 6,5$ & $1756 \pm 104$ & $12,5 \pm 4,4$ & $38,5 \pm 11,8$ & $46,1 \pm 0,8$ & $254,1 \pm 8,4$ \\
\hline & 9 & $270,9 \pm 3,7$ & $2056 \pm 26$ & $54,5 \pm 10,0$ & $225,4 \pm 41,9$ & $40,0 \pm 2,6$ & $258,2 \pm 12,9$ \\
\hline & 10 & $259,7 \pm 1,8$ & $1722 \pm 225$ & $9,0 \pm 3,5$ & $28,2 \pm 18,0$ & $41,1 \pm 2,0$ & $201,3 \pm 26,5$ \\
\hline & 11 & $458,2 \pm 13,2$ & $2884 \pm 246$ & $59,1 \pm 14,5$ & $236,5 \pm 47,0$ & $59,6 \pm 1,0$ & $318,0 \pm 20,8$ \\
\hline & 12 & $347,2 \pm 2,2$ & $2230 \pm 63$ & $42,8 \pm 3,7$ & $217,8 \pm 33,3$ & $39,2 \pm 1,6$ & $197,0 \pm 18,0$ \\
\hline & 13 & $270,4 \pm 4,2$ & $1605 \pm 59$ & $35,5 \pm 2,0$ & $138,4 \pm 17,8$ & $31,4 \pm 1,8$ & $119,9 \pm 10,8$ \\
\hline & 14 & $300,3 \pm 3,2$ & $1805 \pm 130$ & $18,9 \pm 2,5$ & $41,6 \pm 18,1$ & $26,1 \pm 0,8$ & $105,4 \pm 10,8$ \\
\hline & 15 & $230,8 \pm 1,1$ & $1603 \pm 53$ & $32,6 \pm 4,2$ & $192,5 \pm 7,2$ & $36,3 \pm 2,5$ & $204,4 \pm 6,7$ \\
\hline & Média & $308,0 \pm 62,9$ & $1918 \pm 445$ & $31,8 \pm 16,9$ & $128,4 \pm 87,7$ & $39,7 \pm 7,9$ & $200,8 \pm 57,9$ \\
\hline \multirow{8}{*}{ 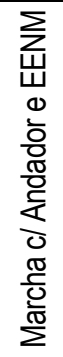 } & 1 & $541,0 \pm 13,7$ & $1709 \pm 233$ & $96,7 \pm 6,7$ & $186,8 \pm 48,0$ & $48,8 \pm 1,3$ & $180,2 \pm 15,2$ \\
\hline & 2 & $267,5 \pm 52,1$ & $636 \pm 88$ & $16,4 \pm 3,3$ & $29,1 \pm 7,9$ & $34,9 \pm 2,9$ & $87,0 \pm 14,6$ \\
\hline & 5 & $229,8 \pm 32,4$ & $688 \pm 135$ & $30,8 \pm 7,6$ & $80,2 \pm 32,4$ & $30,2 \pm 3,8$ & $94,2 \pm 14,3$ \\
\hline & 7 & $239,5 \pm 54,3$ & $513 \pm 120$ & $28,1 \pm 8,4$ & $48,5 \pm 14,6$ & $36,7 \pm 8,1$ & $68,4 \pm 10,5$ \\
\hline & 11 & $394,0 \pm 33,6$ & $829 \pm 70$ & $28,9 \pm 5,0$ & $44,1 \pm 3,6$ & $52,9 \pm 4,7$ & $110,8 \pm 11,2$ \\
\hline & 13 & $208,0 \pm 66,8$ & $381 \pm 42$ & $16,6 \pm 6,8$ & $23,0 \pm 3,2$ & $13,6 \pm 6,5$ & $31,3 \pm 4,8$ \\
\hline & 14 & $227,7 \pm 39,0$ & $664 \pm 109$ & $50,7 \pm 5,1$ & $68,7 \pm 10,1$ & $28,9 \pm 10,3$ & $73,1 \pm 13,6$ \\
\hline & Média & $297,1 \pm 123,2$ & $769 \pm 423$ & $37,8 \pm 27,2$ & $67,7 \pm 55,6$ & $35,2 \pm 13,6$ & $91,9 \pm 44,6$ \\
\hline
\end{tabular}




\subsection{Atividade Muscular}

O parâmetro referente à atividade muscular utilizado foi o valor médio do RMS do sinal mioelétrico, dentro do intervalo de exercício, normalizado pela MCV. Estas médias do RMS foram calculadas para cada repetição realizada por cada paciente e tratadas estatisticamente a fim de encontrar diferenças significativas entre os músculos para cada exercício, e também as diferenças nas atividades musculares de um mesmo músculo para os três exercícios executados.

$\mathrm{Na}$ figura 48 são apresentados os valores médios das atividades musculares para os pacientes 1, 2, 3 e 4 . As médias para os 6 músculos analisados em ambos os lados são representadas por barras e seus respectivos erros padrões obtidos pela análise estatístico com nível de significância de 5\%. As diferentes letras maiúsculas representam diferenças significativas entre os músculos do mesmo lado para um mesmo exercício executado. As diferentes letras minúsculas entre parênteses representam diferenças significativas para um mesmo músculo entre os exercícios que foram executados.

Pode-se observar na figura 48 que o músculo tríceps foi o que apresentou maior atividade durante a marcha com andador e durante a elevação para alívio da pressão em ambos os lados para os pacientes 1, 2 e 3 . No entanto para o paciente 4 este mesmo músculo só teve maior atividade no lado esquerdo durante a elevação. O músculo tríceps apresentou maior atividade durante a marcha se comparado à elevação para o paciente 1 no lado esquerdo, no lado direito e para o paciente 2 não houve diferenças significativas na atividade do tríceps entre estes dois exercícios. Além do tríceps outros músculos apresentaram médias significativamente maiores como o trapézio inferior (paciente 1) e o peitoral maior (paciente 4), durante a 
elevação para alívio da pressão. Para o exercício de propulsão da cadeira de rodas, as atividades musculares foram geralmente menores comparando aos outros dois exercícios executados.

A figura 49 apresenta as médias das atividades musculares dos pacientes 5, 6, 7 e 8. Pode-se observar que novamente o tríceps apresentou maior atividade durante a marcha e a elevação, aparecendo também alta atividade no trapézio inferior direito para o paciente 8 e esquerdo para o paciente 5 durante a elevação. Para a propulsão da cadeira os músculos com maior atividade foram os deltóides (anterior e posterior), porém os músculos em geral neste exercício apresentaram novamente atividade menor se comparado às outras duas atividades.

As atividades musculares dos pacientes 9, 10, 11 e 12 são apresentadas na figura 50. Nestes casos o tríceps também apresentou maior atividade muscular durante a marcha e a elevação, exceto para o lado esquerdo dos pacientes 9 e 12 durante a elevação onde os músculos com maior atividade foram o peitoral maior, trapézio inferior e deltóide anterior. Geralmente as atividades musculares durante a propulsão da cadeira foram menores comparadas aos outros dois exercícios, porém para o paciente 10 as atividades musculares foram maiores durante a propulsão da cadeira comparado com a elevação para alívio da pressão, se desconsiderada a alta atividade do tríceps durante a elevação.

Na figura 51 são apresentadas as médias das atividades musculares do pacientes 13, 14 e 15. Nestes casos o músculo tríceps sempre apresentou maior atividade durante a marcha e a elevação para alívio da pressão. Para o paciente 13 os músculos peitoral maior e deltóide anterior do lado esquerdo também apresentaram altos valores. O paciente 15 também apresentou alta atividade no peitoral maior e trapézio inferior do lado esquerdo durante a elevação. 


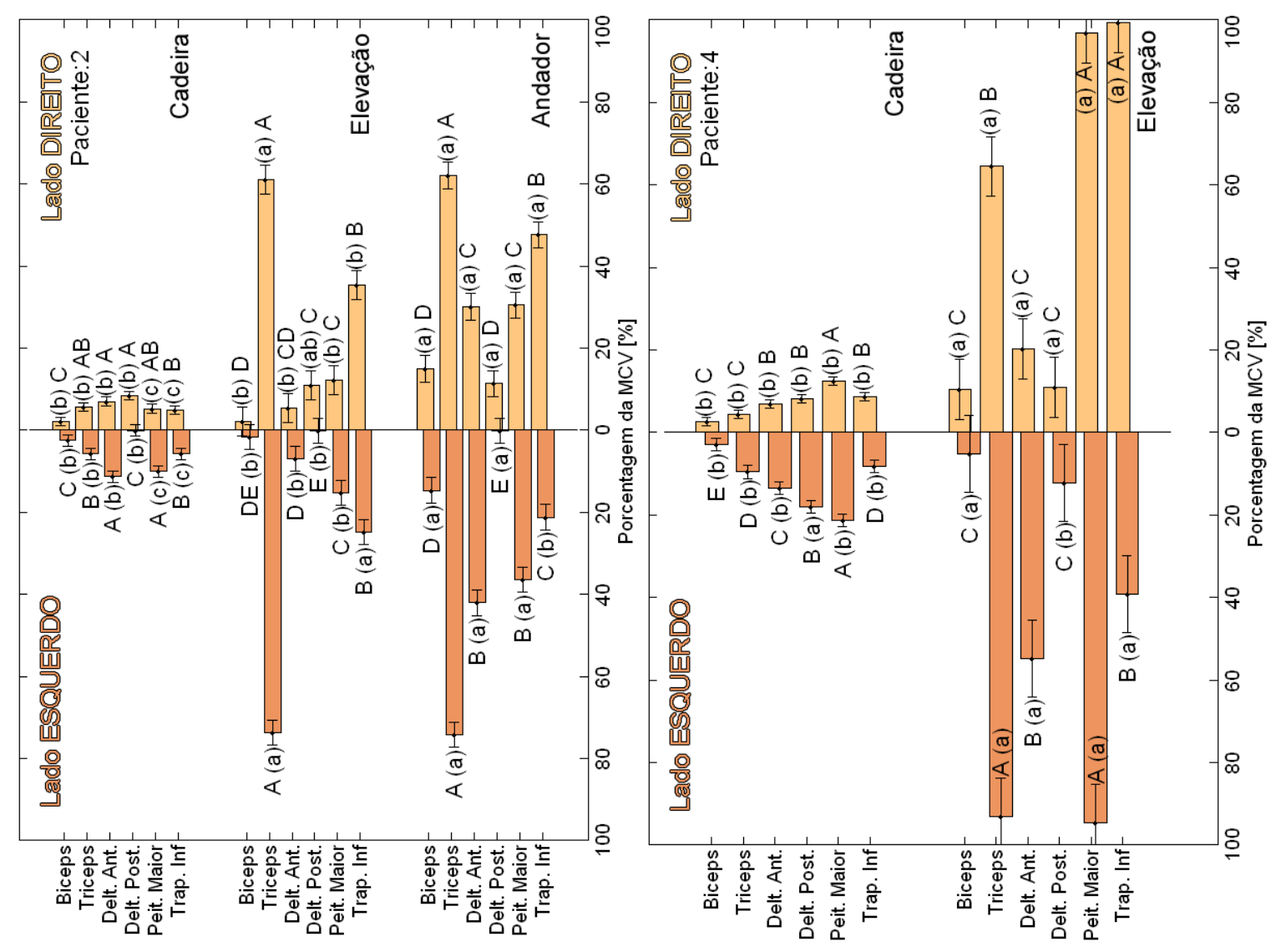

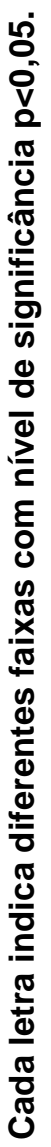

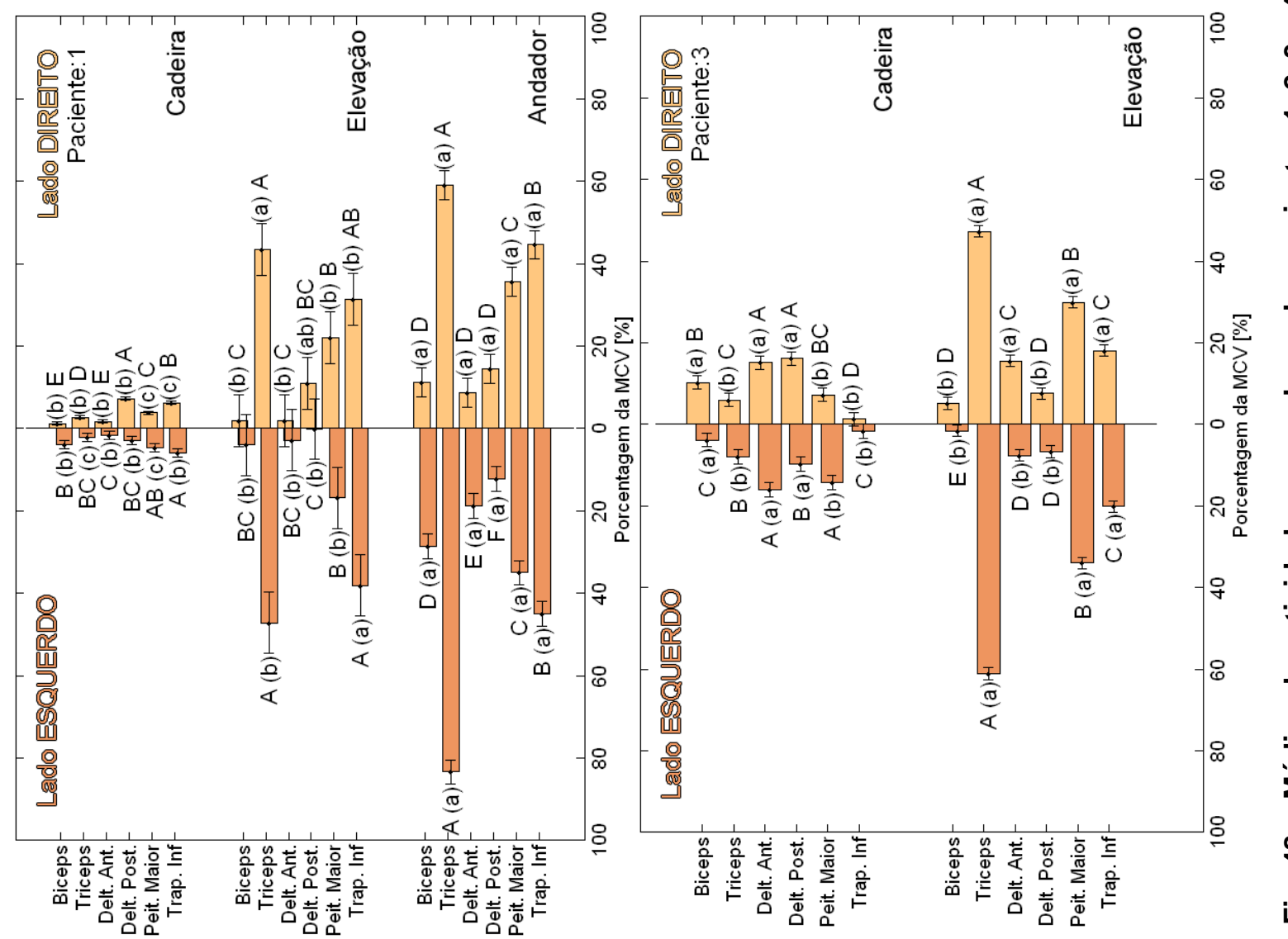




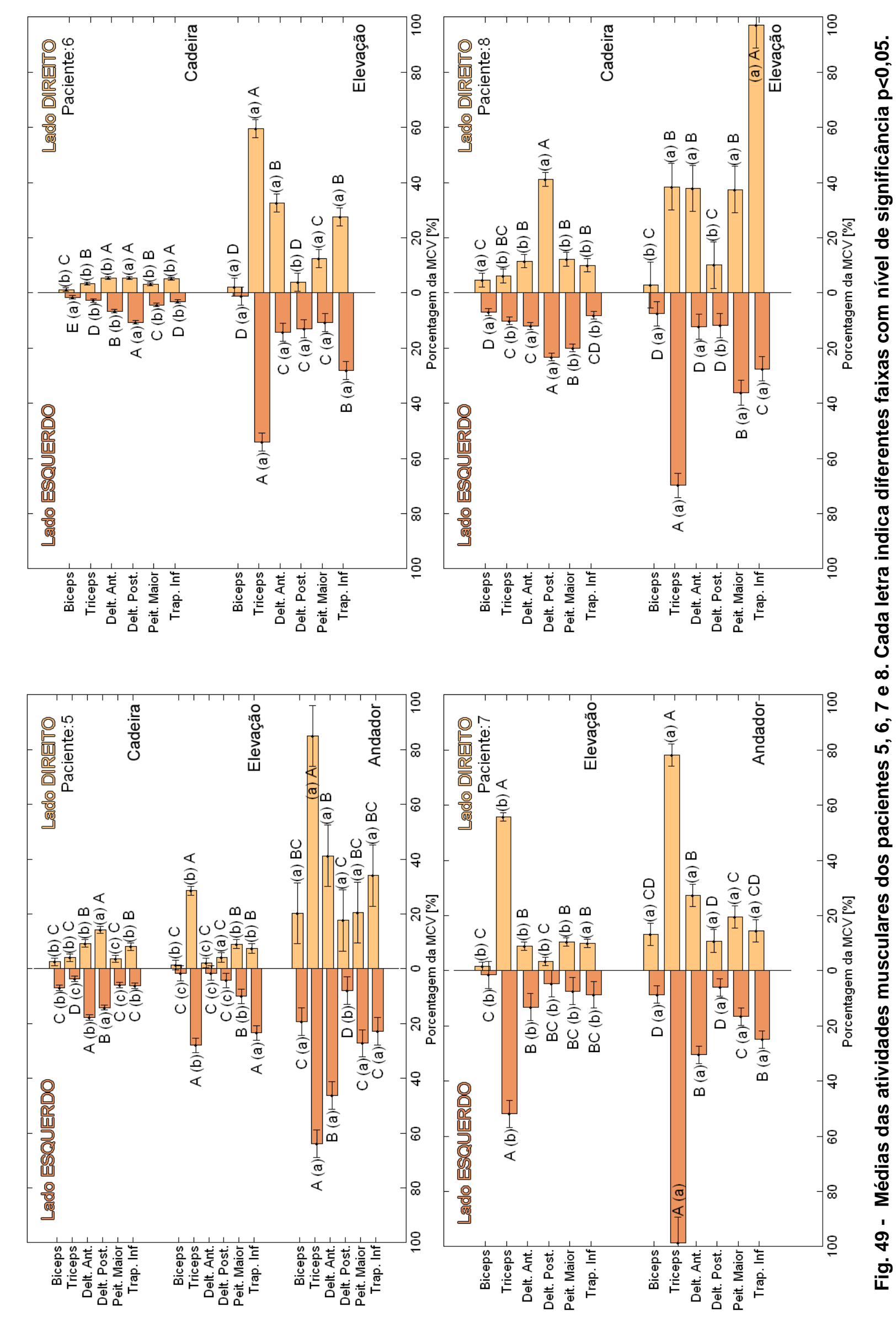




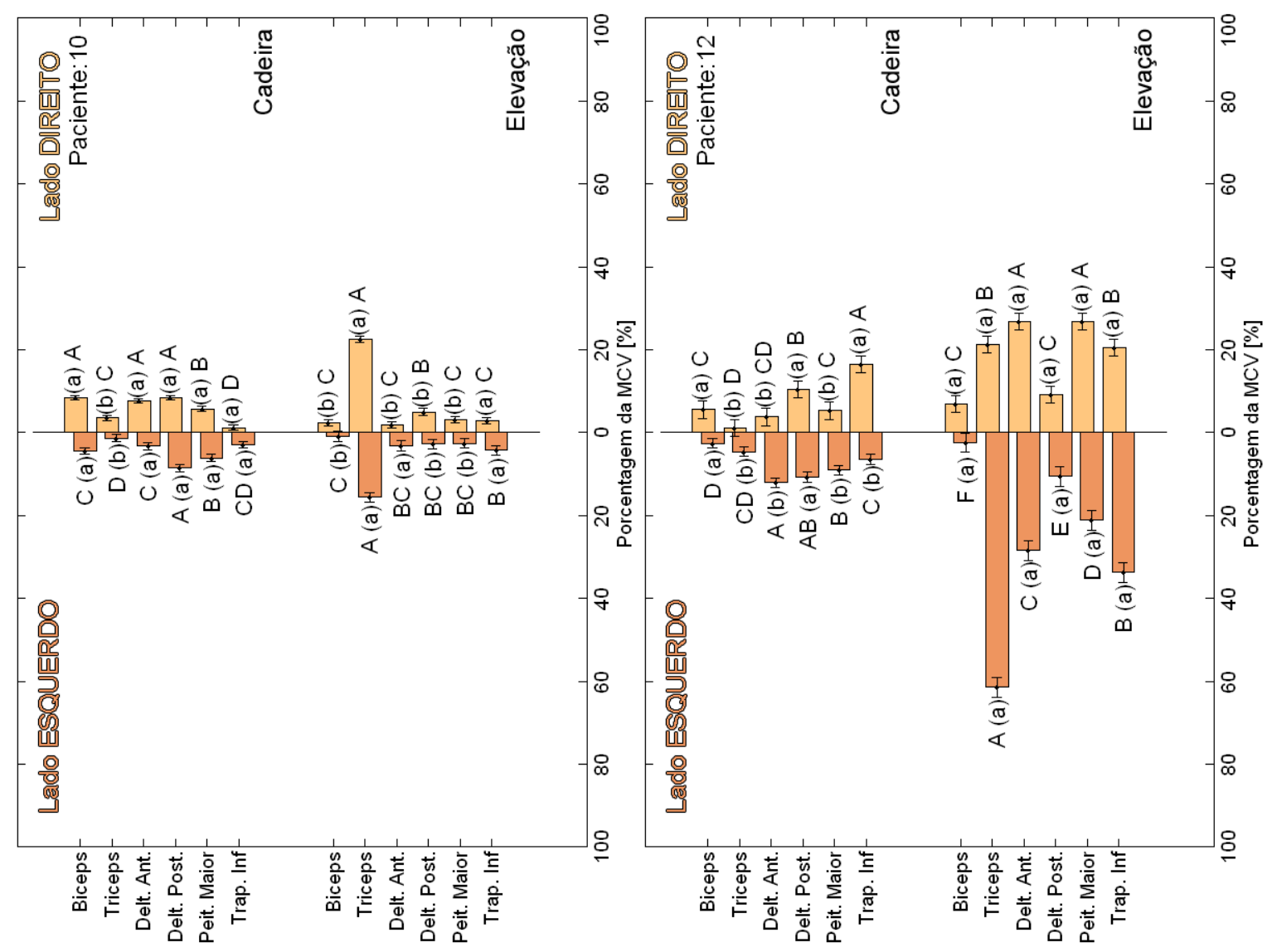

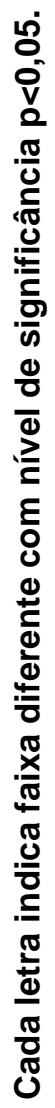
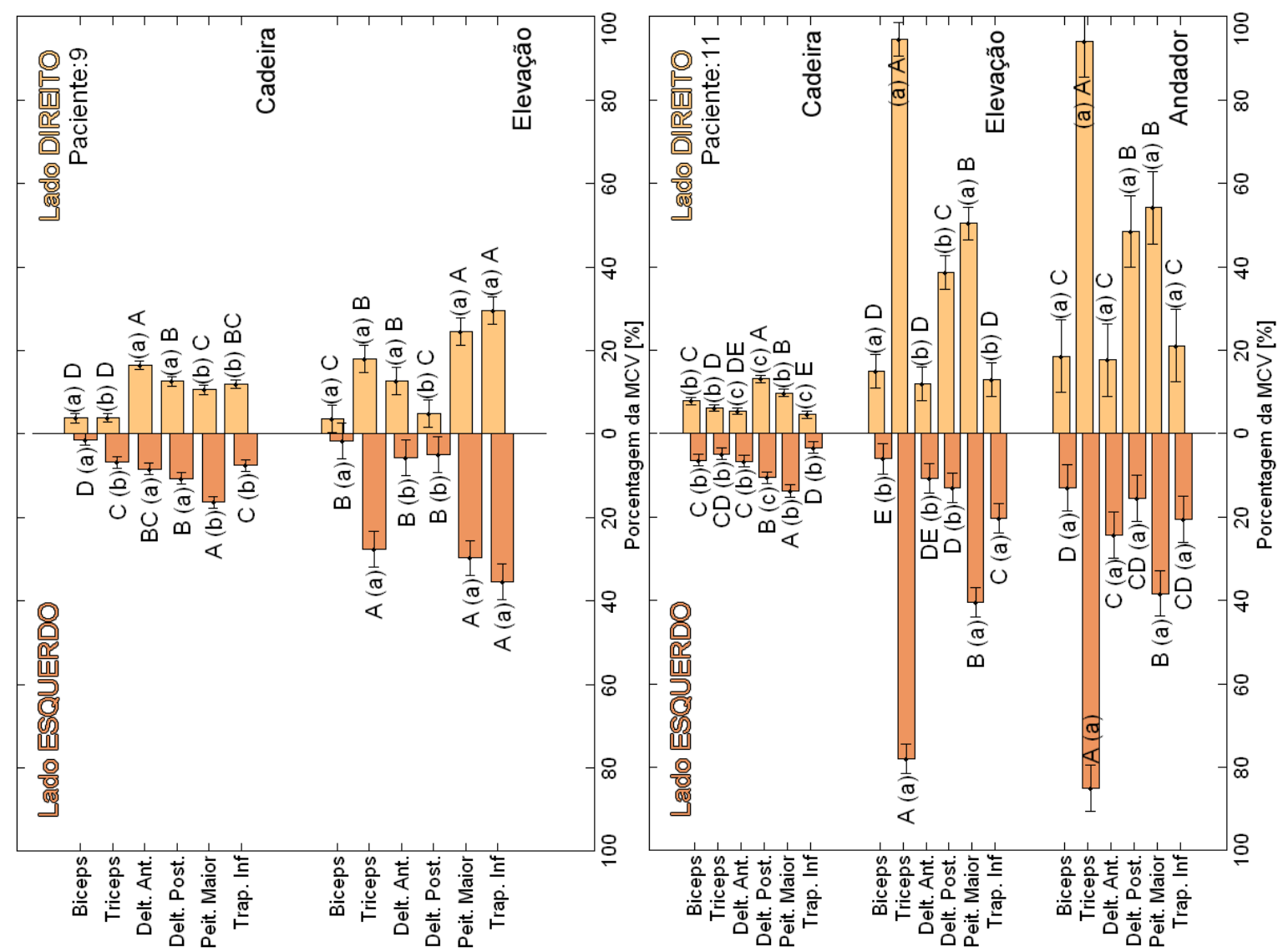

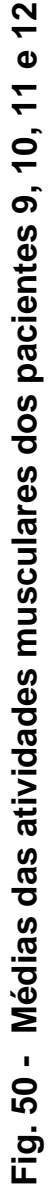



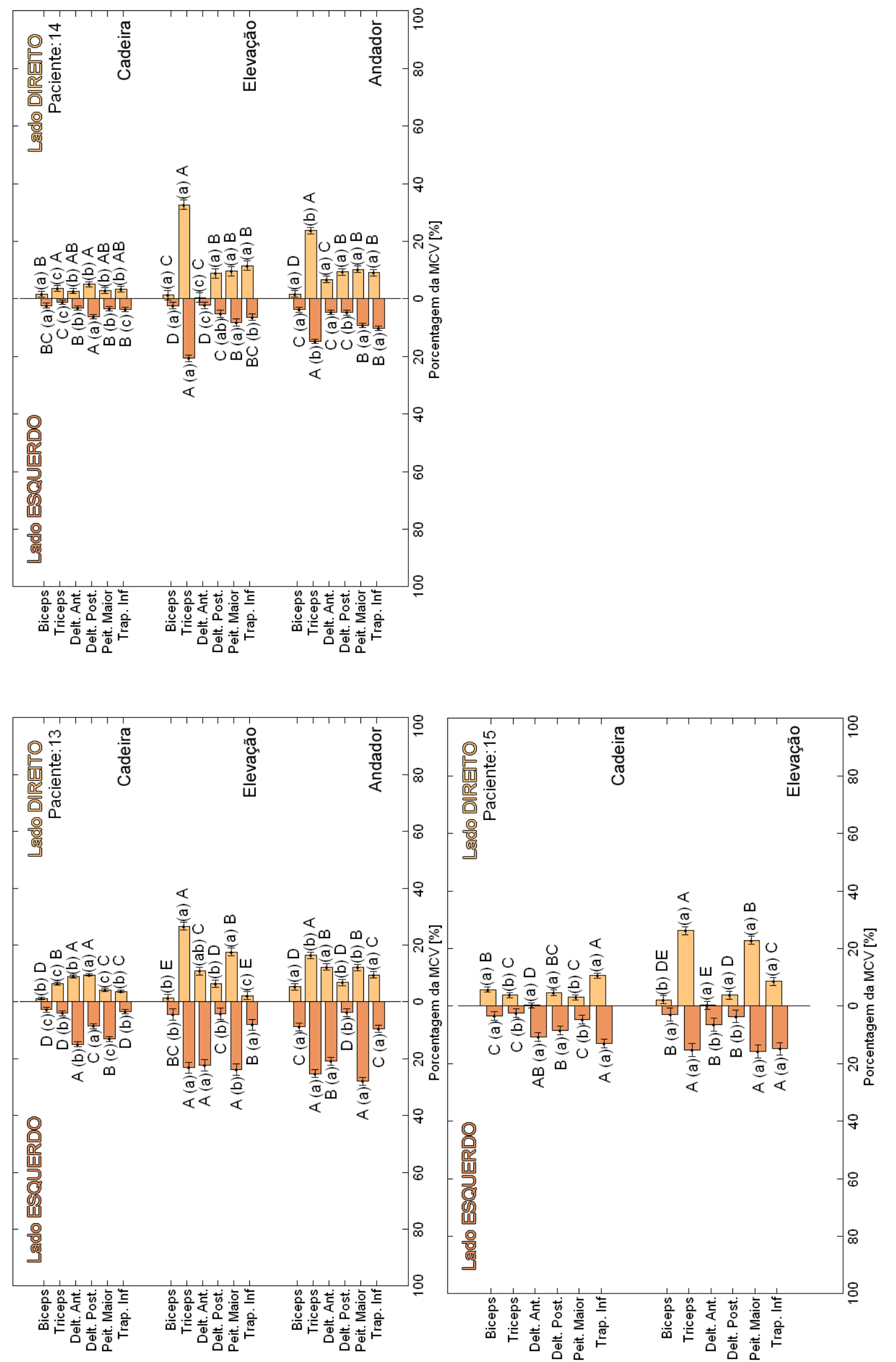
A figura 52 apresenta as médias das atividades musculares de todos pacientes em ambos os lados durante os três exercícios executados. Pode-se observar que na média o músculo tríceps foi o que apresentou maior atividade durante a marcha e durante a elevação, seguido dos músculos peitoral maior e trapézio inferior para ambos os lados. Para a marcha com andador o músculo deltóide anterior também apresentou alta atividade muscular, estatisticamente igual aos músculos peitoral maior e trapézio. O tríceps e o deltóide anterior apresentaram maior atividade durante a marcha se comparado com suas atividades durante os outros dois exercícios, já o peitoral maior e o trapézio inferior apresentaram valores estatisticamente iguais entre a marcha e a elevação. Para a propulsão da cadeira de rodas o músculo com maior atividade foi o deltóide posterior em ambos os lados, e para o lado esquerdo o deltóide anterior e o peitoral maior também apresentaram maior atividade. Durante a propulsão da cadeira a maioria dos músculos apresentou baixa atividade muscular se comparado aos outros dois exercícios, exceto o deltóide posterior esquerdo que teve maior resposta comparando com a marcha e a elevação para alívio da pressão. 


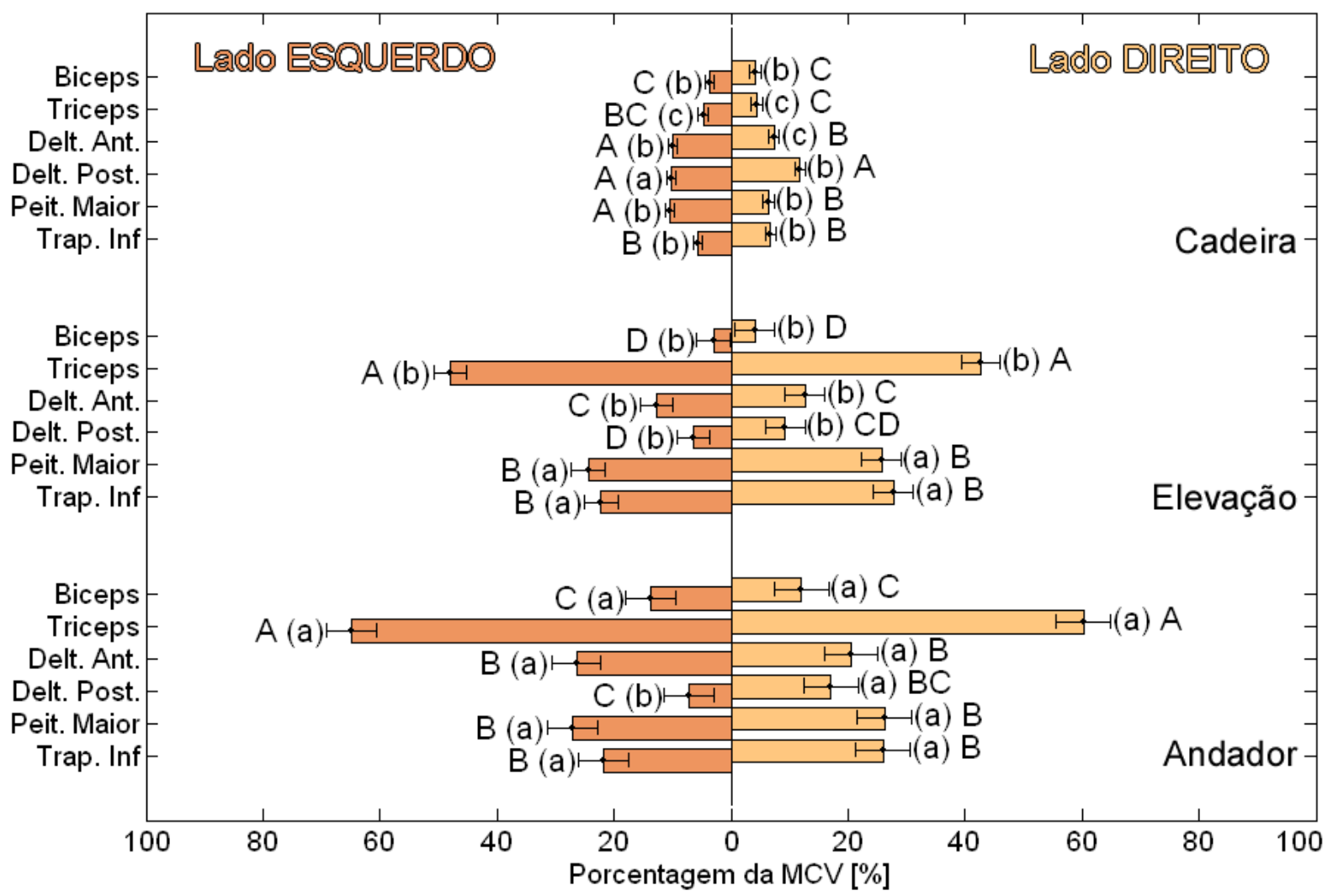

Fig. 52 - Médias das atividades musculares entre todos paciente analisados para os 3 exercícios executados. As atividades musculares são apresentadas como uma porcentagem da MCV. As médias de cada músculo são representadas pelas barras e seus respectivos erros padrões. Cada letra indica diferentes faixas com nível de significância $\mathrm{p}<0,05$. As letras maiúsculas representam diferentes atividades musculares entre os músculos do mesmo lado para um mesmo exercício. As letras minúsculas, entre parênteses, representam diferentes atividades musculares de um mesmo músculo entre os 3 exercícios executados.

Na tabela 10 são apresentadas as médias e desvios padrões das atividades musculares dos 6 músculos do ombro direito, que foram analisados durante os exercícios executadas por cada paciente. Na tabela 11 são apresentadas as médias e desvios padrões das atividades musculares de cada paciente para o lado esquerdo. 
Tab. 10 - Médias e Desvios Padrões das atividades musculares médias no lado Direito durante os exercícios realizados.

\begin{tabular}{|c|c|c|c|c|c|c|c|}
\hline \multirow{2}{*}{ 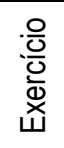 } & \multirow{2}{*}{ 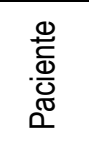 } & \multicolumn{6}{|c|}{ Músculo } \\
\hline & & $\begin{array}{c}\text { Bíceps } \\
\text { [\% da MCV] }\end{array}$ & $\begin{array}{c}\text { Tríceps } \\
\text { [\% da MCV] }\end{array}$ & $\begin{array}{l}\text { Delt. Anterior } \\
\text { [\% da MCV] }\end{array}$ & $\begin{array}{l}\text { Delt. Posterior } \\
\text { [\% da MCV] }\end{array}$ & $\begin{array}{c}\text { Peitoral Maior } \\
{[\% \text { da MCV] }}\end{array}$ & $\begin{array}{l}\text { Trapézio Inf. } \\
\text { [\% da MCV] }\end{array}$ \\
\hline \multirow{15}{*}{ 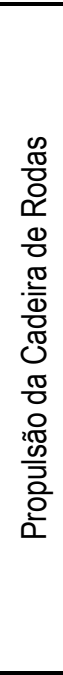 } & 1 & $1,2 \pm 0,1$ & $2,7 \pm 0,2$ & $1,8 \pm 0,3$ & $7,3 \pm 0,5$ & $3,8 \pm 0,7$ & $6,2 \pm 0,5$ \\
\hline & 2 & $2,2 \pm 0,9$ & $5,6 \pm 1,3$ & $7,0 \pm 2,4$ & $8,4 \pm 0,8$ & $5,3 \pm 1,0$ & $4,9 \pm 1,2$ \\
\hline & 3 & $10,2 \pm 4,2$ & $6,0 \pm 0,7$ & $15,2 \pm 3,2$ & $16,2 \pm 1,8$ & $7,2 \pm 1,2$ & $1,3 \pm 1,0$ \\
\hline & 4 & $2,6 \pm 1,3$ & $4,3 \pm 1,0$ & $6,9 \pm 1,9$ & $8,3 \pm 1,0$ & $12,5 \pm 2,1$ & $8,8 \pm 2,4$ \\
\hline & 5 & $2,6 \pm 1,1$ & $4,1 \pm 1,3$ & $9,3 \pm 2,5$ & $14,2 \pm 2,2$ & $3,7 \pm 0,6$ & $8,1 \pm 1,8$ \\
\hline & 6 & $1,3 \pm 0,2$ & $3,4 \pm 0,9$ & $5,5 \pm 0,4$ & $5,5 \pm 0,9$ & $3,1 \pm 0,7$ & $5,1 \pm 1,1$ \\
\hline & 8 & $4,7 \pm 1,2$ & $6,2 \pm 1,2$ & $11,5 \pm 1,4$ & $41,2 \pm 7,1$ & $12,2 \pm 0,8$ & $10,1 \pm 2,5$ \\
\hline & 9 & $3,8 \pm 0,7$ & $3,9 \pm 0,8$ & $16,5 \pm 2,0$ & $12,6 \pm 1,8$ & $10,6 \pm 2,1$ & $12,0 \pm 0,9$ \\
\hline & 10 & $8,4 \pm 1,1$ & $3,6 \pm 1,1$ & $7,6 \pm 0,6$ & $8,5 \pm 0,5$ & $5,8 \pm 0,7$ & $1,2 \pm 0,4$ \\
\hline & 11 & $7,8 \pm 1,9$ & $6,2 \pm 0,7$ & $5,4 \pm 1,2$ & $13,1 \pm 0,3$ & $9,8 \pm 1,1$ & $4,6 \pm 0,4$ \\
\hline & 12 & $5,6 \pm 5,4$ & $1,1 \pm 0,5$ & $3,8 \pm 1,9$ & $10,4 \pm 1,0$ & $5,3 \pm 1,4$ & $16,5 \pm 4,3$ \\
\hline & 13 & $1,2 \pm 0,3$ & $6,4 \pm 0,8$ & $8,9 \pm 1,0$ & $9,5 \pm 0,7$ & $4,2 \pm 0,4$ & $3,8 \pm 0,5$ \\
\hline & 14 & $1,7 \pm 0,1$ & $3,7 \pm 0,3$ & $2,8 \pm 1,5$ & $5,1 \pm 0,6$ & $2,8 \pm 0,6$ & $3,4 \pm 2,4$ \\
\hline & 15 & $5,8 \pm 1,8$ & $3,8 \pm 1,0$ & $1,3 \pm 0,6$ & $4,6 \pm 0,4$ & $3,1 \pm 0,6$ & $10,6 \pm 2,4$ \\
\hline & Média & $4,2 \pm 3,4$ & $4,4 \pm 1,7$ & $7,4 \pm 4,8$ & $11,8 \pm 9,1$ & $6,4 \pm 3,6$ & $6,8 \pm 4,5$ \\
\hline \multirow{16}{*}{ 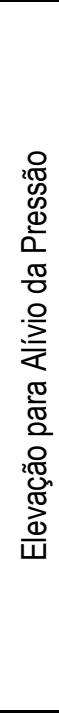 } & 1 & $1,9 \pm 0,2$ & $43,4 \pm 13,1$ & $1,9 \pm 0,6$ & $10,9 \pm 3,6$ & $22,1 \pm 1,5$ & $31,5 \pm 3,8$ \\
\hline & 2 & $2,2 \pm 1,7$ & $61,2 \pm 5,9$ & $5,3 \pm 1,6$ & $11,0 \pm 2,5$ & $12,3 \pm 1,5$ & $35,4 \pm 8,7$ \\
\hline & 3 & $5,2 \pm 0,5$ & $47,3 \pm 3,1$ & $15,6 \pm 2,7$ & $7,6 \pm 1,4$ & $29,9 \pm 2,4$ & $18,1 \pm 1,1$ \\
\hline & 4 & $10,5 \pm 5,1$ & $64,5 \pm 11,5$ & $20,3 \pm 1,3$ & $11,0 \pm 2,4$ & $96,7 \pm 12,2$ & $99,3 \pm 14,7$ \\
\hline & 5 & $1,4 \pm 0,2$ & $28,5 \pm 4,8$ & $2,2 \pm 0,7$ & $4,1 \pm 0,6$ & $9,1 \pm 0,9$ & $7,5 \pm 2,3$ \\
\hline & 6 & $2,2 \pm 0,7$ & $59,5 \pm 4,7$ & $32,6 \pm 7,9$ & $4,0 \pm 0,7$ & $12,5 \pm 2,5$ & $27,6 \pm 6,7$ \\
\hline & 7 & $1,7 \pm 0,4$ & $55,8 \pm 3,1$ & $9,0 \pm 1,0$ & $3,5 \pm 0,3$ & $10,4 \pm 3,5$ & $9,9 \pm 0,3$ \\
\hline & 8 & $2,9 \pm 0,6$ & $38,5 \pm 4,2$ & $37,8 \pm 15,7$ & $10,1 \pm 2,4$ & $37,5 \pm 4,7$ & $97,2 \pm 24,4$ \\
\hline & 9 & $3,6 \pm 0,5$ & $17,9 \pm 2,5$ & $12,8 \pm 3,1$ & $4,8 \pm 1,7$ & $24,6 \pm 6,8$ & $29,5 \pm 6,6$ \\
\hline & 10 & $2,4 \pm 0,9$ & $22,5 \pm 1,1$ & $1,9 \pm 0,4$ & $5,0 \pm 1,1$ & $3,1 \pm 0,7$ & $3,0 \pm 2,0$ \\
\hline & 11 & $15,0 \pm 5,0$ & $94,6 \pm 11,6$ & $11,9 \pm 1,4$ & $38,7 \pm 4,5$ & $50,4 \pm 4,1$ & $13,0 \pm 1,7$ \\
\hline & 12 & $6,8 \pm 1,4$ & $21,3 \pm 3,1$ & $26,8 \pm 5,3$ & $9,2 \pm 1,1$ & $26,8 \pm 1,8$ & $20,5 \pm 3,0$ \\
\hline & 13 & $1,4 \pm 0,4$ & $26,6 \pm 2,7$ & $10,9 \pm 3,2$ & $6,4 \pm 1,4$ & $17,6 \pm 1,7$ & $2,2 \pm 0,7$ \\
\hline & 14 & $1,3 \pm 0,2$ & $32,7 \pm 3,9$ & $1,0 \pm 0,2$ & $8,9 \pm 2,1$ & $9,6 \pm 1,4$ & $11,6 \pm 3,3$ \\
\hline & 15 & $2,1 \pm 0,5$ & $26,3 \pm 3,1$ & $1,3 \pm 0,1$ & $3,8 \pm 1,4$ & $22,8 \pm 1,0$ & $8,7 \pm 1,4$ \\
\hline & Média & $4,0 \pm 4,2$ & $42,7 \pm 21,2$ & $12,7 \pm 12,5$ & $9,3 \pm 8,6$ & $25,7 \pm 22,8$ & $27,7 \pm 30,6$ \\
\hline \multirow{8}{*}{ 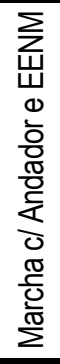 } & 1 & $11,2 \pm 1,9$ & $59,0 \pm 6,4$ & $8,8 \pm 1,1$ & $14,5 \pm 1,0$ & $35,7 \pm 5,1$ & $44,6 \pm 4,5$ \\
\hline & 2 & $15,0 \pm 1,7$ & $62,1 \pm 3,3$ & $30,2 \pm 4,3$ & $11,4 \pm 1,1$ & $30,5 \pm 4,3$ & $47,7 \pm 7,2$ \\
\hline & 5 & $20,3 \pm 14,0$ & $85,1 \pm 33,2$ & $41,3 \pm 4,2$ & $17,6 \pm 14,9$ & $20,5 \pm 2,5$ & $34,0 \pm 4,6$ \\
\hline & 7 & $13,2 \pm 3,0$ & $78,3 \pm 13,0$ & $27,4 \pm 4,3$ & $10,8 \pm 5,0$ & $19,5 \pm 3,0$ & $14,5 \pm 8,2$ \\
\hline & 11 & $18,6 \pm 4,2$ & $94,2 \pm 24,5$ & $17,7 \pm 0,6$ & $48,5 \pm 10,4$ & $54,2 \pm 5,5$ & $21,1 \pm 0,7$ \\
\hline & 13 & $5,4 \pm 0,7$ & $16,4 \pm 2,6$ & $12,3 \pm 1,1$ & $6,8 \pm 1,7$ & $12,1 \pm 2,4$ & $9,5 \pm 0,7$ \\
\hline & 14 & $1,6 \pm 0,5$ & $23,7 \pm 2,9$ & $6,8 \pm 0,7$ & $9,4 \pm 1,3$ & $10,2 \pm 1,3$ & $9,1 \pm 2,1$ \\
\hline & Média & $12,0 \pm 8,1$ & $60,3 \pm 31,9$ & $20,5 \pm 12,1$ & $17,1 \pm 14,8$ & $26,2 \pm 14,7$ & $26,0 \pm 15,8$ \\
\hline
\end{tabular}


Tab. 11 - Médias e Desvios Padrões das atividades musculares médias no lado Esquerdo durante os exercícios realizados.

\begin{tabular}{|c|c|c|c|c|c|c|c|}
\hline \multirow{2}{*}{ 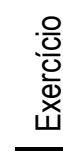 } & \multirow{2}{*}{ 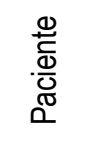 } & \multicolumn{6}{|c|}{ Músculo } \\
\hline & & $\begin{array}{c}\text { Bíceps } \\
\text { [\% da MCV] }\end{array}$ & $\begin{array}{c}\text { Tríceps } \\
\text { [\% da MCV] }\end{array}$ & $\begin{array}{l}\text { Delt. Anterior } \\
\text { [\% da MCV] }\end{array}$ & $\begin{array}{l}\text { Delt. Posterior } \\
{[\% \text { da MCV] }}\end{array}$ & $\begin{array}{c}\text { Peitoral Maior } \\
{[\% \text { da MCV] }}\end{array}$ & $\begin{array}{l}\text { Trapézio Inf. } \\
\text { [\% da MCV] }\end{array}$ \\
\hline \multirow{15}{*}{ 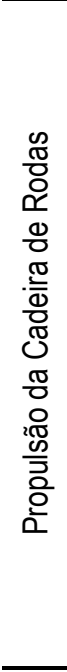 } & 1 & $3,8 \pm 0,6$ & $2,2 \pm 0,4$ & $1,7 \pm 0,6$ & $3,0 \pm 2,5$ & $4,6 \pm 0,4$ & $5,8 \pm 0,8$ \\
\hline & 2 & $2,5 \pm 1,9$ & $5,8 \pm 2,9$ & $11,2 \pm 1,2$ & $0,9 \pm 0,2$ & $10,0 \pm 1,7$ & $5,7 \pm 1,7$ \\
\hline & 3 & $3,8 \pm 1,0$ & $7,9 \pm 3,0$ & $16,1 \pm 4,1$ & $9,7 \pm 1,5$ & $14,2 \pm 2,9$ & $1,7 \pm 0,2$ \\
\hline & 4 & $2,9 \pm 0,9$ & $9,5 \pm 0,8$ & $13,5 \pm 3,8$ & $18,0 \pm 4,0$ & $21,2 \pm 2,1$ & $8,1 \pm 2,5$ \\
\hline & 5 & $6,9 \pm 2,2$ & $3,6 \pm 0,8$ & $17,7 \pm 1,3$ & $14,1 \pm 1,2$ & $5,9 \pm 0,6$ & $6,1 \pm 0,7$ \\
\hline & 6 & $1,6 \pm 0,3$ & $2,7 \pm 0,7$ & $6,6 \pm 1,3$ & $10,6 \pm 1,3$ & $4,3 \pm 0,4$ & $3,0 \pm 0,9$ \\
\hline & 8 & $6,9 \pm 1,0$ & $10,1 \pm 1,3$ & $12,0 \pm 1,2$ & $23,2 \pm 2,7$ & $19,9 \pm 2,4$ & $8,1 \pm 0,8$ \\
\hline & 9 & $1,3 \pm 0,3$ & $6,7 \pm 2,0$ & $8,4 \pm 1,6$ & $10,6 \pm 2,4$ & $16,3 \pm 2,1$ & $7,5 \pm 2,9$ \\
\hline & 10 & $4,4 \pm 1,6$ & $1,3 \pm 0,2$ & $3,3 \pm 1,0$ & $8,6 \pm 1,1$ & $6,1 \pm 1,8$ & $2,9 \pm 1,2$ \\
\hline & 11 & $6,3 \pm 1,8$ & $4,9 \pm 0,8$ & $6,6 \pm 1,8$ & $10,5 \pm 1,6$ & $13,7 \pm 3,2$ & $3,3 \pm 0,4$ \\
\hline & 12 & $2,6 \pm 0,6$ & $4,6 \pm 0,9$ & $12,1 \pm 3,3$ & $10,7 \pm 1,0$ & $9,0 \pm 0,5$ & $6,4 \pm 2,1$ \\
\hline & 13 & $2,7 \pm 0,6$ & $4,0 \pm 0,8$ & $14,9 \pm 2,2$ & $8,5 \pm 1,6$ & $13,0 \pm 0,5$ & $3,4 \pm 0,6$ \\
\hline & 14 & $2,3 \pm 0,9$ & $1,1 \pm 0,3$ & $3,1 \pm 0,6$ & $6,2 \pm 0,6$ & $3,4 \pm 0,4$ & $3,6 \pm 2,1$ \\
\hline & 15 & $3,4 \pm 1,6$ & $2,3 \pm 0,7$ & $10,7 \pm 1,2$ & $8,5 \pm 1,1$ & $4,6 \pm 1,2$ & $12,9 \pm 4,5$ \\
\hline & Média & $3,7 \pm 2,1$ & $4,7 \pm 3,0$ & $9,9 \pm 5,2$ & $10,2 \pm 5,7$ & $10,5 \pm 6,1$ & $5,6 \pm 3,3$ \\
\hline \multirow{16}{*}{ 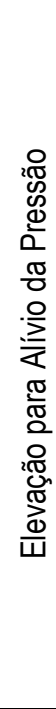 } & 1 & $3,9 \pm 0,8$ & $47,2 \pm 11,8$ & $2,8 \pm 0,1$ & $1,2 \pm 0,1$ & $16,8 \pm 1,5$ & $38,0 \pm 11,7$ \\
\hline & 2 & $1,7 \pm 0,4$ & $73,7 \pm 9,0$ & $6,9 \pm 1,3$ & $0,8 \pm 0,1$ & $15,2 \pm 1,0$ & $24,8 \pm 2,5$ \\
\hline & 3 & $1,6 \pm 0,2$ & $61,1 \pm 3,4$ & $7,6 \pm 0,8$ & $6,6 \pm 0,5$ & $34,0 \pm 2,8$ & $20,1 \pm 2,4$ \\
\hline & 4 & $5,2 \pm 1,5$ & $93,0 \pm 19,7$ & $54,7 \pm 15,2$ & $12,1 \pm 2,0$ & $94,6 \pm 12,9$ & $39,1 \pm 9,1$ \\
\hline & 5 & $1,6 \pm 0,4$ & $27,9 \pm 5,9$ & $1,6 \pm 0,2$ & $4,3 \pm 1,7$ & $10,1 \pm 0,4$ & $23,4 \pm 5,8$ \\
\hline & 6 & $1,2 \pm 0,2$ & $53,9 \pm 7,9$ & $14,1 \pm 3,9$ & $13,1 \pm 2,5$ & $10,6 \pm 1,3$ & $28,0 \pm 7,1$ \\
\hline & 7 & $1,5 \pm 0,1$ & $51,9 \pm 14,9$ & $13,1 \pm 3,7$ & $4,7 \pm 0,5$ & $7,4 \pm 1,4$ & $8,7 \pm 1,2$ \\
\hline & 8 & $7,5 \pm 2,1$ & $69,8 \pm 12,1$ & $12,2 \pm 6,0$ & $11,8 \pm 4,2$ & $36,2 \pm 4,7$ & $27,5 \pm 5,2$ \\
\hline & 9 & $1,7 \pm 0,5$ & $27,6 \pm 11,2$ & $5,7 \pm 0,9$ & $5,0 \pm 2,0$ & $29,7 \pm 4,3$ & $35,4 \pm 5,8$ \\
\hline & 10 & $0,9 \pm 0,1$ & $15,6 \pm 2,6$ & $3,1 \pm 0,6$ & $2,7 \pm 0,7$ & $2,5 \pm 0,3$ & $4,3 \pm 3,2$ \\
\hline & 11 & $6,0 \pm 1,2$ & $77,9 \pm 11,7$ & $10,7 \pm 1,0$ & $13,1 \pm 1,2$ & $40,4 \pm 3,7$ & $20,3 \pm 1,7$ \\
\hline & 12 & $2,4 \pm 0,5$ & $61,4 \pm 5,3$ & $28,4 \pm 4,9$ & $10,5 \pm 1,7$ & $21,1 \pm 1,6$ & $33,7 \pm 3,8$ \\
\hline & 13 & $4,5 \pm 1,4$ & $23,2 \pm 5,0$ & $22,3 \pm 3,9$ & $4,1 \pm 0,8$ & $23,8 \pm 2,0$ & $8,0 \pm 1,9$ \\
\hline & 14 & $2,3 \pm 0,4$ & $20,6 \pm 3,9$ & $2,2 \pm 0,4$ & $5,2 \pm 1,0$ & $8,2 \pm 1,3$ & $6,3 \pm 0,4$ \\
\hline & 15 & $2,8 \pm 0,3$ & $15,3 \pm 3,1$ & $6,4 \pm 1,7$ & $3,5 \pm 0,7$ & $15,7 \pm 1,2$ & $14,8 \pm 4,8$ \\
\hline & Média & $3,0 \pm 2,1$ & $48,0 \pm 25,5$ & $12,8 \pm 14,0$ & $6,5 \pm 4,6$ & $24,4 \pm 22,1$ & $22,2 \pm 12,1$ \\
\hline \multirow{8}{*}{ 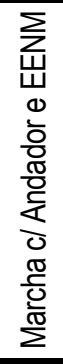 } & 1 & $28,7 \pm 2,3$ & $83,4 \pm 4,3$ & $18,8 \pm 2,4$ & $12,2 \pm 0,5$ & $35,0 \pm 3,9$ & $44,9 \pm 4,9$ \\
\hline & 2 & $14,6 \pm 2,0$ & $74,2 \pm 5,2$ & $42,0 \pm 6,7$ & $1,3 \pm 0,1$ & $36,4 \pm 4,0$ & $21,2 \pm 2,3$ \\
\hline & 5 & $19,4 \pm 4,4$ & $63,8 \pm 13,1$ & $46,1 \pm 5,4$ & $8,0 \pm 1,2$ & $27,2 \pm 3,3$ & $22,8 \pm 9,3$ \\
\hline & 7 & $8,6 \pm 2,8$ & $99,2 \pm 9,4$ & $30,4 \pm 6,0$ & $6,0 \pm 0,7$ & $16,5 \pm 3,3$ & $24,9 \pm 5,7$ \\
\hline & 11 & $13,1 \pm 2,4$ & $85,0 \pm 5,5$ & $24,2 \pm 14,7$ & $15,5 \pm 1,9$ & $38,3 \pm 7,2$ & $20,5 \pm 1,5$ \\
\hline & 13 & $8,8 \pm 0,5$ & $25,3 \pm 3,7$ & $20,8 \pm 1,7$ & $3,7 \pm 1,2$ & $27,9 \pm 2,1$ & $9,5 \pm 1,1$ \\
\hline & 14 & $3,8 \pm 1,6$ & $14,7 \pm 1,5$ & $4,7 \pm 0,5$ & $4,7 \pm 0,4$ & $9,2 \pm 0,9$ & $10,2 \pm 1,6$ \\
\hline & Média & $13,7 \pm 8,1$ & $64,9 \pm 32,2$ & $26,4 \pm 14,3$ & $7,1 \pm 5,0$ & $27,1 \pm 10,8$ & $21,8 \pm 11,6$ \\
\hline
\end{tabular}




\section{CAPÍtulo 4 \\ "Como é que eu posso ler se eu não consigo concentrar minha atenção..." R.S.S. / Super Heróis (1974)}

\section{DISCUSSÃO}

Pacientes portadores de lesão medular além de perderem as funções motoras e sensitivas abaixo do nível de lesão, ainda podem apresentar uma série de outros problemas como: úlceras por pressão, disfunção urinária e intestinal, disreflexia autonômica, atrofia muscular, trombose, hipotensão ortostática, embolia pulmonar, siringomielia e distúrbios do humor (SARAH, 2007; KIRSHBLUM, 2005)

Técnicas de reabilitação são utilizadas para reduzir estes prejuízos aos pacientes, sendo a Estimulação Elétrica Neuromuscular (EENM) uma técnica frequentemente usada tanto para fins terapêuticos quanto funcionais (SIPSKI; RICHARDS, 2006; ORTOLAN et al., 2001). O ser humano apresenta uma fisiologia apropriada para andar e não para manter-se sentado, desta forma, quando pacientes lesados medulares são submetidos a seções de marcha induzida artificialmente, ou simplesmente mantêm-se em pé presos a uma prancha ortostática, apresentam alguns benefícios como a reversão da osteoporose, redução 
da espasticidade, melhor funcionamento dos sistemas circulatório, digestivo e urinário, além de auxiliar na prevenção de úlceras por pressão (KIRSHBLUM, 2005). Além disso, o restabelecimento da marcha, mesmo que artificialmente, apresenta novas perspectivas e ganhos psicológicos a estes pacientes (MANHÃES, 2004).

Desta maneira, vários programas de reabilitação envolvendo a marcha induzida artificialmente são frequentados por pacientes lesados medulares, onde normalmente são analisados seus benefícios. No entanto, existem algumas desvantagens associadas a esta atividade que incluem o aumento do consumo energético comparado à marcha normal (WATERS; MULROY, 1999; ULKAR et al., 2003; CARVALHO et al., 2005) e o risco de induzir danos pelo sobreuso nas articulações dos membros superiores destes sujeitos.

Os membros superiores são apropriados à manipulação de objetos, assim a avaliação do esforço realizado pelo ombro, quando exerce a função de sustentação, torna-se importante para evitar danos a esta articulação e o comprometimento das funções de independência remanescentes (HASTING; GOLDSTEIN, 2004; SAMUELSON et al., 2004).

Poucos trabalhos mensuraram a carga em membros superiores de pacientes lesados medulares durante a marcha. Noreau et al. (1995), Melis et al. (1999), Bachschmidt et al. (2001), Requejo et al. (2005) e Haubert et al. (2006) avaliaram o esforço nos membros superiores de sujeitos normais ou lesados medulares incompletos que andam diariamente com auxílio de bengalas ou muletas, e nenhum estudo ainda foi realizado com pacientes portadores de lesão completa ou que necessitam de EENM para realizar a marcha com andador durante seções de reabilitação. 


\subsection{Cinética}

A propulsão manual da cadeira de rodas é uma importante forma de locomoção para pacientes com deficiência nos membros inferiores, e o ombro é um conjunto complexo de articulações que realiza uma importante função na propulsão da cadeira de rodas. As médias encontradas para os picos de torque no plano sagital, durante os três ciclos iniciais de propulsão da cadeira de rodas, foram de $29,3 \mathrm{~N} \cdot \mathrm{m}$ e $32,4 \mathrm{~N} \cdot \mathrm{m}$ para os lados direito e esquerdo respectivamente (tabelas 8 e 9). Estes valores estão próximos dos valores obtidos por Robertson et al. (1996) que obtiveram picos de torque de $20 \mathrm{~N} \cdot \mathrm{m}$ e $35 \mathrm{~N} \cdot \mathrm{m}$ para usuários e não usuários de cadeiras de rodas durante os ciclos de propulsão.

De Groot et al. (2002) também encontraram diferenças nos ciclos de propulsão da cadeira de rodas entre usuários e não usuários. Apesar dos pacientes do presente trabalho serem usuários de cadeiras de rodas, foram obtidos valores de picos de torque maiores que os encontrados nos usuários de Robertson et al. (1996) e de Groot et al. (2002). Esta diferença pode ser explicada pelo fato deste trabalho estar analisando os ciclos iniciais de propulsão (a partir do repouso) que requerem um esforço maior comparado a um ciclo de propulsão destinado a manter a cadeira em movimento.

Foram encontrados picos de força horizontal de $77,9 \mathrm{~N}$ e $83,1 \mathrm{~N}$ durante os três ciclos iniciais de propulsão da cadeira de rodas (tabelas 8 e 9). Finley et al. (2004) e Fay et al. (2004) encontraram valores de pico de força próximos a $70 \mathrm{~N}$, sendo que os pacientes que apresentaram dores nos ombros realizaram esforços ainda menores (58N) (FINLEY et al., 2004). Cooper et al. (1999) encontraram valores de pico de força de $76 \mathrm{~N}$ e Boninger et al. (2002) valores variando entre $60 \mathrm{~N}$ e $86 \mathrm{~N}$ dependendo do padrão utilizado para a propulsão. 
Os picos de força obtidos no presente trabalho estão próximos dos valores obtidos por Cooper et al. (1999) e Boninger et al. (2002), porem são maiores que os $70 \mathrm{~N}$ obtidos por Finley et al. (2004) e Fay et al. (2004). Esta diferença (apesar de pequena) pode estar relacionada com o maior esforço necessário para iniciar a propulsão da cadeira a partir do repouso, no entanto as médias dos picos de força obtidos (tabelas 8 e 9) ainda são menores que os encontrados por Boninger et al. (2002) durante a propulsão da cadeira utilizando o padrão laço duplo (figura 15).

As médias dos picos de torque obtidos nos três ciclos iniciais da cadeira de rodas $(29,3 \mathrm{~N} \cdot \mathrm{m}$ e $32,4 \mathrm{~N} \cdot \mathrm{m}$ no plano Sagital, $-14,0 \mathrm{~N} \cdot \mathrm{m}$ e $14,4 \mathrm{~N} \cdot \mathrm{m}$ no plano Transversal), conforme valores apresentados nas tabelas 8 e 9, foram maiores que os encontrados por Kulig et al. (1998) para pacientes com baixa paraplegia impulsionando a cadeira com a velocidade habitual $(13,8 \mathrm{~N} \cdot \mathrm{m}$ e $5,8 \mathrm{~N} \cdot \mathrm{m}$ nos planos sagital e transversal respectivamente). Pacientes com alta paraplegia utilizando a velocidade habitual apresentaram picos de torque ainda menores $(12,4 \mathrm{~N} \cdot \mathrm{m}$ e $5,8 \mathrm{~N} \cdot \mathrm{m}$ nos planos sagital e transversal) (KULIG et al., 2001).

Velocidades maiores durante a propulsão da cadeira de rodas requerem maior esforço (ROBERTSON et al., 1995; VEEGER et al., 2002). Kulig et al. (2001) encontraram picos de torque médio de $32,5 \mathrm{~N} \cdot \mathrm{m}$ e $13,3 \mathrm{~N} \cdot \mathrm{m}$ nos planos sagital e transversal respectivamente, com pacientes desenvolvendo sua máxima velocidade. Além disso, diferentes inclinações também interferem no esforço necessário para empurrar a cadeira. Em teste em rampa com inclinação de 8\% (aproximadamente 5 graus $)^{5}$ Kulig et al. (2001) encontraram valores próximos aos obtidos com máxima velocidade. Os picos de torque durante a propulsão inicial da cadeira de rodas (a

\footnotetext{
${ }^{5}$ A máxima inclinação das rampas de acesso, para deficientes físicos, permitida nos Estados Unidos é de $8 \%$ (1:12), de acordo com norma federal do departamento de justiça de 1991.
} 
partir do repouso), obtidos no presente trabalho, se equiparam aos valores encontrados em condições que requerem maior esforço na propulsão da cadeira, como executar a máxima velocidade ou a empurrar a cadeira em uma rampa com inclinação de 8\%.

Os picos de força e torque durante os três ciclos iniciais de propulsão da cadeira de rodas ocorreram nos instantes relativos a 20\%, 50\% e $80 \%$ da execução desta atividade (figura 35), estes instantes estão relacionados com as fases de impulso da cadeira, que segundo Kulig et al. (2001) e Fay et al. (2004) é a fase de maior força durante a propulsão da cadeira de rodas.

Os valores médios tanto de força quanto de torque durante a propulsão da cadeira de rodas foram significativamente menores se comparado à elevação para alívio da pressão (figuras 44 a 47), exceto para o torque esquerdo no plano sagital (figura 45).

Os valores de pico de força obtidos durante a elevação para alívio da pressão foram de $305,5 \mathrm{~N}$ e $308,0 \mathrm{~N}$ para os lados direito e esquerdo respectivamente (tabelas 8 e 9). Estes valores são aproximadamente quatro vezes a força obtida durante a propulsão da cadeira de rodas, van Drongelen et al. (2005a) também encontraram uma força de contato na articulação glenoumeral quatro vezes maior durante elevação para alívio da pressão comparado a propulsão da cadeira de rodas.

Kamnik et al. (1999) ao avaliar paraplégicos completos realizando a transferência da posição sentada para a posição em pé com uso de EENM, encontraram picos de força entre $224 \mathrm{~N}$ e $343 \mathrm{~N}$, esta faixa de forças contêm as médias obtidas durante a elevação pelo presente trabalho.

Durante a elevação para alívio da pressão foram obtidos picos de torque médios de $35,3 \mathrm{~N} \cdot \mathrm{m}$ e $31,8 \mathrm{~N} \cdot \mathrm{m}$ no plano sagital para cada lado (tabelas 8 e 9), estes 
valores também ficaram entre os valores encontrados por Kamnik et al. (1999), porém foram menores que os picos de torque obtidos por Harvey e Crosbie (2000) e van Drongelen et al. (2005b) que foram da ordem de $45 \mathrm{~N} \cdot \mathrm{m}$. Esta diferença pode ter ocorrido pelo fato de Harvey e Crosbie (2000) e van Drongelen et al. (2005b) terem utilizado pacientes tetraplégicos que apresentam maior dificuldade na elevação e manutenção do tronco elevado comparado com pacientes paraplégicos.

Os picos de torque durante a elevação para alívio da pressão ocorreram no início e final desta atividade (figura 36), períodos referentes às fases de elevação e retorno do corpo. Esta resposta é obtida porque o paciente procura manter o ombro alinhado com o ponto de aplicação da força, durante a fase de sustentação do corpo elevado, diminuindo assim o torque neste período.

As médias dos picos de força vertical durante marcha com EENM e andador foram de $339,2 \mathrm{~N}$ e $297,1 \mathrm{~N}$ para os lados direito e esquerdo respectivamente (tabelas 8 e 9). Estes valores estão próximos aos encontrados por Melis et al. (1999) que obteve pacientes que descarregam até $100 \%$ de seu peso nos membros superiores utilizando o andador.

Outros trabalhos encontraram picos de força inferiores, menores que $100 \mathrm{~N}$, (REQUEJO et al., 2005; HAUBERT et al, 2006). No entanto estes resultados foram obtidos com pacientes paraplégicos incompletos que são capazes de andar diariamente com o auxílio de muletas sem o uso de EENM. Diferente dos pacientes com lesão completa que não apresentam qualquer função senso-motora abaixo do nível de lesão, desta maneira necessitam do uso de EENM para executar contrações musculares e não possuem propriocepção nos membros inferiores.

Melis et al. (1999) também avaliaram paraplégicos incompletos que utilizam muletas e na média os picos de força ficaram próximos a $20 \%$ da massa corpórea 
(com pico máximo de 50\%). Além disso, Ulkar et al. (2003) constataram que o consumo energético utilizando andador é maior comparado a muletas canadenses em teste com paraplégicos incompletos aptos a utilizar os dois tipos de equipamentos.

As médias dos picos de torque no ombro (plano sagital) durante a marcha foram de $37,0 \mathrm{~N} \cdot \mathrm{m}$ e $37,8 \mathrm{~N} \cdot \mathrm{m}$ para os lados direito e esquerdo respectivamente (tabelas 8 e 9). Estes valores estão em concordância com Noreau et al. (1995) que obteve picos de torque da ordem de $35 \mathrm{~N} \cdot \mathrm{m}$ analisando a marcha pendular (figura 16). Os valores de torque obtidos no presente trabalho também são próximos aos valores obtidos por Crosbie e Nicol (1990) analisando a marcha recíproca com muletas canadenses $(42 \mathrm{~N} \cdot \mathrm{m})$.

A média dos picos de torque no plano sagital obtida por Bachschmidt et al. (2001), ao analisar a marcha com andador, foi da ordem de 10N.m. Este valor menor pode ser resultado de um melhor alinhamento do ombro com o ponto de aplicação da força uma vez que Bachschmidt et al. avaliaram sujeitos normais. No entanto Bachschmidt et al. (2001) obtiveram picos de torque no plano frontal em torno de $45 \mathrm{~N} \cdot \mathrm{m}$, valores próximos aos obtidos no presente trabalho $(-50,4 \mathrm{~N} \cdot \mathrm{m}$ e $35,2 \mathrm{~N} \cdot \mathrm{m}$ nos lados esquerdo e direito respectivamente) (tabelas 8 e 9). É importante salientar que o torque no plano frontal é uma função da distância entre as manoplas do andador, e mesmo sujeitos normais não teriam como alinhar os ombros com o ponto de aplicação da força, pois se isso fosse realizado de um lado seria compensado pelo lado oposto.

As médias dos valores máximos de força durante a marcha e durante a elevação para alívio da pressão são muito maiores (cerca de 4 vezes) que os picos de força obtidos durante a propulsão da cadeira de rodas (figura 44). Comparando 
os picos de força durante a marcha com os resultados da elevação observa-se que a diferença é pequena, existindo diferença significativa apenas no lado direito (mão dominante dos pacientes que realizaram a marcha).

Os picos de torque nos ombros no plano frontal durante a marcha foram maiores que os picos de torque durante a elevação para o lado direito e menores para o lado esquerdo (figura 45). Quanto aos picos de torque no plano sagital não houve diferença significativa entre os valores obtidos durante a marcha e a elevação, apesar da marcha apresentar médias maiores para ambos os lados. Ou seja, os picos de força e torque durante a marcha e a elevação são similares, porém com tendência a valores maiores durante a marcha principalmente no lado dominante (direito).

Os valores de pico de força e torque representam as magnitudes que a estrutura do ombro deve neutralizar para preservar a integridade da articulação e evitar lesões, enquanto que a integral representa o esforço total aplicado em um intervalo de tempo (HAUBERT et al., 2006).

As médias das integrais da força durante a marcha com EENM e andador foram de 1064N.s e $769 \mathrm{~N} \cdot \mathrm{s}$ para cada lado analisado (tabelas 8 e 9). Valores da mesma grandeza foram obtidos por Haubert et al. (2006) ao analisar a marcha com andador.

A integral da força durante a propulsão da cadeira de rodas apresentou valores bem menores comparados às outras duas atividades executadas pelos pacientes (figura 46), este resultado era de certa forma esperado, pois os picos durante a propulsão foram significativamente menores.

Os picos de força e torque durante a marcha com andador e EENM ocorreram principalmente no final da fase de balanço (figura 37). A fase de suporte duplo 
apresenta valores de força e torque baixos. Desta maneira, foram obtidos valores de integrais menores para a marcha comparada à elevação, onde o paciente mantém uma força praticamente constante em todo intervalo da atividade (figuras 46 e 47).

A elevação para alívio da pressão exigiu um esforço total (durante todo o período do exercício), significativamente maior comparado a um ciclo da marcha, de acordo com as integrais de força e torque obtidas (figuras 46 e 47). No entanto, as integrais foram obtidas em um único ciclo para cada exercício, desta maneira não se pode afirmar que pacientes andando requeiram menos esforço, pois neste caso são realizados vários ciclos da marcha. Além disso, as integrais dos dados cinéticos estão relacionadas com o consumo energético, enquanto que as lesões nas articulações estão associadas aos valores de pico de força e torque.

\subsection{Atividade Muscular}

A elevação para alívio da pressão envolve simultaneamente duas funções biomecânicas: a extensão do cotovelo e a elevação do tronco. A extensão do cotovelo é executada principalmente pelo músculo tríceps braquial, que foi o que apresentou maior atividade durante a elevação (figura 52) assim como encontrado por van Drongelen et al. (2005a). A cabeça longa do tríceps é a porção deste músculo que também participa da articulação do ombro (originando-se na escápula), desta maneira as extensões de cotovelo que requerem maior força necessitam da estabilização da escápula.

Reyes et al. (1995) e van Drongelen et al. (2005a) encontraram baixa atividade nos músculos serrátil anterior e trapézio médio (que são músculos estabilizadores da escápula), porém, não avaliaram a atividade do músculo trapézio inferior. De acordo com os resultados obtidos (figura 52) o trapézio inferior teve participação relevante 
durante o exercício de alívio da pressão, agindo tanto na fixação da escápula (para a extensão do cotovelo) quanto na elevação do tronco (considerando a escápula como ponto fixo). Outro músculo relacionado com a função de elevação do tronco é o peitoral maior (parte esternocostal) que também apresentou atividade significativa durante o exercício de alívio da pressão em concordância com Reyes et al. (1995) e van Drongelen et al. (2005a).

Movimentos de transferência do corpo que requerem tanto as funções de elevação quanto de movimento do tronco apresentam atividade muscular similar à elevação para alívio da pressão (tríceps, trapézio inferior e peitoral maior) acrescido do músculo deltóide anterior, devido à manutenção do corpo inclinado para frente em grande parte desta atividade (PERRY et al., 1996; GAGNON et al., 2003, 2005; FINLEY et al. 2005).

Pacientes tetraplégicos normalmente não apresentam o controle do músculo tríceps, neste caso o deltóide anterior é o músculo que apresenta maior atividade durante a elevação, pois este músculo realiza a extensão do cotovelo através da flexão do ombro com a mão fixada. (GEFEN et al., 1997; HARVEY; CROSBIE, 2000)

Durante a propulsão da cadeira de rodas o músculo que apresentou maior atividade foi o deltóide posterior (figura 52). Os músculos deltóide anterior e peitoral maior também apresentaram atividade significativa durante este exercício.

Schantz et al. (1999) encontraram maior atividade nos músculos tríceps, deltóide anterior e peitoral maior durante a fase de impulso, e na fase de retorno do braço foram os músculos deltóide posterior e trapézio inferior que apresentaram maior atividade. Segundo Schantz et al. (1999) a ordem de ativação dos músculos na fase de impulso é: bíceps, peitoral maior, deltóide anterior e tríceps respectivamente. Esta sequência de ativação durante a fase de impulso pode ser observada na figura 
35, assim como a atividade do deltóide posterior na fase de retorno.

Chow et al. (2001) obtiveram maior resposta nos músculos tríceps, trapézio inferior e peitoral maior durante a propulsão da cadeira e baixos valores no deltóide, porém Chow et al. analisaram pacientes atletas de elite.

Mulroy et al. (1996, 2004) e van Drongelen et al. (2005a) encontraram maior atividade muscular durante a propulsão da cadeira nos músculos do manguito rotador, deltóide e peitoral maior. Os músculos peitoral maior e supraespinhal (do manguito rotador) tiveram maior participação na fase de impulso da cadeira, enquanto que na fase de retorno os músculos mais ativos foram os deltóides médio e posterior, o supraespinhal e o subescapular (músculos do manguito rotador).

Os músculos do manguito rotador não foram avaliados no presente trabalho por se tratarem de músculos profundos e necessitar do uso de eletrodos de agulha. Além disso, de acordo com Reyes et al. (1995) este conjunto de músculos apresenta baixa atividade durante a elevação para alívio da pressão sendo preservados por músculos maiores que agem diretamente entre o tronco e o braço (peitoral maior e grande dorsal) aliviando a carga aplicada na articulação glenoumeral. Segundo van Drongelen et al. (2005a) o manguito rotador tem atividade relevante durante a propulsão da cadeira de rodas, porém durante este exercício, a atividade geral dos músculos é menor se comparada à marcha com andador e EENM (figura 52) e também ao exercício de elevação (van DRONGELEN et al., 2005a).

Durante a marcha com andador e EENM os músculos com maior atividade observada foram o tríceps, peitoral maior e trapézio inferior assim, como durante a elevação para alívio da pressão. Esta equivalência ocorre porque durante a marcha o paciente também suporta o peso do tronco com os membros superiores e tem que manter o cotovelo estendido ou estabilizado (figura 52). Além destes três músculos 
(tríceps, peitoral maior e trapézio inferior) o deltóide anterior também teve atividade significativa durante a marcha (figura 52), presente em duas situações: no avanço do andador e quando o tronco se manteve inclinado para frente. Esta resposta é nítida no paciente 7 (apêndice A7, figura A7.6) que é um paciente alto e consequentemente anda com uma maior inclinação.

O músculo bíceps apresentou atividade significativa apenas em curtos intervalos durante o avanço do andador (apêndices A1, A2, A5, A7, A11 e A13) exibindo uma baixa atividade média considerando todo o ciclo analisado.

O tríceps foi o músculo mais requisitado tanto durante a marcha com EENM quanto durante a elevação para alívio da pressão, porém durante a marcha o tríceps apresentou atividade significantemente maior comparado à elevação (figura 52).

Com exceção do deltóide posterior esquerdo todos os outros músculos estiveram mais ativos durante a marcha, comparado aos outros dois exercícios executados, sendo que durante a propulsão da cadeira a atividade muscular foi significativamente menor se comparada à elevação para alívio da pressão e à marcha com EENM (figura 52).

\subsection{Considerações Finais}

Os fatores que podem contribuir para o desenvolvimento de complicações nos ombros estão relacionados com o esforço realizado frequentemente durante a propulsão da cadeira de rodas, e principalmente às altas cargas que são aplicadas nesta articulação durante outras atividades executadas diariamente por estes indivíduos, como por exemplo, a transferência e a elevação para alívio da pressão.

Segundo Veeger et al. (2002) a propulsão da cadeira de rodas em baixa velocidade não parece levar a altas forças de contato na articulação glenoumeral. A força aplicada 
à articulação glenoumeral é dependente da seção dos músculos pertencentes à articulação. A adaptação muscular, de acordo com a demanda, aumentará a seção do músculo levando a uma menor tensão sem diminuir a força. O lado negativo desta adaptação é o possível surgimento de uma força excessiva que pode gerar uma lesão na articulação. Desta maneira, programas de exercícios para os membros superiores em lesados medulares devem ser bem balanceados para proporcionar a adaptação muscular sem sobrecarregar as articulações (VEEGER et al. 2002).

Pacientes paraplégicos realizam a elevação do corpo para alívio da pressão várias vezes ao dia para evitar úlceras por pressão. Esta atividade, no entanto, solicita grande esforço dos membros superiores e é frequentemente identificada como possível fonte de patologias no ombro. Além disso, como este exercício requer a manutenção de um esforço considerável durante um intervalo de tempo, resulta geralmente no aumento da pressão intratorácica, que pode gerar complicações como a siringomielia pós-traumática (KIRSHBLUM, 2005).

A elevação para alívio da pressão exige um esforço significativamente maior comparado a um ciclo da marcha, de acordo com as integrais de força e torque obtidas (figuras 46 e 47). No entanto, as integrais dos dados cinéticos estão relacionadas com o consumo energético, enquanto que as lesões nas articulações estão associadas aos valores de pico de força e torque. Além disso, uma marcha é composta por vários ciclos, desta maneira apresenta um consumo energético maior comparado a um único ciclo de elevação.

Para efeito de comparação o torque no plano sagital dos membros inferiores durante a marcha normal varia de $32 \mathrm{~N} \cdot \mathrm{m}$ a $42 \mathrm{~N} \cdot \mathrm{m}$ para a articulação do joelho e de $42 \mathrm{~N} \cdot \mathrm{m}$ a $84 \mathrm{~N} \cdot \mathrm{m}$ para a articulação do quadril (WINTER et al., 1996). Pacientes paraplégicos ao realizarem a marcha com EENM e andador apresentaram picos de 
torque nos ombros da ordem de $37 \mathrm{~N} \cdot \mathrm{m}$ no plano sagital (tabelas 8 e 9), ou seja, o torque aplicado ao ombro é da mesma ordem de grandeza do torque aplicado aos membros inferiores (principalmente ao joelho). No entanto, o ombro é uma articulação com características próprias para a manipulação de objetos, diferente dos membros inferiores que são articulações de carga e tem como principal função sustentar e locomover o corpo.

Programas de reabilitação utilizando a marcha induzida eletricamente e andador apresentam vários benefícios aos pacientes (ORTOLAN et al., 2001; MANHÃES, 2004; KIRSHBLUM, 2005; SIPSKI; RICHARDS, 2006), no entanto, podem gerar complicações nos ombros pela sobrecarga desta articulação.

Ninomya et al. (2007) analisaram por meio de ultra-som os ombros de lesados medulares participantes do programa de reabilitação no Laboratório de Biomecânica e Reabilitação do Aparelho Locomotor (HC/Unicamp) do Departamento de Ortopedia e Traumatologia da Faculdade de Ciências Médicas da Unicamp. Segundo Ninomya et al. (2007) todos os pacientes paraplégicos analisados, que realizam a marcha com andador, mostraram algum tipo de lesão nos ombros comprovada por alteração ultrassonográfica. Das lesões constatadas metade estava relacionada com o manguito rotador, sendo que dentro deste grupo muscular a incidência de lesão foi de $44 \%$ no músculo supraespinhal e de 56\% no subescapular. Desta maneira, exercícios que requerem grandes esforços dos membros superiores em lesados medulares podem gerar complicações nas articulações do ombro. Lesados medulares, submetidos a seções de reabilitação que executam esforços significativos como a marcha com EENM, devem ser continuamente monitorados, por métodos de ultra-som ou ressonância magnética, para evitar o comprometimento dos membros superiores e possíveis perdas das funções de independência remanescentes. 


\section{CAPÍtulo 5}

"... Que o mel é doce é coisa que me nego a afirmar, mas que parece doce isso eu afirmo plenamente..." R.S.S. / Faça, Fuce, Force.

\section{CONCLUSõeS}

O objetivo deste trabalho foi avaliar o esforço e a atividade muscular dos ombros em pacientes paraplégicos, durante seções de reabilitação realizadas por meio de marcha induzida artificialmente (estimulação elétrica) utilizando um andador, e comparar com duas atividades diárias executadas por estes pacientes.

Com os resultados obtidos pode-se concluir que o músculo mais ativo do ombro, tanto durante a marcha quanto na elevação para alívio da pressão, foi o tríceps braquial. Durante a marcha com EENM e andador também foram constatadas atividades significativas nos músculos: peitoral maior (porção esternocostal), trapézio inferior e deltóide anterior. Entre os três exercícios executados pelos pacientes, a marcha com EENM apresentou maior atividade para todos os músculos avaliados (com exceção apenas do deltóide posterior esquerdo).

Verificou-se que a marcha com EENM e andador executada por pacientes paraplégicos, exige maior esforço comparado à propulsão da cadeira de rodas (chegando a picos de força quatro vezes maior). 
Comparando a elevação para alívio da pressão com a marcha utilizando EENM e andador, pode-se concluir que a marcha apresentou maiores possibilidades de causar danos às articulações principalmente no lado dominante, uma vez que os picos de força e torque no plano frontal foram próximos para o lado esquerdo e significantemente maiores para o lado direito dos pacientes analisados.

Desta maneira, pode-se concluir que a marcha com EENM e andador, realizada por lesados medulares submetidos a seções de reabilitação, requer esforços significativos dos membros superiores destes pacientes, podendo gerar complicações nas articulações de seus ombros.

Sendo assim, lesados medulares submetidos a seções de reabilitação que executam esforços significativos devem ser continuamente monitorados para evitar o comprometimento dos membros superiores e a consequente perda das funções de independência remanescentes. 


\section{REFERÊNCIAS}

ALMEIDA, M.A.F. (1997). "Filtragem Digital de Sinais Biomédicos". Florianópolis. 116p. Dissertação (Mestrado) - Programa de Pós-Graduação em Engenharia Elétrica, Universidade Federal de Santa Catarina. 1997.

ASIA - American Spinal Injury Association (1992): "International standard for neurological and functional classification of spinal cord injury". Revised 1992. Chicago: American Spinal Injury Association and International Medical Society of Paraplegia - ASIA/IMSOP, 1992.

BACHSCHMIDT, R.A.; HARRIS, G.F.; SIMONEAU G.G. (2001): "Walker-assisted gait in rehabilitation: A study of biomechanics and instrumentation". IEEE Trans Neural System and Rehabil Eng. v.9, n.1, p.96-105, 2001.

BAJD, T.; KRALJ, A.; TURK, R.; BENKO, H.; SEGA, J. (1983): "The use of a four channel electrical stimulator as an ambulatory aid for paraplegic patients". Phys Ther. v.63, p.116-1120, 1983.

BALLINGER D.A.; RINTALA, D.H.; HART, K.A., (2000): "The relation of shoulder pain and range-of motion problems to functional limitations, disability, and perceived health of men with spinal cord injury: A multifaceted longitudinak study." Arch Phys Med Rehabil. v.81, p.1575-1581, 2000.

BARBEAU, H., LADOUCER, M., MIRBAGHERI, M.M., KEANEY, R.E. (2002): “The effect of locomotion training combined with functional electrical stimulation in chronic spinal cord injury subjects". Brain Researsh Reviews v.40, p.274-291, 2002.

BASMAJIAN, J.V.; DeLUCA, C.J. (1985). "Muscle Alive: Their Functions Revealed by Electromyography". ISBN:O-683-00414-X. $5^{\text {th }}$ ed. Baltimore, Williams \& Wilkins, $561 p$.

BATENI, H.; MAKI, B.E.: (2005): "Assistive devices for balance and mobility: benefits, demands, and adverse consequences". Arch Phys Med Rehabil. v.86, p.134-145, January 2005.

BONINGER, M.L.; SOUZA, A.L.; COOPER, R.A.; FITZGERALD, S.G.; KOONTZ, A.M.; FAY, B.T. (2002): "Propulsion Patterns and Pushrim Biomechanics in Manual Wheelchair Propulsion". Arch Phys Med Rehabil. v.83, p.718-723, 2002. 
CALAIS-GERMAIN, B. (1991): "Anatomia para o movimento: Introdução à análise das técnicas corporais”. São Paulo: Ed. Manole, 1991. 302p.

CALANCIE, B., NEEDHAM-SHORPSHIRE, B., JACOBS, P., WILLER, K., ZYCH, G., GREEN, B.A..(1994): "Involuntary stepping after chronic spinal cord injury: Evidence for a central rhythm generator for locomotion in man". Brain v.117, p.1143-1159, 1994.

CARVALHO, D.C., de CÁSSIA, Z.M., SERENI, J.M., CLIQUET Jr., A., (2005): "Metabolic and cardiorespiratory responses of tetraplegic subjects during treadmill walking using neuromuscular electrical stimulation and partial body weight support." Spinal Cord. v.43, p.400-405, 2005.

CHANDLER, R.F.; CLAUSER, C.E.; McCONVILLE, J.T.; REYNOLDS, H.M.; YOUNG, J.W. (1975): "Investigation of inertial properties of the human body." AMRL Technical Report, Wright-Patterson Air Force Base, p.74-137, 1975.

CHOW, J.W.; MILIKAN, T.A.; CARLTON, L.G.; MORSE, M.I.; CHAE, W. (2001): "Biomechanical comparison of two racing wheelchair propulsion techniques". Medicine \& Science in Spots \& Exercise v.33, n.3, p.476-484, 2001.

CLARYS, J.P.P.; LEWILLIE, L. (1992): "Clinical and kinesiological electromyography by Le Dr. Duchenne (De Boulogne)". In: CAPOZZO, A.; MARCHETTI, M.; TOSI, V. Biolocomotion: a century of research using moving pictures. Roma, Promograph, p.89-114, 1992.

CLAUSER, C.E.; McCONVILLE, J.T.; YOUNG, J.W. (1969): "Weight, volume, and center of mass of segments of the human body". AMRL Technical Report, Wright-Patterson Air Force Base, p.69-70, 1969.

CLIQUET Jr., A., BAXENDALE, R.H., ANDREWS, B.J. (1989): "Paraplegic locomotion and its metabolic energy expenditure". In: ROSE, F.C., JONES, R., VRBOVÁ, G. (Eds.). Neuromuscular Stimulation: Basic Concepts and Clinical Implications, V.13 of Comprehensive Neurologic Rehabilitation, New York: Demos, 1989. p.139-146.

COOPER, R.A.; BONINGER, M.L.; SHIMADA, S.D.; LAWRENCE, B.M. (1999): "Glenohumeral joint kinematics and kinetks for three coordinate system representations during wheelchair propulsion". Am J Phys Med Rehabil. v.78, n.5, p.435-446, 1999.

CROSBIE, W.J.; NICOL, A.C. (1990): "Reciprocal aided gait in paraplegia," Paraplegia, p.353-363, 1990.

de GROOT, S.; VEEGER, H.E.J; HOLLANDER, A.P.; van der WOUDE, L.H.V. (2002): "Wheelchair propulsion technique and mechanical efficiency after 3 wk of practice". Medicine \& Science in Sports \& Exercise, p.756-766, 2002. 
de LEVA, P. (1996): "Adjustments to Zatsiorsky-Seluyanov's segment inertia parameters". J Biomechanics. v. 29, n.9, p.1223-1230, 1996.

DELSYS Inc. [on-line]. (1996): Tutorials \& WhitePapers: "A discussion on Surface Electromyography: Detection and Recording". Acesso em: 21/03/2000. Disponível em: <http://www.delsys.com/library/tutorials.htm>.

DEMPSTER, W.T.; GABEL, W.C.; FELTS, W.J.L. (1959): "The anthropometry of manual work space for the seated subjects". Am J Phys Anthrop. v.17, p.289-317, 1959.

DIETZ, V. (2002): "Proprioception and locomotor disorders" Nature Reviews v.3, p.781-790, 2002.

DIETZ, V., COLOMBO, G., JENSEN, L., BAUNGARTNER, L. (1995): "Locomotor capacity of spinal cord in paraplegics patients". Ann Neurol. v.37, p.574-582, 1995.

FAY, B.T.; BONINGER, M.L.; FITZGERALD, S.G.; SOUZA, A.L.; COOPER, R.A.; KOONTZ, A.M. (2004): "Manual wheelchair pushrim dynamics in people with multiple sclerosis. Arch. Phys. Med. Rehabil v.85, p.935-942, June 2004.

FINLEY, M.A.; McQUADE, K.J.; RODGERS, M.M. (2005): "Scapular kinematics during transfers in manual wheelchair users with and without shoulder impingement". Clinical Biomechanics v. 20, p.32-40, 2005.

FINLEY, M.A.; RASCH, E. K.; KEYSER, R.E.; RODGERS, M.M. (2004): "The biomechanics of wheelchair propulsion in individuals with and without upper-limb impairment”. J Rehabil Research Develop. v.41, n.3B, p.385-394, 2004.

FINLEY, M.A.; RODGERS, M.M. (2004): "Prevalence and identification of shoulder pathology in athletic and nonathletic wheelchair users with shoulder pain: A pilot study". J Rehabil Res Dev. v.41, p.395-402, 2004.

FOUAD, K., PERSON, K. (2004): "Restoring walking after spinal cord injury". Progress in Neurobiology v.73, p.107-126, 2004

FRANCA, J.E.M. (2003): "Avaliação da locomoção do paraplégico sob estimulação elétrica neuromuscular". 204p. Dissertação (Mestrado em eng. elétrica) - Escola de Engenharia de São Carlos, Universidade de São Paulo, São Carlos, 2003.

GAGNON, D.; NADEAU, S.; GRAVEL, D.; NOREAU, L.; LARIVIĖRE, C.; GAGNON, D. (2003): "Biomechanical analysis of a posterior transfer maneuver on a level surface in individuals with high and low-level spinal cord injuries". Clinical Biomechanics v.18, p.319-331, 2003. 
GAGNON, D.; NADEAU, S.; GRAVEL, D.; NOREAU, L.; LARIVIÈRE, C.; McFADYEN, B. (2005): "Movement patters and muscular demandes during posterior transfers toward an elevated surface in individuals with spinal cord injury". Spinal Cord. v.43, p.74-84, 2005.

GEFEN, J.Y.; GELMAN, A.S.; HERBISON, G.J.; COHEN, M.E.; SCHMIDT, R.R. (1997): "Use of shoulder flexors to achieve isometric elbow extension in C6 tetraplegic patients during weight shift. Spinal Cord v.35, p. 308-313, 1997.

GIANINI, P.E.S; CHAMLIAN, T.R.; ARAKAKI, J.C. (2006): "Shoulder pain in spinal cord injury". Acta Ortop Bras. ISSN:1413-7852. v.14, n.1, p.44-47, 2006.

GUYTON, A. C.; HALL, J. E. (1997): "Tratado de Fisiologia Médica”. 9.ed. Rio de Janeiro, Guanabara Koogan S.A., 1014 p.

HAMILL, J.; KNUTZEN, K.M. (1999): "Bases Biomecânicas do Movimento Humano". Barueri: Editora Manole, 1999. 532p. ISBN: 85-204-0779-X.

HANAVAN, E.P. (1964): "A mathematical model of the human body". $A M R L$ Technical Report, Wright-Patterson Air Force Base, p.64-102, 1964.

HARVEY, L.A.; CROSBIE, J. (2000): "Biomechanical analysis of a weight-relief maneuver in C5 and C6 quadriplegia". Arch Phys Med Rehabil. v.81, p.500-505. April 2000.

HASTING, J., GOLDSTEIN, B. (2004): "Paraplegia and shoulder". Physical Med Rehab Clinics of North America v.15, p.699-718, 2004.

HATZE, H. (1980): "A mathematical model for the computational determination of parameter values of anthropomorphic segments." Journal of Biomechanics v.13, p.833-843, 1980.

HAUBERT, L.L., GUTIERREZZ, D.D., NEWSAM, C.J., GRONLEY, J.K., MULROY, S.J. PERRY, J. (2006): "A comparison of shoulder joint forces during ambulation with crutches versus a walker in persons with incomplete spinal cord injury". Arch Phys Med Rehabil. v.87, p.63-70, 2006.

JENSEN, M.P., HOFFMAN, A.J., CARDENAS, D.D. (2005): "Chronic pain in individuals with spinal cord injury: A survey and longitudinal study". Spinal Cord. v.43, p.704-712, 2005.

KAMNIK, R; BAJD, T.; KRALJ, A. (1999): "Functional electrical stimulation and arm supported sit-to-stand transfer after paraplegia: A study of kinetic parameters". Artif Organs. v.23, n.5, p.413-417, 1999.

KENDALL, F.P., MCCREARY, E.K., PROVANCE, P.G. (1993): “Muscles: Testing and Function." 4th ed. Williams \& Wilkins, Baltimore, April 1993. 448p. 
KIRSHBLUM, S. (2005): "Rehabilitation of spinal cord injury". In: DeLISA, J. et al. Physical Medicine \& Rehabilitation: Principles and Practice. Ed: Lippincott Williams \& Wilkins, 2005. Cap 79, p.1715-1751.

KULIG, K.K.; RAO, S.S.R.; MULROY, S.J.; NEWSAM, C.J.; GRONLEY, J.K.; BONTRAGER, E.L.; PERRY, J. (1998): "Shoulder joint kinetics during the push phase of wheelchair propulsion". Clinical Orthopaedics and Related Research n.354, p.132-143, 1998.

KULIG, K.K.; NEWSAM, C.J.; MULROY, S.J.; RAO, S.S.R.; GRONLEY, J.K.; BONTRAGER, E.L.; PERRY, J. (2001):"'The effect of level of spinal cord injury on shoulder joint kinetics during manual wheelchair propulsion. Clin. Biomech. v.16, n.9, p.744-51, 2001.

LAMB, T., YANG, J.F., (2000): "Could different directions of infant stepping be controlled by the same locomotor central pattern generator?" J. Neurophysiol v.83, p.2814-2824, 2000.

MANHÃES, R.B. (2004): "A Engenharia de Reabilitação e as Características Psicossociais de Pessoas com Lesão Medular Submetidas a um Programa de Estimulação Elétrica Neuromuscular". 231p. Dissertação (Mestrado) - Escola de Engenharia de São Carlos, Universidade de São Paulo, São Carlos 2004.

MELIS, E.H.; TORRES-MORENO, R.; BARBEAU, H.; LEMAIRE E.D. (1999): "Analysis of assisted-gait characteristics in persons with incomplete spinal cord injury." Spinal Cord. v.37, p.430-439, 1999.

MILLER, D.I., NELSON, R.C. (1973): "Biomechanics of sport" Lea and Febiger, Philadelphia.

MULROY, S.J.; FARROKHI, S.; NEWSAM, C.J.; PERRY, J. (2004): "Effects of spinal cord injury level on the activity of shoulder muscles during wheelchair propulsion: An electromyographic study". Arch Phys Med Rehabil. v.85, p.925-934, June 2004.

MULROY, S.J.; GRONLEY, J.K.; NEWSAM, C.J.; PERRY, J. (1996): “Electromyographic activity of shoulder muscles during wheelchair propulsion by paraplegic persons. Arch Phys Med Rehabil. v.77, p.187-93, 1996.

MUNIH, M., ICHIE, M., (2001): "Current status and future prospects for upper and lower extremity motor system neuroprostheses". Neuromodulation. v.4, n.4, p.176-186, 2001.

NINOMYA, A.F.; de JESUS, C.L.M.; AULETTA, L.L.; RIMKUS, C.M.; FERREIRA, D.M.; ZOPPI FILHO, A.; CLIQUET Jr., A. (2007): "Shoulder of patients with spinal cord injuries submitted to rehabilitation program: A clinical and ultrasound based assessment”. Acta Ortop Bras. v.15, p.109-117, 2007. 
NOREAU, L; RICHARDS, C.L.; COMEAU, F.; TARDIF, D. (1995): "Biomechanical analysis of swing-through gait in paraplegic and nondisabled individuals," $J$ Biomech. v.28, p.689-700, 1995.

NSCISC - National Spinal Cord Injury Statistical Center (2006): "Spinal Cord Injury: Facts and Figures at a Glance". University of Alabama at Birminghan. Disponível em: <http://www.spinalcord.uab.edu>. Acesso em: 23/05/2007.

NUSSBAUM, M.A., XUDONG, Z. (2000): "Heuristic for location upper extremity joint centers from a reduced set of surface markers". Human Movement Science. v.19, p.797-816, 2000.

OLSON, W.H. (1998): "Basics Concepts of Medical Instrumentation". In: WEBSTER, J.G. (Eds.). Medical Instrumentation: Application and Design. $3^{\mathfrak{a} e d .}$ New York: John Wiley \& Sons, 1998. Capítulo1, p.1-43. ISBN:0-471-15368-0.

ORTOLAN, R.L., CUNHA, F.L.; CARVALHO, D.C.L.; FRANCA, J.E.M.; MARIA, A.S.L.S.; SILVA, O.L.; CLIQUET JR, A. (2001): "Trends in orthopedic biomechanics applied to rehabilitation". Acta Ortop Bras. ISSN:1413-7852. v.9, n.3, p.44-58, 2001.

ORTOLAN, R.L. (2002): "Estudo e Avaliação de Técnicas de Processamento do Sinal Mioelétrico para o Controle de Sistemas de Reabilitação". 2002. 113p. Dissertação (Mestrado em Eng. Elétrica) - Depto. Eng. Elétrica da Escola de Engenharia de São Carlos, Universidade de São Paulo, São Carlos, (2002).

ORTOLAN, R.L., MORI, R.N., PEREIRA, R.R., CABRAL, C.M.N, PEREIRA, J.C., CLIQUET Jr., A. (2003): "Evaluation of adaptive/nonadaptive filtering and wavelet transform techniques for noise reduction in EMG mobile acquisition equipment". IEEE Trans Neural System and Rehabil Eng. v.11, n.1, p.60-69, 2003.

ORTOLAN, R.L.; ITIKI, C.; CLIQUET Jr, A. (2004): "Análise de parâmetros temporais e espectrais do EMG para classificação de diferentes padrões de contrações". Proceedings of the International Federation for Medical and Biological Eng. ISSN:1727-1983. v.5, p.1151-1154, Set 2004.

ORTOLAN, R.L.; REIS, G.S.; MAGRO, L.S.; KOEKE, P.U.; PARIZOTTO, N.A.; CIQUET Jr., A. (2005): "Tratamento de Terapia Vibratória em Pacientes com Espasticidade". Fisioterapia em Movimento. ISSN: 0103-5150. v.18, n.1, p.67-74, Jan/Mar 2005.

PEROTTO, A.O., (1994): "Anatomical guide for the electromiographer: Limbs \& Trunk". 3rd ed. Charles C Tomas Publisher, Springfield IL, 1994.

PERRY, J. (1992): "Gait Analysis : Normal and Pathological Function". SLACK Incorporated, New Jersey. 556p. 
PERRY, J.; GRONLEY, J.K.; NEWSAM, K.J.; REYES, M.L.; MULROY, S.J.(1996): "Electromyographic analysis of the shoulder muscles during depression transfers in subjects with low-level paraplegia". Arch Phys Med Rehabil. v.77, p.350-355, April 1996.

PERSON, K, (2000): "Teaching the spinal cord to walk". Science magazine. v.279, n.5349, p.319, 2000.

REQUEJO, P.S.; WAHL D.P.; BONTRAGER E.L.; NEWSAM, C.J.; GRONLEY, J.K.; MULROY, S.J. PERRY, J. (2005): "Upper extremity kinetics during lofstrand crutch-assisted gait”. Med Eng Physics. v.27, p.19-29, 2005.

REYES, M.L., GRONLEY, J.K., NEWSAM, C.J., MULROY, S.J. PERRY, J. (1995): "Electromyographic analysis of shoulder muscles of men with low-level paraplegia during a weight relief raise". Arch Phys Med Rehabil. v.76, p.433-439, 1995.

RASCH, P.J. (1991): "Cinesiologia e Anatomia Aplicada". Rio de Janeiro: Editora Guanabara Koogan, 1991. 204p.

ROBERTSON, R.N. ;SHIMADA, S.D.; COOPER, R.A.; ENSMINGER, G. (1995): "Joint kinetics and kinematics for three speeds of wheelchair propulsion". Proceedings of RESNA '95 Annual Conference, Vancouver, BC, June 1995. p:355-357.

ROBERTSON, R.N.; BONINGER, M.L.; COOPER, R.A.; SHIMADA, S.D. (1996): "Pushrim forces and joint kinetics during wheelchair propulsion". Arch Phys Med Rehab. v.77, p.856-864, 1996.

SALISBURY K.S., CHOY, N.L., NITZ, J. (2003): "Shoulder pain, range of motion, and functional motor skills after acute tetraplegia". Arch Phys Med Rehabil. v.84, p.1480-1485, 2003.

SAMUELSSON, K.A.M, TROPP, H., GERDLE., B. (2004): "Shoulder pain and its consequences in paraplegic spinal cord-injured, wheelchair users". Spinal Cord v.42, p. 41-46, 2004.

SARAH - Rede Sarah de Hospitais de Reabilitação [on-line]. Brasília, 2007. "Lesão Medular". Disponível em:<http://www.sarah.br/paginas/doencas/po/index.htm>. Acesso em: 06/05/2007.

SCHANTZ, P.; BJÖRKMAN, P.; SANDERBERG, M.; ANDERSON, E. (1999): "Movement and muscle activity pattern in wheelchair ambulation by persons with para-and tetraplegia". Scand. J. Med. v.31, p.67-76, 1999. 
SENIAM - Surface Electromyography for the Non-Invasive Assessment of Muscles. [on-line]. 2007. "Recommendations: Sensor Placement". Disponível em: <http://www.seniam.org>. Acesso em 08/05/2007.

SIPSKI, M.L., RICHARDS, R.S. (2006): "Spinal cord injury rehabilitation". Am J Med Rehabil. v.85, n.4, p.310-342, 2006.

ULKAR, B; YAVUZER, G. GUNER, R. ERGIN, S. (2003): "Energy expediture of the paraplegic gait: Comparison between different walking aids and normal subjects". Intern J Rehabil Res. v.26, n.3, p.213-217, 2003.

van DRONGELEN, S., van der WOUDE, L.H., JANSSEN, T.W., ANGENOT, E.L., CHADWICK, E.K., VEEGER, D.H. (2005a): "Glenohumeral contact forces and muscle forces evaluated in wheelchair-related activities of daily living in ablebodied subjects versus subjects with paraplegia and tetraplegia." Arch Phys Med Rehabil. v.86, p.1434-1440, 2005.

van DRONGELEN, S.; van der WOUDE, L.H.; JANSSEN, T.W.; ANGENOT, E.L.; CHADWICK, E.K.; VEEGER, D.H. (2005b): "Mechanical load on the upper extremity during wheelchair activities". Arch Phys Med Rehabil. v.86, p.12141220, 2005.

VEEGER, H.E.J.; ROZENDAAL, L.A.; van der HELM, F.C.T. (2002): "Load on the shoulder in low intensity wheelchair propulsion". Clin Biomech. v.17, p.211-218, 2002.

WATERS R.L., MULROY S. (1999): "The energy expenditure of normal and pathologic gait”. Gait Posture. v.9, p.207-231, 1999.

WERNING, A., NANASSY, A., MÜLLER, S. (1998): "Maintenance of locomotor abilities following Laufband (treadmill) therapy in para- and tetraplegic person: follow-up studies". Spinal Cord v.36, p.744-749, 1998.

WINTER, D.A.; ENG, J.J.; ISHAC, J.J. (1996): "Three-dimensional moments, power, and work in normal gait: Implications for clinical assessment," In: HARRIS, G.F.; SMITH, P.A. Human Motion Analysis, Current Applications and Future Directions, Piscataway, NJ: IEEE Press, 1996, p.74-77.

ZATSIORSKY, V.; SELUYANOV, V. (1983): "The mass and inertia characteristics of the main segments of the human body". In: MATSUI, H.; KOBAYASHI, K. (eds). Biomechanics VIII-B. Champaingn, IL: Human Kinetics Publishers, p.1152-1159. 


\section{Apêndice - PACIENTES}

\section{ReSUltados Individuais dos PaCientes ANALISADOS}

Este apêndice apresenta as médias dos resultados de cada paciente analisado durante as atividades executadas. Os exames foram realizados entre 04/09/2006 a 09/09/2006 para os pacientes 1 a 7 e entre 23/01/2007 a 03/02/2007 para os pacientes 8 a 15 .

O conjunto de resultados de cada paciente é constituído por: características do exercício, diagrama do movimento, dados cinéticos (Forças e Torques) e da atividade muscular dos músculos superficiais do ombro durante as atividades executadas.

Os diagramas dos movimentos apresentados são referentes a ultima repetição de cada exercício.

As médias dos dados cinéticos e das atividades musculares entre as repetições de cada exercício são apresentadas em função da porcentagem de execução do exercício. 


\section{A1 - Paciente 1}

\section{A1.1 - Propulsão da Cadeira de Rodas}

Tab. A1.1 - Características dos 3 ciclos iniciais de propulsão da cadeira de rodas

\begin{tabular}{lccc}
\hline & $\begin{array}{c}\text { Tempo } \\
{[\mathrm{s}]}\end{array}$ & $\begin{array}{c}\text { Distância } \\
{[\mathrm{cm}]}\end{array}$ & $\begin{array}{c}\text { Velocidade } \\
{[\mathrm{cm} / \mathrm{s}]}\end{array}$ \\
\hline Média & 3,26 & 67,44 & 20,51 \\
Desvio Padrão & 0,49 & 15,67 & 1,84 \\
\hline
\end{tabular}

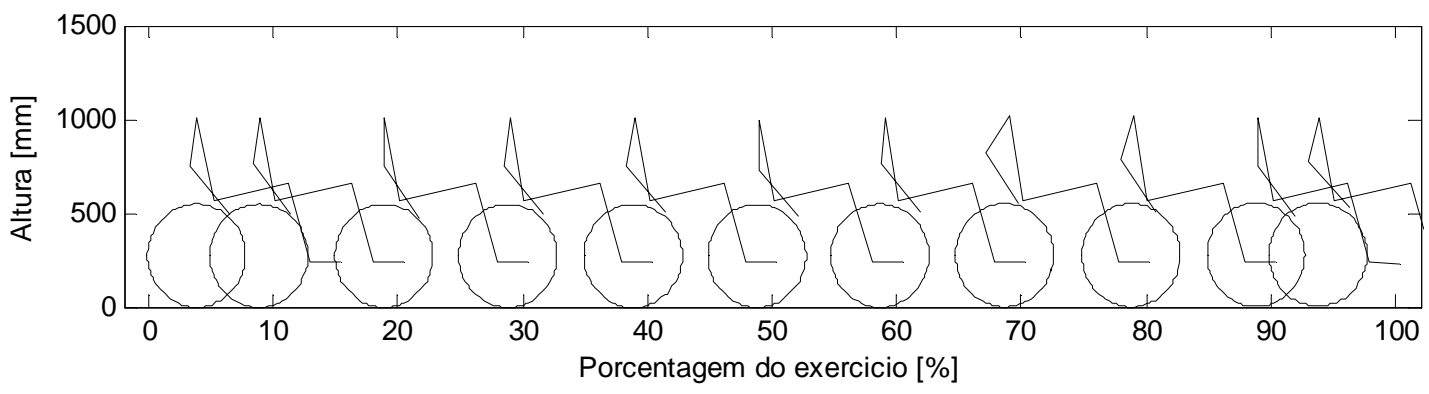

Fig. A1.1 Diagrama do movimento do Paciente 1 durante a Propulsão da Cadeira de Rodas.
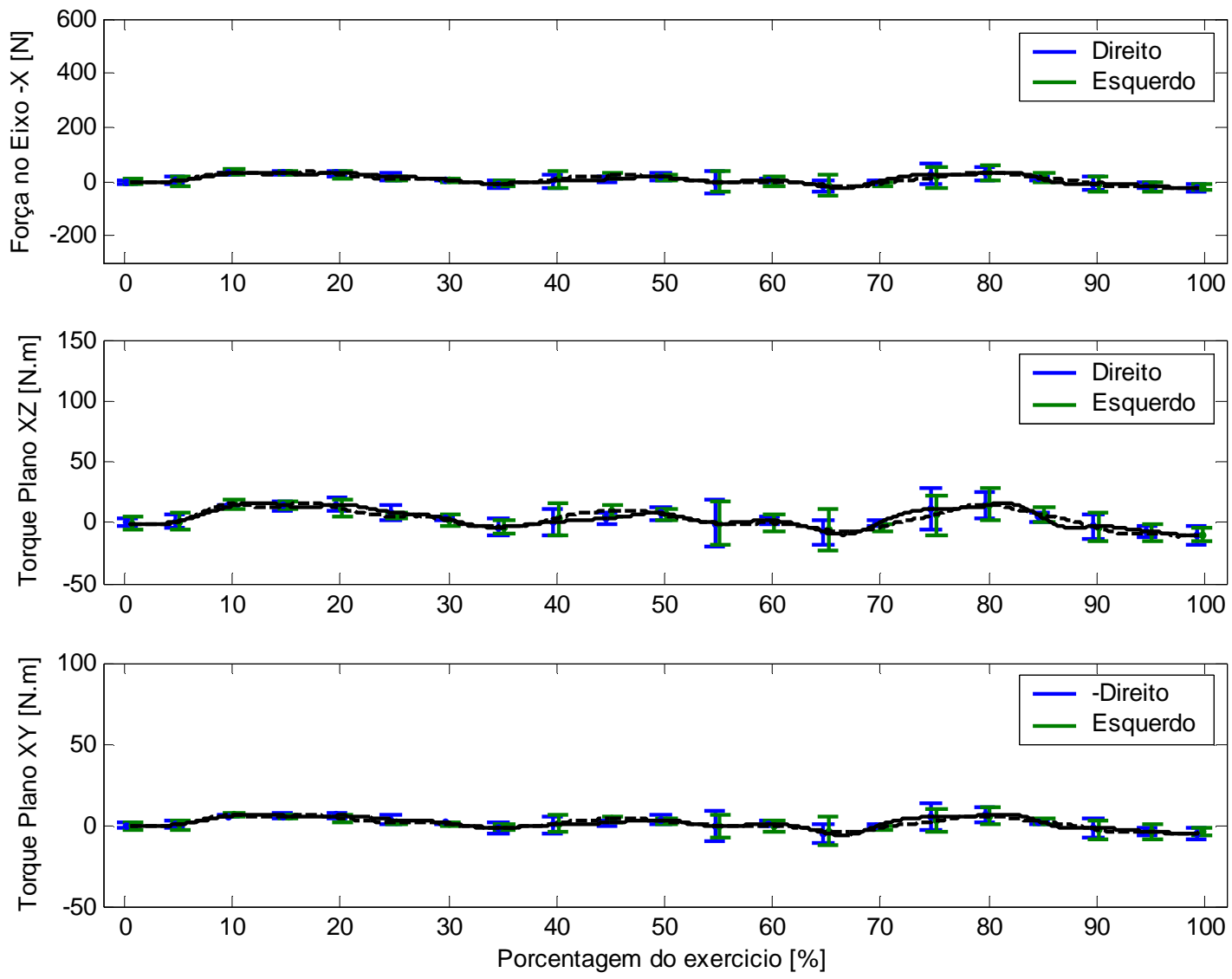

Fig. A1.2 Médias e Desvios Padrões dos Dados Cinéticos do Paciente 1 durante a Propulsão da Cadeira de Rodas. As linhas tracejadas representam as médias do lado esquerdo. 

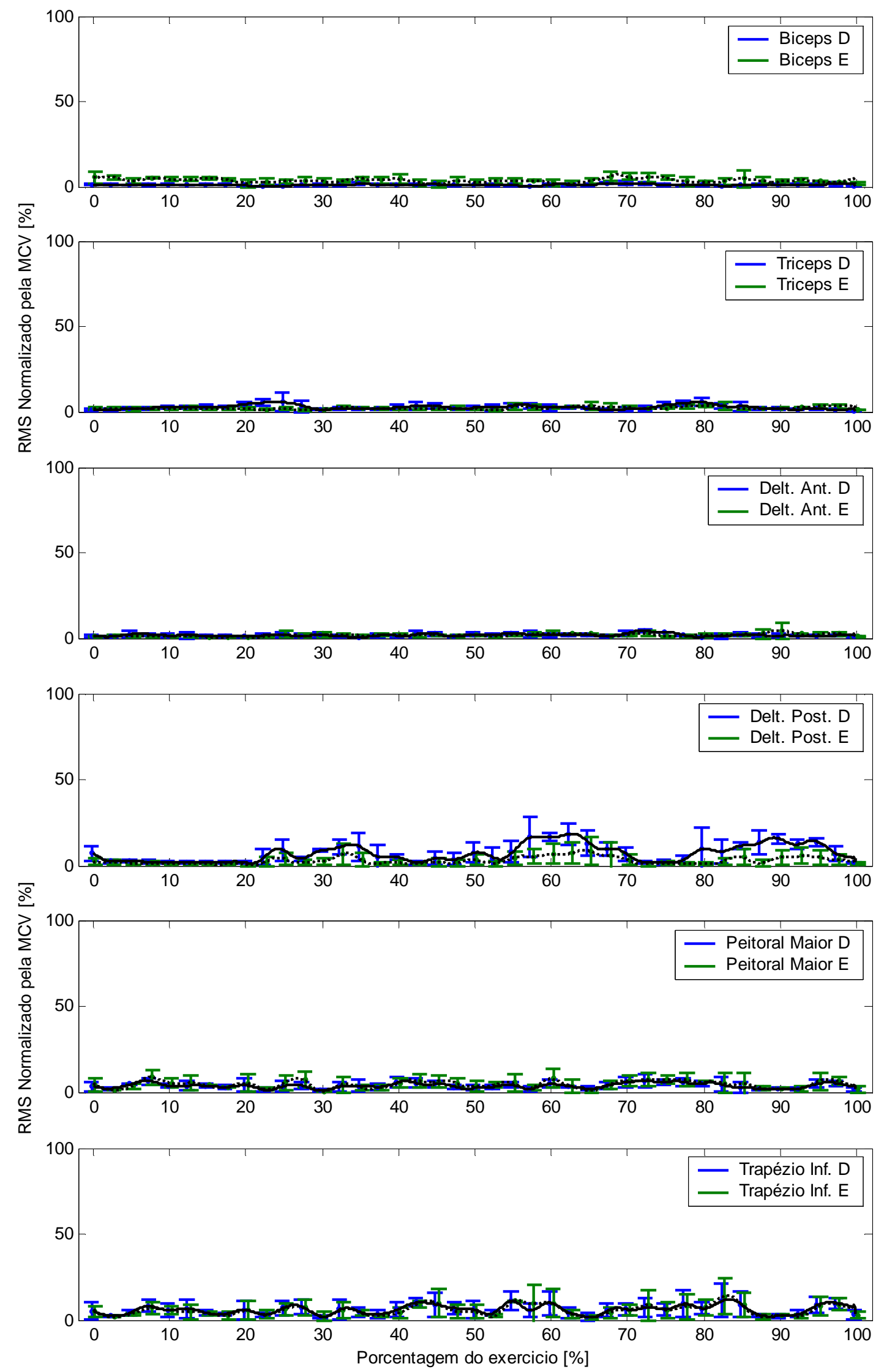

Fig. A1.3 Médias e Desvios Padrões das Atividades Musculares do Paciente 1 durante a Propulsão da Cadeira de Rodas. As linhas tracejadas representam as médias do lado esquerdo. 


\section{A1.2 - Elevação para Alívio da pressão}

Tab. A1.2 - Características da elevação para alívio da pressão

\begin{tabular}{lcc}
\hline & $\begin{array}{c}\text { Tempo } \\
{[\mathrm{s}]}\end{array}$ & $\begin{array}{c}\text { Elevação } \\
{[\mathrm{cm}]}\end{array}$ \\
\hline Média & 5,82 & 16,95 \\
Desvio Padrão & 0,80 & 0,22 \\
\hline
\end{tabular}

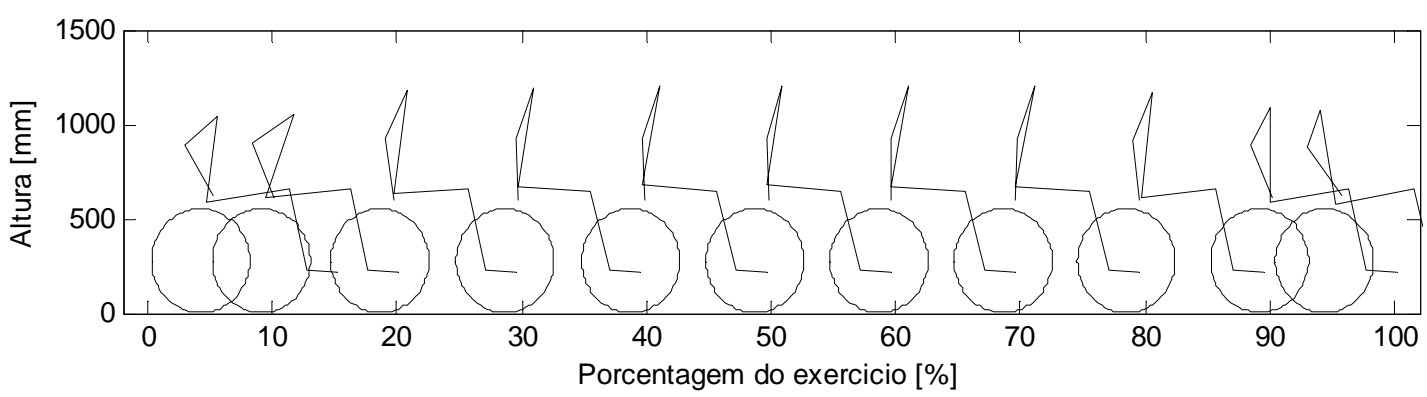

Fig. A1.4 Diagrama do movimento do Paciente 1 durante a Elevação para Alívio da pressão.
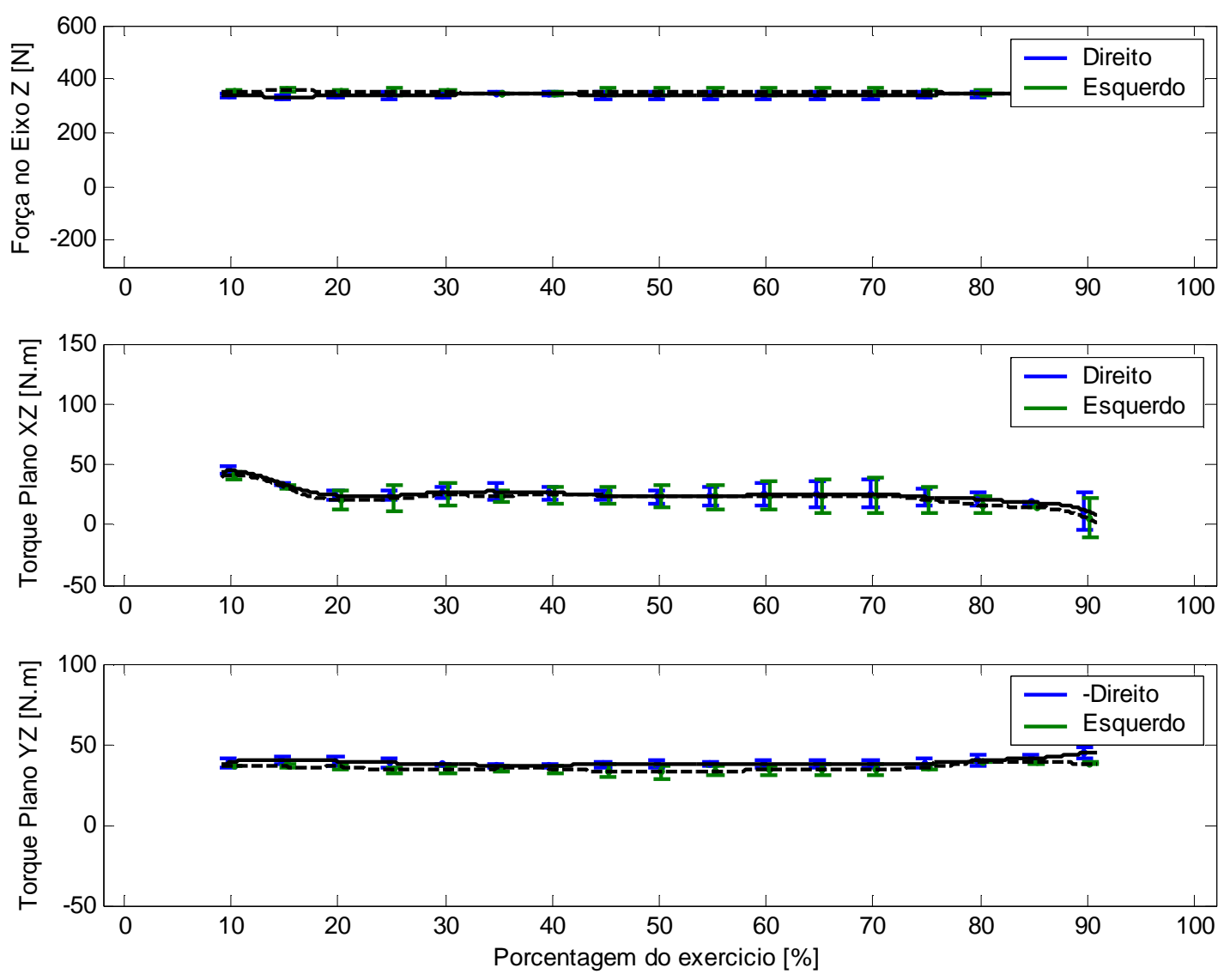

Fig. A1.5 Médias e Desvios Padrões dos Dados Cinéticos do Paciente 1 durante a Elevação para Alívio da pressão. As linhas tracejadas representam as médias do lado esquerdo. 

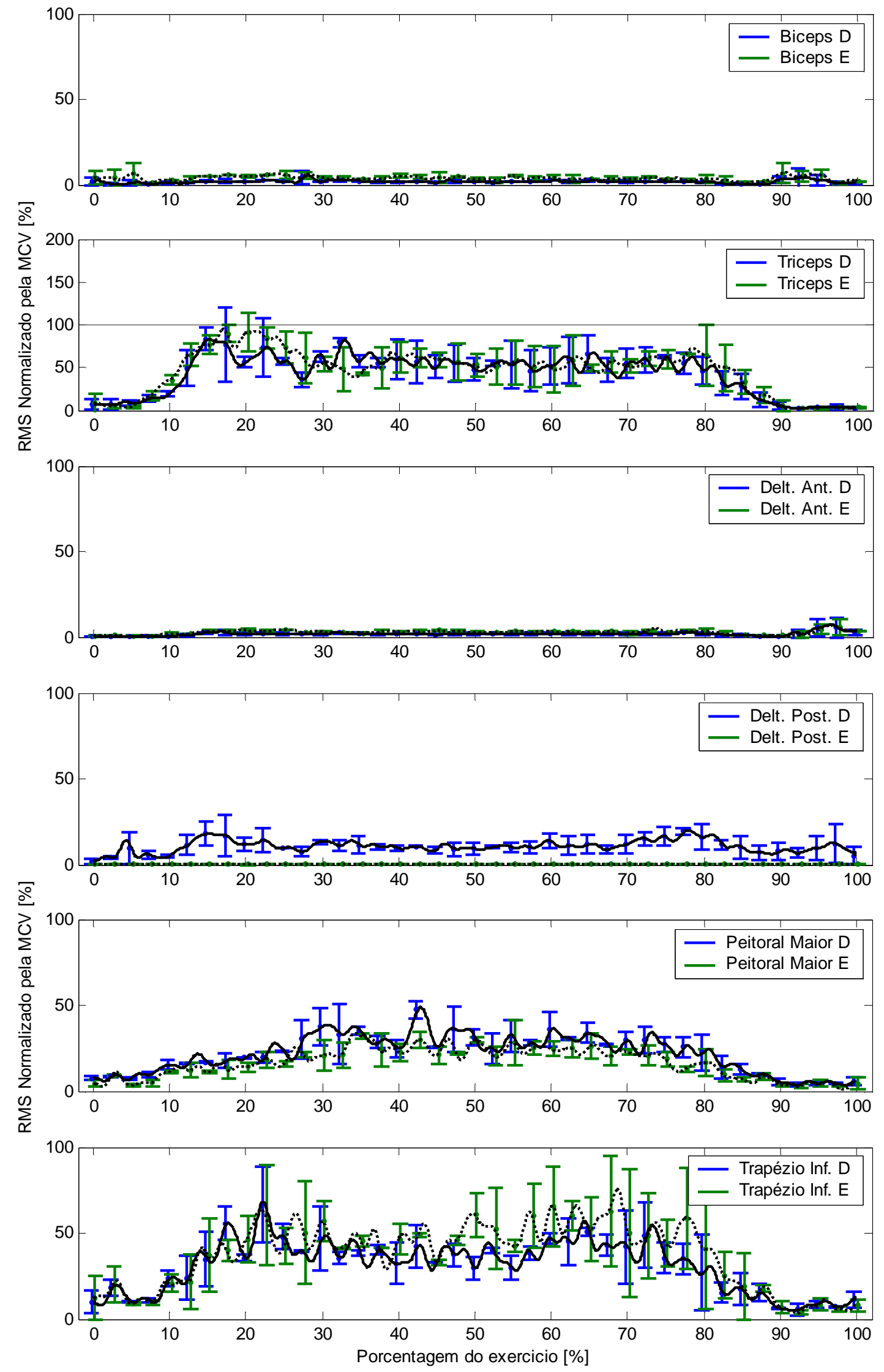

Fig. A1.6 Médias e Desvios Padrões das Atividades Musculares do Paciente 1 durante a Elevação para Alívio da pressão. As linhas tracejadas representam as médias do lado esquerdo. 


\section{A1.3 - MARCHA COM ANDADOR E EENM}

Tab. A1.3 - Características da passada com andador e EENM

\begin{tabular}{lcccc}
\hline & $\begin{array}{c}\text { Tempo } \\
{[\mathrm{s}]}\end{array}$ & $\begin{array}{c}\text { Passada } \\
{[\mathrm{cm}]}\end{array}$ & $\begin{array}{c}\text { Velocidade } \\
{[\mathrm{cm} / \mathrm{s}]}\end{array}$ & $\begin{array}{c}\text { Cadência } \\
\text { [passos/min] }\end{array}$ \\
\hline Média & 7,19 & 52,45 & 7,28 & 16,71 \\
Desvio Padrão & 0,32 & 6,10 & 0,56 & 0,75 \\
\hline
\end{tabular}

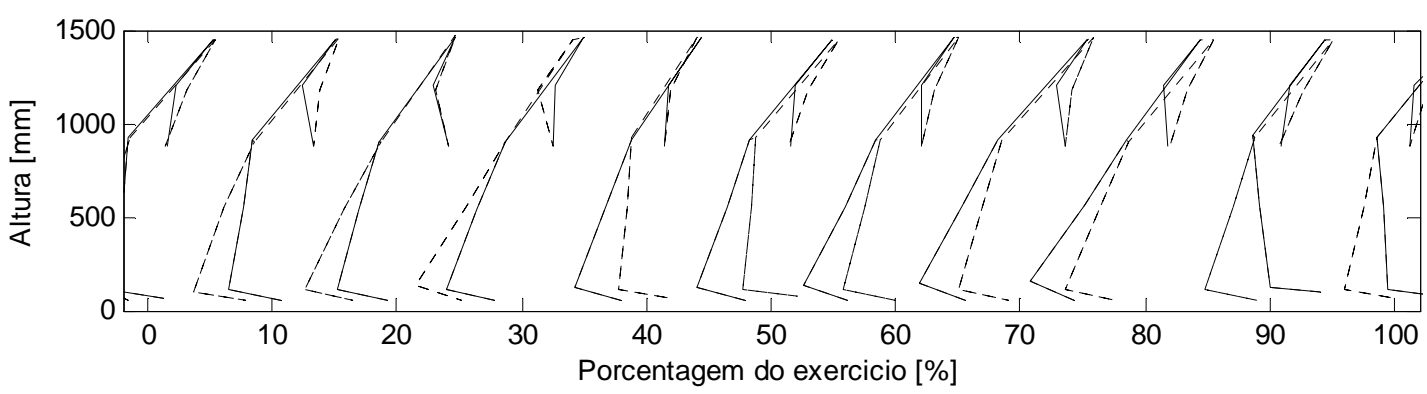

Fig. A1.7 Diagrama do movimento do Paciente 1 durante a Marcha com Andador e EENM.
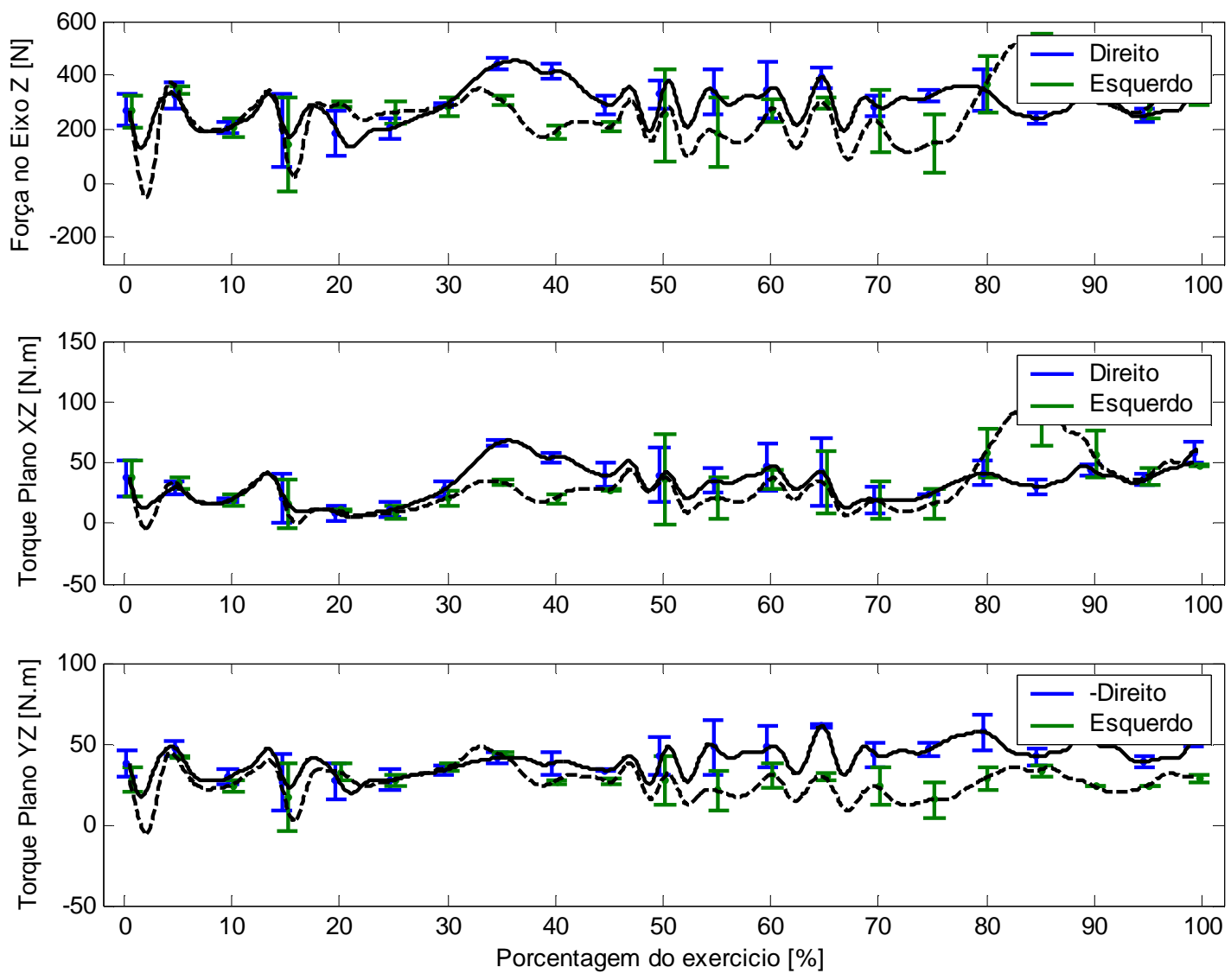

Fig. A1.8 Médias e Desvios Padrões dos Dados Cinéticos do Paciente 1 durante a Marcha com Andador e EENM. As linhas tracejadas representam as médias do lado esquerdo. 

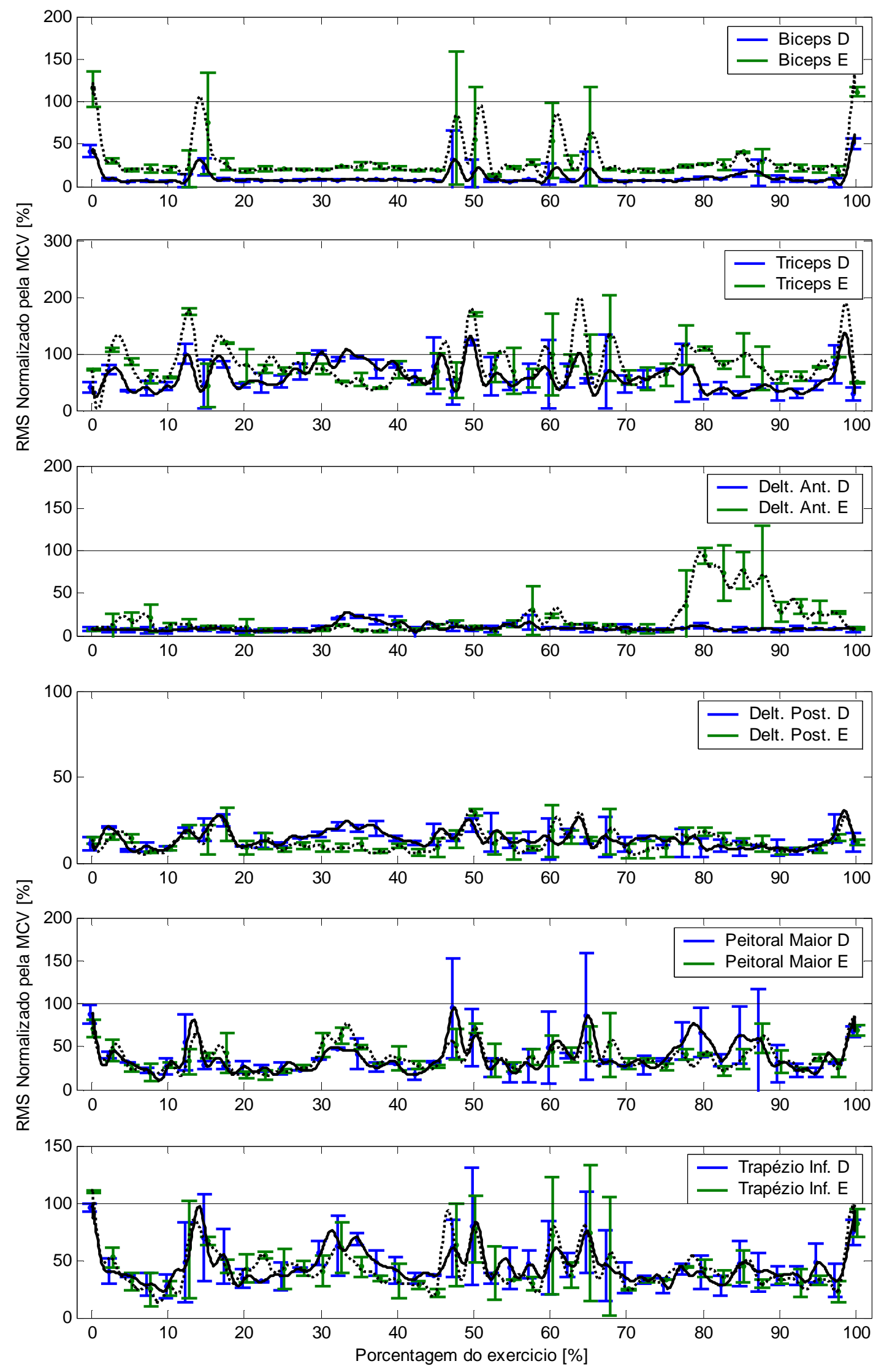

Fig. A1.9 Médias e Desvios Padrões das Atividades Musculares do Paciente 1 durante a Marcha com Andador e EENM. As linhas tracejadas representam as médias do lado esquerdo. 


\section{A2 - Paciente 2}

\section{A2.1 - Propulsão da Cadeira de Rodas}

Tab. A2.1 - Características dos 3 ciclos iniciais de propulsão da cadeira de rodas

\begin{tabular}{lccc}
\hline & $\begin{array}{c}\text { Tempo } \\
{[\mathrm{s}]}\end{array}$ & $\begin{array}{c}\text { Distância } \\
{[\mathrm{cm}]}\end{array}$ & $\begin{array}{c}\text { Velocidade } \\
{[\mathrm{cm} / \mathrm{s}]}\end{array}$ \\
\hline Média & 3,15 & 96,57 & 30,83 \\
Desvio Padrão & 0,33 & 6,89 & 3,51 \\
\hline
\end{tabular}

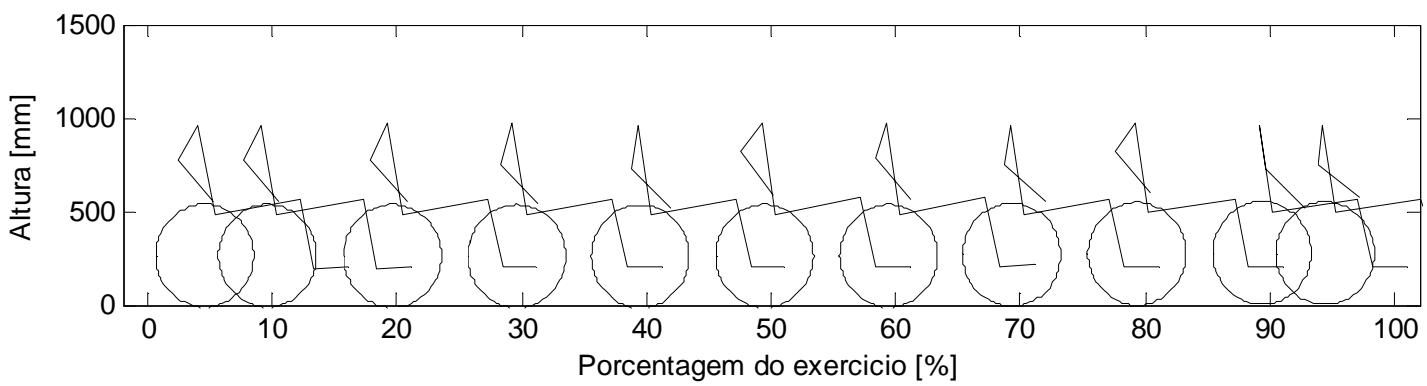

Fig. A2.1 Diagrama do movimento do Paciente 2 durante a Propulsão da Cadeira de Rodas.
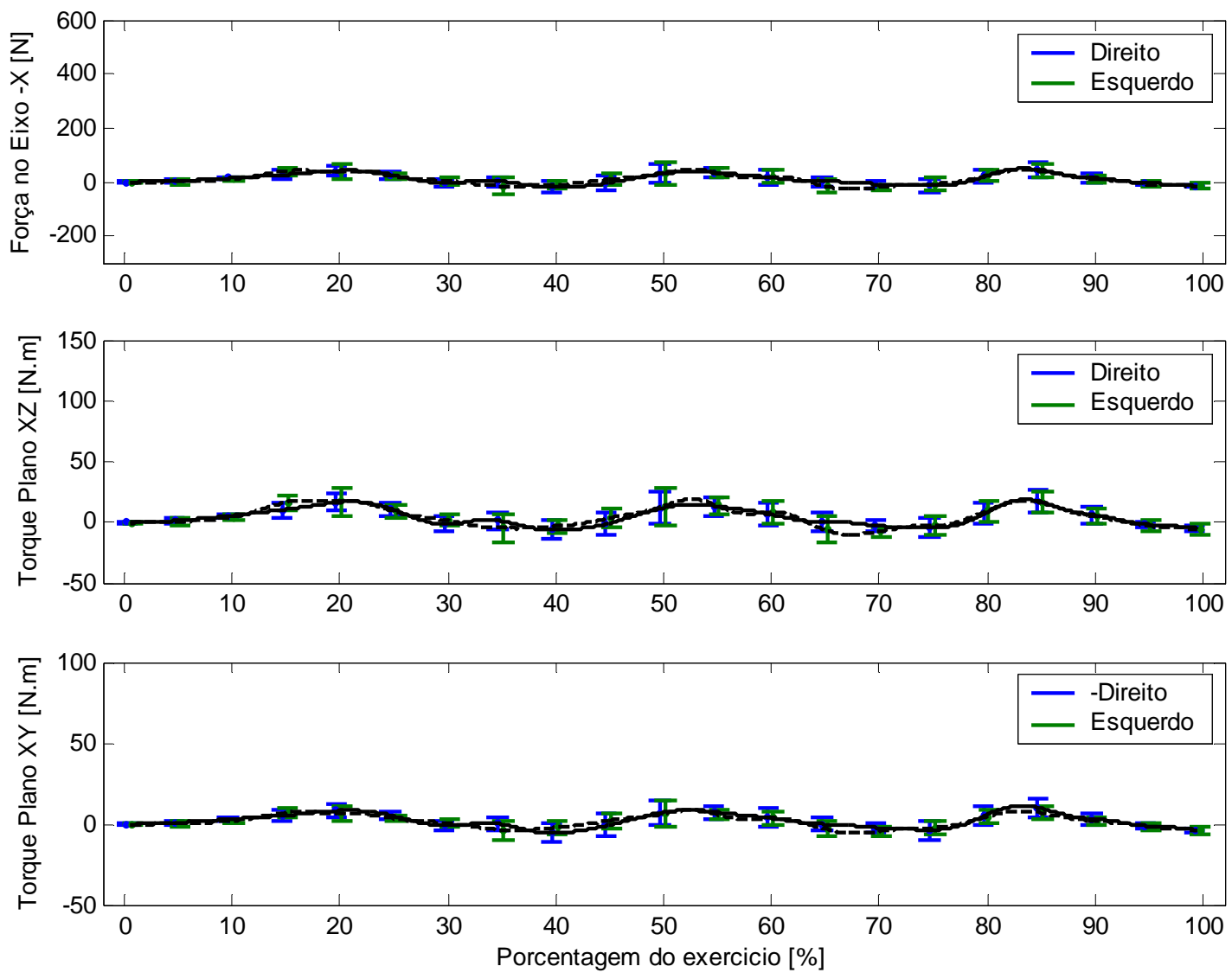

Fig. A2.2 Médias e Desvios Padrões dos Dados Cinéticos do Paciente 2 durante a Propulsão da Cadeira de Rodas. As linhas tracejadas representam as médias do lado esquerdo. 

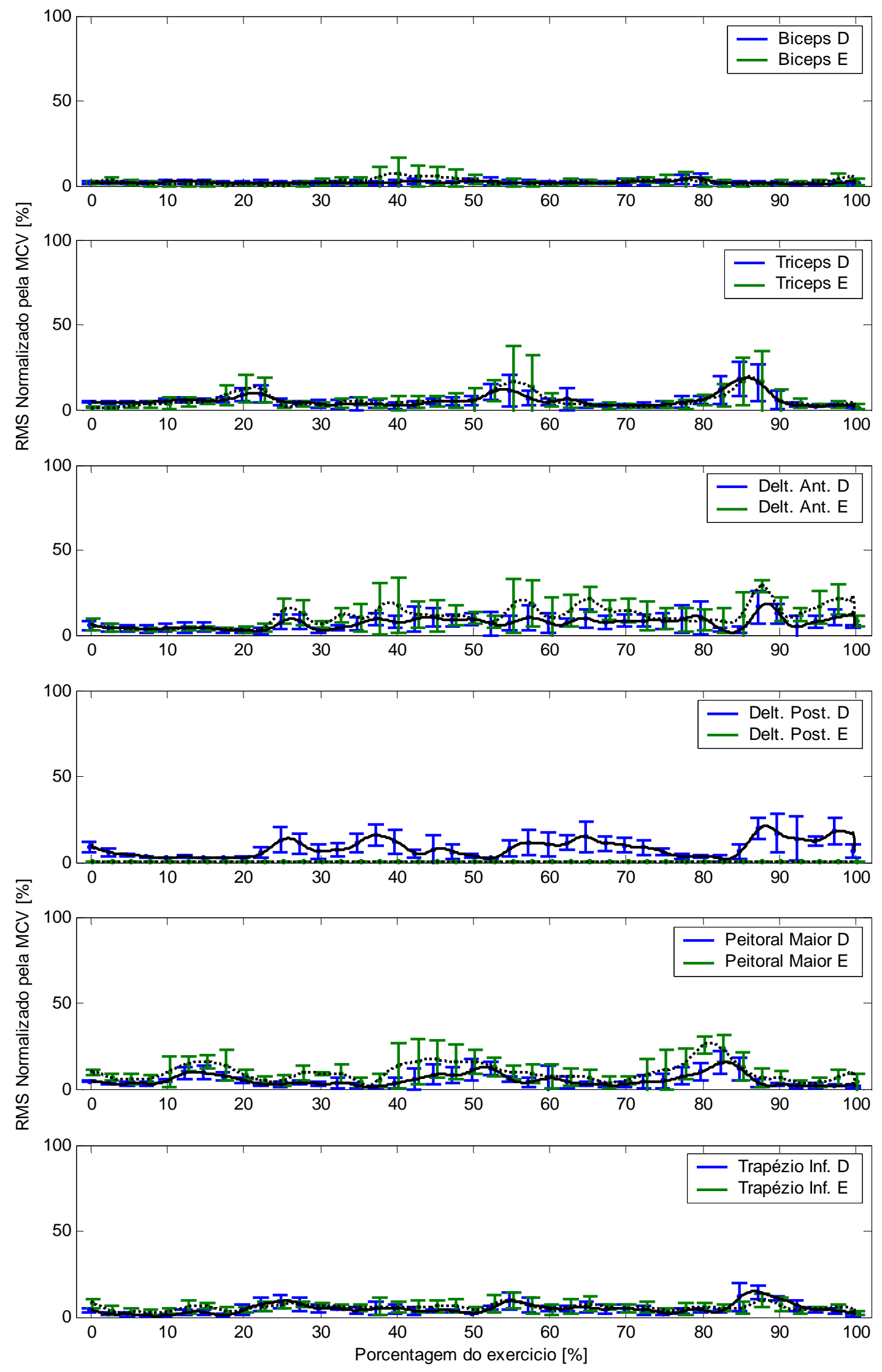

Fig. A2.3 Médias e Desvios Padrões das Atividades Musculares do Paciente 2 durante a Propulsão da Cadeira de Rodas. As linhas tracejadas representam as médias do lado esquerdo. 


\section{A2.2 - Elevação para Alívio da pREssão}

Tab. A2.2 - Características da elevação para alívio da pressão

\begin{tabular}{lcc}
\hline & $\begin{array}{c}\text { Tempo } \\
{[\mathrm{s}]}\end{array}$ & $\begin{array}{c}\text { Elevação } \\
{[\mathrm{cm}]}\end{array}$ \\
\hline Média & 7,12 & 26,39 \\
Desvio Padrão & 0,05 & 0,96 \\
\hline
\end{tabular}

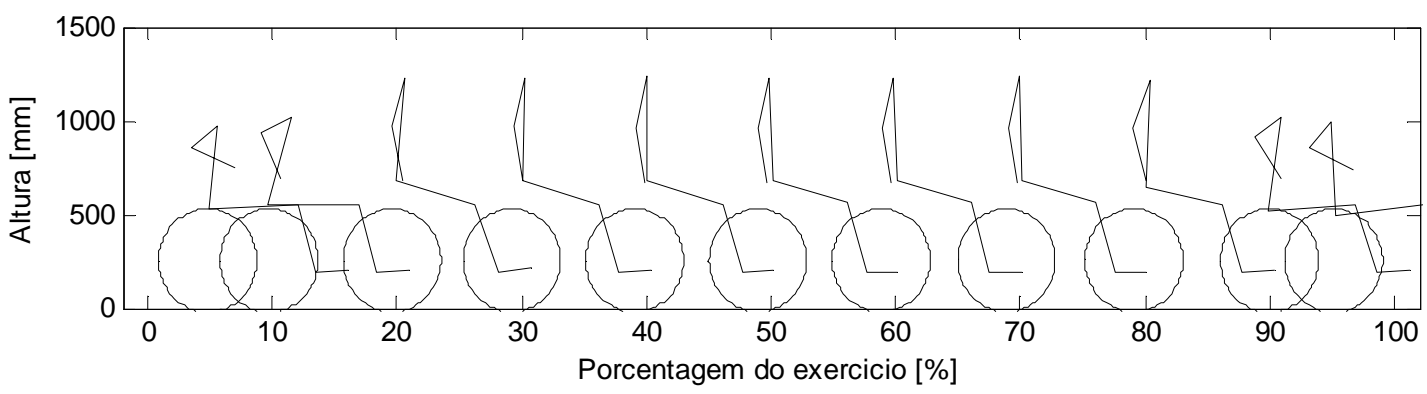

Fig. A2.4 Diagrama do movimento do Paciente 2 durante a Elevação para Alívio da pressão.
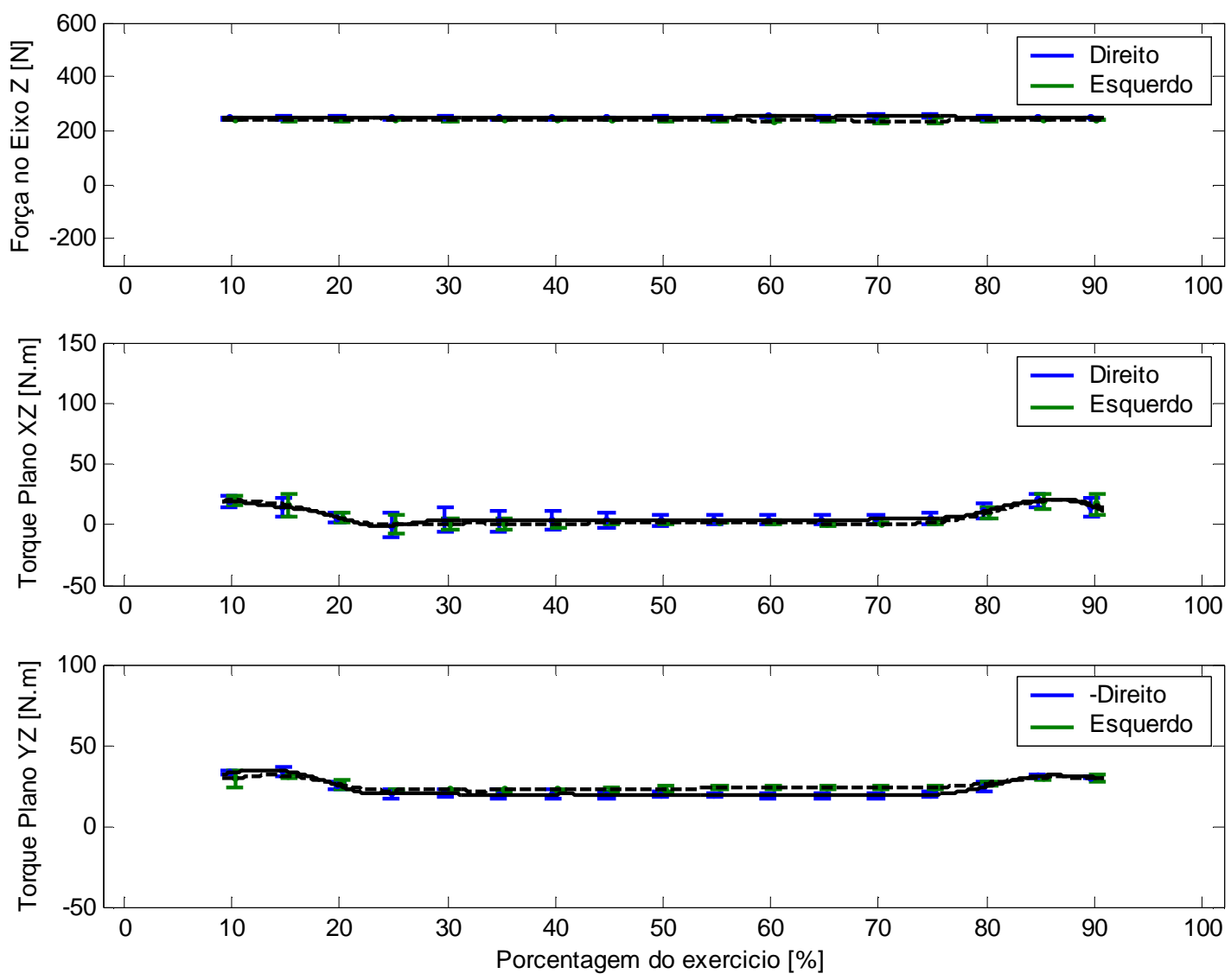

Fig. A2.5 Médias e Desvios Padrões dos Dados Cinéticos do Paciente 2 durante a Elevação para Alívio da pressão. As linhas tracejadas representam as médias do lado esquerdo. 

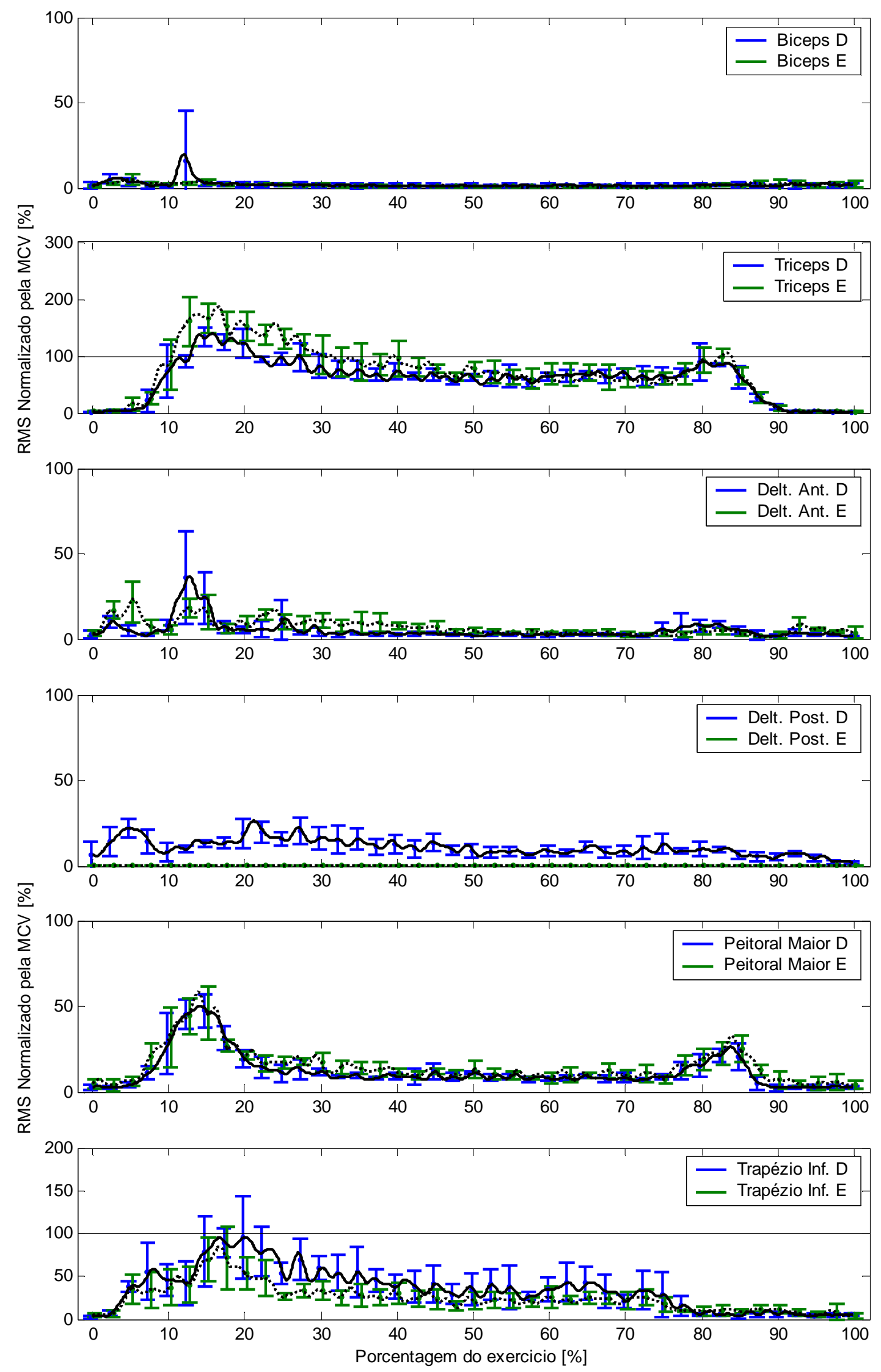

Fig. A2.6 Médias e Desvios Padrões das Atividades Musculares do Paciente 2 durante a Elevação para Alívio da pressão. As linhas tracejadas representam as médias do lado esquerdo. 


\section{A2.3 - MARCHA COM ANDADOR E EENM}

Tab. A2.3 - Características da passada com andador e EENM

\begin{tabular}{lcccc}
\hline & $\begin{array}{c}\text { Tempo } \\
{[\mathrm{s}]}\end{array}$ & $\begin{array}{c}\text { Passada } \\
{[\mathrm{cm}]}\end{array}$ & $\begin{array}{c}\text { Velocidade } \\
{[\mathrm{cm} / \mathrm{s}]}\end{array}$ & $\begin{array}{c}\text { Cadência } \\
\text { [passos/min] }\end{array}$ \\
\hline Média & 7,65 & 62,36 & 8,20 & 15,77 \\
Desvio Padrão & 0,59 & 9,85 & 1,53 & 1,24 \\
\hline
\end{tabular}

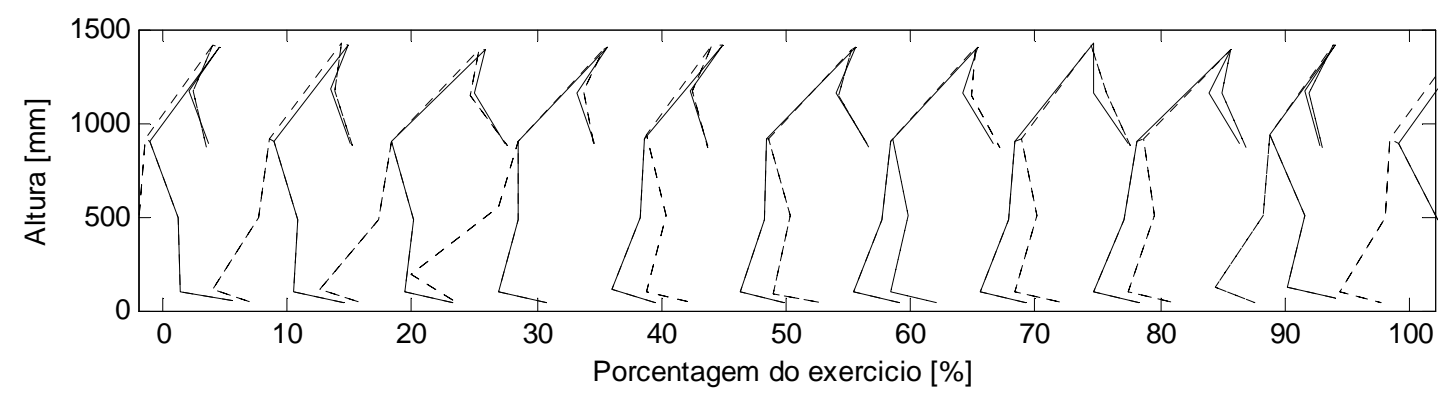

Fig. A2.7 Diagrama do movimento do Paciente 2 durante a Marcha com Andador e EENM.
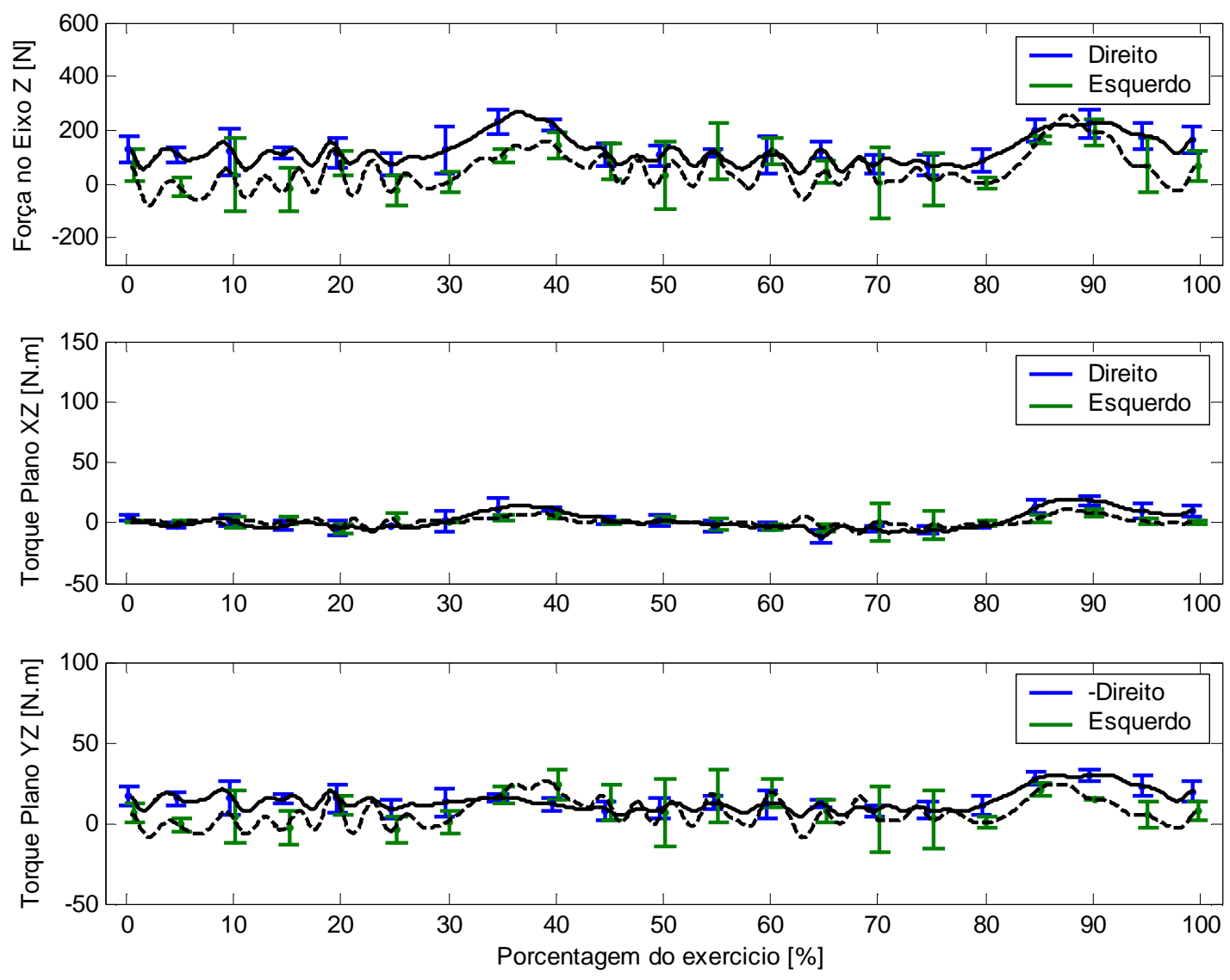

Fig. A2.8 Médias e Desvios Padrões dos Dados Cinéticos do Paciente 2 durante a Marcha com Andador e EENM. As linhas tracejadas representam as médias do lado esquerdo. 

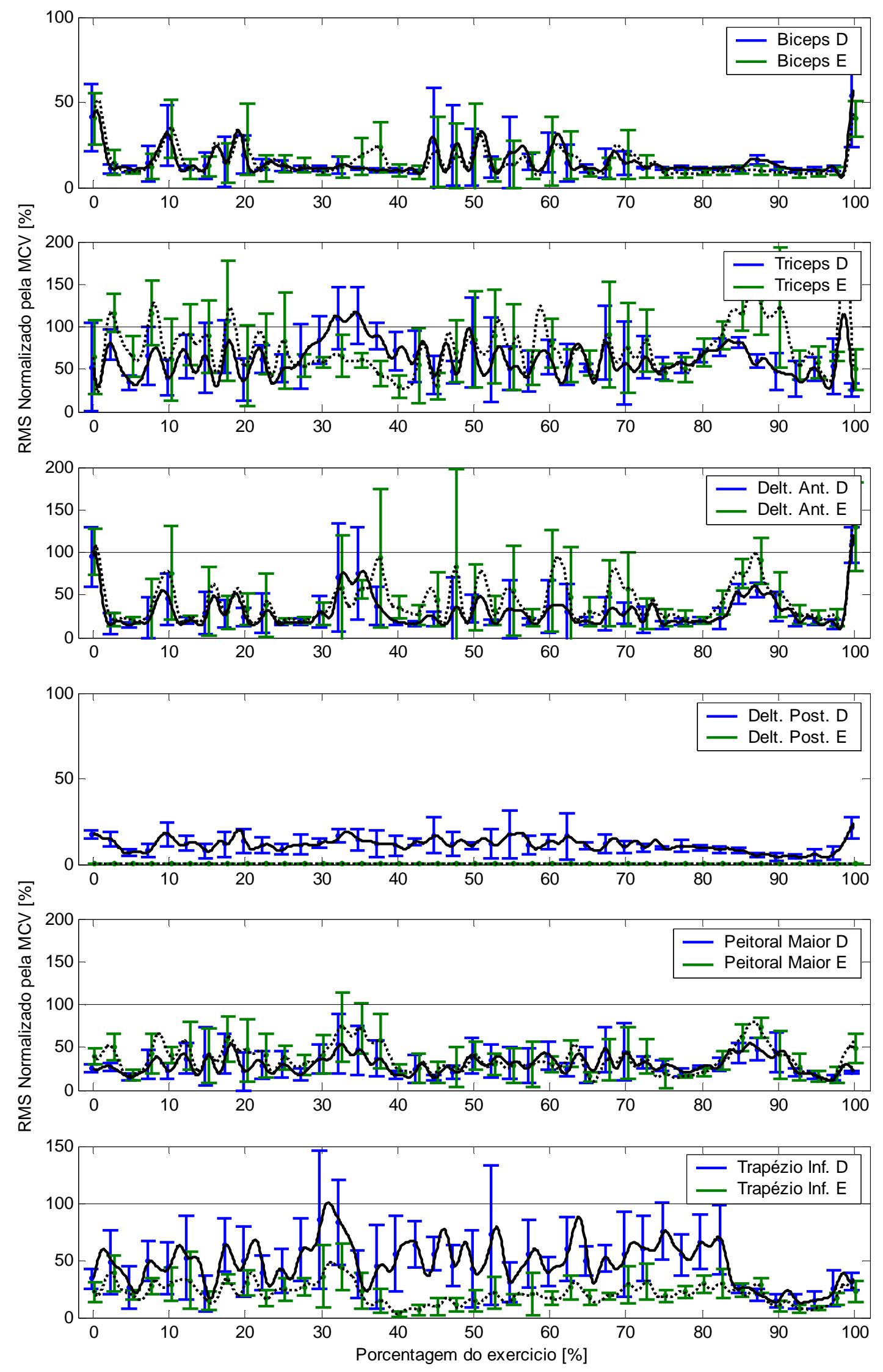

Fig. A2.9 Médias e Desvios Padrões das Atividades Musculares do Paciente 2 durante a Marcha com Andador e EENM. As linhas tracejadas representam as médias do lado esquerdo. 


\section{A3 - Paciente 3}

\section{A3.1 - Propulsão da Cadeira de Rodas}

Tab. A3.1 - Características dos 3 ciclos iniciais de propulsão da cadeira de rodas

\begin{tabular}{lccc}
\hline & $\begin{array}{c}\text { Tempo } \\
{[\mathrm{s}]}\end{array}$ & $\begin{array}{c}\text { Distância } \\
{[\mathrm{cm}]}\end{array}$ & $\begin{array}{c}\text { Velocidade } \\
{[\mathrm{cm} / \mathrm{s}]}\end{array}$ \\
\hline Média & 3,34 & 112,68 & 33,93 \\
Desvio Padrão & 0,21 & 19,67 & 6,76 \\
\hline
\end{tabular}

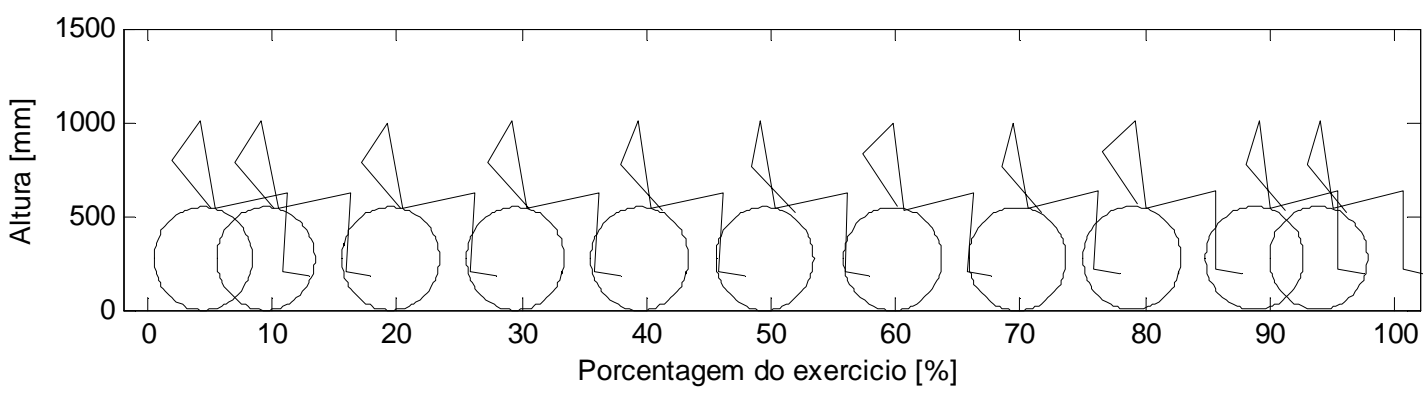

Fig. A3.1 Diagrama do movimento do Paciente 3 durante a Propulsão da Cadeira de Rodas.
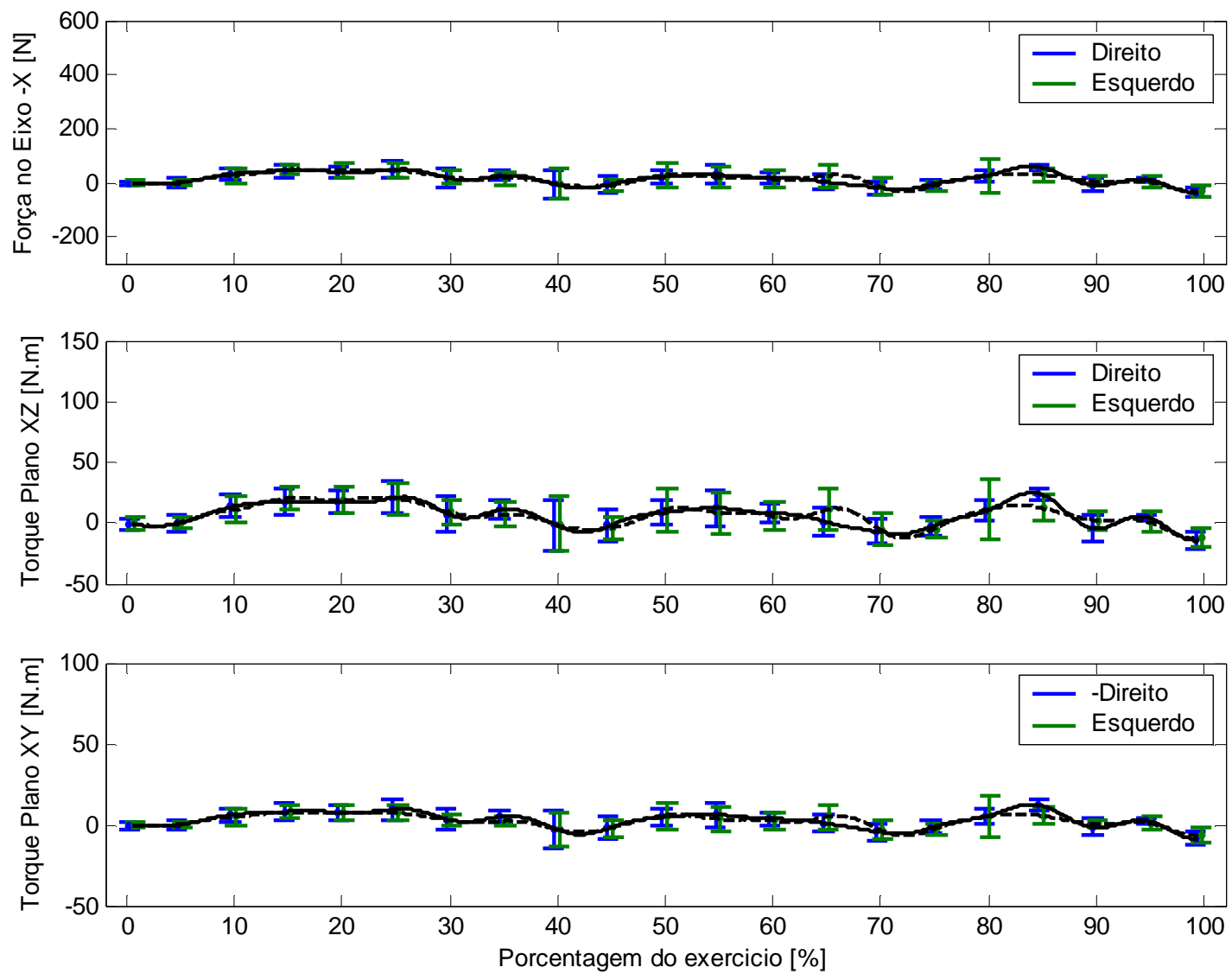

Fig. A3.2 Médias e Desvios Padrões dos Dados Cinéticos do Paciente 3 durante a Propulsão da Cadeira de Rodas. As linhas tracejadas representam as médias do lado esquerdo. 

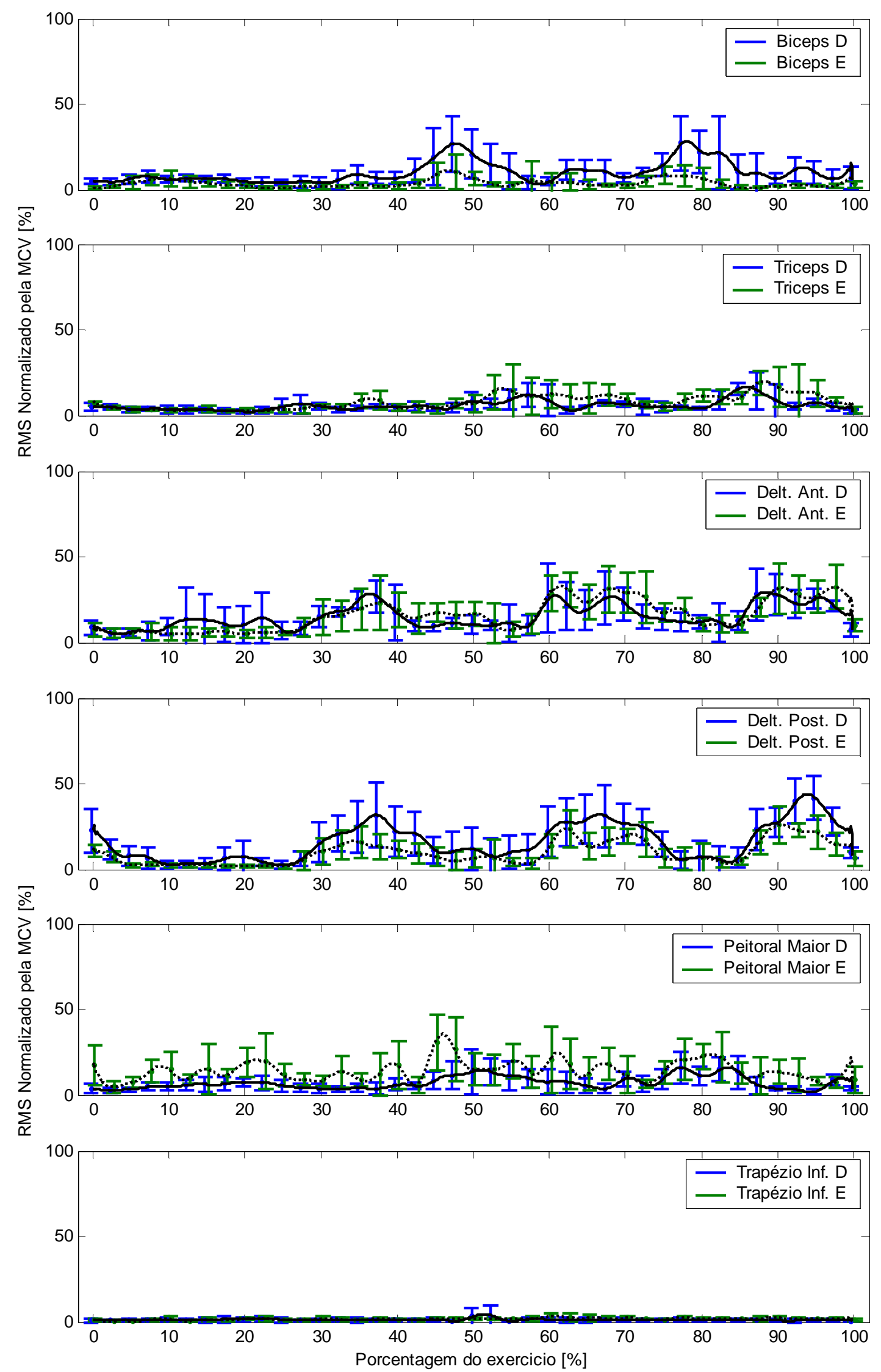

Fig. A3.3 Médias e Desvios Padrões das Atividades Musculares do Paciente 3 durante a Propulsão da Cadeira de Rodas. As linhas tracejadas representam as médias do lado esquerdo. 


\section{A3.2 - Elevação para Alívio da PRESsão}

Tab. A3.2 - Características da elevação para alívio da pressão

\begin{tabular}{lcc}
\hline & $\begin{array}{c}\text { Tempo } \\
{[\mathrm{s}]}\end{array}$ & $\begin{array}{c}\text { Elevação } \\
{[\mathrm{cm}]}\end{array}$ \\
\hline Média & 6,92 & 17,86 \\
Desvio Padrão & 0,70 & 0,96 \\
\hline
\end{tabular}

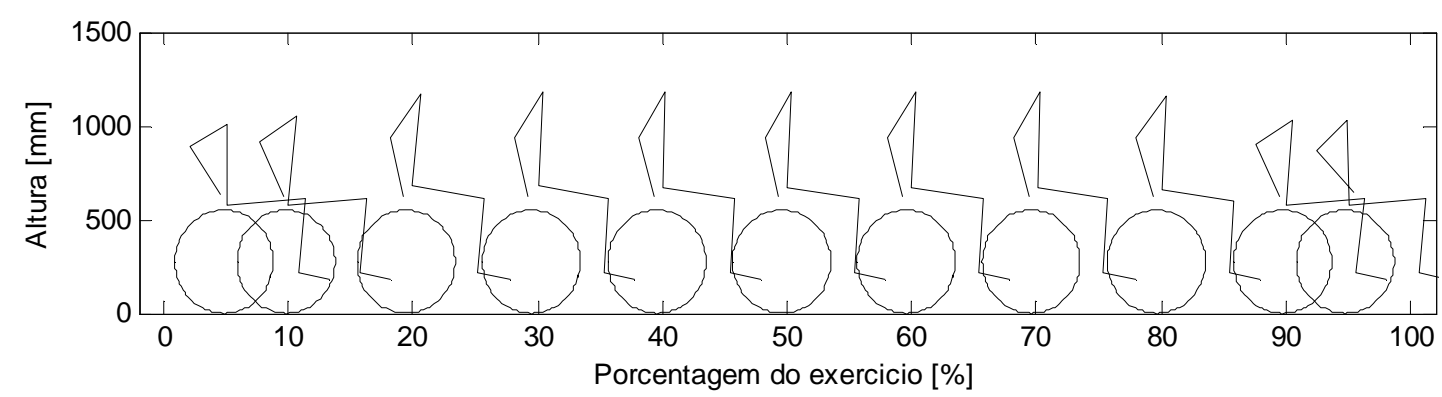

Fig. A3.4 Diagrama do movimento do Paciente 3 durante a Elevação para Alívio da pressão.
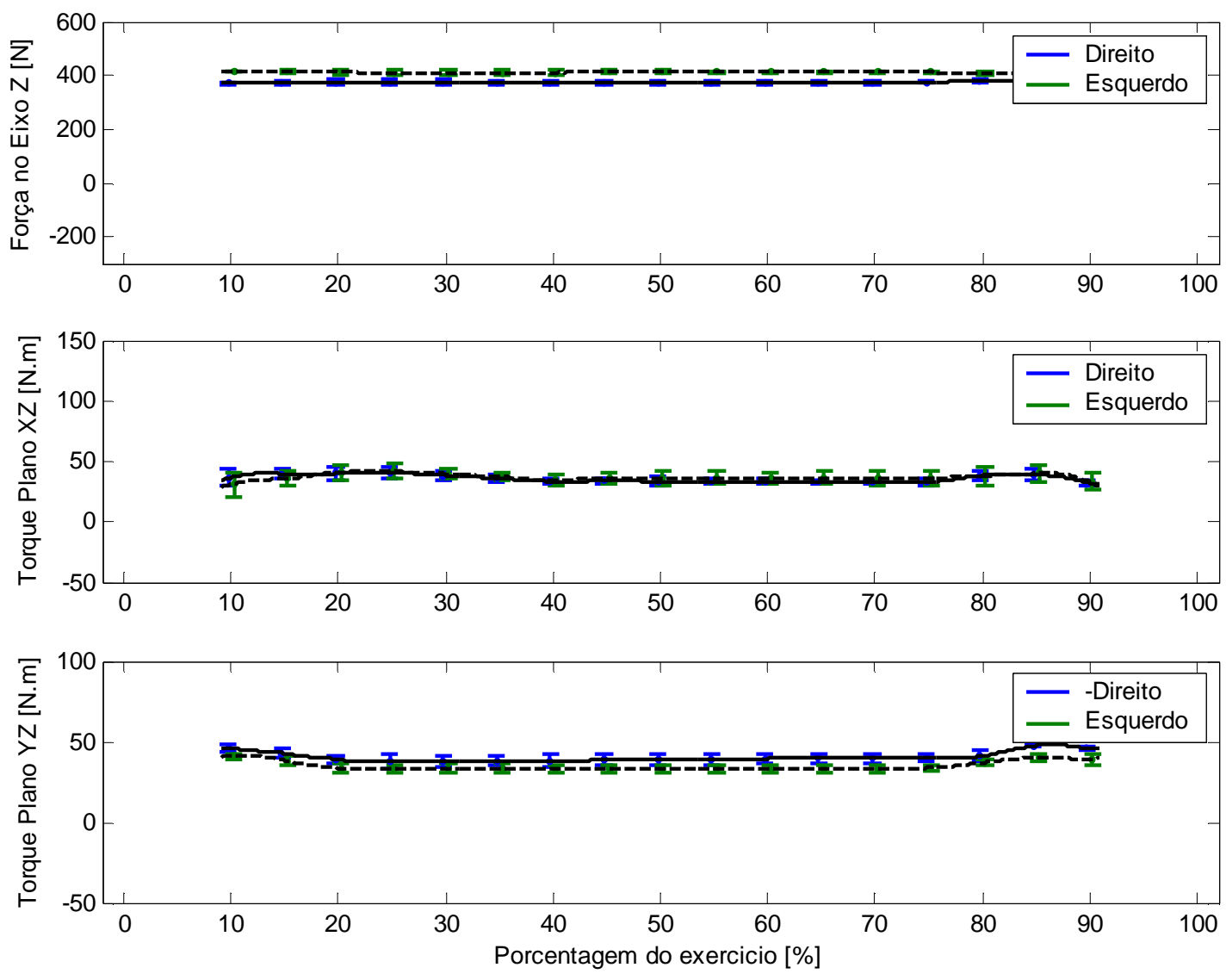

Fig. A3.5 Médias e Desvios Padrões dos Dados Cinéticos do Paciente 3 durante a Elevação para Alívio da pressão. As linhas tracejadas representam as médias do lado esquerdo. 

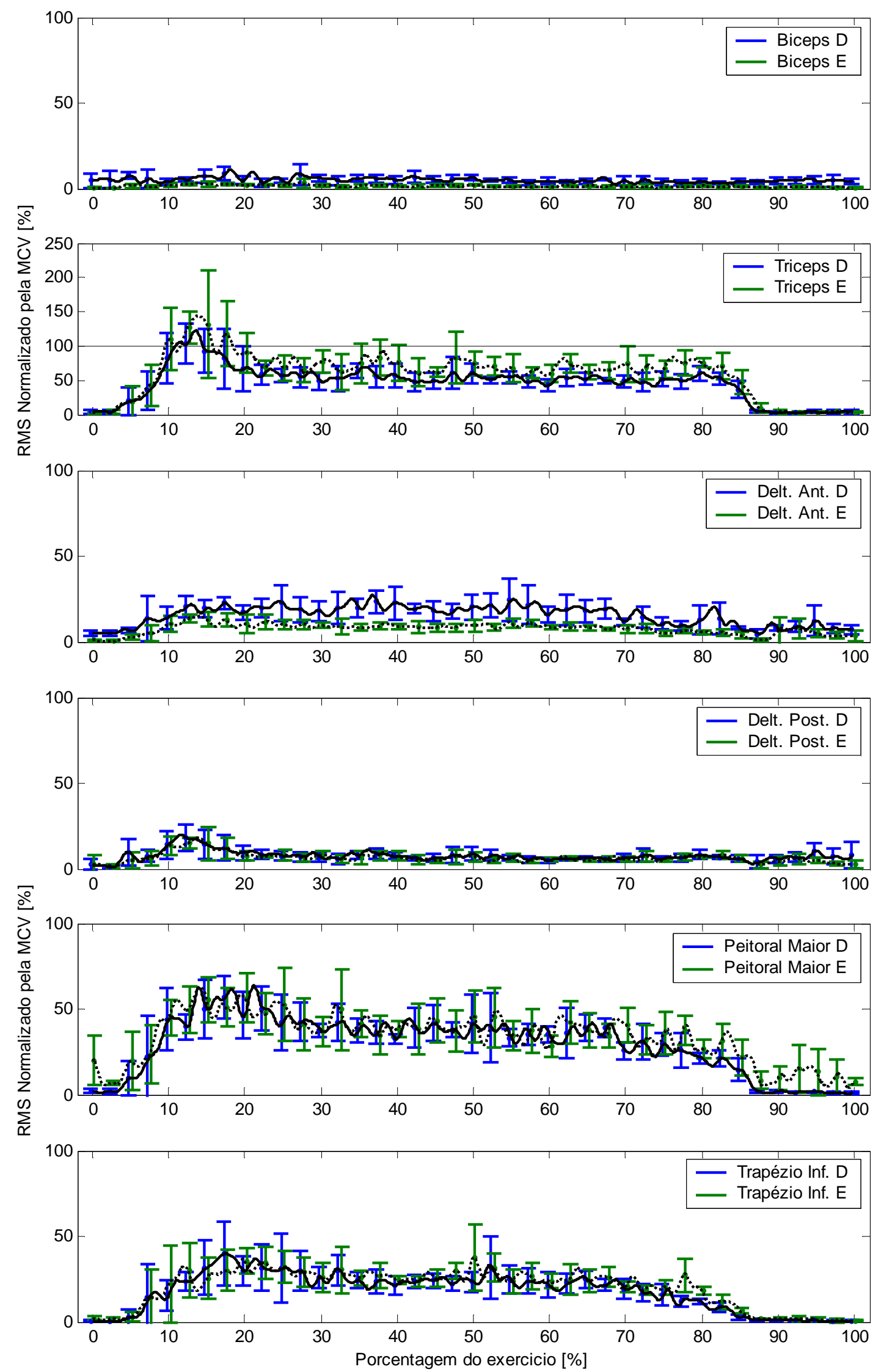

Fig. A3.6 Médias e Desvios Padrões das Atividades Musculares do Paciente 3 durante a Elevação para Alívio da pressão. As linhas tracejadas representam as médias do lado esquerdo. 


\section{A4.1 - PROPUlsão da CADEIRA de Rodas}

Tab. A4.1 - Características dos 3 ciclos iniciais de propulsão da cadeira de rodas

\begin{tabular}{lccc}
\hline & $\begin{array}{c}\text { Tempo } \\
{[\mathrm{s}]}\end{array}$ & $\begin{array}{c}\text { Distância } \\
{[\mathrm{cm}]}\end{array}$ & $\begin{array}{c}\text { Velocidade } \\
{[\mathrm{cm} / \mathrm{s}]}\end{array}$ \\
\hline Média & 3,48 & 100,90 & 29,18 \\
Desvio Padrão & 0,49 & 11,54 & 2,87 \\
\hline
\end{tabular}

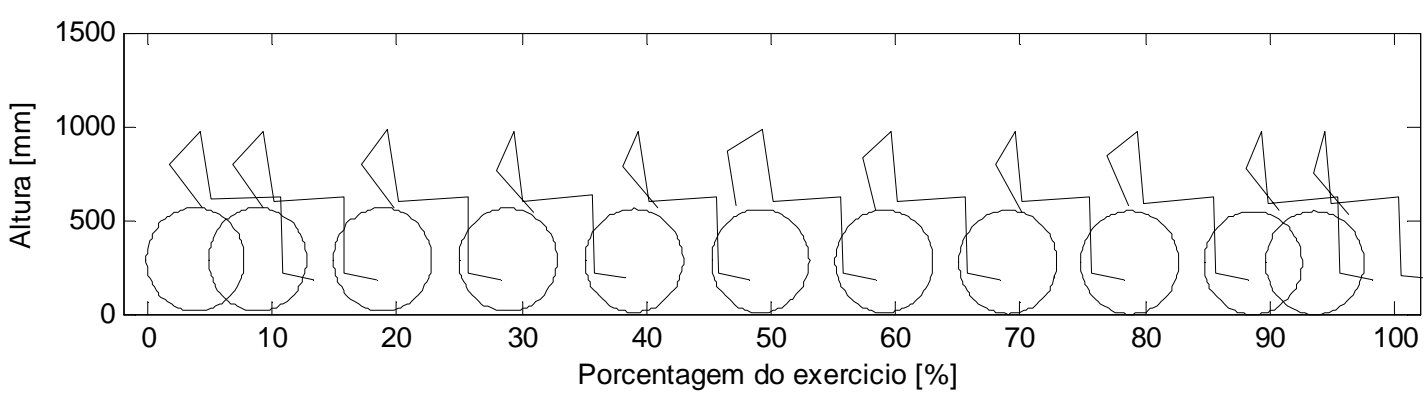

Fig. A4.1 Diagrama do movimento do Paciente 4 durante a Propulsão da Cadeira de Rodas.
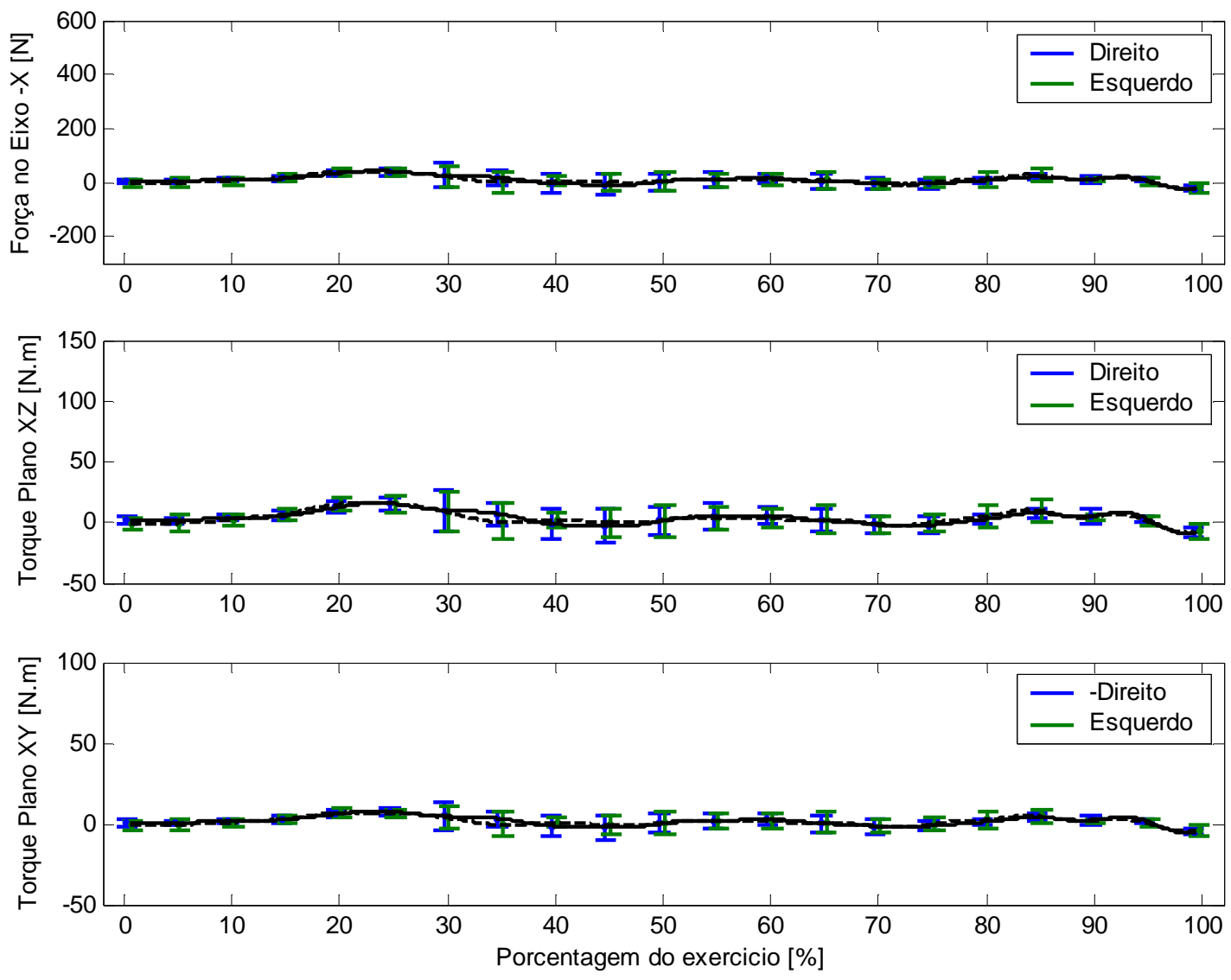

Fig. A4.2 Médias e Desvios Padrões dos Dados Cinéticos do Paciente 4 durante a Propulsão da Cadeira de Rodas. As linhas tracejadas representam as médias do lado esquerdo. 

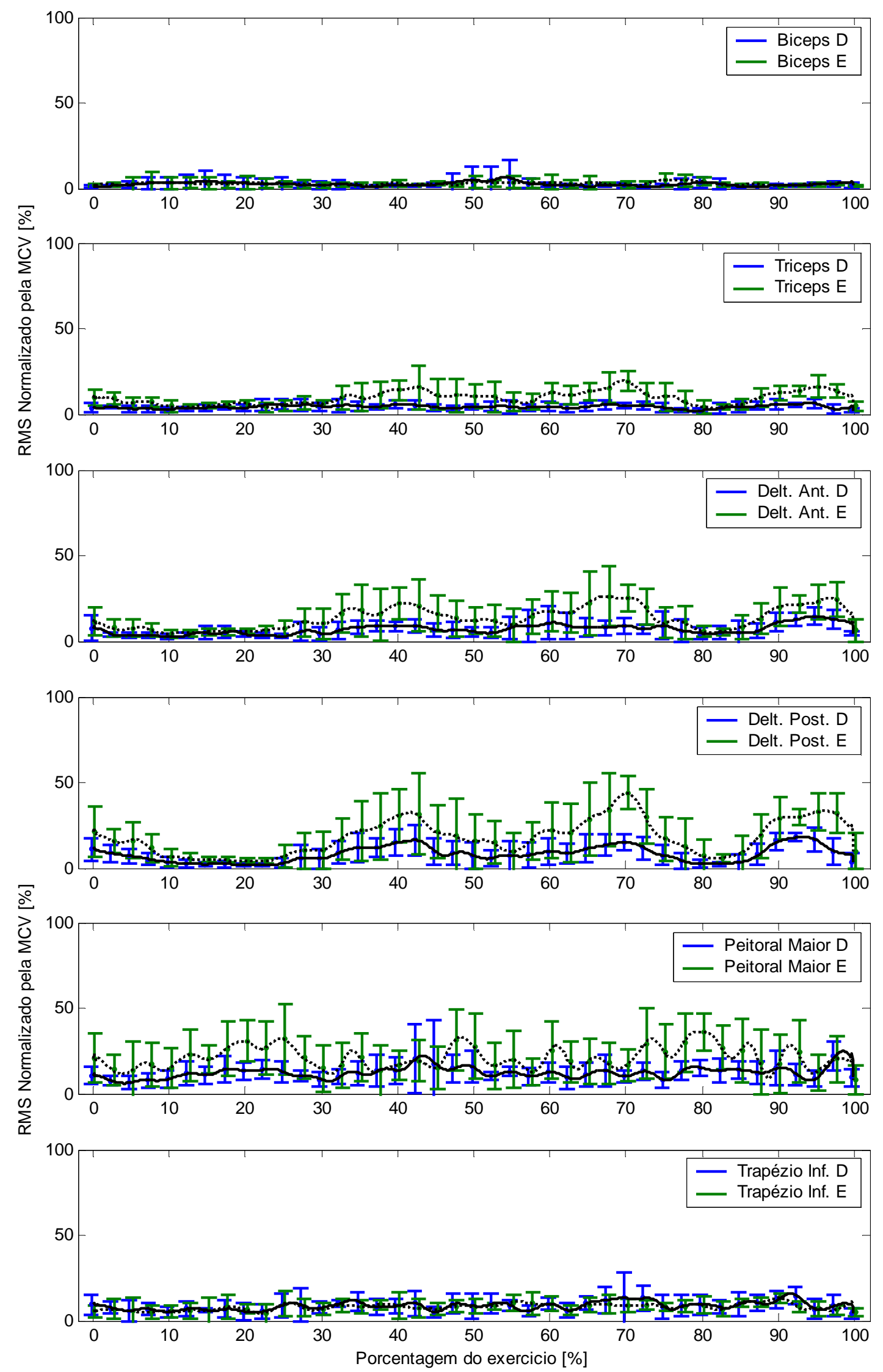

Fig. A4.3 Médias e Desvios Padrões das Atividades Musculares do Paciente 4 durante a Propulsão da Cadeira de Rodas. As linhas tracejadas representam as médias do lado esquerdo. 


\section{A4.2 - Elevação para Alívio da PRESsão}

Tab. A4.2 - Características da elevação para alívio da pressão

\begin{tabular}{lcc}
\hline & Tempo & Elevação \\
& {$[\mathrm{s}]$} & {$[\mathrm{cm}]$} \\
Média & 5,35 & 12,31 \\
Desvio Padrão & 0,37 & 1,88 \\
\hline
\end{tabular}

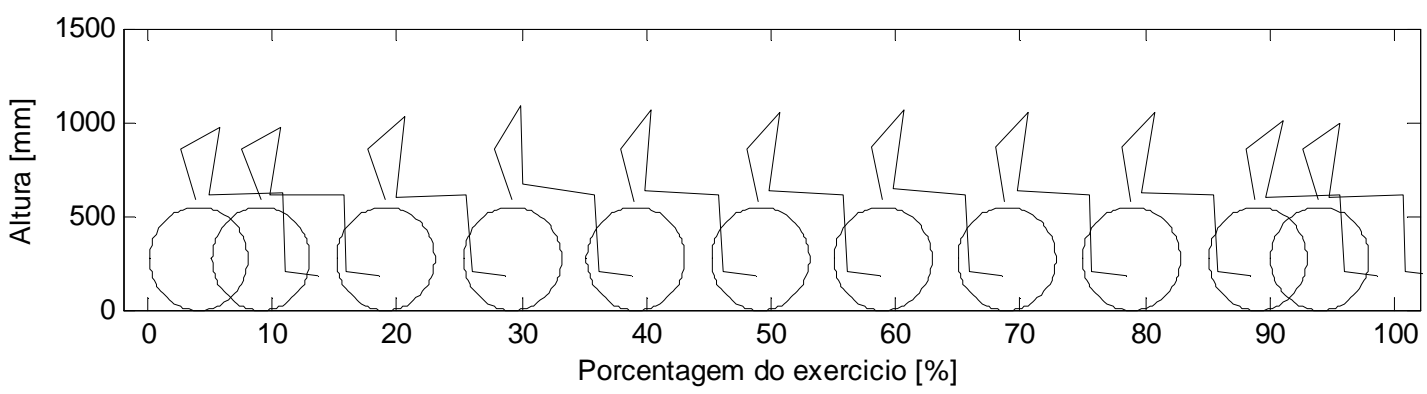

Fig. A4.4 Diagrama do movimento do Paciente 4 durante a Elevação para Alívio da pressão.
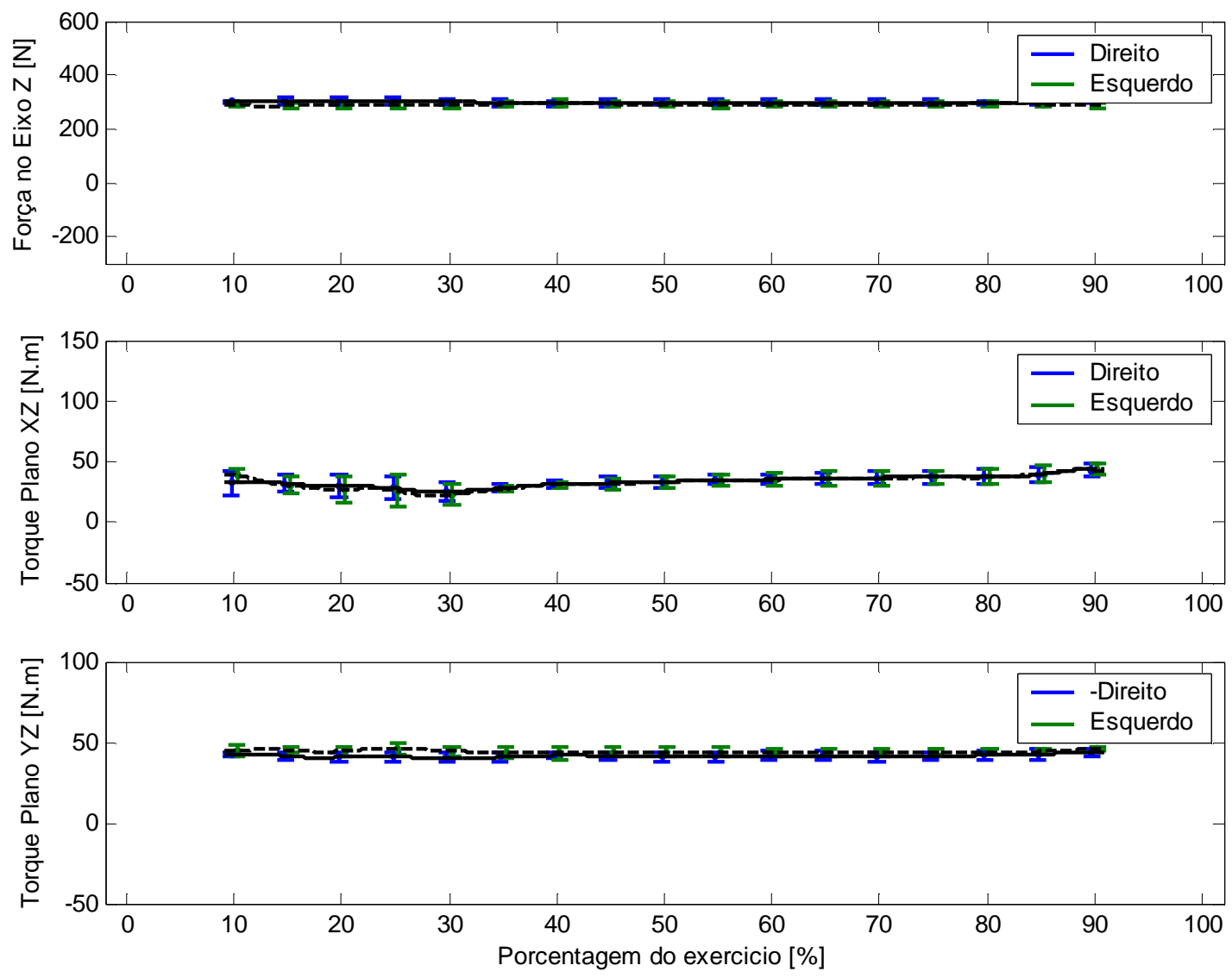

Fig. A4.5 Médias e Desvios Padrões dos Dados Cinéticos do Paciente 4 durante a Elevação para Alívio da pressão. As linhas tracejadas representam as médias do lado esquerdo. 

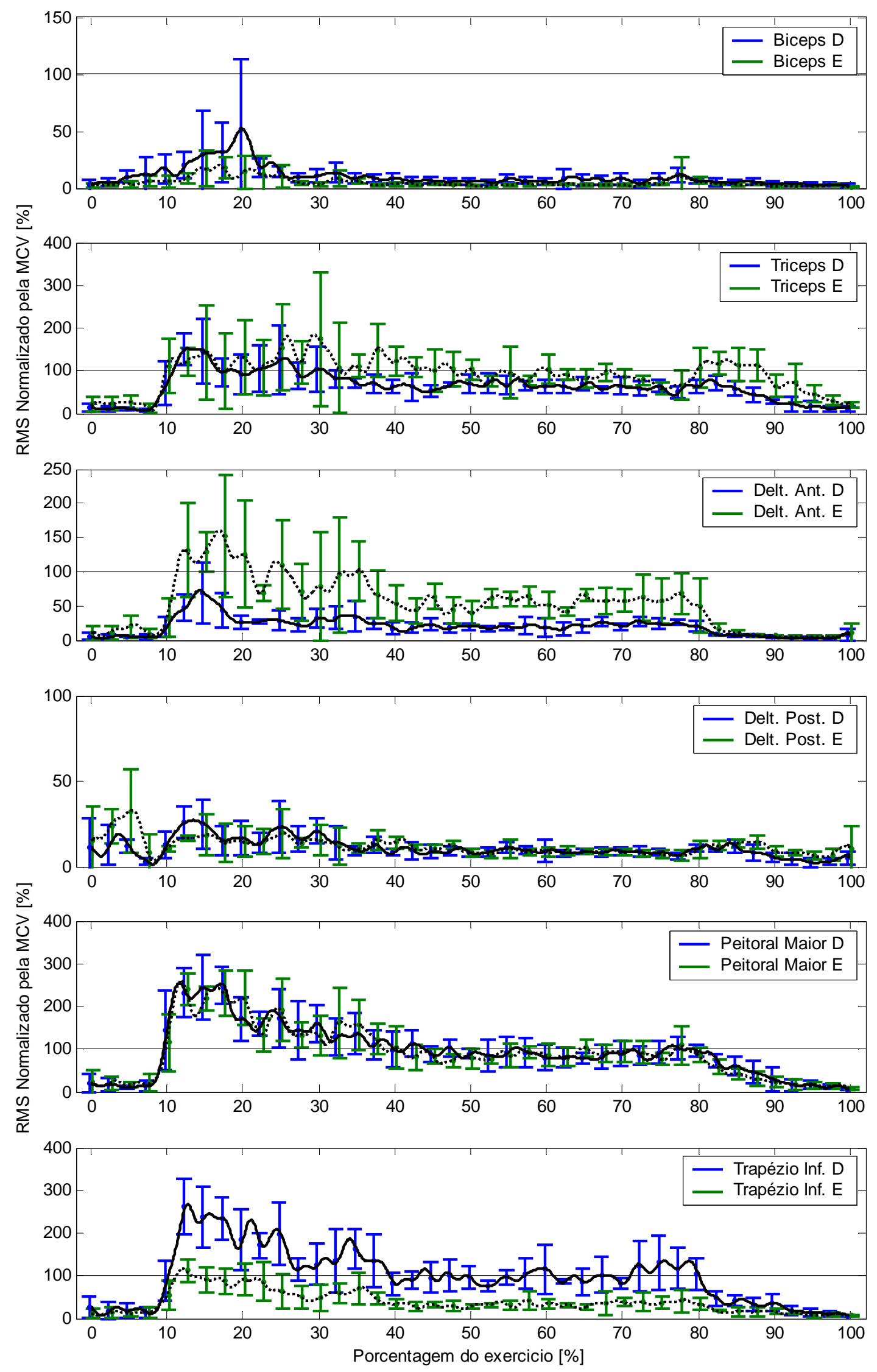

Fig. A4.6 Médias e Desvios Padrões das Atividades Musculares do Paciente 4 durante a Elevação para Alívio da pressão. As linhas tracejadas representam as médias do lado esquerdo. 


\section{A5 - Paciente 5}

Exame realizado 09/09/2006

\section{A5.1 - Propulsão da CADEIRA de Rodas}

Tab. A5.1 - Características dos 3 ciclos iniciais de propulsão da cadeira de rodas

\begin{tabular}{lccc}
\hline & $\begin{array}{c}\text { Tempo } \\
{[\mathrm{s}]}\end{array}$ & $\begin{array}{c}\text { Distância } \\
{[\mathrm{cm}]}\end{array}$ & $\begin{array}{c}\text { Velocidade } \\
{[\mathrm{cm} / \mathrm{s}]}\end{array}$ \\
\hline Média & 2,94 & 115,48 & 39,65 \\
Desvio Padrão & 0,21 & 23,64 & 9,84 \\
\hline
\end{tabular}

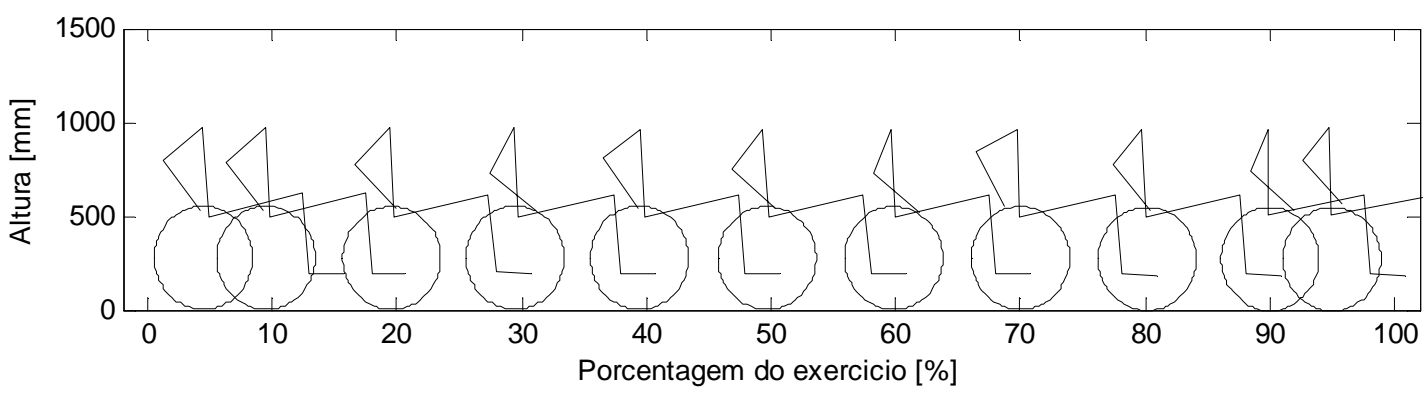

Fig. A5.1 Diagrama do movimento do Paciente 5 durante a Propulsão da Cadeira de Rodas.
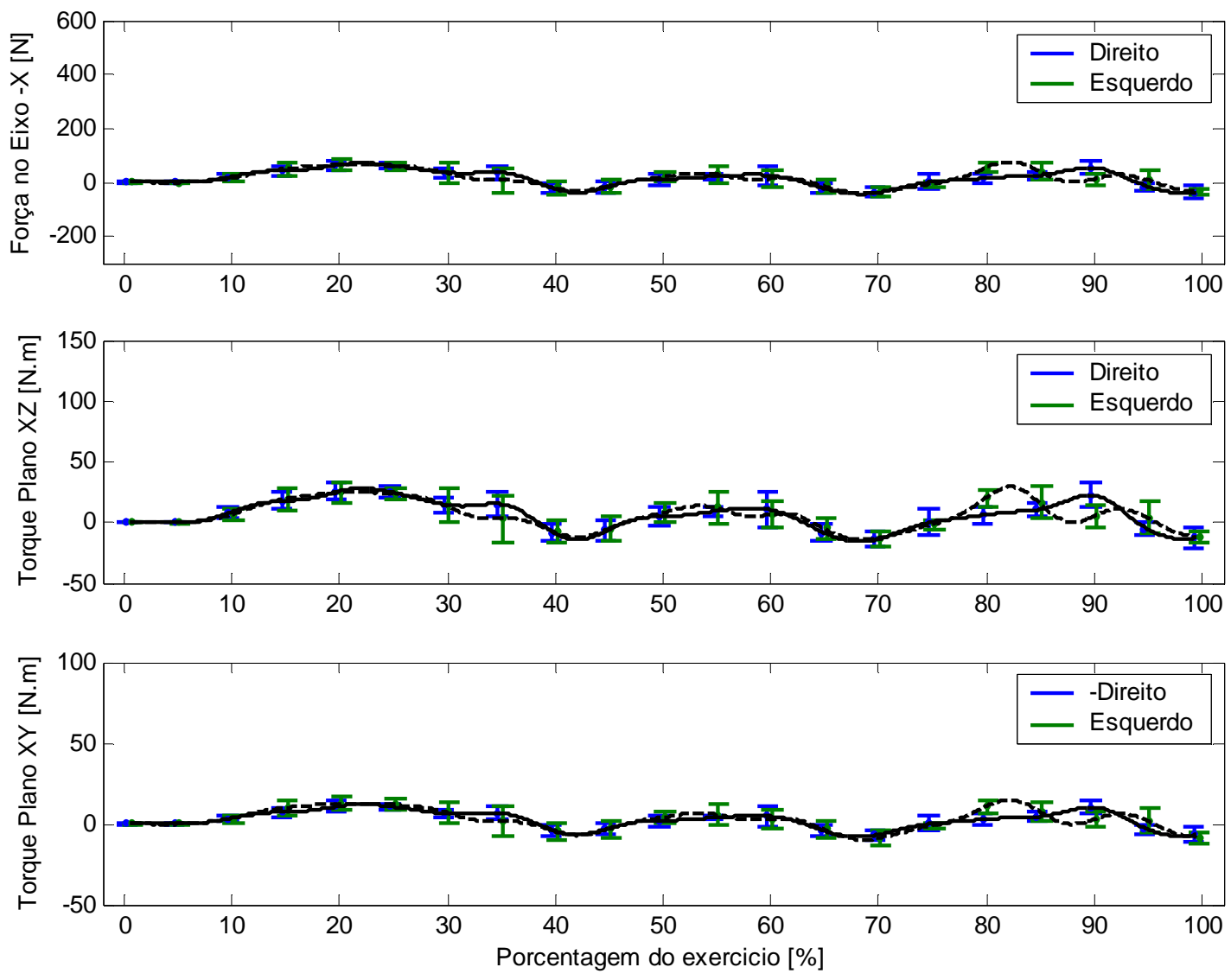

Fig. A5.2 Médias e Desvios Padrões dos Dados Cinéticos do Paciente 5 durante a Propulsão da Cadeira de Rodas. As linhas tracejadas representam as médias do lado esquerdo. 

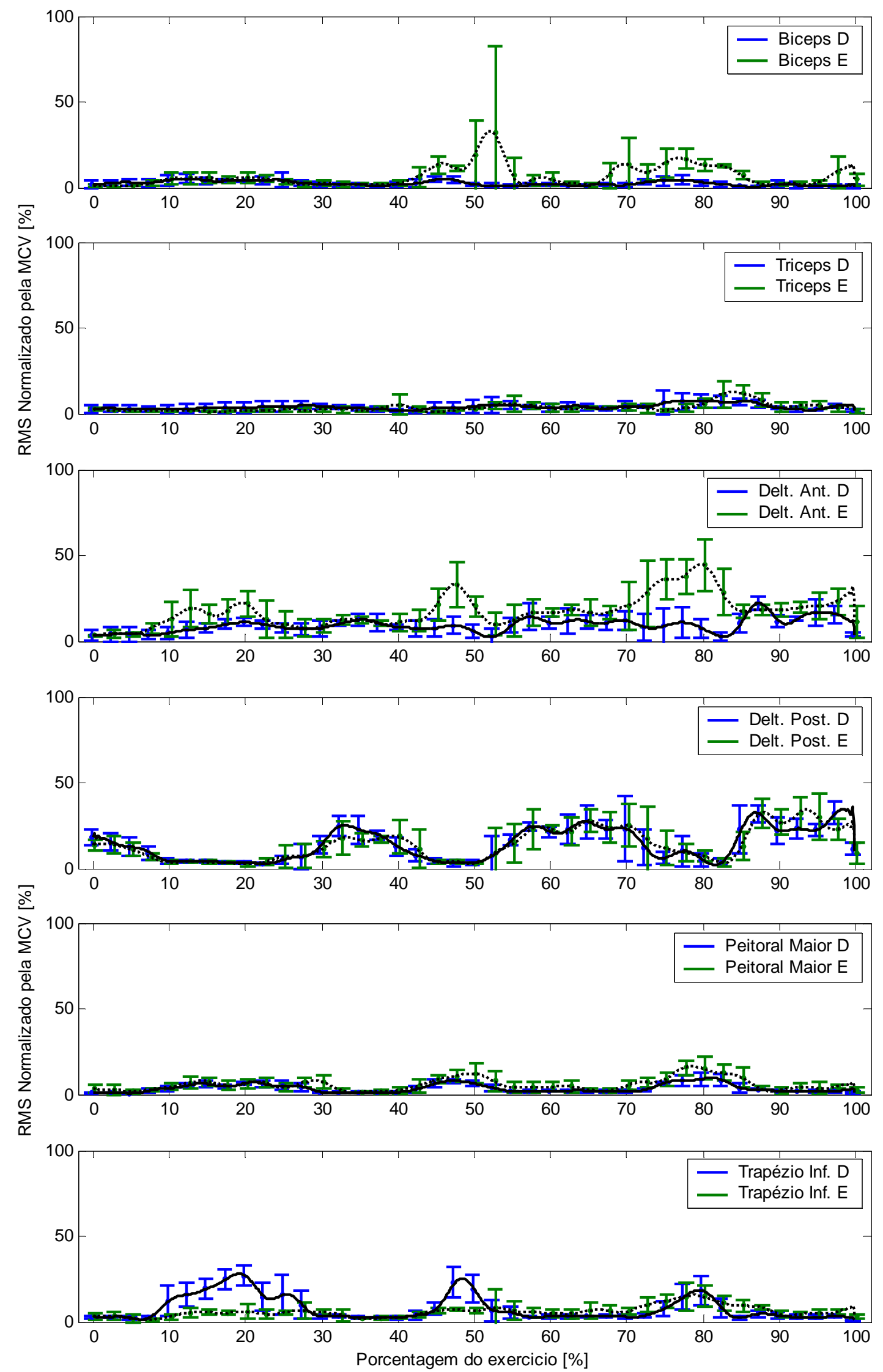

Fig. A5.3 Médias e Desvios Padrões das Atividades Musculares do Paciente 5 durante a Propulsão da Cadeira de Rodas. As linhas tracejadas representam as médias do lado esquerdo. 


\section{A5.2 - Elevação para Alívio da PRESsão}

Tab. A5.2 - Características da elevação para alívio da pressão

\begin{tabular}{lcc}
\hline & $\begin{array}{c}\text { Tempo } \\
{[\mathrm{s}]}\end{array}$ & $\begin{array}{c}\text { Elevação } \\
{[\mathrm{cm}]}\end{array}$ \\
\hline Média & 6,39 & 12,43 \\
Desvio Padrão & 0,26 & 0,12 \\
\hline
\end{tabular}

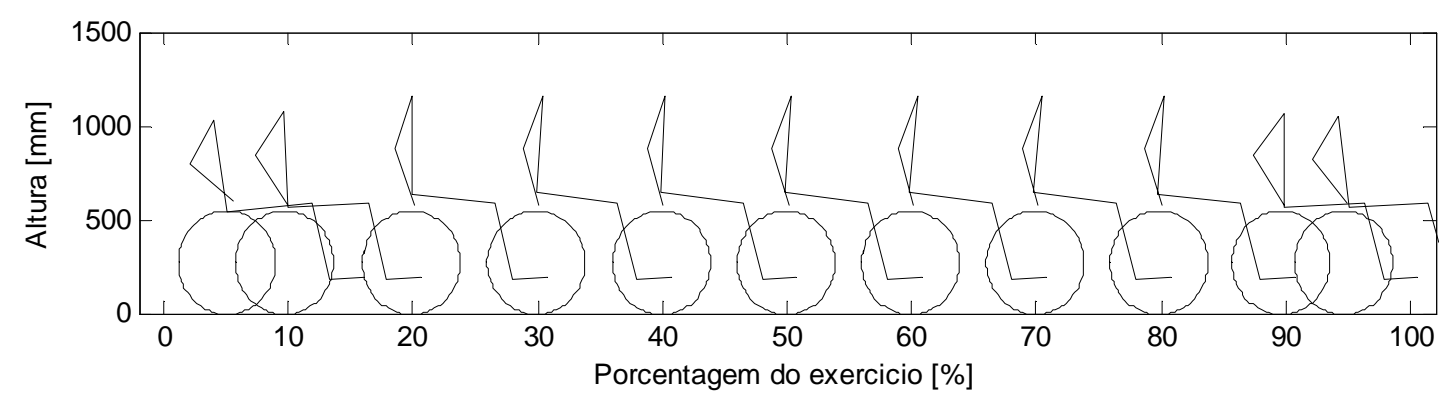

Fig. A5.4 Diagrama do movimento do Paciente 5 durante a Elevação para Alívio da pressão.
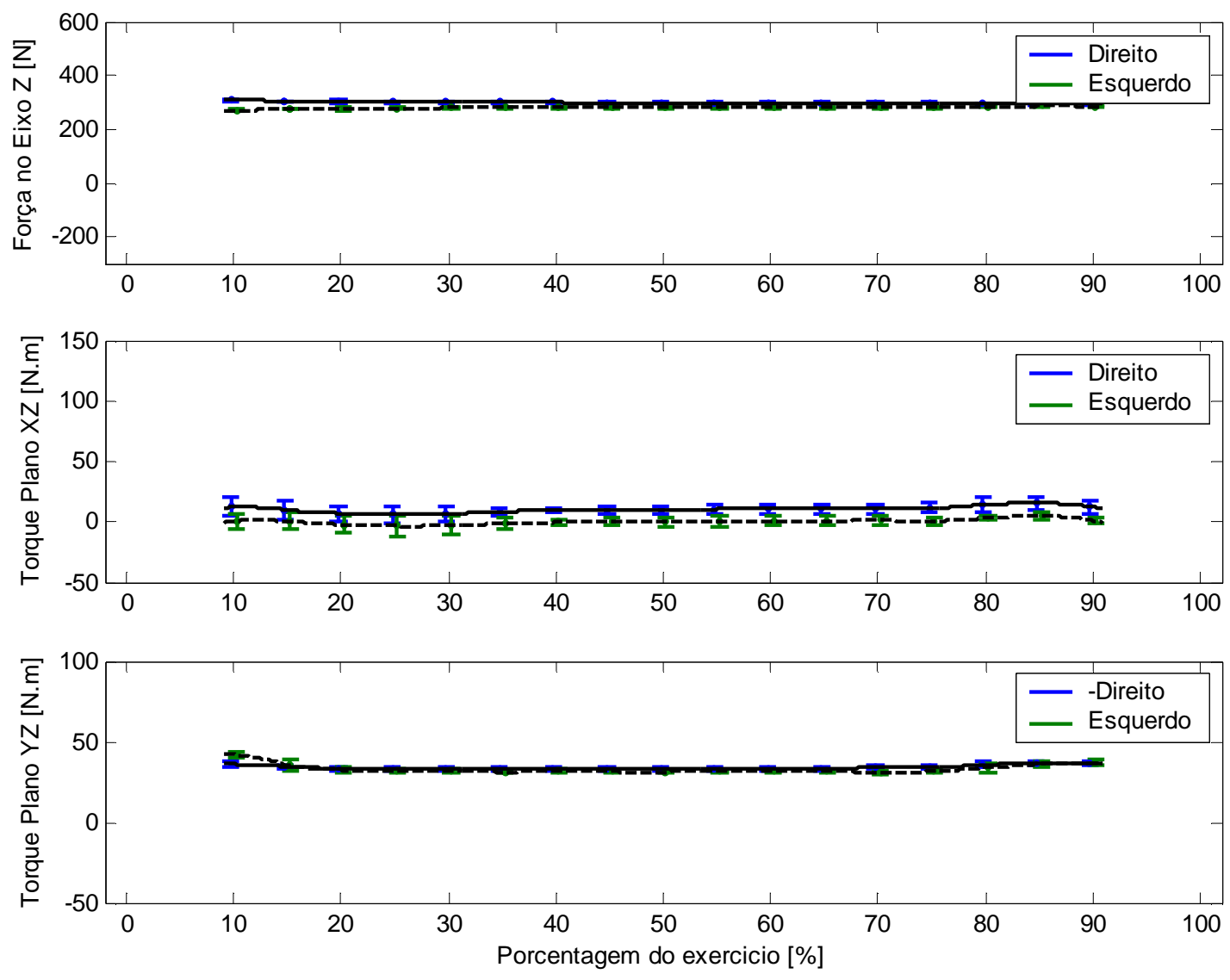

Fig. A5.5 Médias e Desvios Padrões dos Dados Cinéticos do Paciente 5 durante a Elevação para Alívio da pressão. As linhas tracejadas representam as médias do lado esquerdo. 

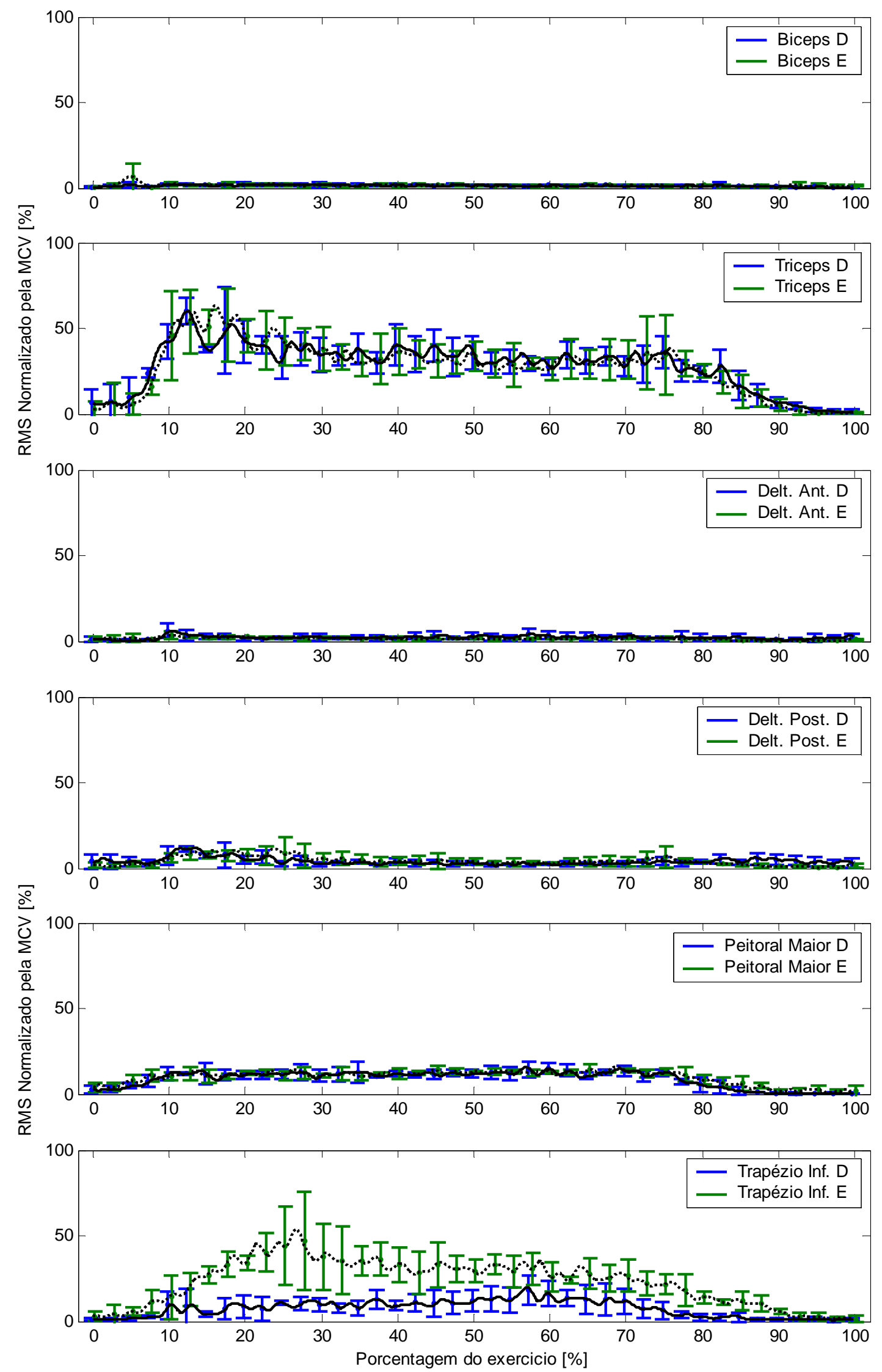

Fig. A5.6 Médias e Desvios Padrões das Atividades Musculares do Paciente 5 durante a Elevação para Alívio da pressão. As linhas tracejadas representam as médias do lado esquerdo. 


\section{A5.3 - MARCHA COM ANDADOR E EENM}

Tab. A5.3 - Características da passada com andador e EENM

\begin{tabular}{lcccc}
\hline & $\begin{array}{c}\text { Tempo } \\
{[\mathrm{s}]}\end{array}$ & $\begin{array}{c}\text { Passada } \\
{[\mathrm{cm}]}\end{array}$ & $\begin{array}{c}\text { Velocidade } \\
{[\mathrm{cm} / \mathrm{s}]}\end{array}$ & $\begin{array}{c}\text { Cadência } \\
\text { [passos/min] }\end{array}$ \\
\hline Média & 7,83 & 57,12 & 7,35 & 15,43 \\
Desvio Padrão & 0,79 & 5,13 & 0,93 & 1,43 \\
\hline
\end{tabular}

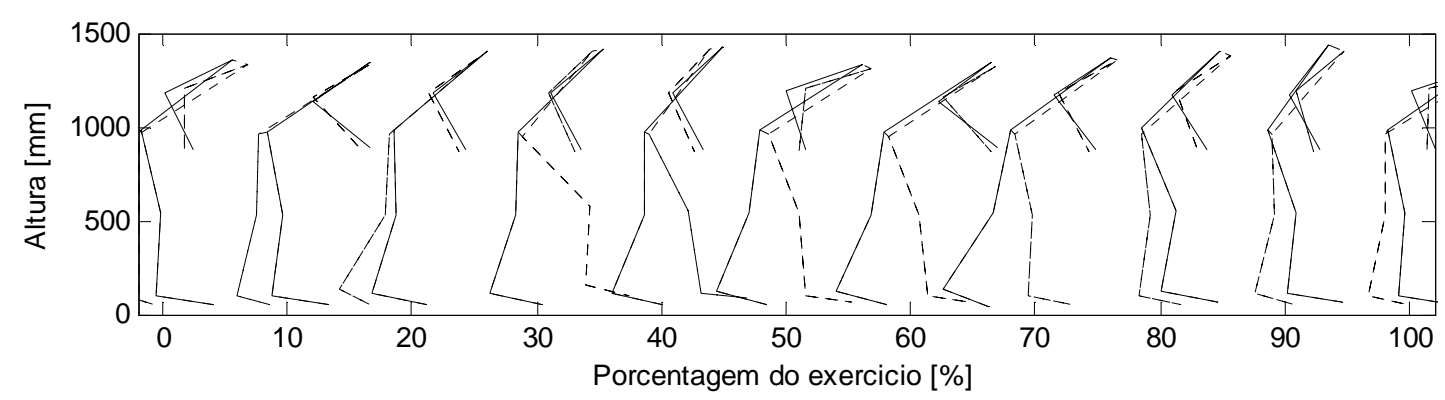

Fig. A5.7 Diagrama do movimento do Paciente 5 durante a Marcha com Andador e EENM.
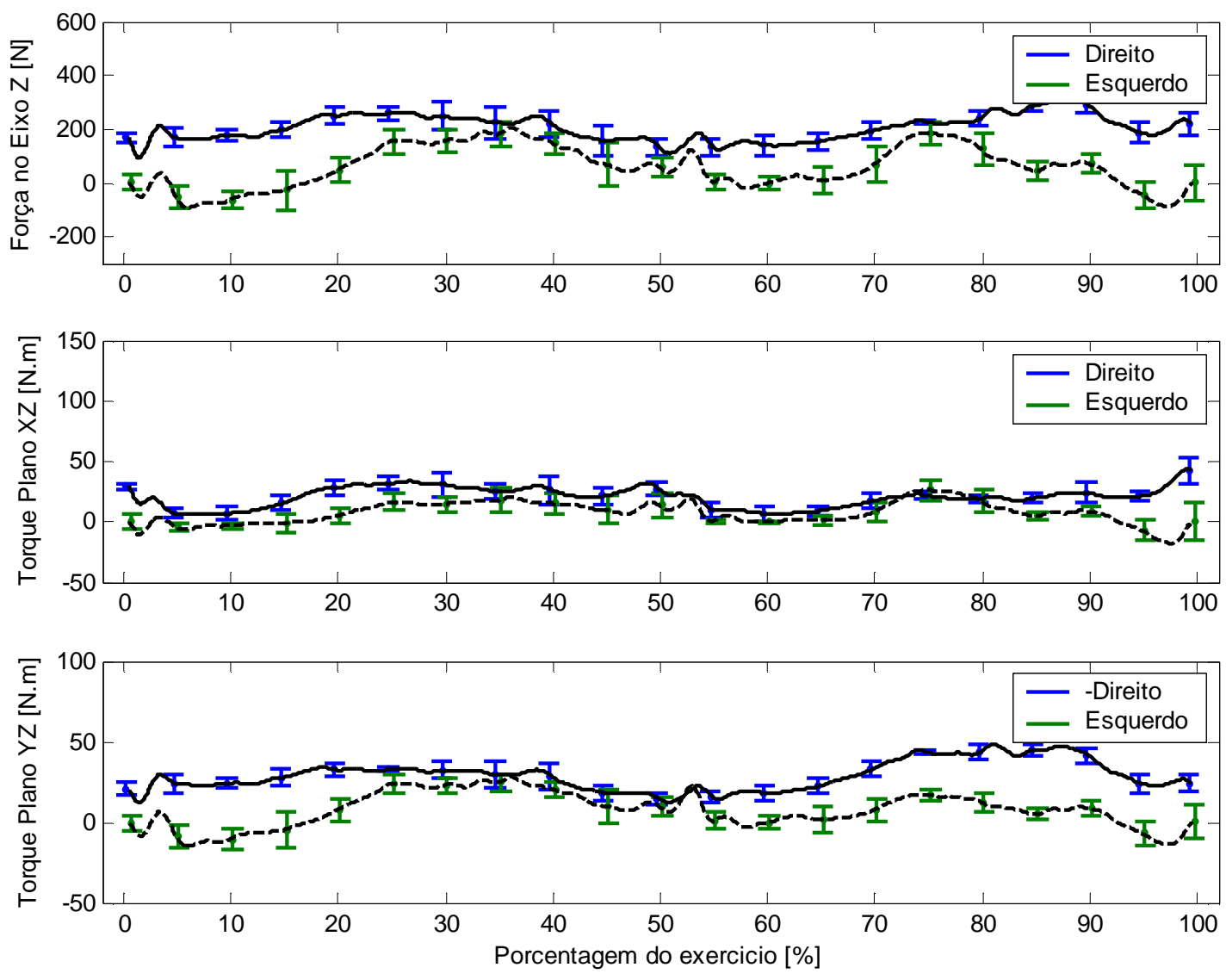

Fig. A5.8 Médias e Desvios Padrões dos Dados Cinéticos do Paciente 5 durante a Marcha com Andador e EENM. As linhas tracejadas representam as médias do lado esquerdo. 

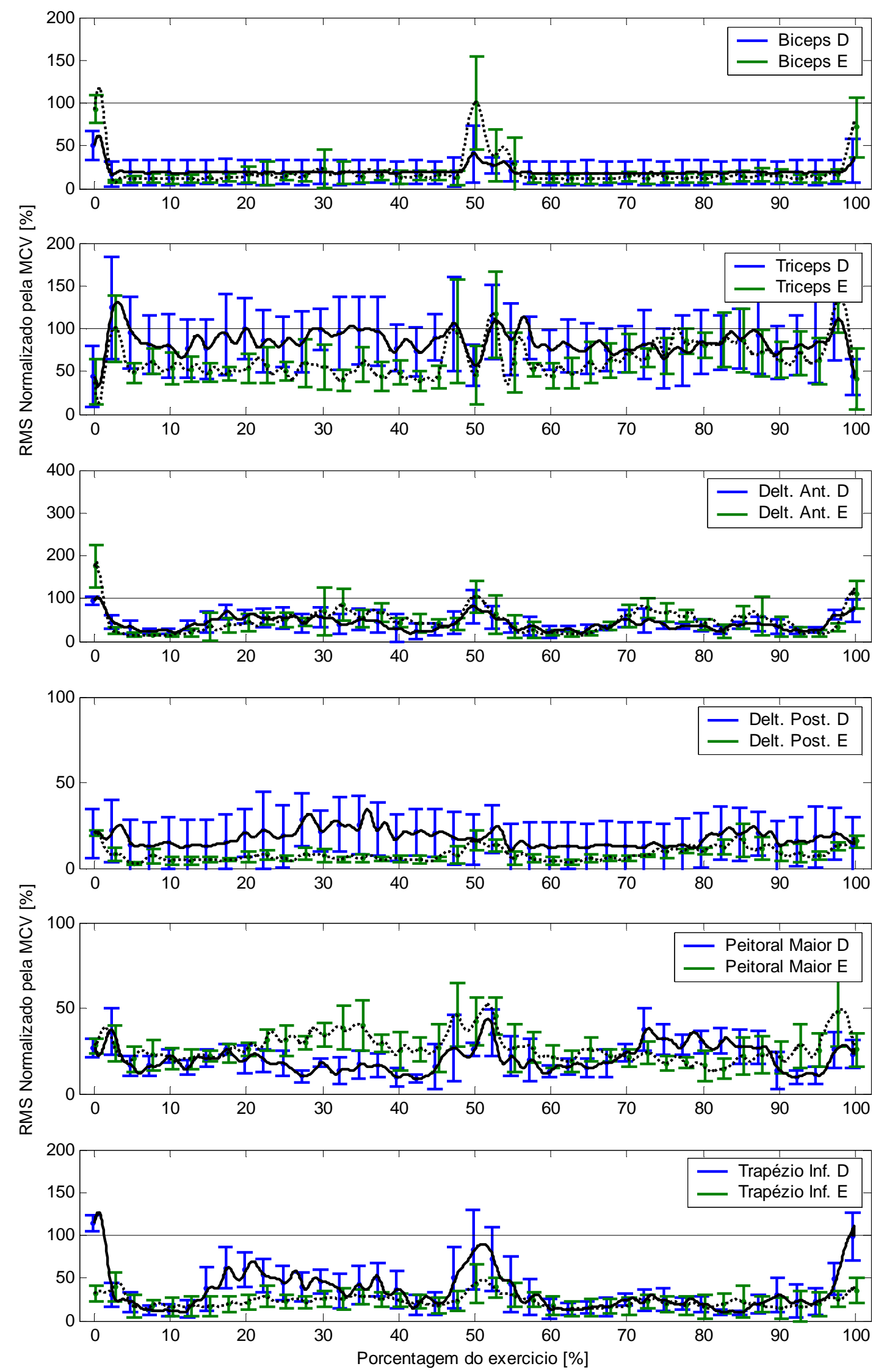

Fig. A5.9 Médias e Desvios Padrões das Atividades Musculares do Paciente 5 durante a Marcha com Andador e EENM. As linhas tracejadas representam as médias do lado esquerdo. 


\section{A6.1 - PROPUlsão da CADEIRA de Rodas}

Tab. A6.1 - Características dos 3 ciclos iniciais de propulsão da cadeira de rodas

\begin{tabular}{lccc}
\hline & $\begin{array}{c}\text { Tempo } \\
{[\mathrm{s}]}\end{array}$ & $\begin{array}{c}\text { Distância } \\
{[\mathrm{cm}]}\end{array}$ & $\begin{array}{c}\text { Velocidade } \\
{[\mathrm{cm} / \mathrm{s}]}\end{array}$ \\
\hline Média & 3,96 & 203,41 & 51,30 \\
Desvio Padrão & 0,16 & 26,61 & 5,18 \\
\hline
\end{tabular}

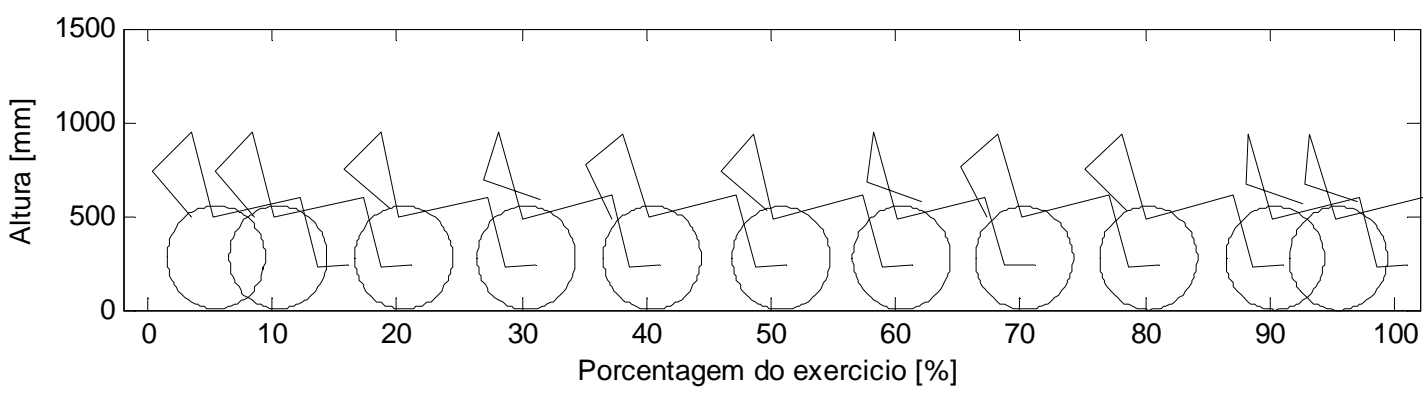

Fig. A6.1 Diagrama do movimento do Paciente 6 durante a Propulsão da Cadeira de Rodas.
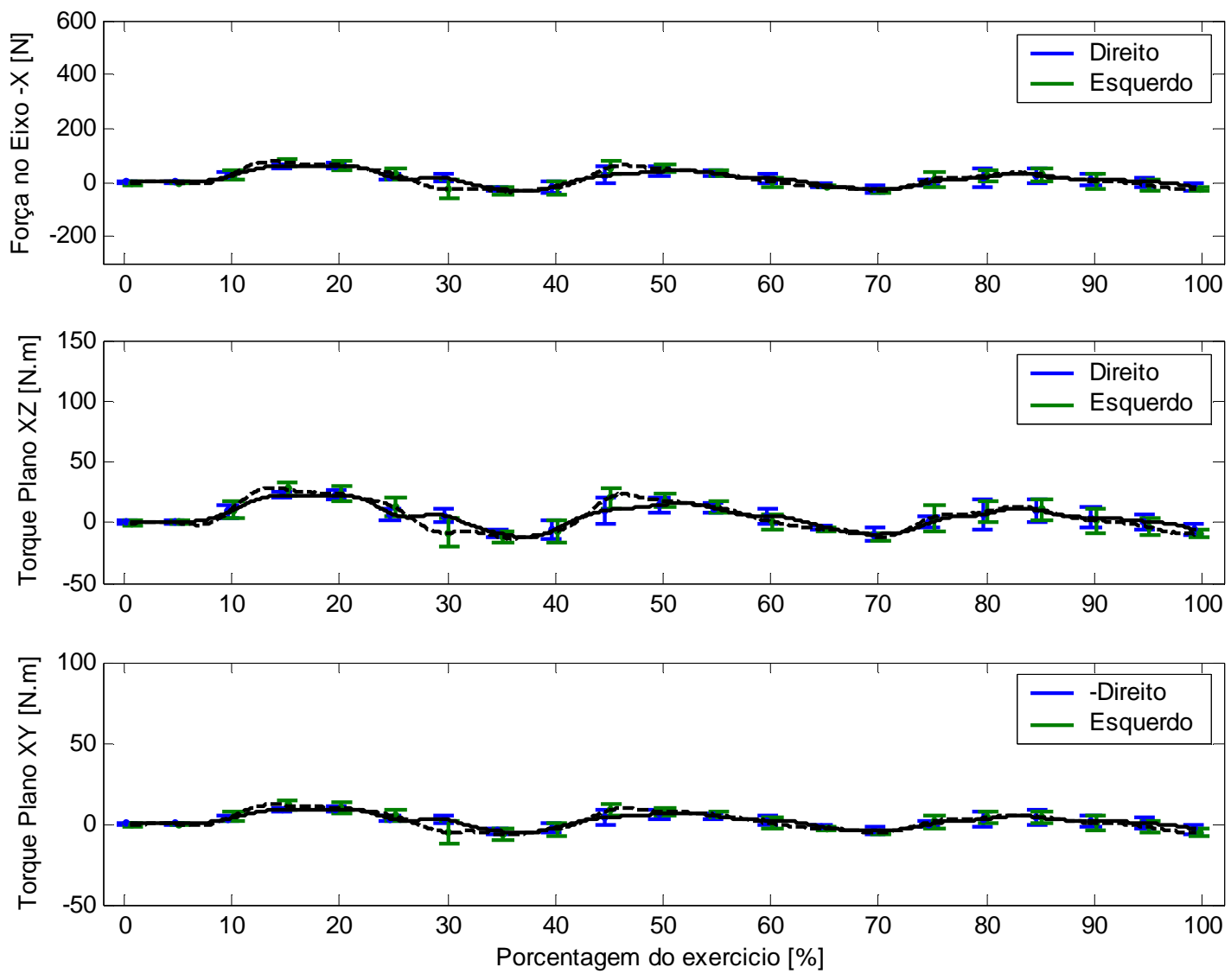

Fig. A6.2 Médias e Desvios Padrões dos Dados Cinéticos do Paciente 6 durante a Propulsão da Cadeira de Rodas. As linhas tracejadas representam as médias do lado esquerdo. 

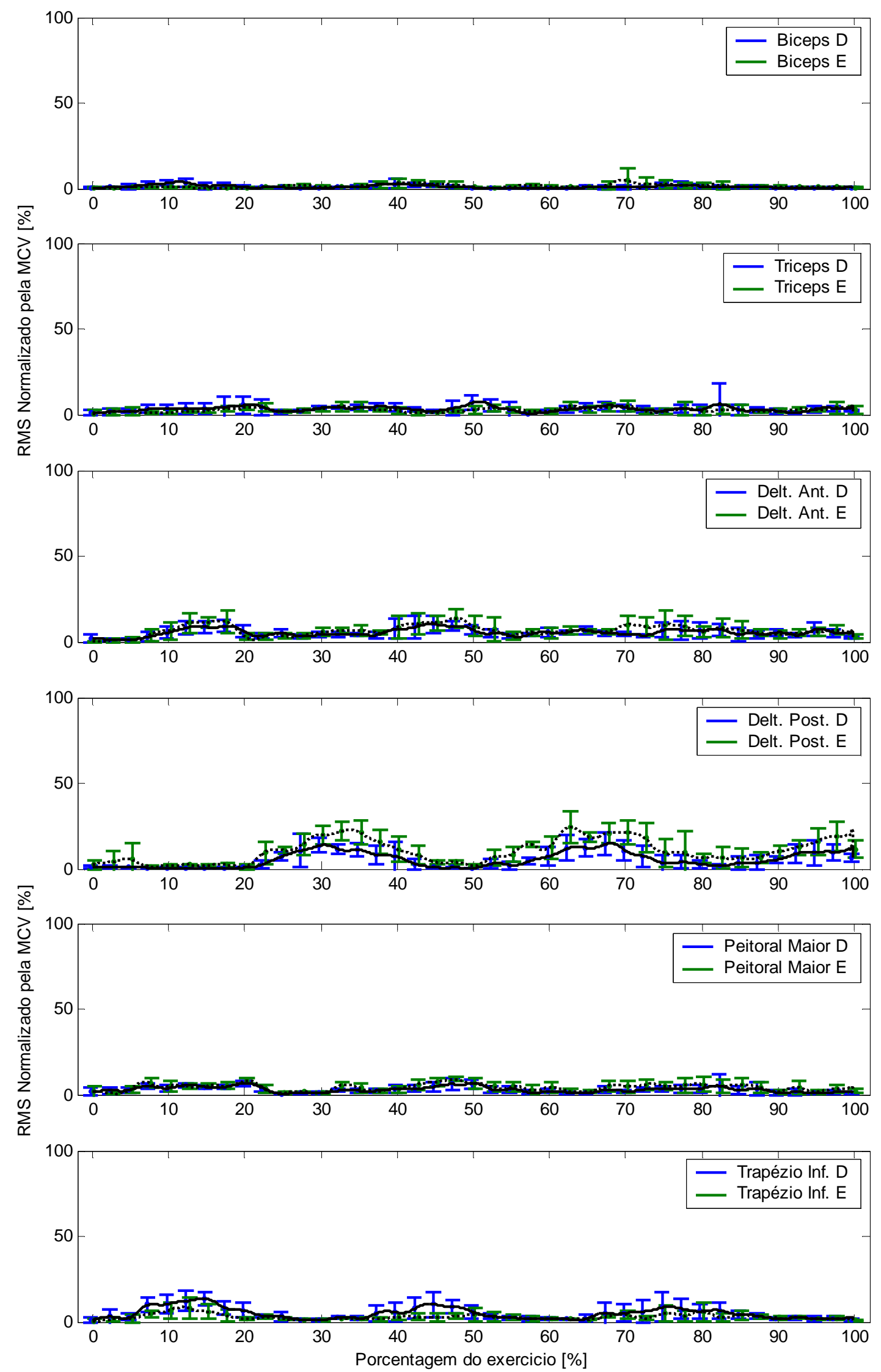

Fig. A6.3 Médias e Desvios Padrões das Atividades Musculares do Paciente 6 durante a Propulsão da Cadeira de Rodas. As linhas tracejadas representam as médias do lado esquerdo. 


\section{A6.2 - Elevação para Alívio da PRESsão}

Tab. A6.2 - Características da elevação para alívio da pressão

\begin{tabular}{lcc}
\hline & $\begin{array}{c}\text { Tempo } \\
{[\mathrm{s}]}\end{array}$ & $\begin{array}{c}\text { Elevação } \\
{[\mathrm{cm}]}\end{array}$ \\
\hline Média & 5,33 & 22,85 \\
Desvio Padrão & 0,57 & 1,12 \\
\hline
\end{tabular}

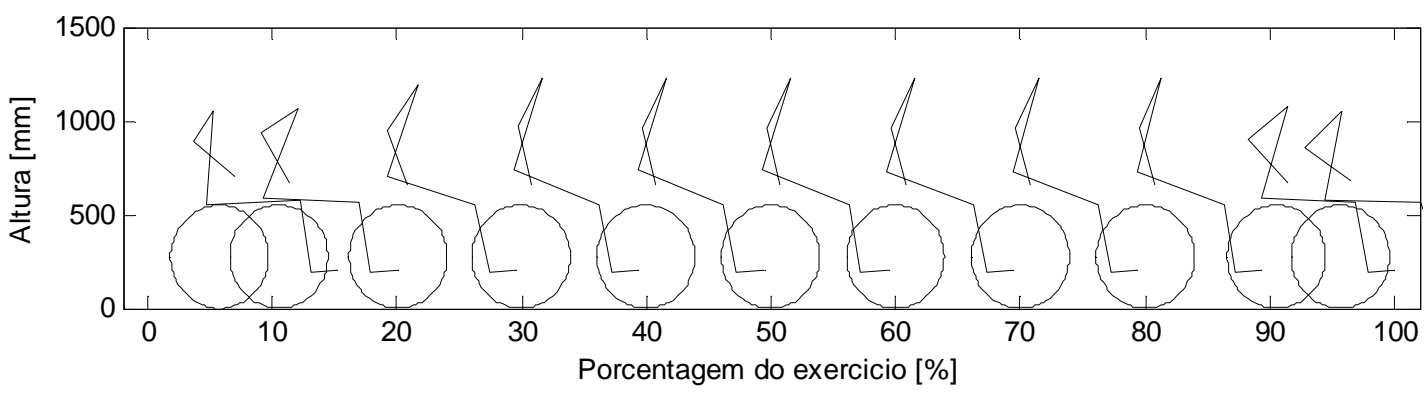

Fig. A6.4 Diagrama do movimento do Paciente 6 durante a Elevação para Alívio da pressão.
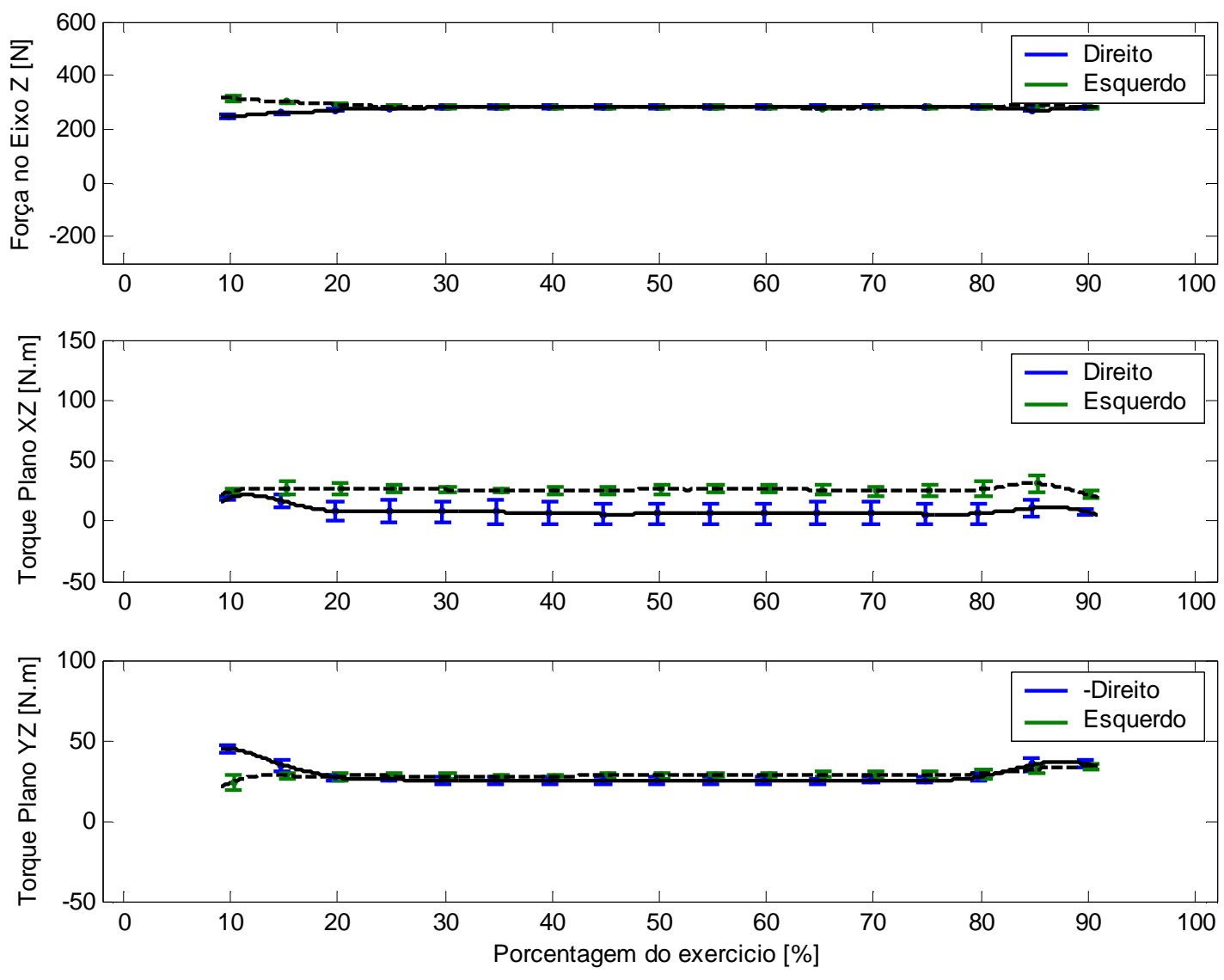

Fig. A6.5 Médias e Desvios Padrões dos Dados Cinéticos do Paciente 6 durante a Elevação para Alívio da pressão. As linhas tracejadas representam as médias do lado esquerdo. 

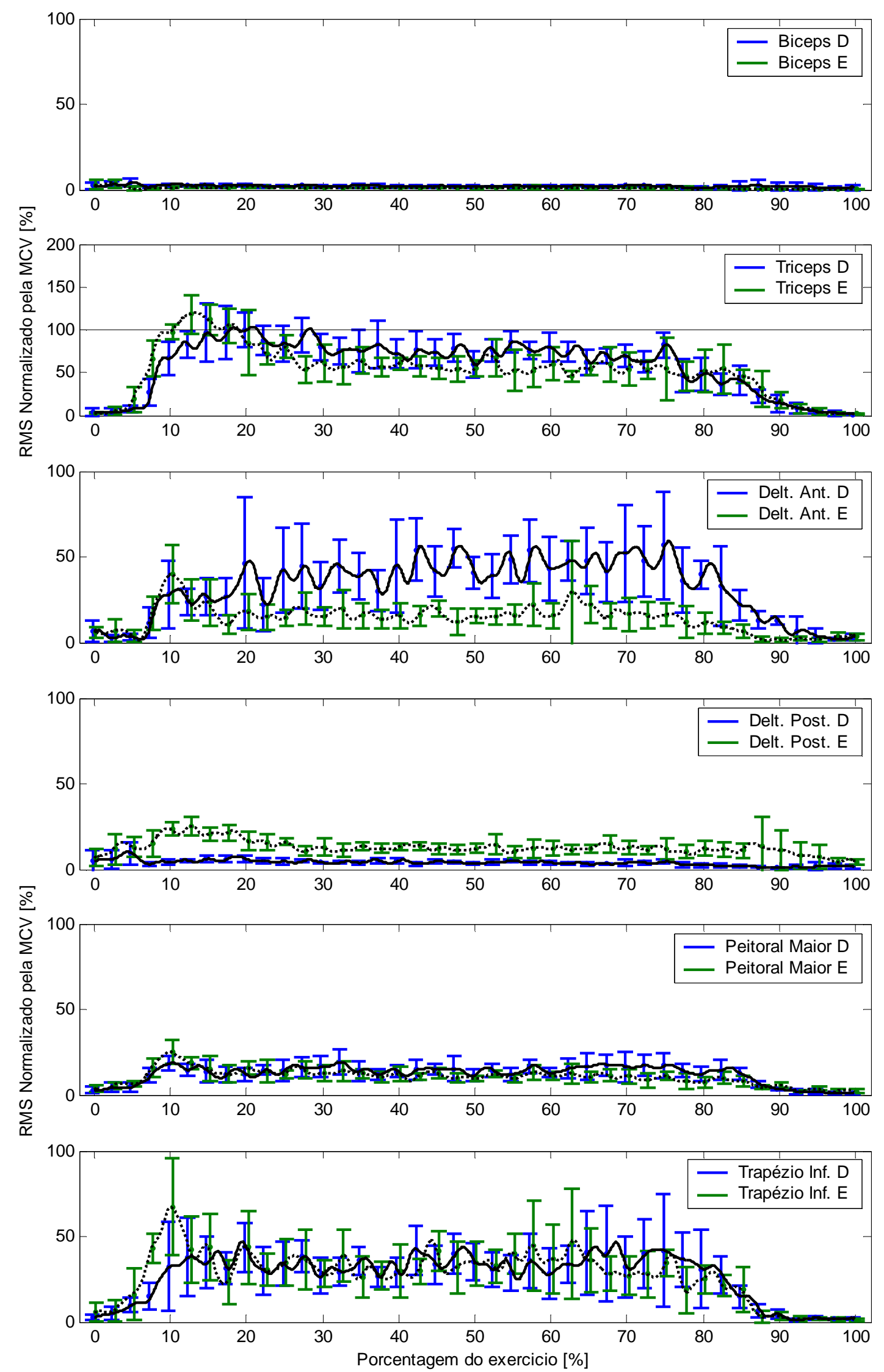

Fig. A6.6 Médias e Desvios Padrões das Atividades Musculares do Paciente 6 durante a Elevação para Alívio da pressão. As linhas tracejadas representam as médias do lado esquerdo. 


\section{A7.1 - ElEVAÇÃo PARA ALÍVIO da PRESSÃo}

Tab. A7.1 - Características da elevação para alívio da pressão

\begin{tabular}{lcc}
\hline & Tempo & Elevação \\
& {$[\mathrm{s}]$} & {$[\mathrm{cm}]$} \\
\hline Média & 6,25 & 29,72 \\
Desvio Padrão & 1,05 & 0,42 \\
\hline
\end{tabular}

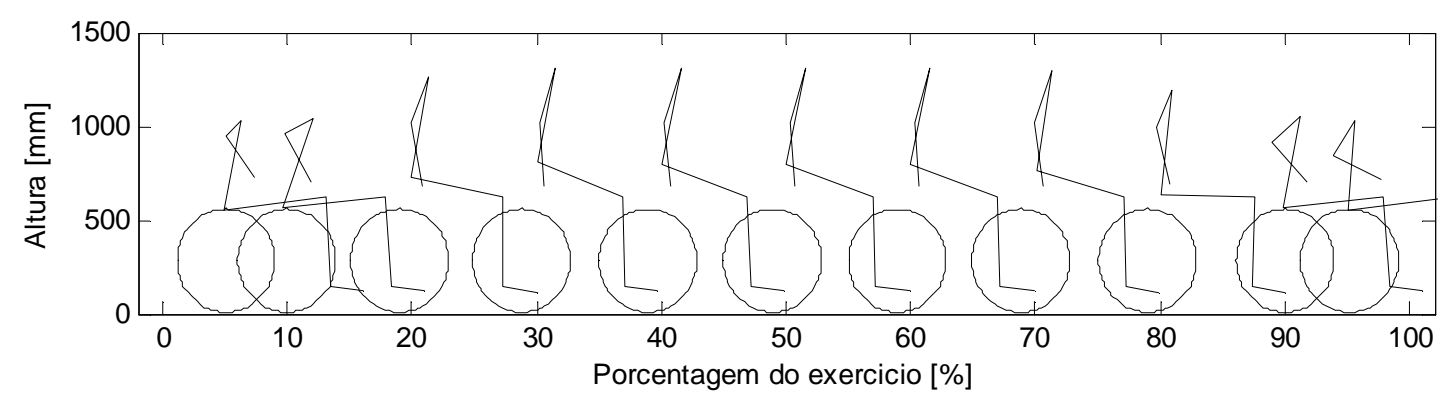

Fig. A7.1 Diagrama do movimento do Paciente 7 durante a Elevação para Alívio da pressão.
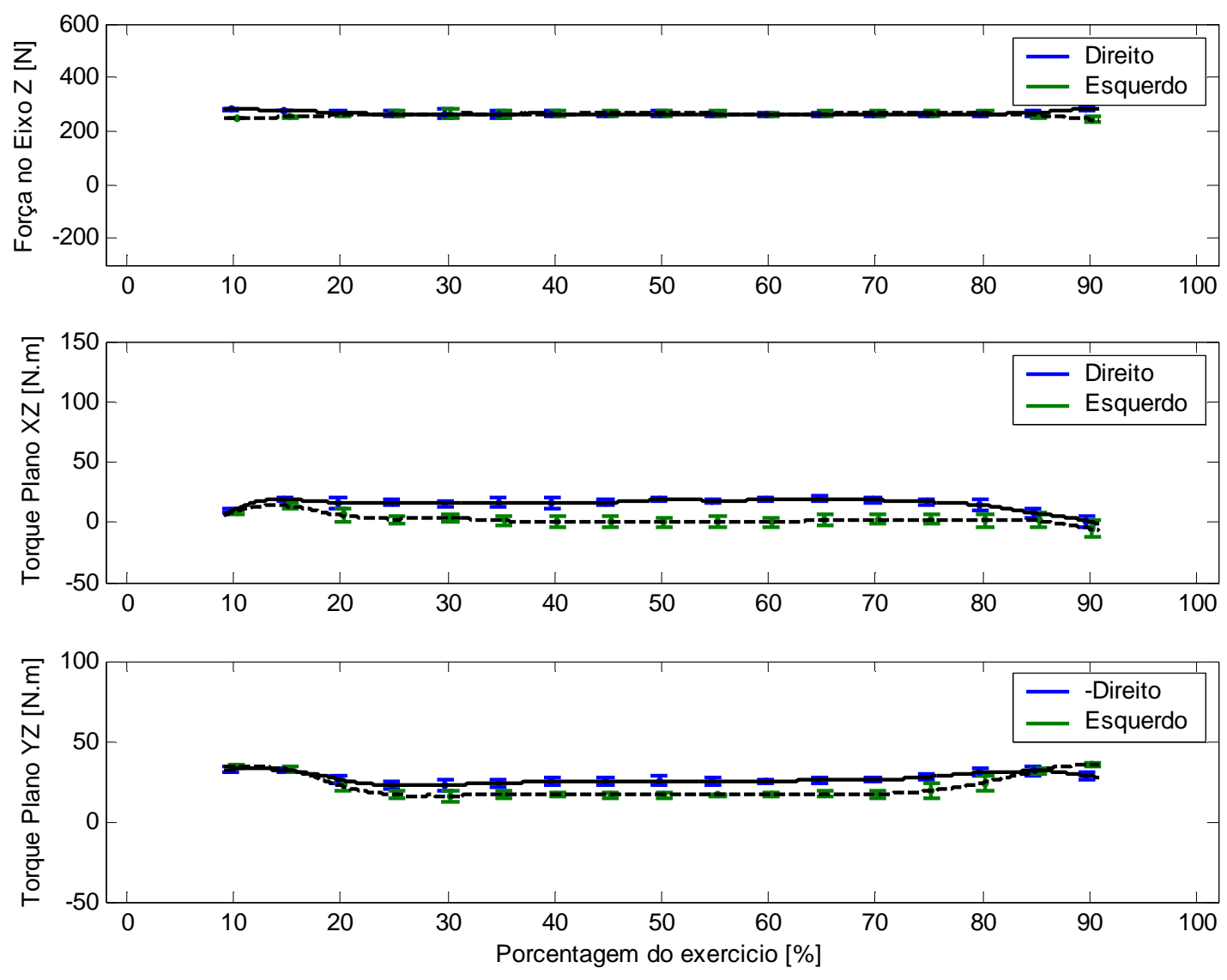

Fig. A7.2 Médias e Desvios Padrões dos Dados Cinéticos do Paciente 7 durante a Elevação para Alívio da pressão. As linhas tracejadas representam as médias do lado esquerdo. 

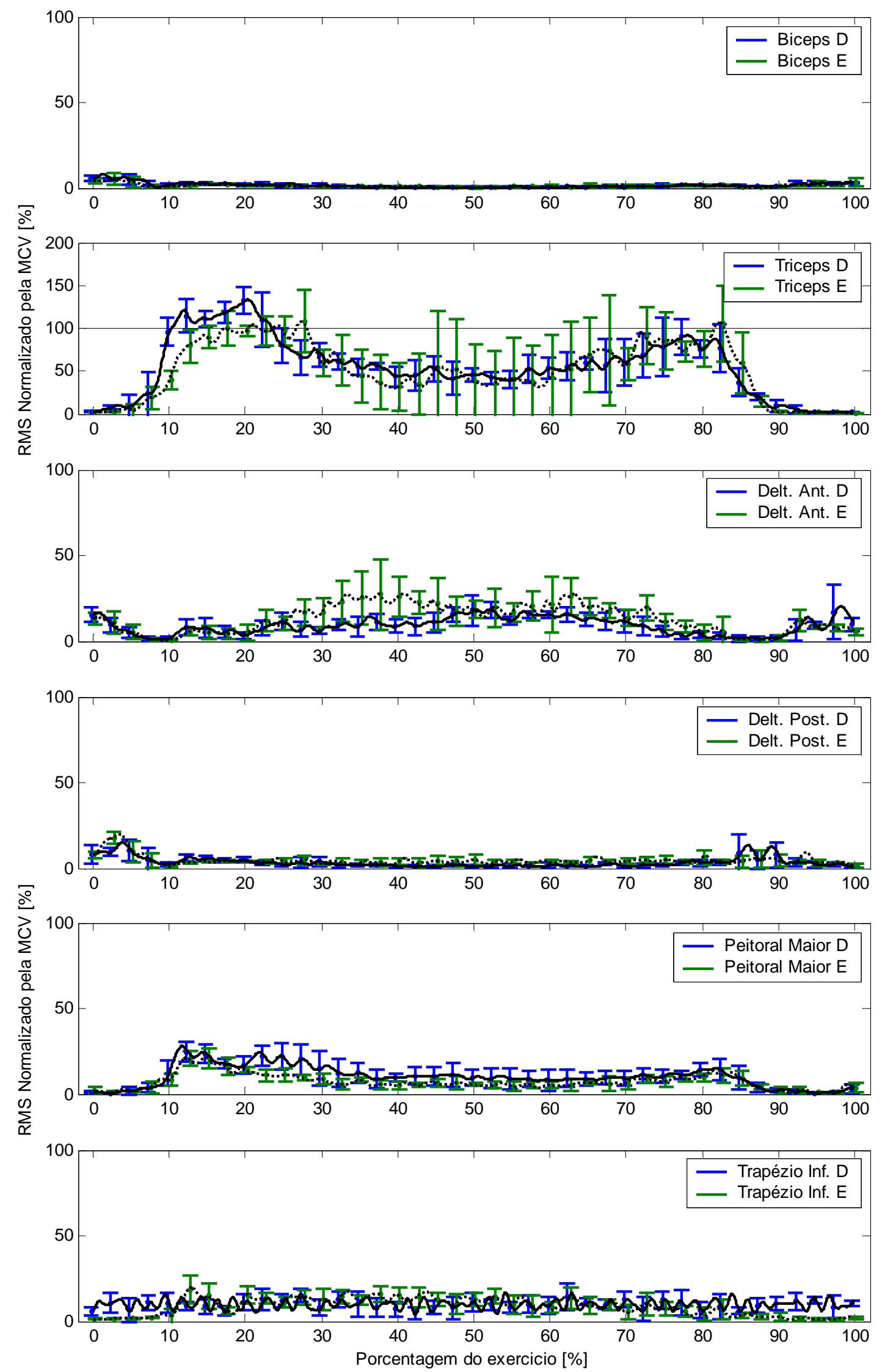

Fig. A7.3 Médias e Desvios Padrões das Atividades Musculares do Paciente 7 durante a Elevação para Alívio da pressão. As linhas tracejadas representam as médias do lado esquerdo. 


\section{A7.2 - MARCHA COM ANDADOR E EENM}

Tab. A7.2 - Características da passada com andador e EENM

\begin{tabular}{lcccc}
\hline & $\begin{array}{c}\text { Tempo } \\
{[\mathrm{s}]}\end{array}$ & $\begin{array}{c}\text { Passada } \\
{[\mathrm{cm}]}\end{array}$ & $\begin{array}{c}\text { Velocidade } \\
{[\mathrm{cm} / \mathrm{s}]}\end{array}$ & $\begin{array}{c}\text { Cadência } \\
\text { [passos/min] }\end{array}$ \\
\hline Média & 5,92 & 73,05 & 12,36 & 20,31 \\
Desvio Padrão & 0,27 & 8,94 & 1,56 & 0,91 \\
\hline
\end{tabular}

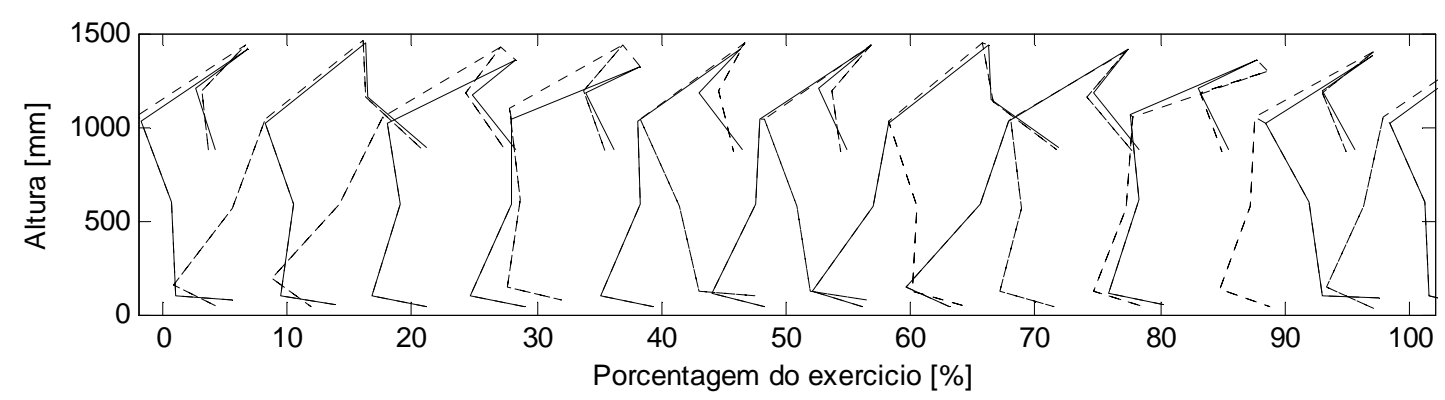

Fig. A7.4 Diagrama do movimento do Paciente 7 durante a Marcha com Andador e EENM.
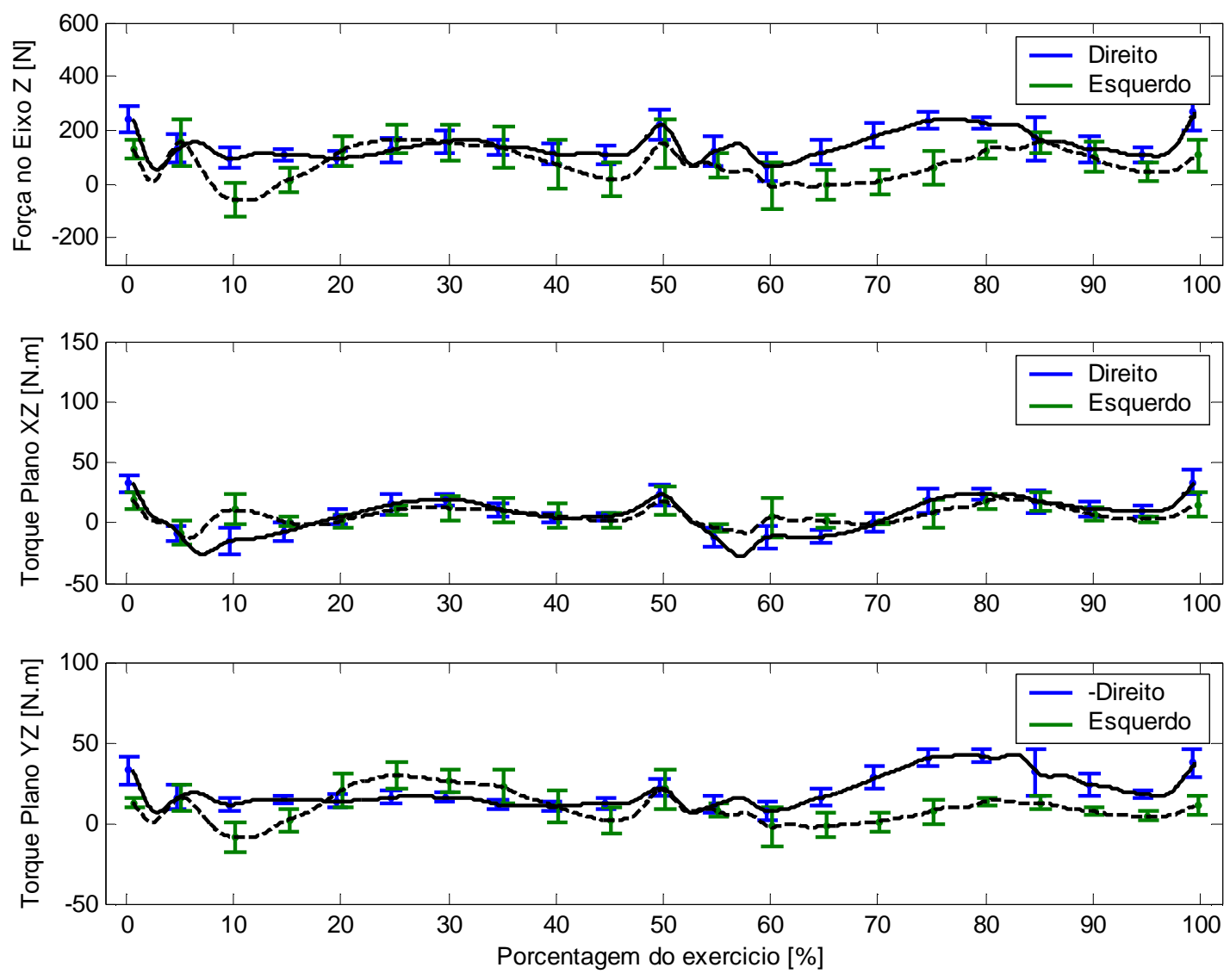

Fig. A7.5 Médias e Desvios Padrões dos Dados Cinéticos do Paciente 7 durante a Marcha com Andador e EENM. As linhas tracejadas representam as médias do lado esquerdo. 

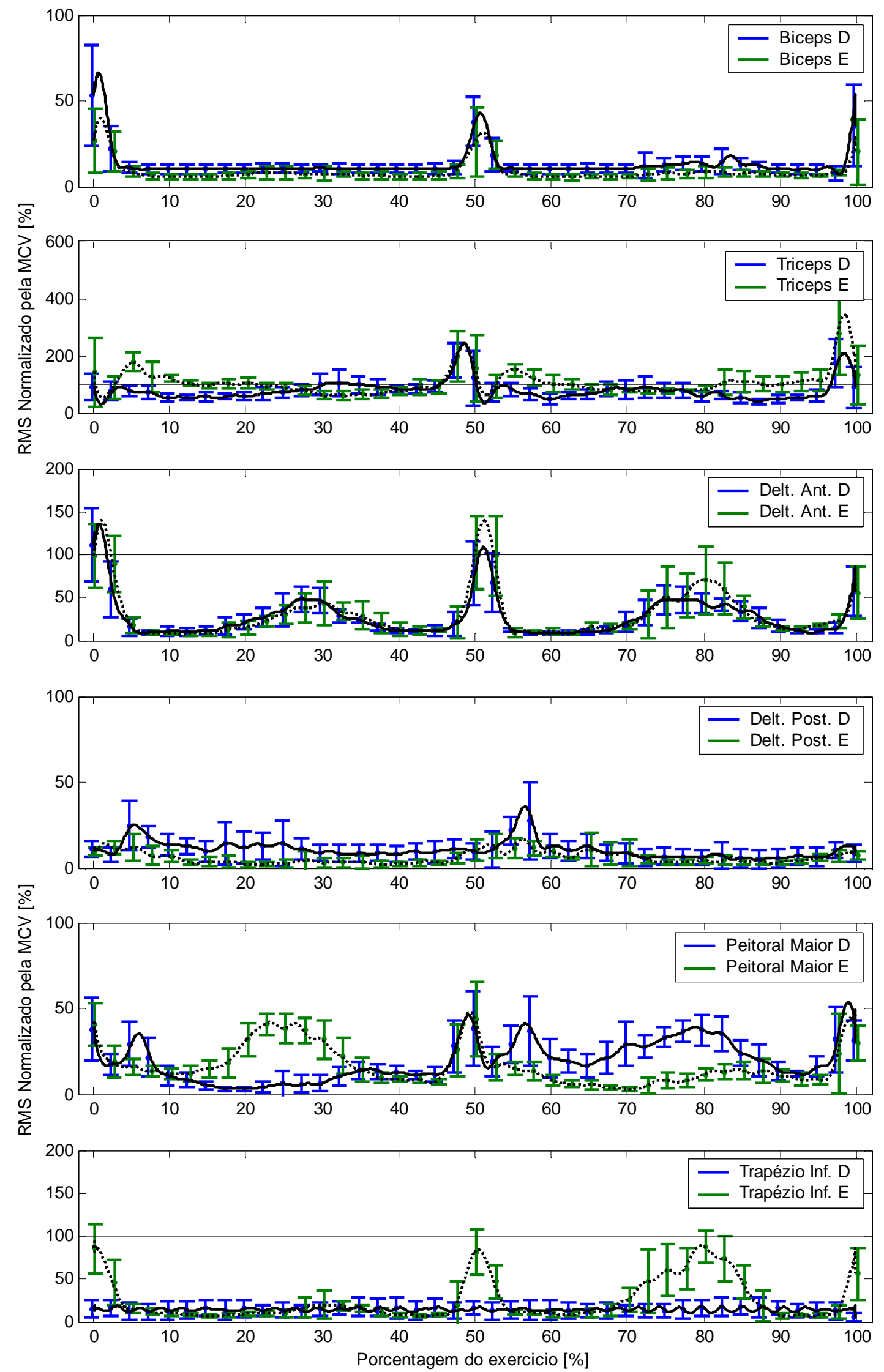

Fig. A7.6 Médias e Desvios Padrões das Atividades Musculares do Paciente 7 durante a Marcha com Andador e EENM. As linhas tracejadas representam as médias do lado esquerdo. 


\section{A8 - Paciente 8}

\section{A8.1 - PROPUlsão da CADEIRA de Rodas}

Tab. A8.1 - Características dos 3 ciclos iniciais de propulsão da cadeira de rodas

\begin{tabular}{lccc}
\hline & $\begin{array}{c}\text { Tempo } \\
{[\mathrm{s}]}\end{array}$ & $\begin{array}{c}\text { Distância } \\
{[\mathrm{cm}]}\end{array}$ & $\begin{array}{c}\text { Velocidade } \\
{[\mathrm{cm} / \mathrm{s}]}\end{array}$ \\
\hline Média & 4,02 & 165,50 & 41,37 \\
Desvio Padrão & 0,37 & 8,14 & 2,67 \\
\hline
\end{tabular}

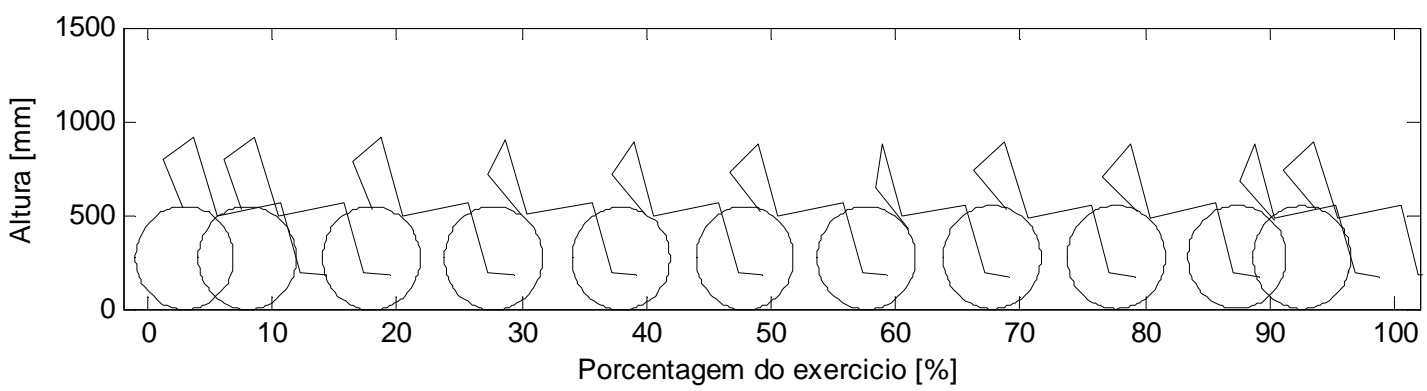

Fig. A8.1 Diagrama do movimento do Paciente 8 durante a Propulsão da Cadeira de Rodas.
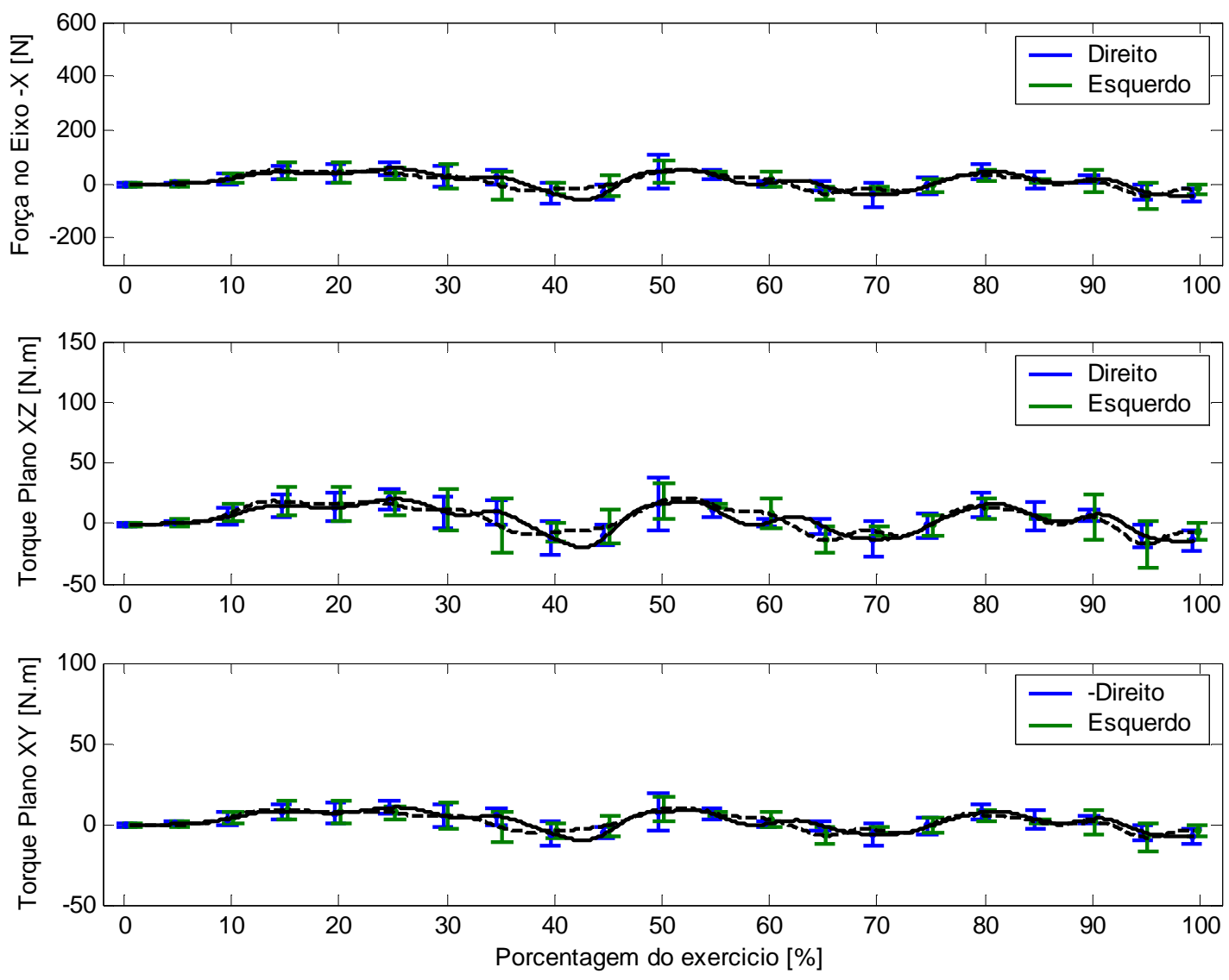

Fig. A8.2 Médias e Desvios Padrões dos Dados Cinéticos do Paciente 8 durante a Propulsão da Cadeira de Rodas. As linhas tracejadas representam as médias do lado esquerdo. 

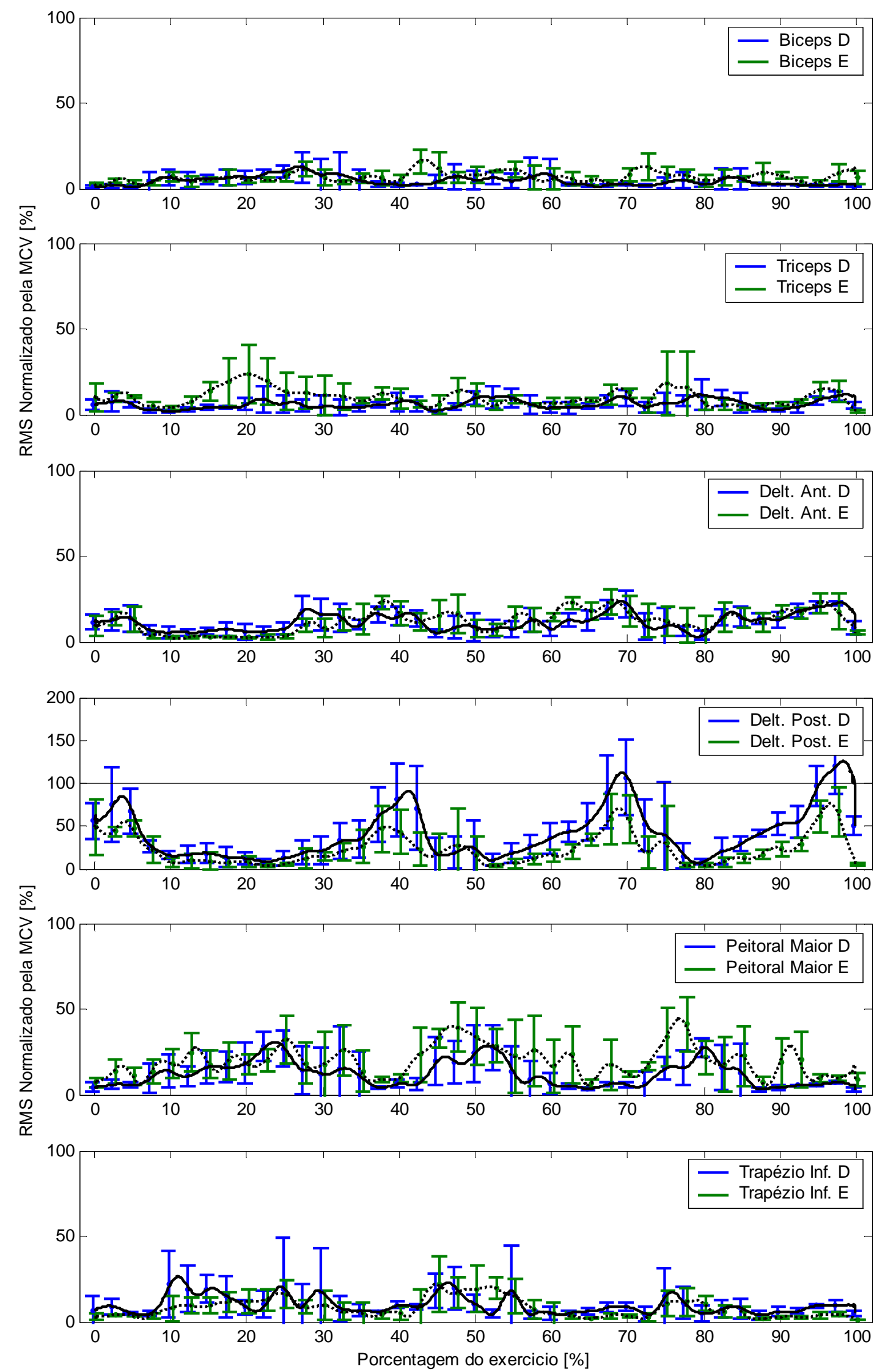

Fig. A8.3 Médias e Desvios Padrões das Atividades Musculares do Paciente 8 durante a Propulsão da Cadeira de Rodas. As linhas tracejadas representam as médias do lado esquerdo. 


\section{A8.2 - Elevação para Alívio da PRESsão}

Tab. A8.2 - Características da elevação para alívio da pressão

\begin{tabular}{lcc}
\hline & $\begin{array}{c}\text { Tempo } \\
{[\mathrm{s}]}\end{array}$ & $\begin{array}{c}\text { Elevação } \\
{[\mathrm{cm}]}\end{array}$ \\
\hline Média & 6,65 & 18,22 \\
Desvio Padrão & 0,30 & 1,23 \\
\hline
\end{tabular}

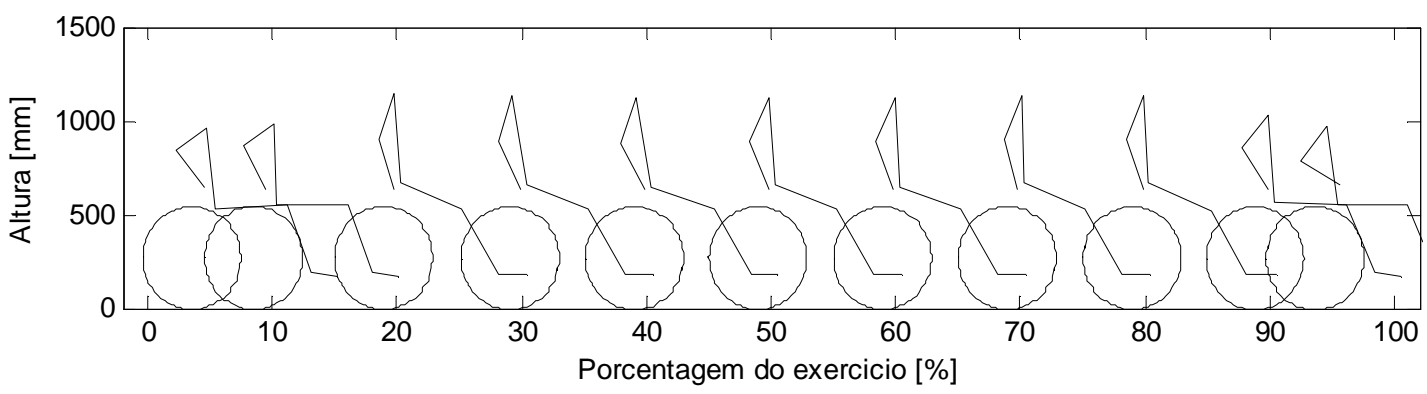

Fig. A8.4 Diagrama do movimento do Paciente 8 durante a Elevação para Alívio da pressão.
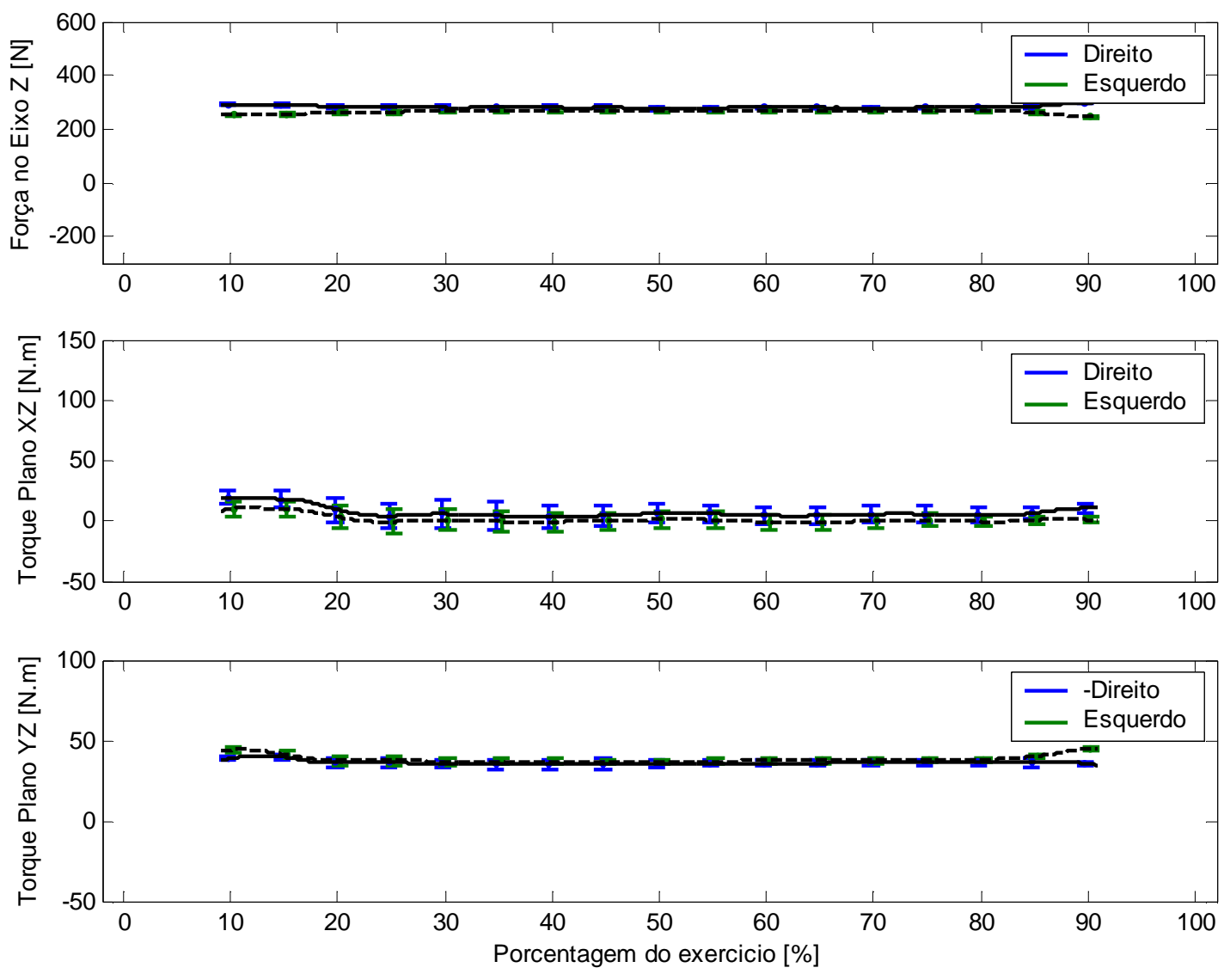

Fig. A8.5 Médias e Desvios Padrões dos Dados Cinéticos do Paciente 8 durante a Elevação para Alívio da pressão. As linhas tracejadas representam as médias do lado esquerdo. 

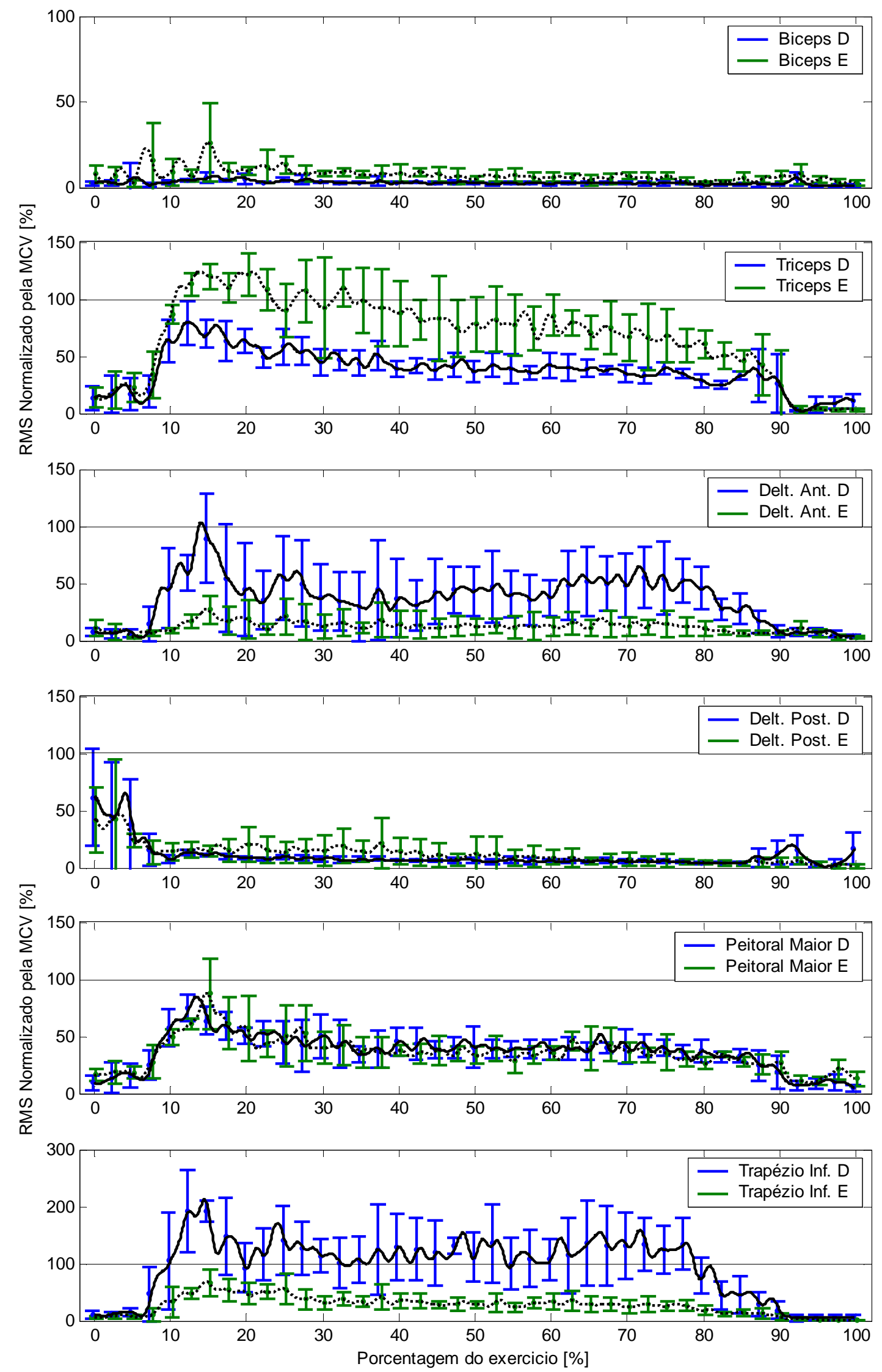

Fig. A8.6 Médias e Desvios Padrões das Atividades Musculares do Paciente 8 durante a Elevação para Alívio da pressão. As linhas tracejadas representam as médias do lado esquerdo. 


\section{A9.1 - PROPUlsão da CADEIRA de Rodas}

Tab. A9.1 - Características dos 3 ciclos iniciais de propulsão da cadeira de rodas

\begin{tabular}{lccc}
\hline & $\begin{array}{c}\text { Tempo } \\
{[\mathrm{s}]}\end{array}$ & $\begin{array}{c}\text { Distância } \\
{[\mathrm{cm}]}\end{array}$ & $\begin{array}{c}\text { Velocidade } \\
{[\mathrm{cm} / \mathrm{s}]}\end{array}$ \\
\hline Média & 4,29 & 116,34 & 27,54 \\
Desvio Padrão & 0,35 & 25,80 & 7,92 \\
\hline
\end{tabular}

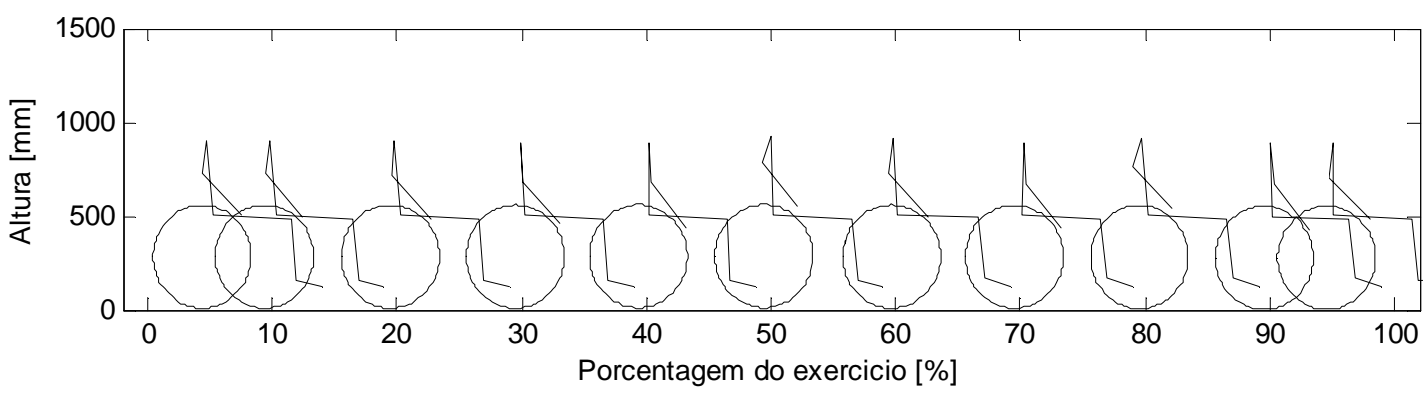

Fig. A9.1 Diagrama do movimento do Paciente 9 durante a Propulsão da Cadeira de Rodas.
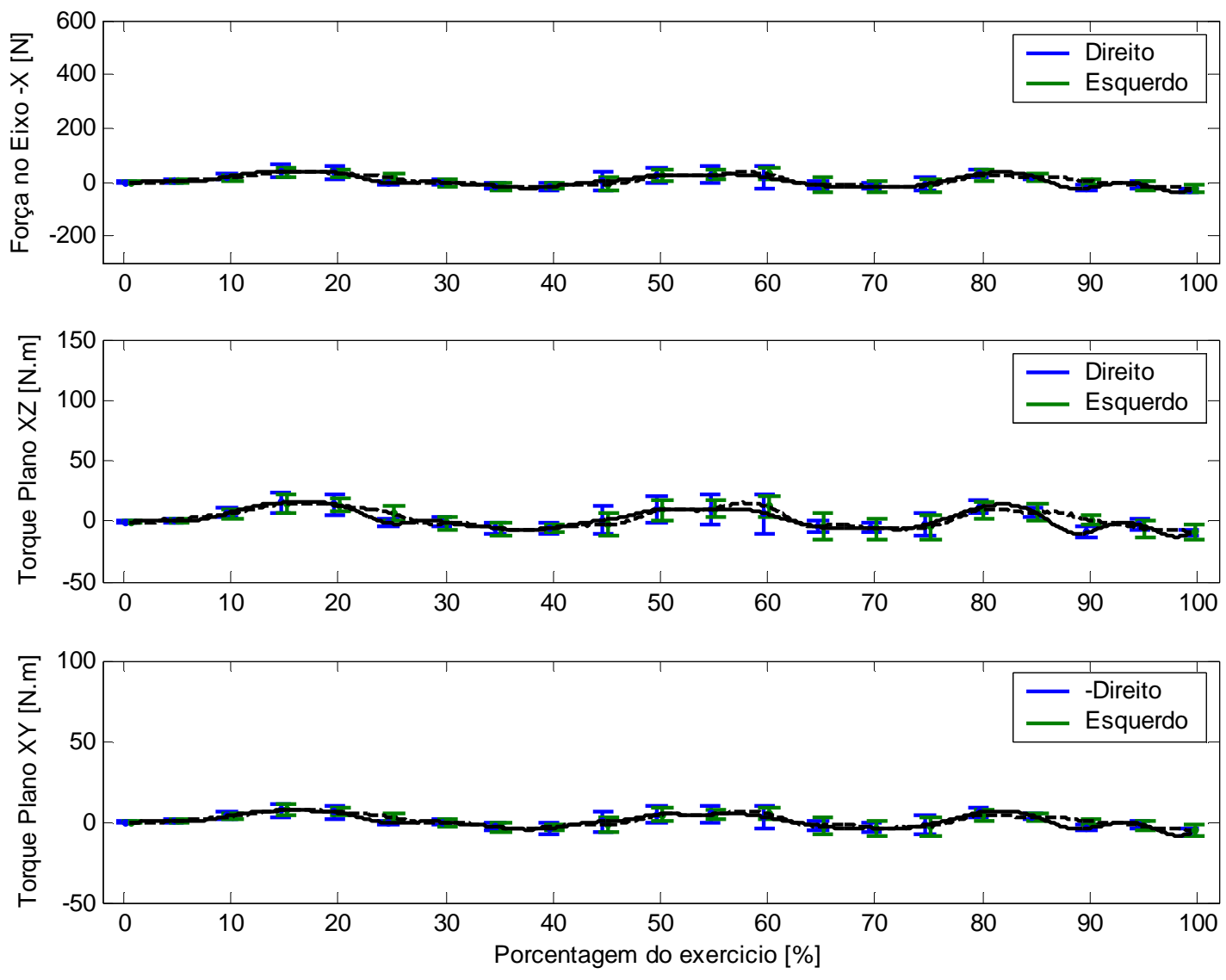

Fig. A9.2 Médias e Desvios Padrões dos Dados Cinéticos do Paciente 9 durante a Propulsão da Cadeira de Rodas. As linhas tracejadas representam as médias do lado esquerdo. 

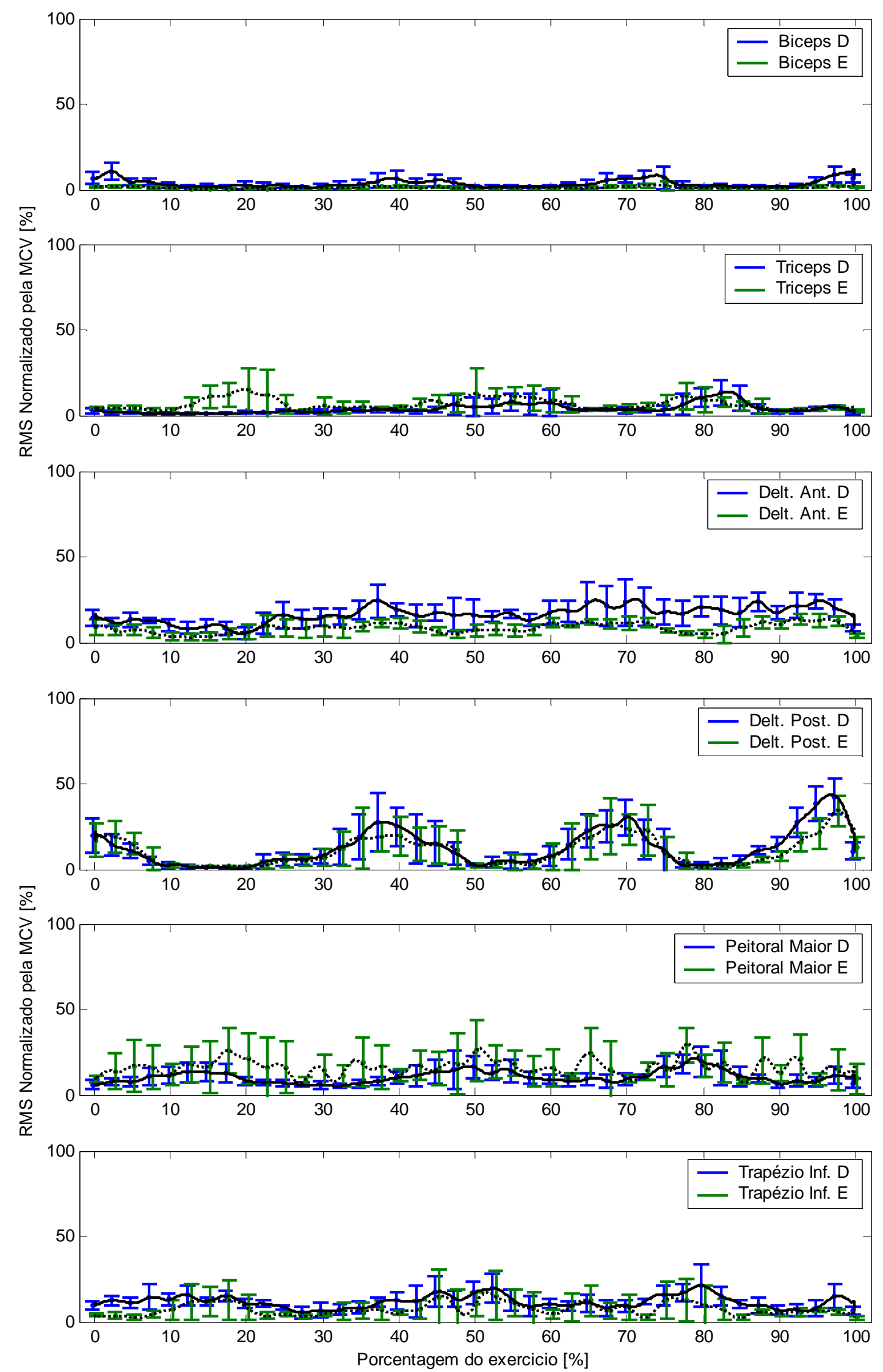

Fig. A9.3 Médias e Desvios Padrões das Atividades Musculares do Paciente 9 durante a Propulsão da Cadeira de Rodas. As linhas tracejadas representam as médias do lado esquerdo. 


\section{A9.2 - Elevação para Alívio da PRESsão}

Tab. A9.2 - Características da elevação para alívio da pressão

\begin{tabular}{lcc}
\hline & $\begin{array}{c}\text { Tempo } \\
{[\mathrm{s}]}\end{array}$ & $\begin{array}{c}\text { Elevação } \\
{[\mathrm{cm}]}\end{array}$ \\
\hline Média & 7,88 & 14,63 \\
Desvio Padrão & 0,06 & 0,64 \\
\hline
\end{tabular}

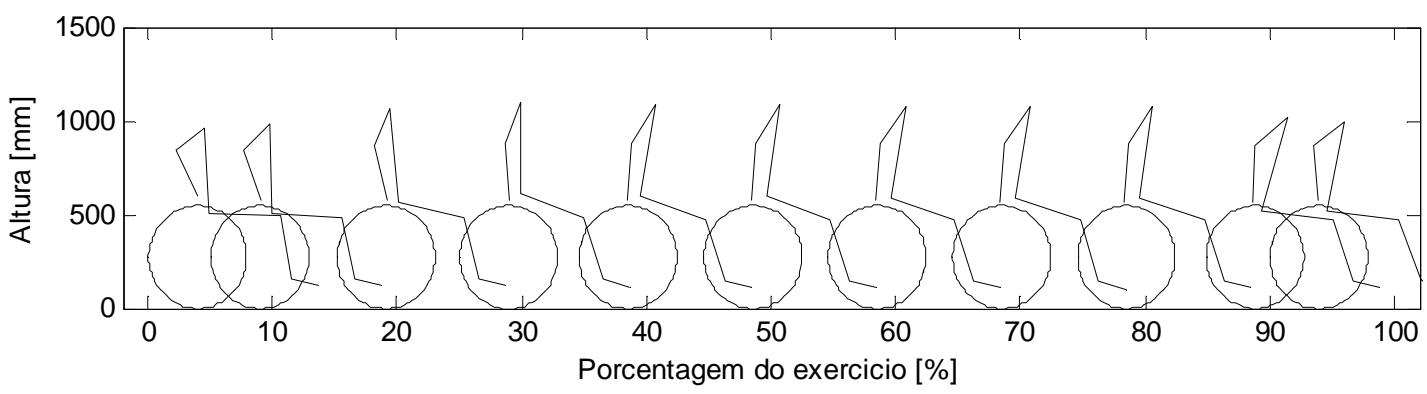

Fig. A9.4 Diagrama do movimento do Paciente 9 durante a Elevação para Alívio da pressão.
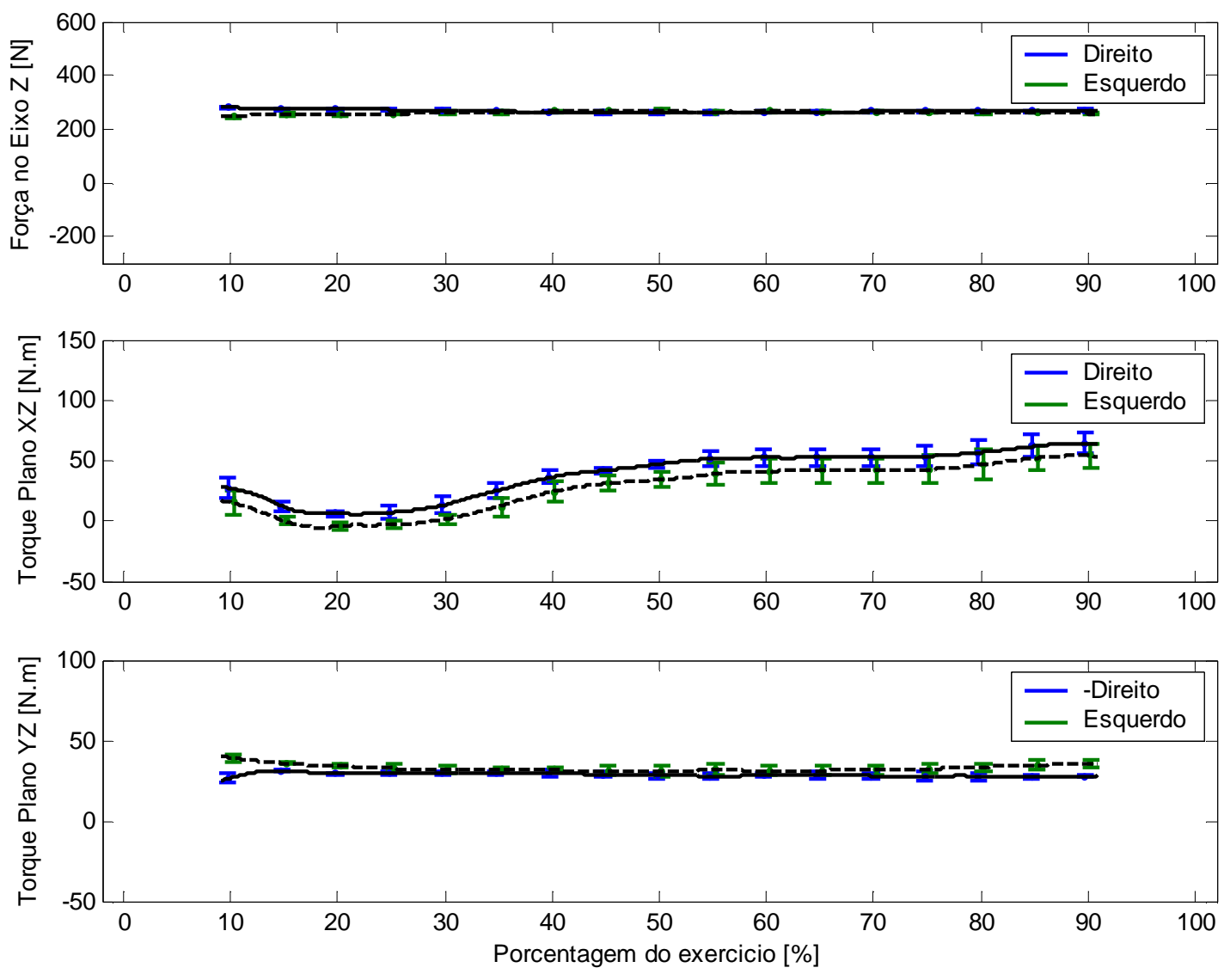

Fig. A9.5 Médias e Desvios Padrões dos Dados Cinéticos do Paciente 9 durante a Elevação para Alívio da pressão. As linhas tracejadas representam as médias do lado esquerdo. 

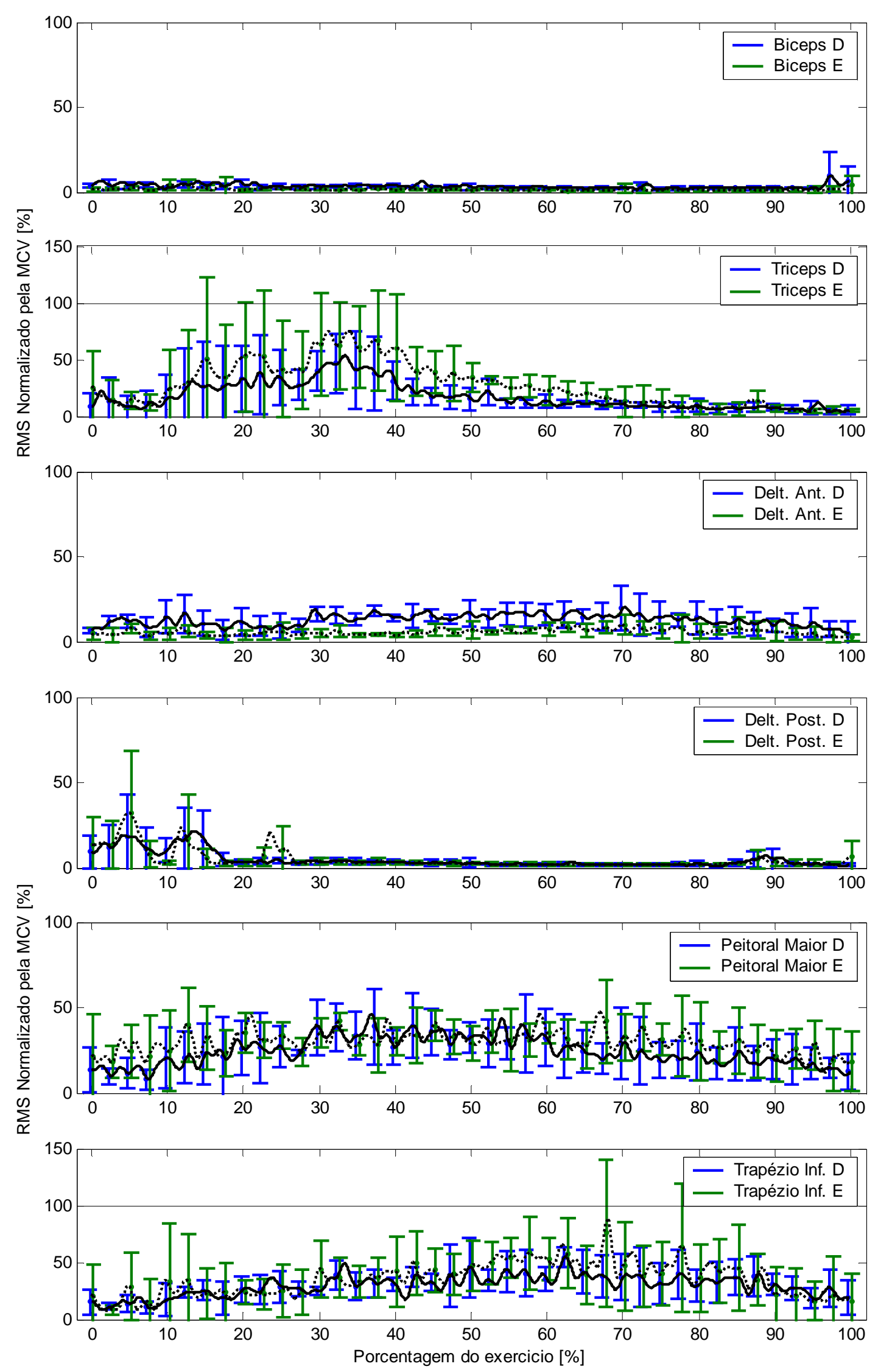

Fig. A9.6 Médias e Desvios Padrões das Atividades Musculares do Paciente 9 durante a Elevação para Alívio da pressão. As linhas tracejadas representam as médias do lado esquerdo. 


\section{A10.1 - Propulsão da CADEIRA de Rodas}

Tab. A10.1 - Características dos 3 ciclos iniciais de propulsão da cadeira de rodas

\begin{tabular}{lccc}
\hline & $\begin{array}{c}\text { Tempo } \\
{[\mathrm{s}]}\end{array}$ & $\begin{array}{c}\text { Distância } \\
{[\mathrm{cm}]}\end{array}$ & $\begin{array}{c}\text { Velocidade } \\
{[\mathrm{cm} / \mathrm{s}]}\end{array}$ \\
\hline Média & 3,67 & 218,49 & 59,90 \\
Desvio Padrão & 0,24 & 19,72 & 8,66 \\
\hline
\end{tabular}

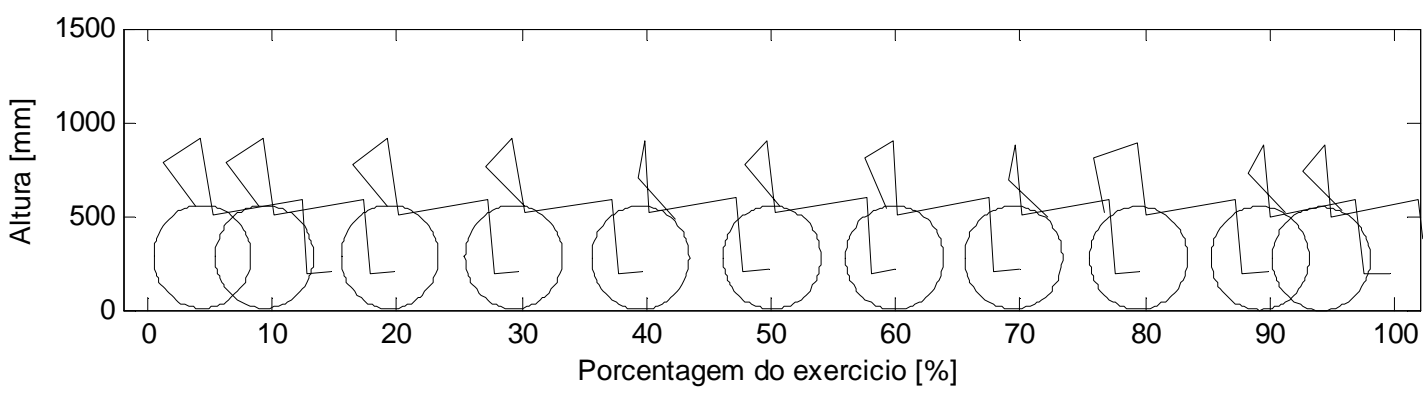

Fig. A10.1 Diagrama do movimento do Paciente 10 durante a Propulsão da Cadeira de Rodas.
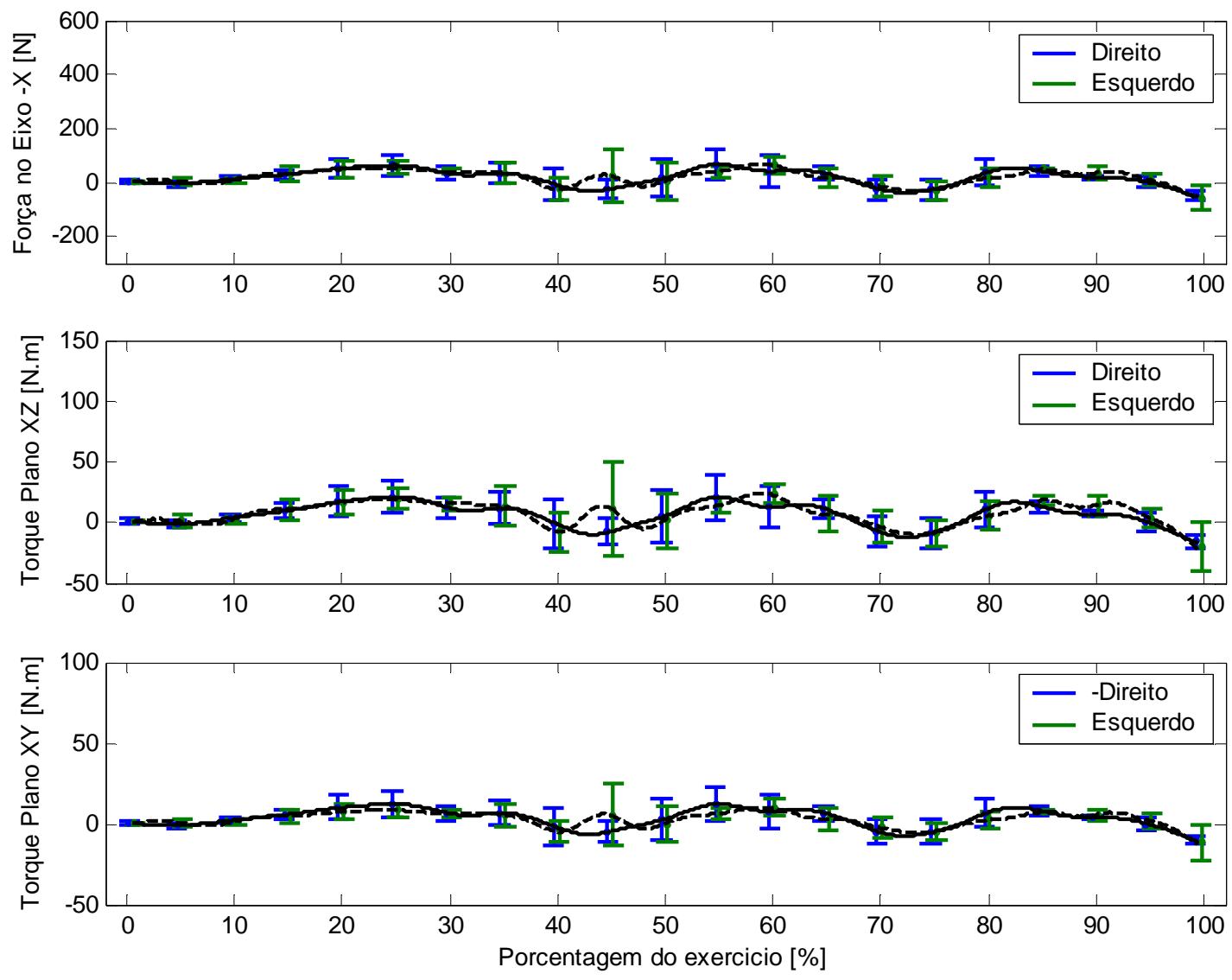

Fig. A10.2 Médias e Desvios Padrões dos Dados Cinéticos do Paciente 10 durante a Propulsão da Cadeira de Rodas. As linhas tracejadas representam as médias do lado esquerdo. 

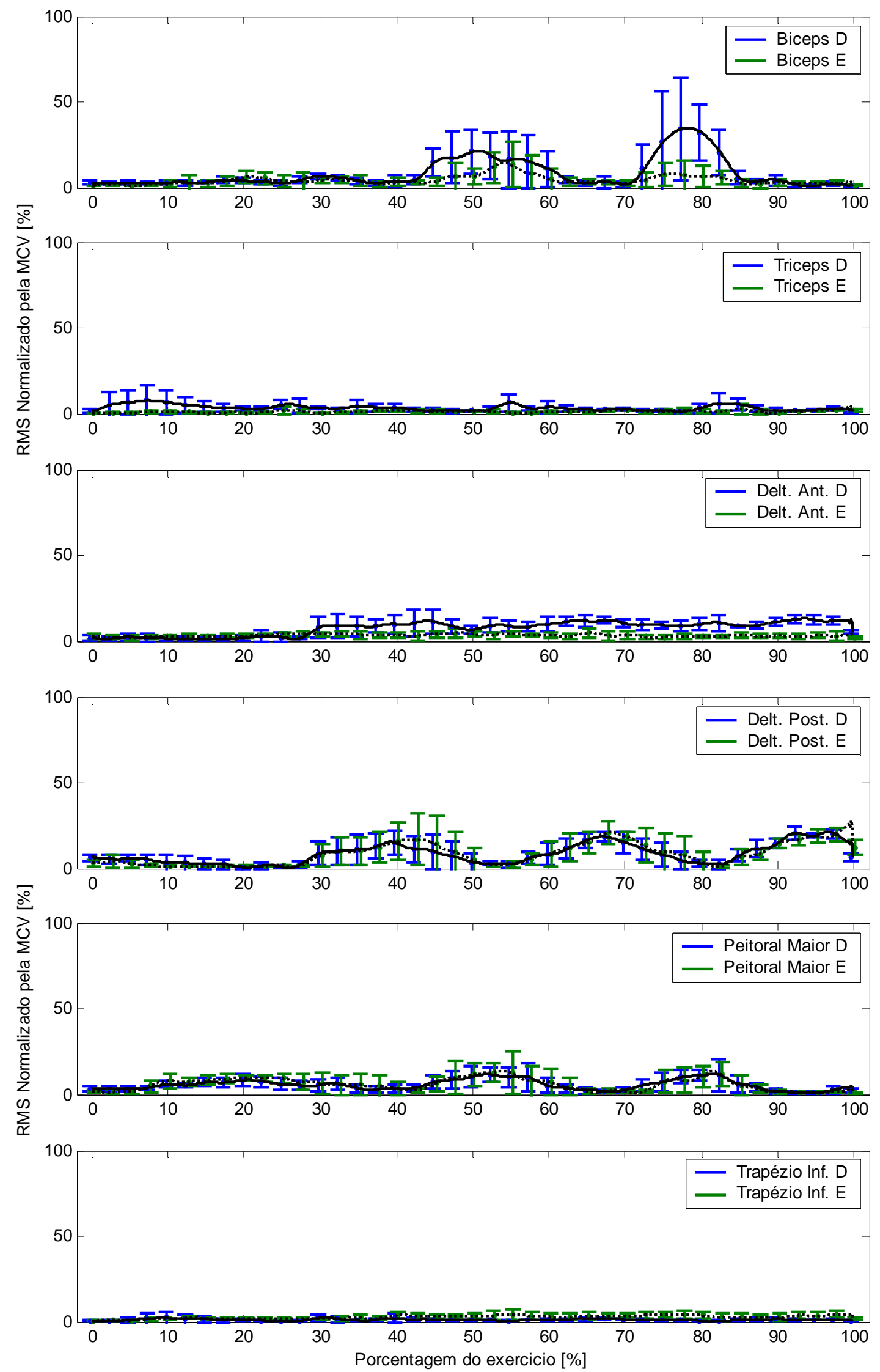

Fig. A10.3 Médias e Desvios Padrões das Atividades Musculares do Paciente 10 durante a Propulsão da Cadeira de Rodas. As linhas tracejadas representam as médias do lado esquerdo. 


\section{A10.2 - EleVAÇÃo para ALÍVIO da PRESSÃo}

Tab. A10.2 - Características da elevação para alívio da pressão

\begin{tabular}{lcc}
\hline & $\begin{array}{c}\text { Tempo } \\
{[\mathrm{s}]}\end{array}$ & $\begin{array}{c}\text { Elevação } \\
{[\mathrm{cm}]}\end{array}$ \\
\hline Média & 6,85 & 30,23 \\
Desvio Padrão & 0,94 & 5,12 \\
\hline
\end{tabular}

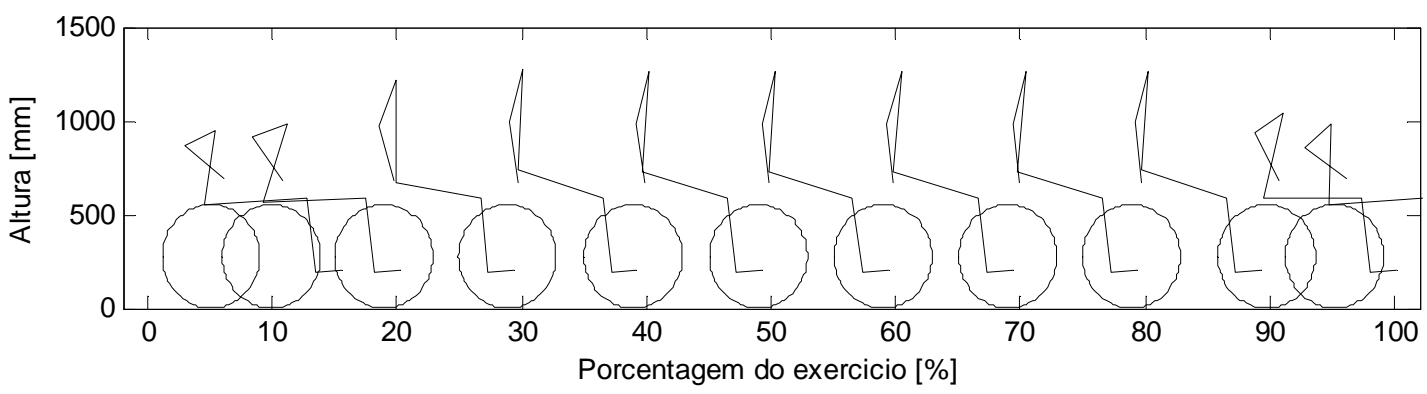

Fig. A10.4 Diagrama do movimento do Paciente 10 durante a Elevação para Alívio da pressão.
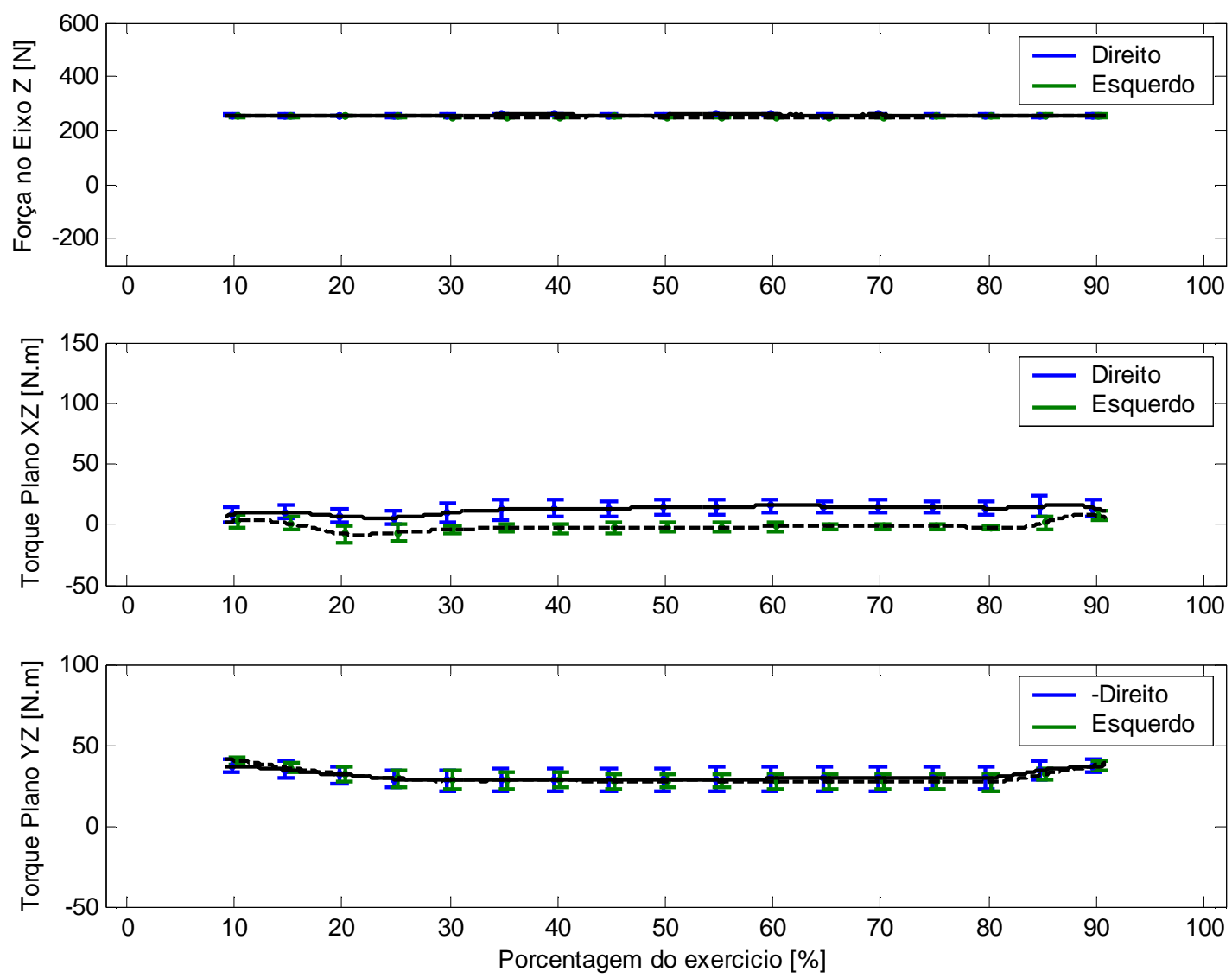

Fig. A10.5 Médias e Desvios Padrões dos Dados Cinéticos do Paciente 10 durante a Elevação para Alívio da pressão. As linhas tracejadas representam as médias do lado esquerdo. 

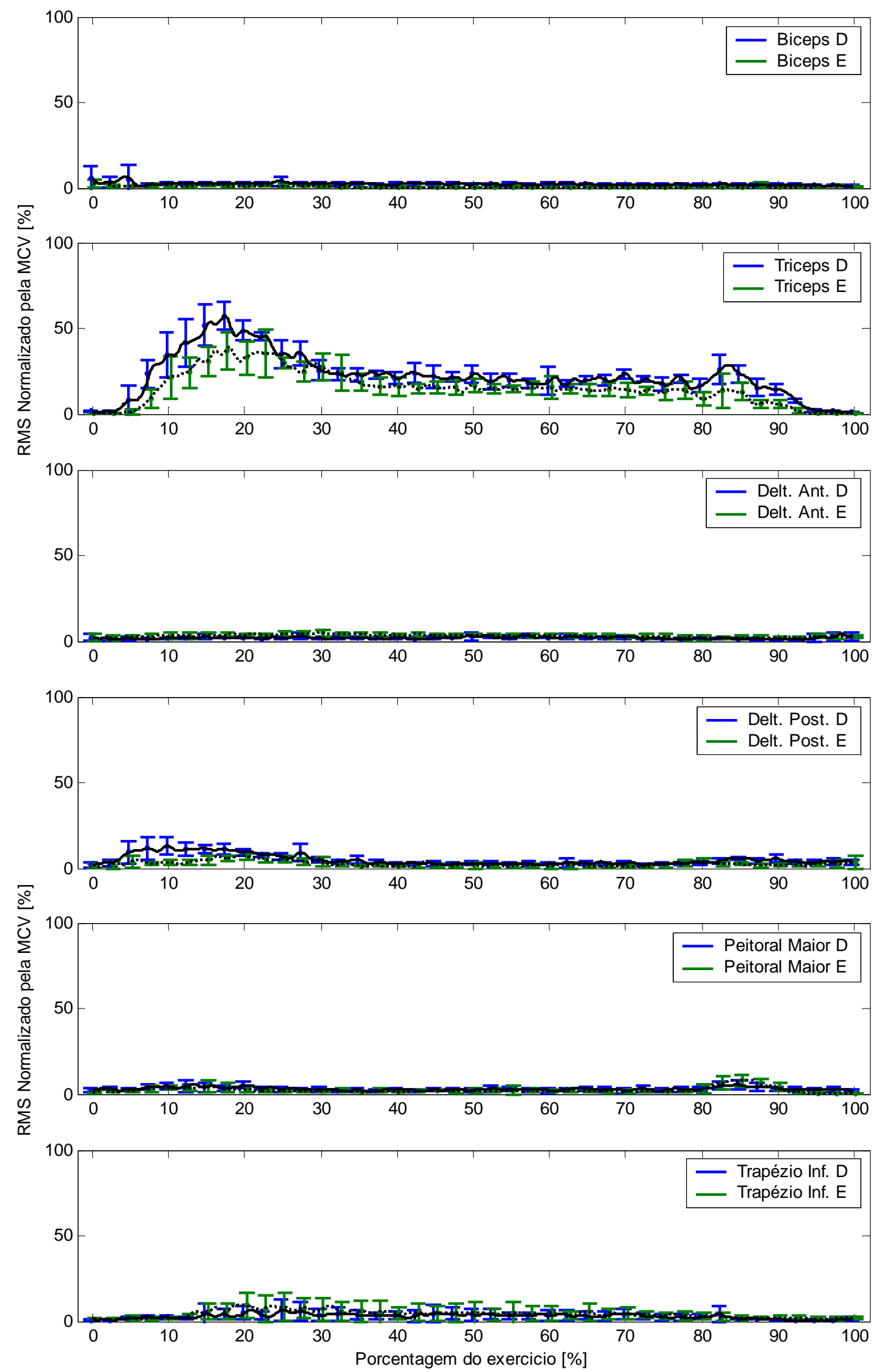

Fig. A10.6 Médias e Desvios Padrões das Atividades Musculares do Paciente 10 durante a Elevação para Alívio da pressão. As linhas tracejadas representam as médias do lado esquerdo. 


\section{A11.1 - PRopulsão da CADEIRA de Rodas}

Tab. A11.1 - Características dos 3 ciclos iniciais de propulsão da cadeira de rodas

\begin{tabular}{lccc}
\hline & $\begin{array}{c}\text { Tempo } \\
{[\mathrm{s}]}\end{array}$ & $\begin{array}{c}\text { Distância } \\
{[\mathrm{cm}]}\end{array}$ & $\begin{array}{c}\text { Velocidade } \\
{[\mathrm{cm} / \mathrm{s}]}\end{array}$ \\
\hline Média & 3,55 & 178,01 & 50,40 \\
Desvio Padrão & 0,39 & 12,63 & 4,63 \\
\hline
\end{tabular}

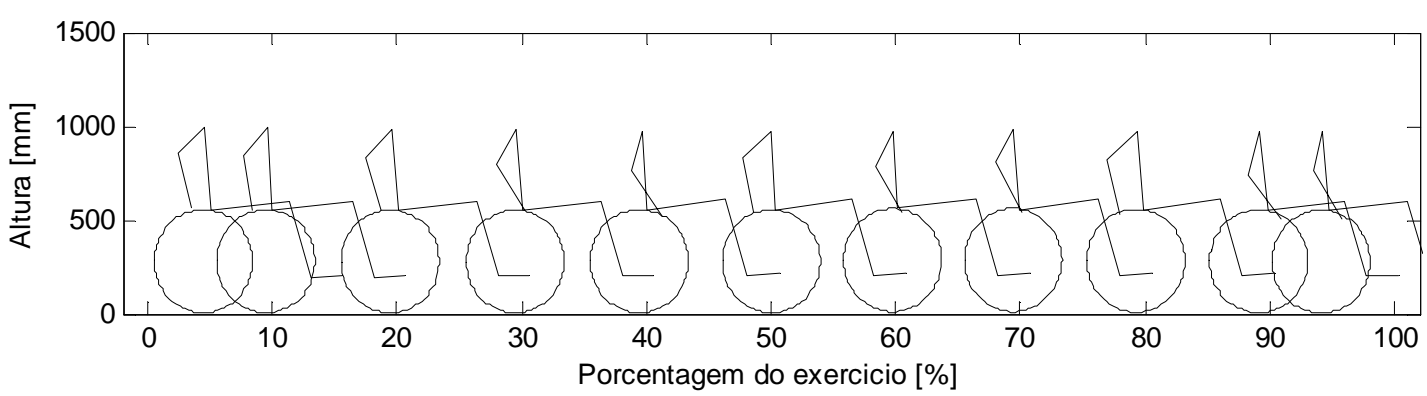

Fig. A11.1 Diagrama do movimento do Paciente 11 durante a Propulsão da Cadeira de Rodas.
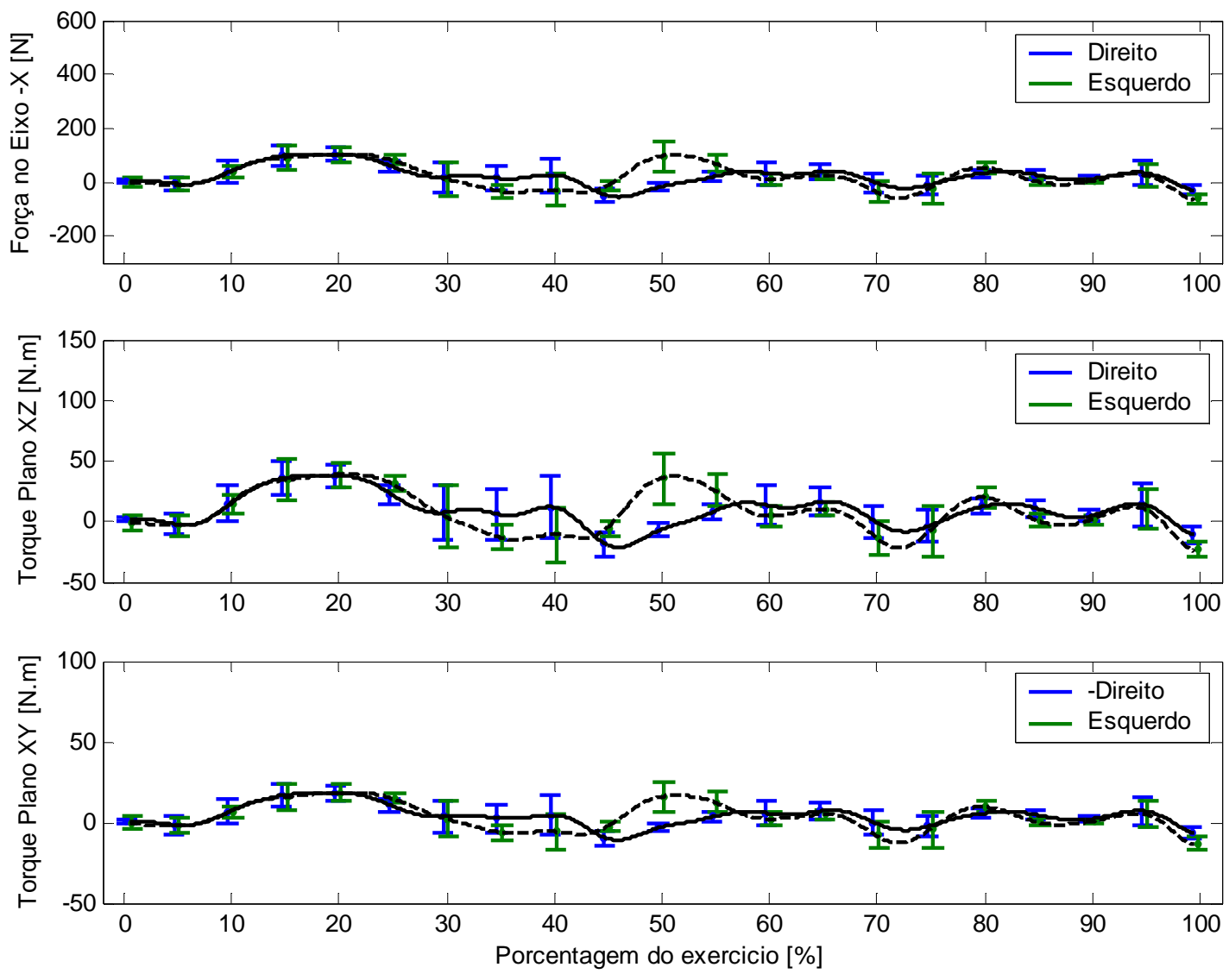

Fig. A11.2 Médias e Desvios Padrões dos Dados Cinéticos do Paciente 11 durante a Propulsão da Cadeira de Rodas. As linhas tracejadas representam as médias do lado esquerdo. 

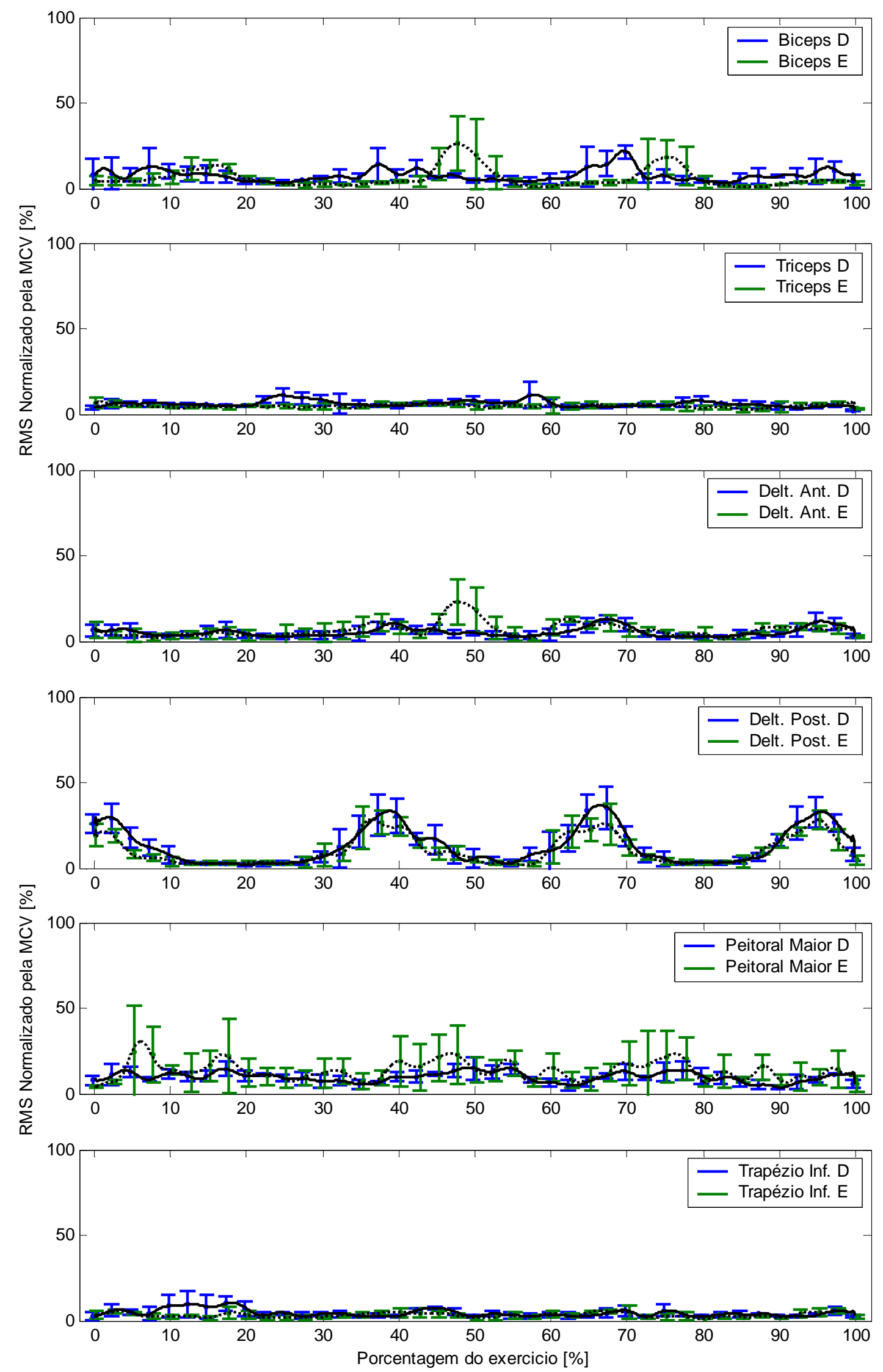

Fig. A11.3 Médias e Desvios Padrões das Atividades Musculares do Paciente 11 durante a Propulsão da Cadeira de Rodas. As linhas tracejadas representam as médias do lado esquerdo. 


\section{A11.2 - Elevação para Alívio da pressão}

Tab. A11.2 - Características da elevação para alívio da pressão

\begin{tabular}{lcc}
\hline & Tempo & Elevação \\
& {$[\mathrm{s}]$} & {$[\mathrm{cm}]$} \\
\hline Média & 6,51 & 23,12 \\
Desvio Padrão & 0,42 & 0,86 \\
\hline
\end{tabular}

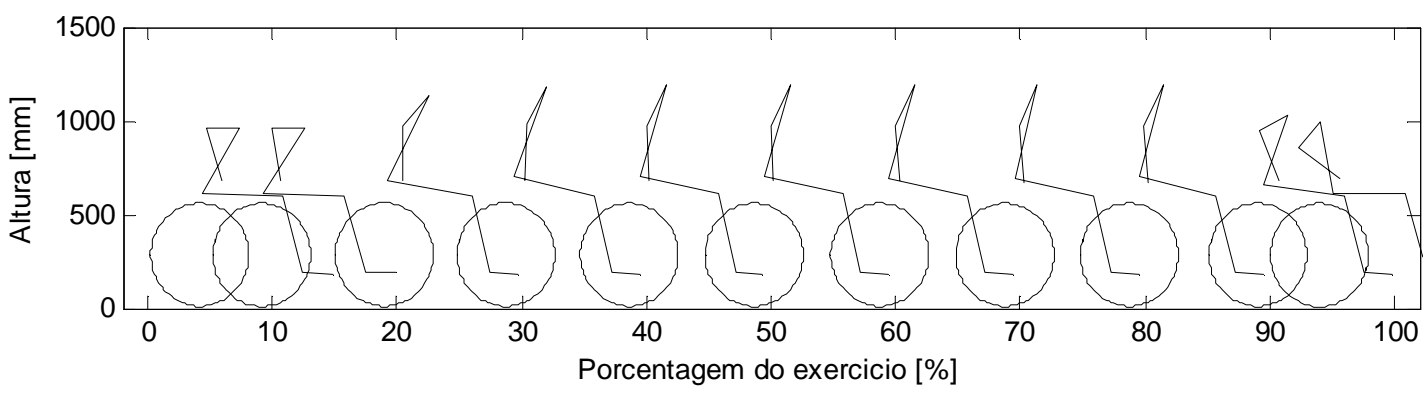

Fig. A11.4 Diagrama do movimento do Paciente 11 durante a Elevação para Alívio da pressão.
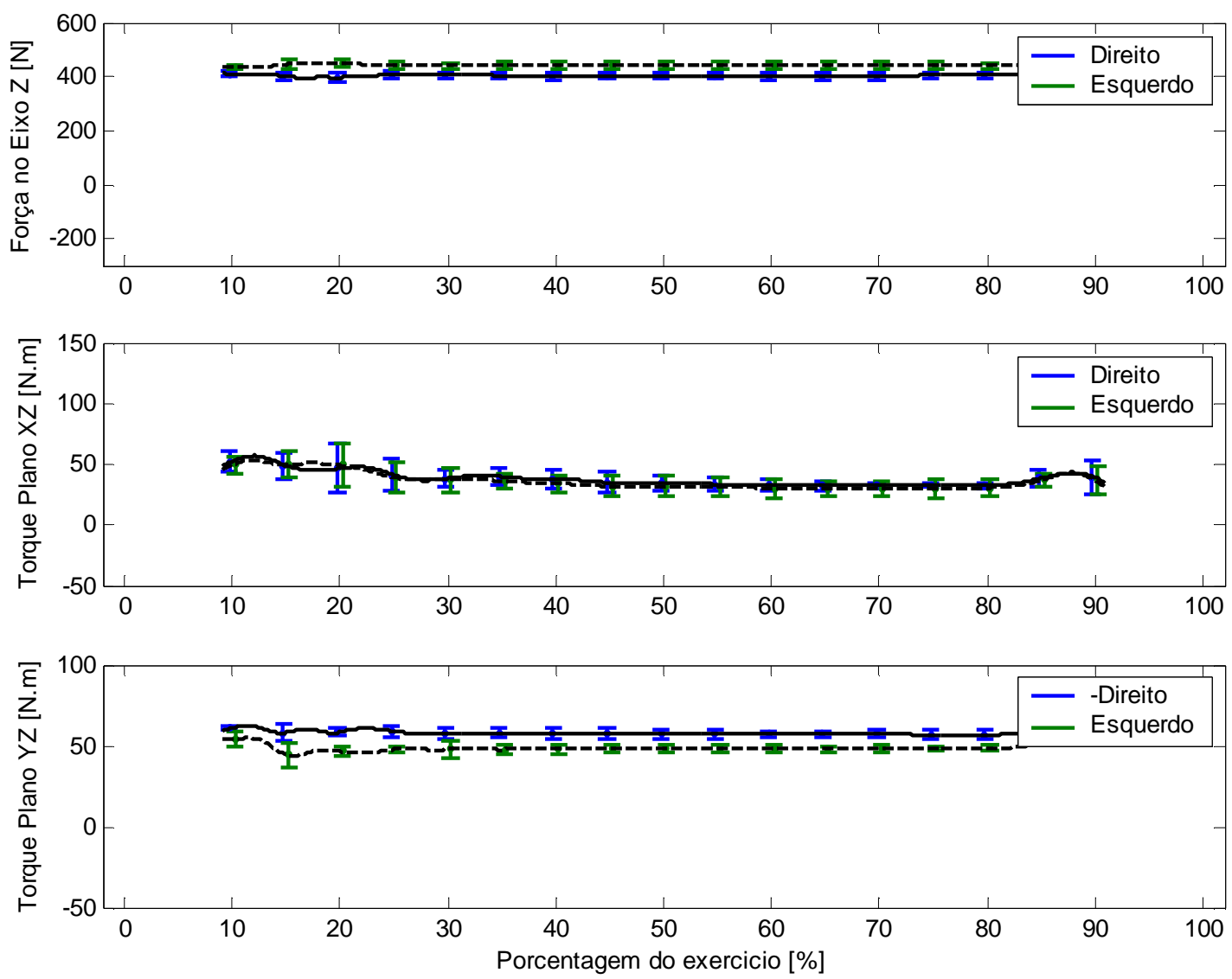

Fig. A11.5 Médias e Desvios Padrões dos Dados Cinéticos do Paciente 11 durante a Elevação para Alívio da pressão. As linhas tracejadas representam as médias do lado esquerdo. 

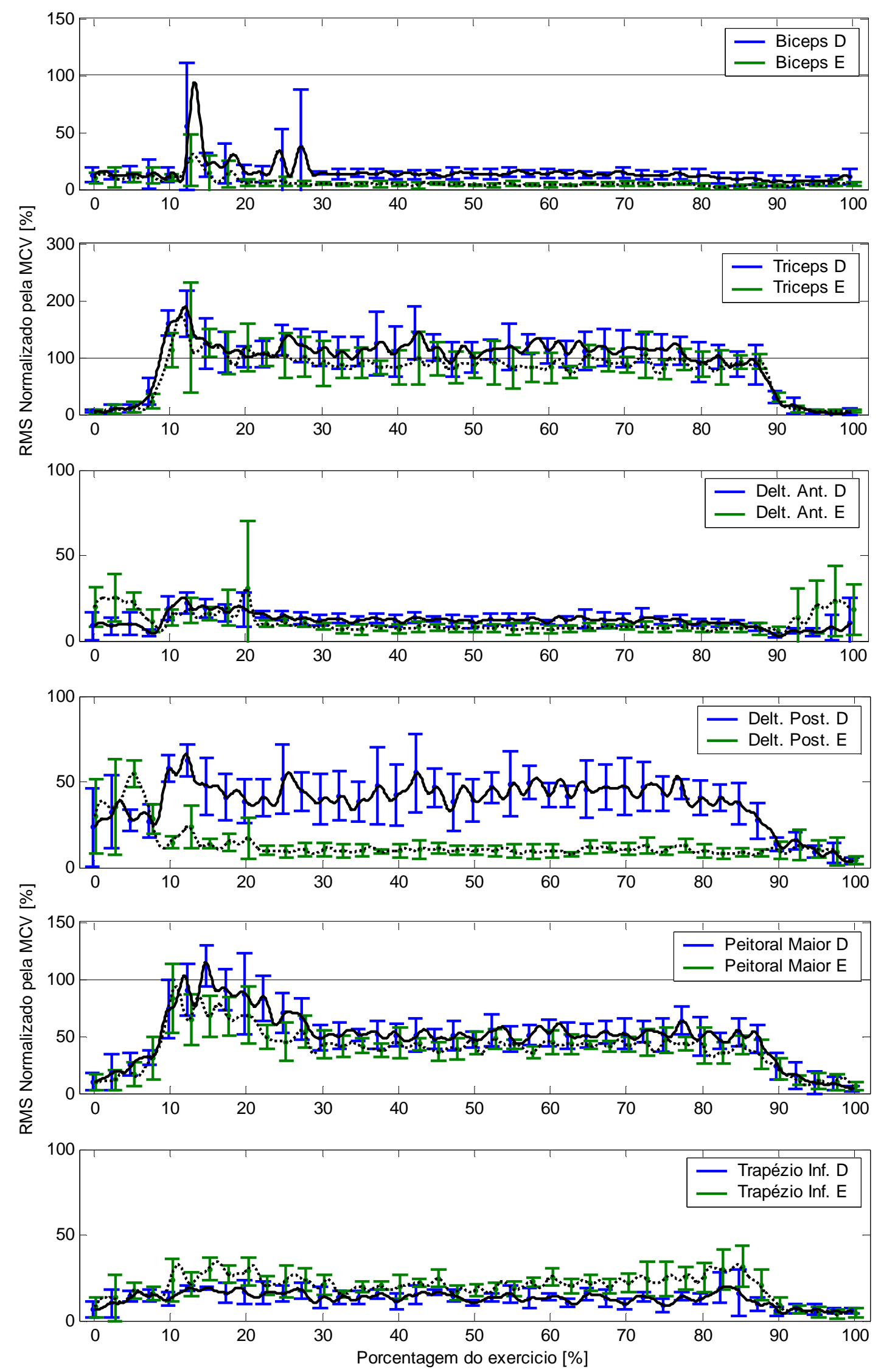

Fig. A11.6 Médias e Desvios Padrões das Atividades Musculares do Paciente 11 durante a Elevação para Alívio da pressão. As linhas tracejadas representam as médias do lado esquerdo. 


\section{A11.3 - MARCHA COM ANDADOR E EENM}

Tab. A11.3 - Características da passada com andador e EENM

\begin{tabular}{lcccc}
\hline & $\begin{array}{c}\text { Tempo } \\
{[\mathrm{s}]}\end{array}$ & $\begin{array}{c}\text { Passada } \\
{[\mathrm{cm}]}\end{array}$ & $\begin{array}{c}\text { Velocidade } \\
{[\mathrm{cm} / \mathrm{s}]}\end{array}$ & $\begin{array}{c}\text { Cadência } \\
\text { [passos/min] }\end{array}$ \\
\hline Média & 6,63 & 65,92 & 10,07 & 18,26 \\
Desvio Padrão & 0,69 & 3,51 & 1,51 & 1,87 \\
\hline
\end{tabular}

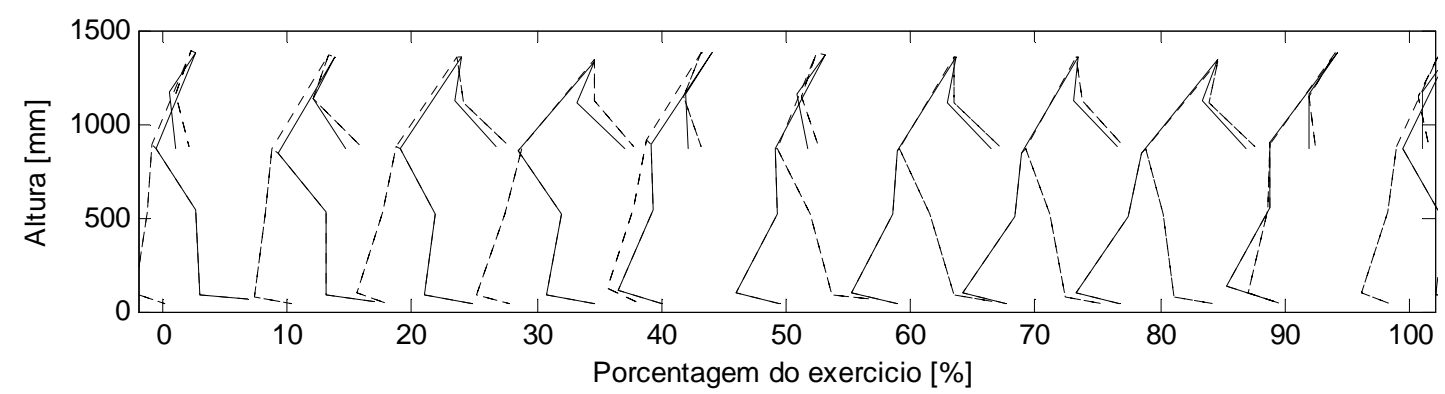

Fig. A11.7 Diagrama do movimento do Paciente 11 durante a Marcha com Andador e EENM.
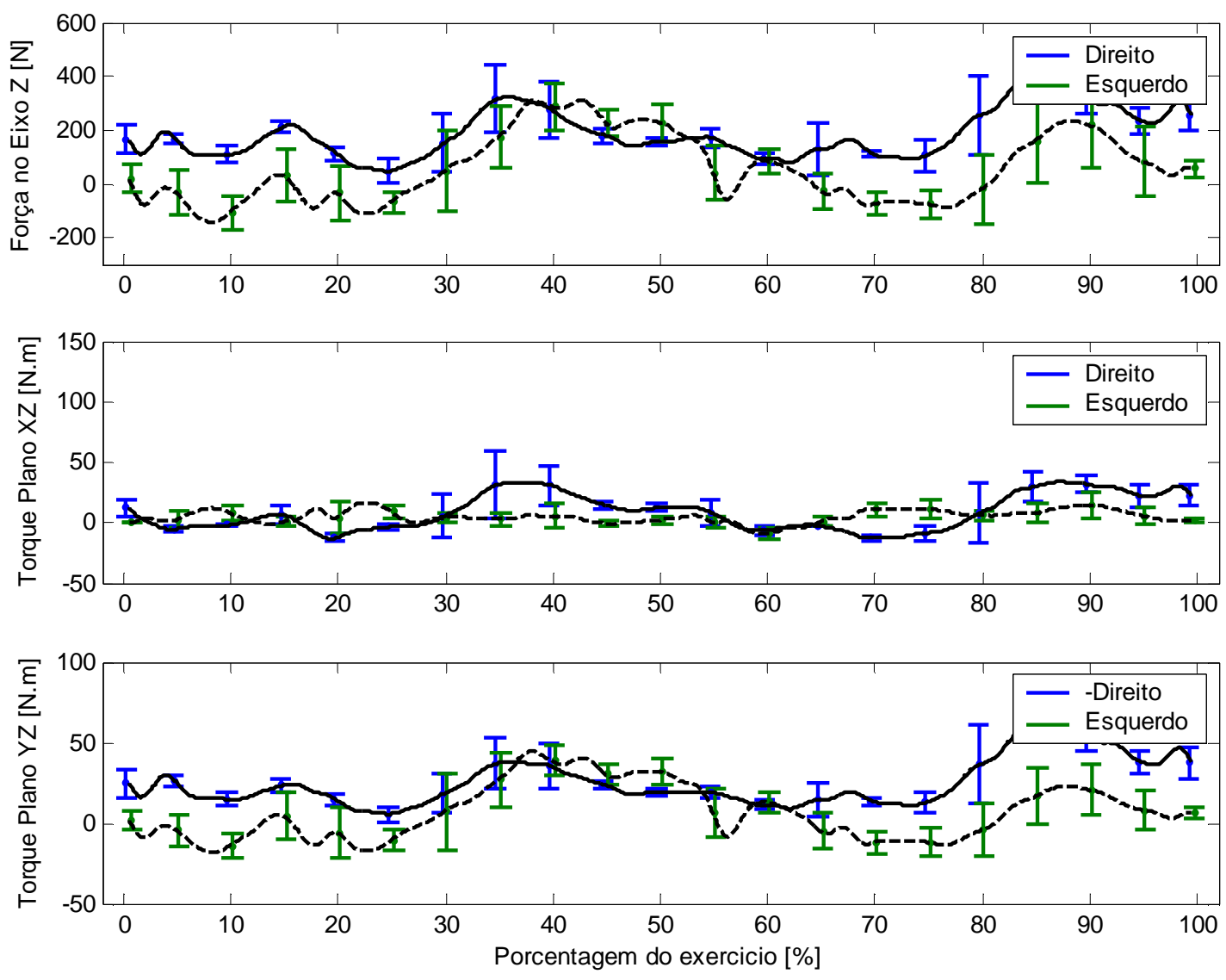

Fig. A11.8 Médias e Desvios Padrões dos Dados Cinéticos do Paciente 11 durante a Marcha com Andador e EENM. As linhas tracejadas representam as médias do lado esquerdo. 

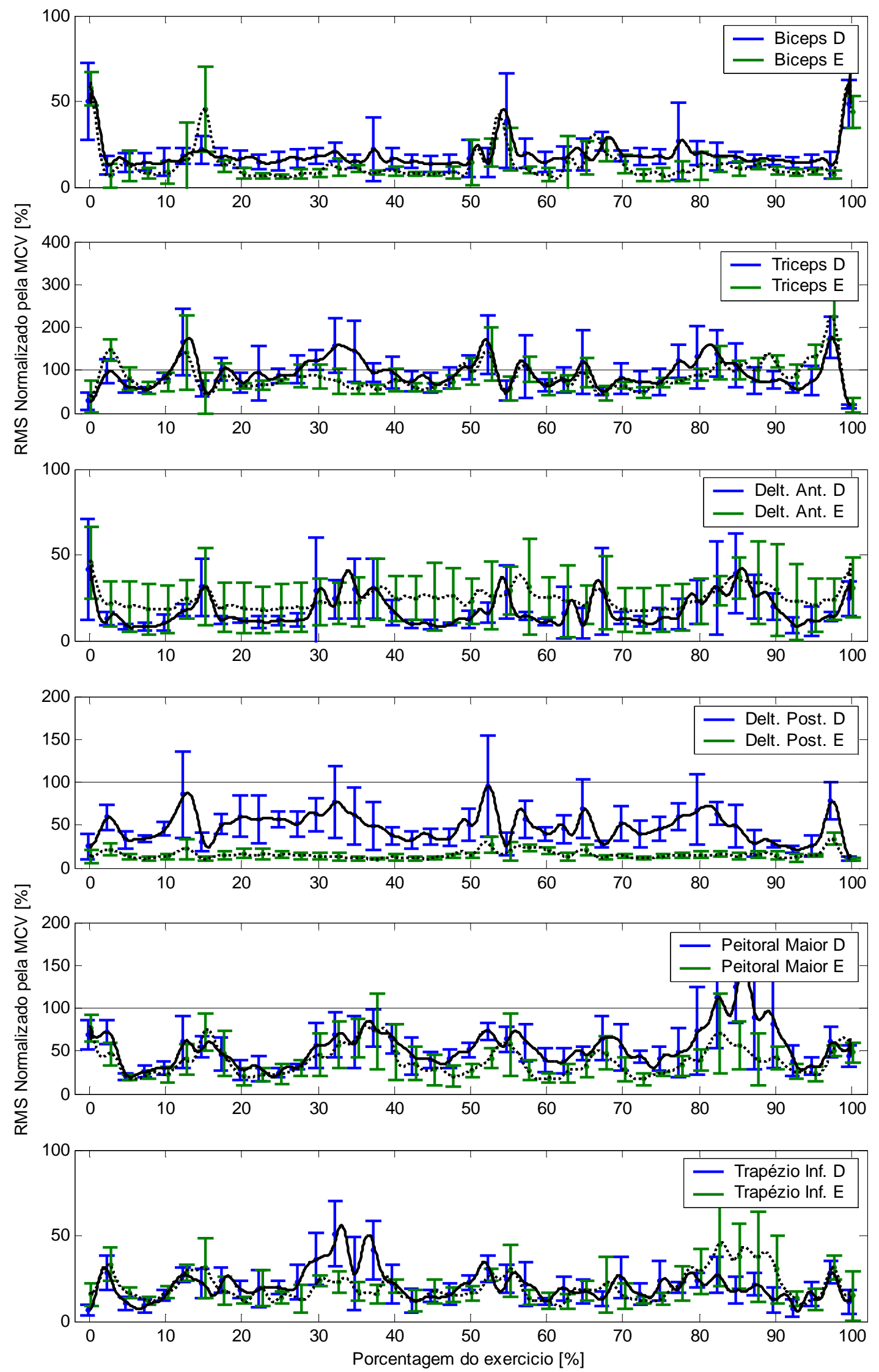

Fig. A11.9 Médias e Desvios Padrões das Atividades Musculares do Paciente 11 durante a Marcha com Andador e EENM. As linhas tracejadas representam as médias do lado esquerdo. 


\section{A12.1 - PROPUlsão da CADEIRA de RodAs}

Tab. A12.1 - Características dos 3 ciclos iniciais de propulsão da cadeira de rodas

\begin{tabular}{lccc}
\hline & $\begin{array}{c}\text { Tempo } \\
{[\mathrm{s}]}\end{array}$ & $\begin{array}{c}\text { Distância } \\
{[\mathrm{cm}]}\end{array}$ & $\begin{array}{c}\text { Velocidade } \\
{[\mathrm{cm} / \mathrm{s}]}\end{array}$ \\
\hline Média & 3,63 & 153,82 & 42,49 \\
Desvio Padrão & 0,19 & 18,58 & 5,44 \\
\hline
\end{tabular}

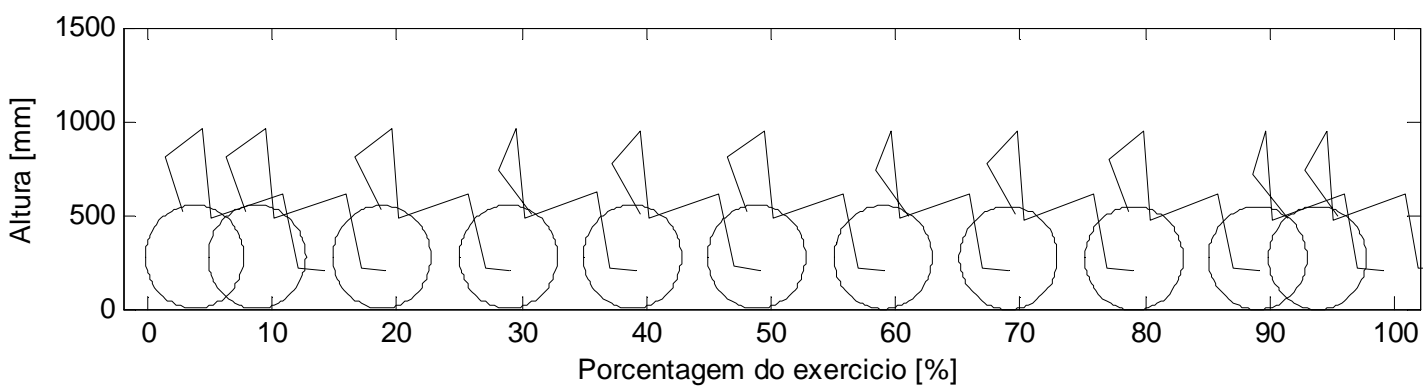

Fig. A12.1 Diagrama do movimento do Paciente 12 durante a Propulsão da Cadeira de Rodas.
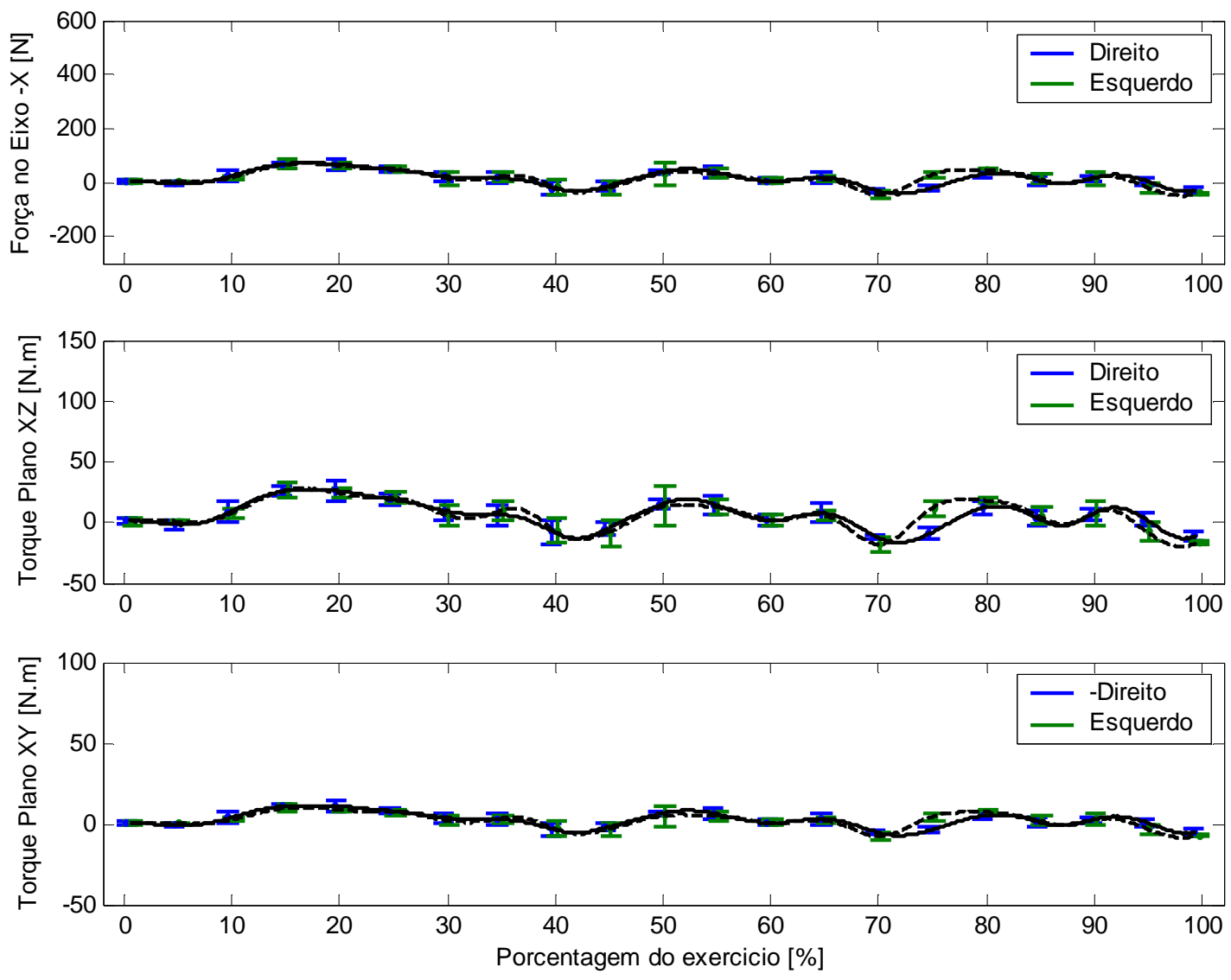

Fig. A12.2 Médias e Desvios Padrões dos Dados Cinéticos do Paciente 12 durante a Propulsão da Cadeira de Rodas. As linhas tracejadas representam as médias do lado esquerdo. 

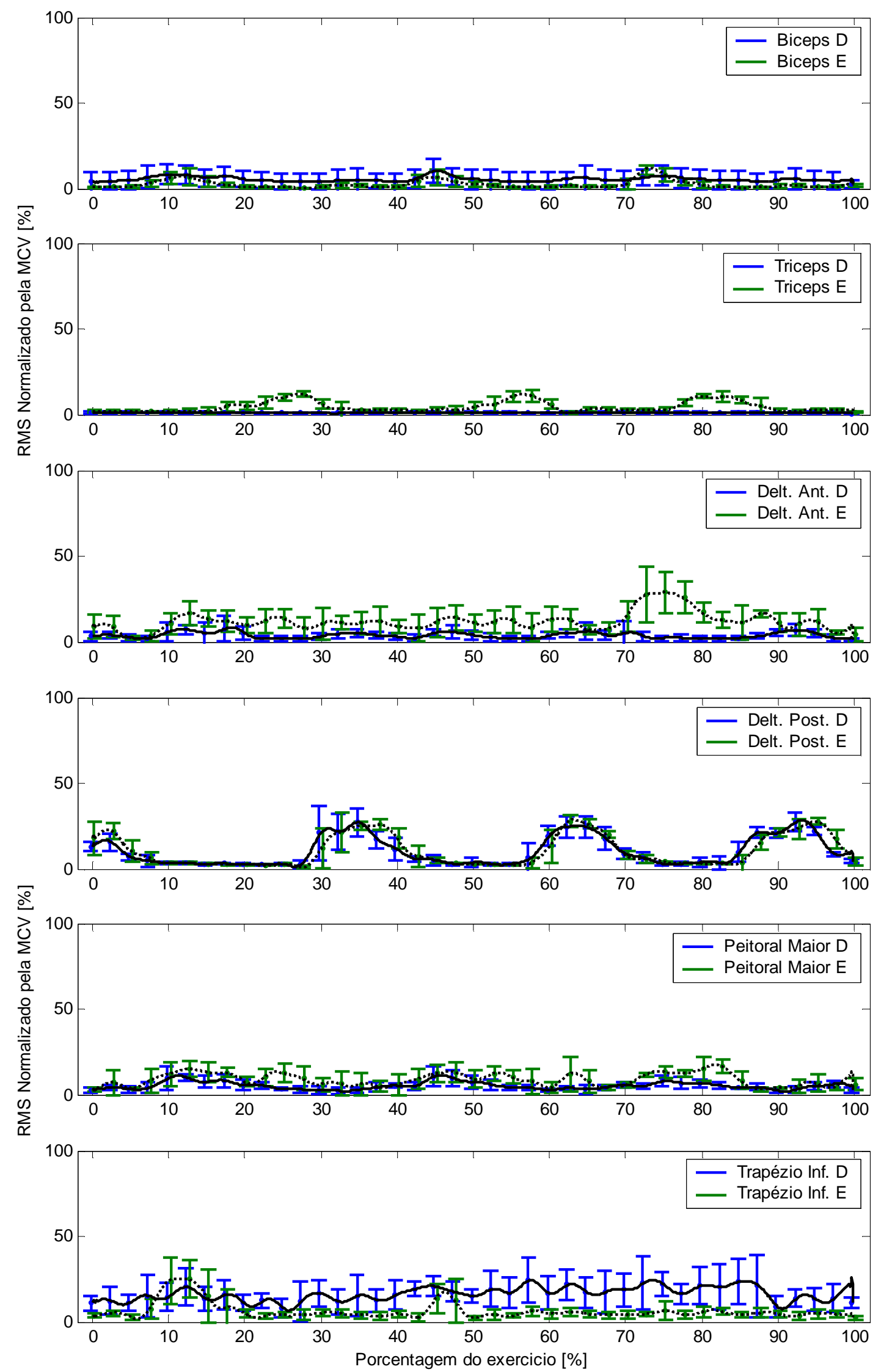

Fig. A12.3 Médias e Desvios Padrões das Atividades Musculares do Paciente 12 durante a Propulsão da Cadeira de Rodas. As linhas tracejadas representam as médias do lado esquerdo. 


\section{A12.2 - Elevação para Alívio da PRESsão}

Tab. A12.2 - Características da elevação para alívio da pressão

\begin{tabular}{lcc}
\hline & $\begin{array}{c}\text { Tempo } \\
{[\mathrm{s}]}\end{array}$ & $\begin{array}{c}\text { Elevação } \\
{[\mathrm{cm}]}\end{array}$ \\
\hline Média & 6,59 & 22,23 \\
Desvio Padrão & 0,22 & 0,84 \\
\hline
\end{tabular}

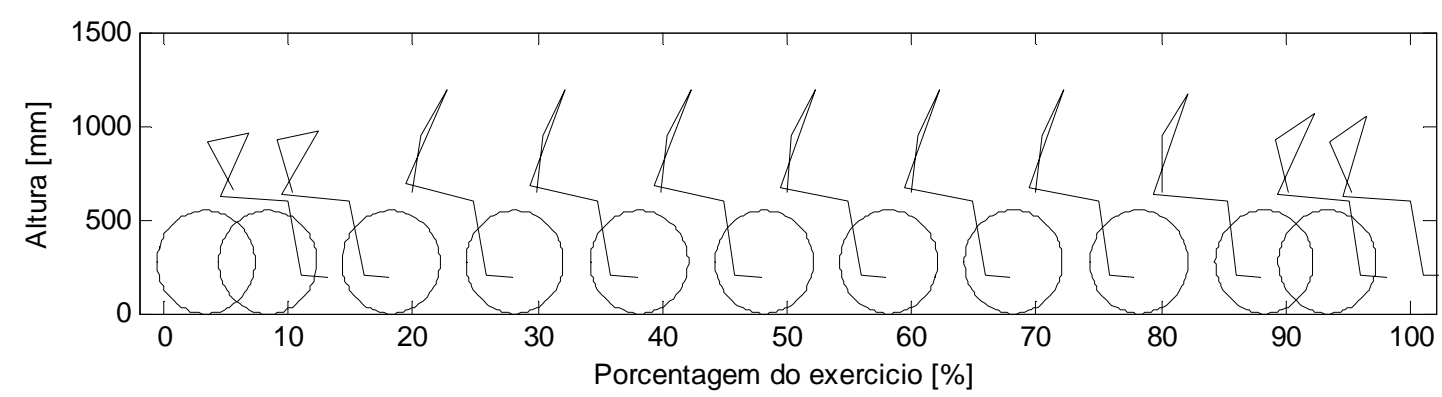

Fig. A12.4 Diagrama do movimento do Paciente 12 durante a Elevação para Alívio da pressão.
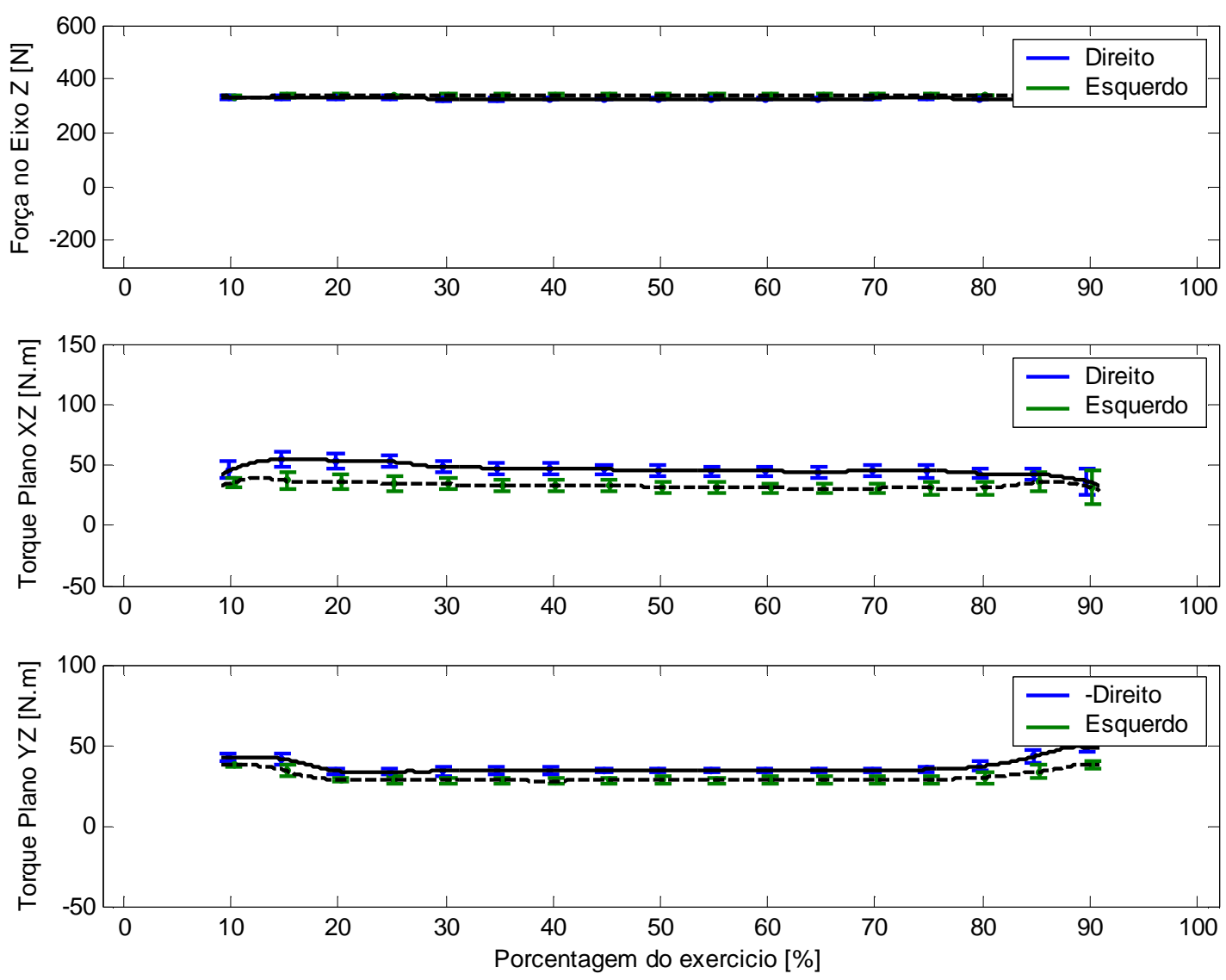

Fig. A12.5 Médias e Desvios Padrões dos Dados Cinéticos do Paciente 12 durante a Elevação para Alívio da pressão. As linhas tracejadas representam as médias do lado esquerdo. 

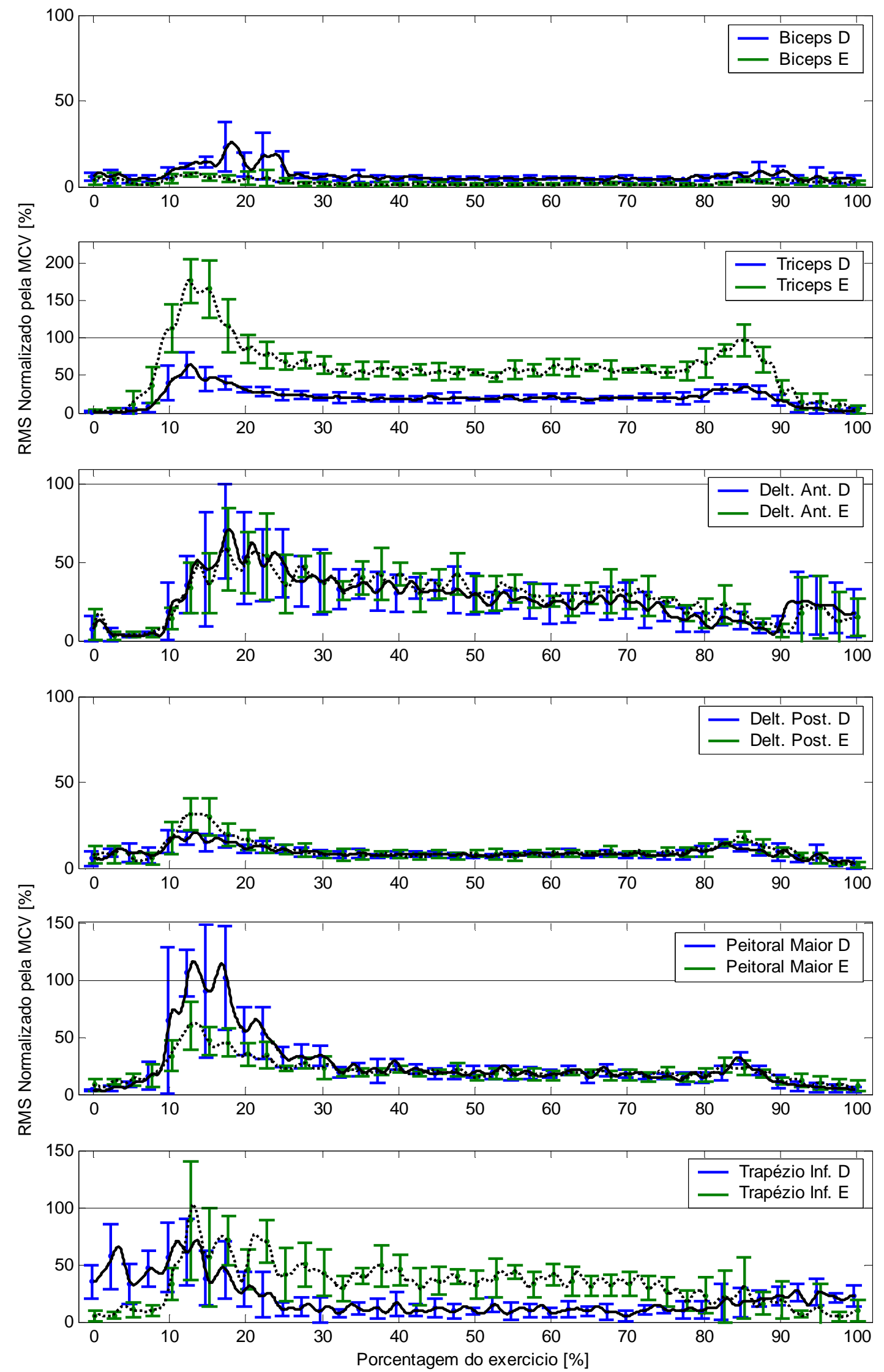

Fig. A12.6 Médias e Desvios Padrões das Atividades Musculares do Paciente 12 durante a Elevação para Alívio da pressão. As linhas tracejadas representam as médias do lado esquerdo. 


\section{A13 - Paciente 13}

\section{A13.1 - PROPUlsão da CADEIRA de Rodas}

Tab. A13.1 - Características dos 3 ciclos iniciais de propulsão da cadeira de rodas

\begin{tabular}{lccc}
\hline & $\begin{array}{c}\text { Tempo } \\
{[\mathrm{s}]}\end{array}$ & $\begin{array}{c}\text { Distância } \\
{[\mathrm{cm}]}\end{array}$ & $\begin{array}{c}\text { Velocidade } \\
{[\mathrm{cm} / \mathrm{s}]}\end{array}$ \\
\hline Média & 3,58 & 161,40 & 45,08 \\
Desvio Padrão & 0,28 & 27,02 & 6,02 \\
\hline
\end{tabular}

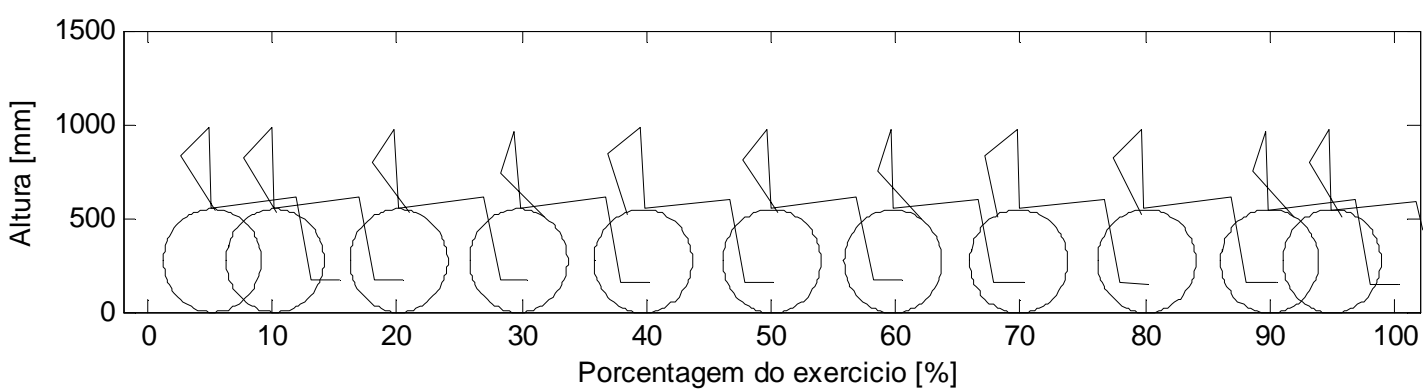

Fig. A13.1 Diagrama do movimento do Paciente 13 durante a Propulsão da Cadeira de Rodas.
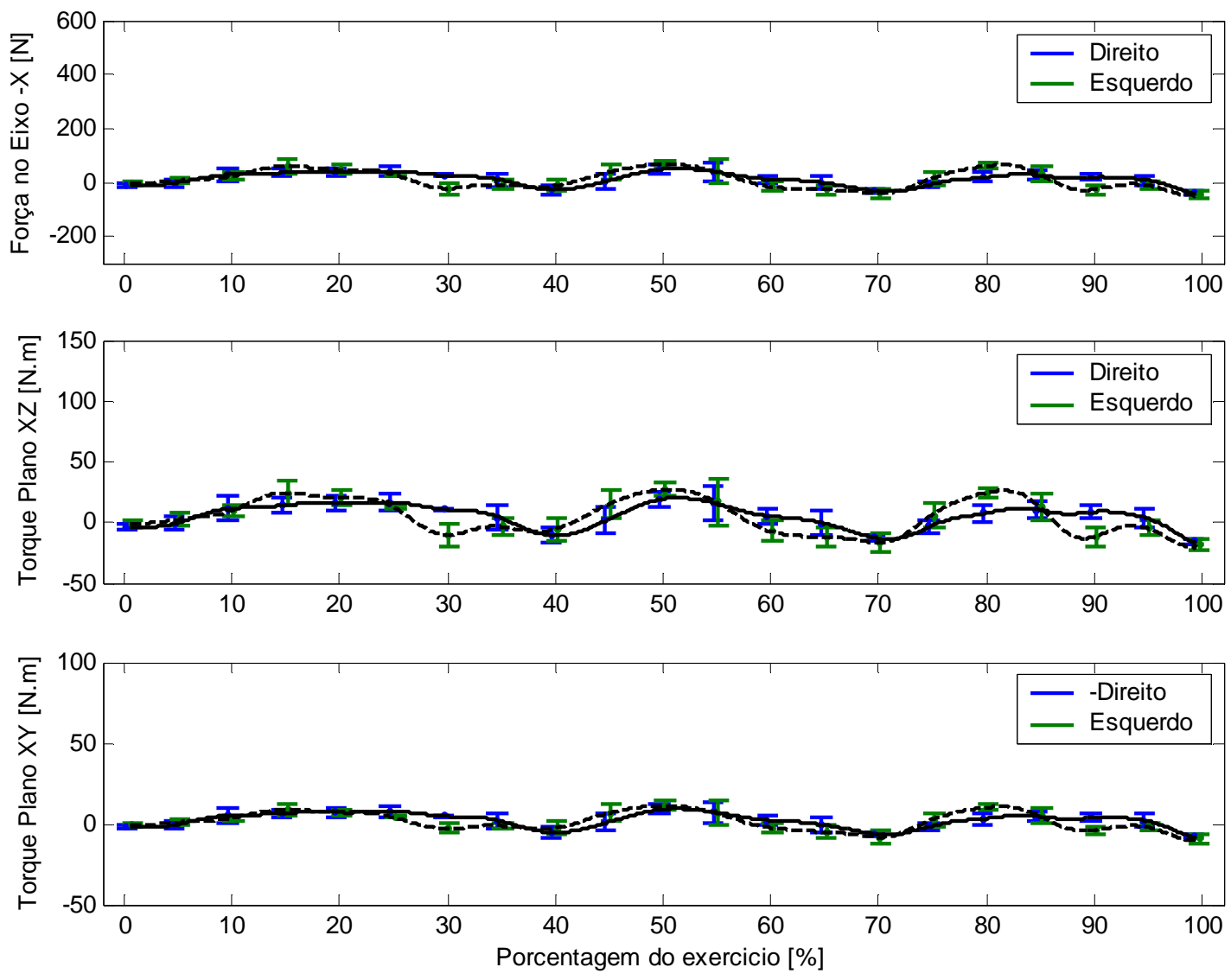

Fig. A13.2 Médias e Desvios Padrões dos Dados Cinéticos do Paciente 13 durante a Propulsão da Cadeira de Rodas. As linhas tracejadas representam as médias do lado esquerdo. 

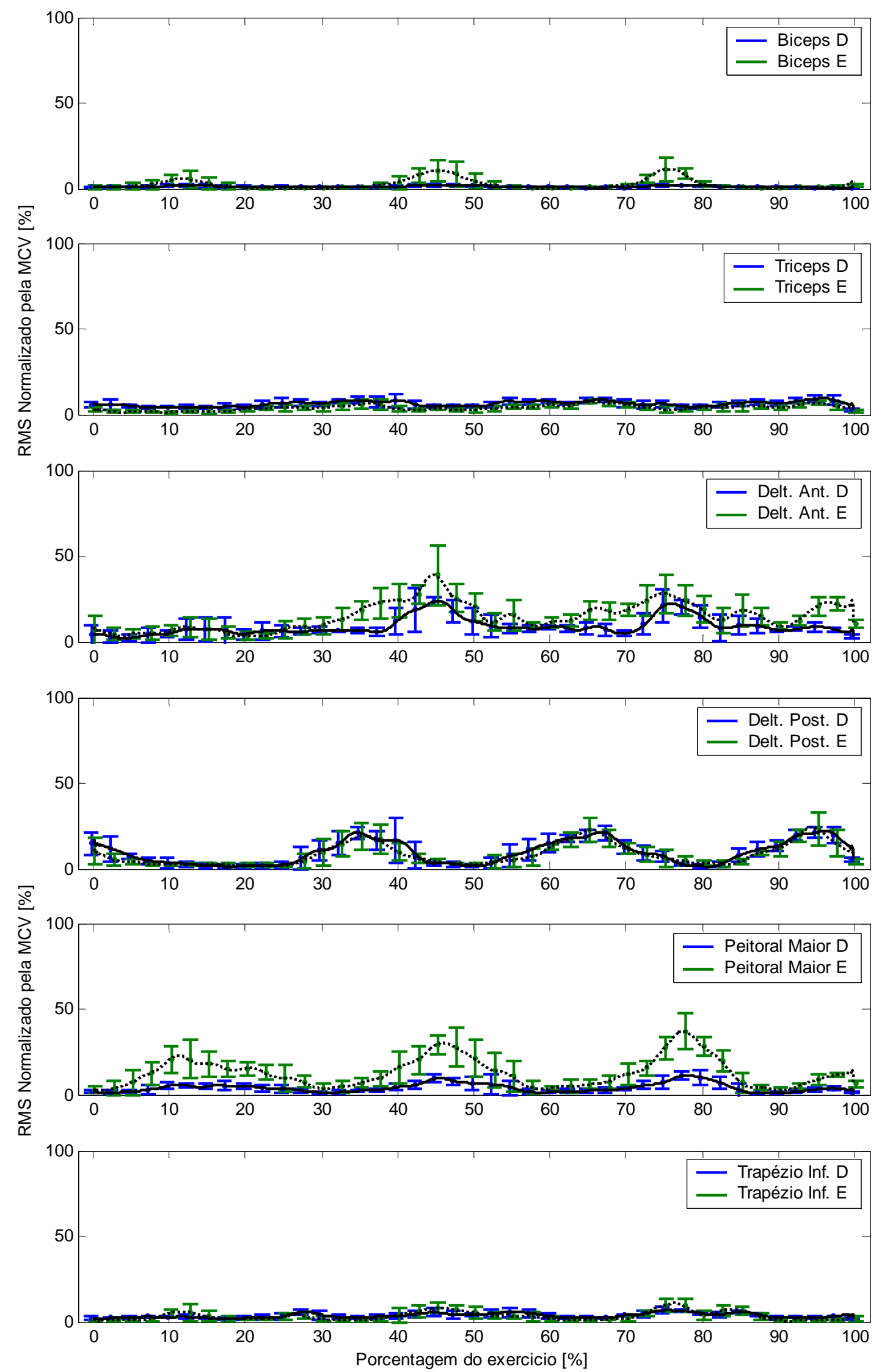

Fig. A13.3 Médias e Desvios Padrões das Atividades Musculares do Paciente 13 durante a Propulsão da Cadeira de Rodas. As linhas tracejadas representam as médias do lado esquerdo. 


\section{A13.2 - EleVAÇÃo para AlívIO da PRESSÃo}

Tab. A13.2 - Características da elevação para alívio da pressão

\begin{tabular}{lcc}
\hline & Tempo & $\begin{array}{c}\text { Elevação } \\
{[\mathrm{s}]}\end{array}$ \\
\hline $\mathrm{cm}]$ \\
\hline Média & 6,08 & 27,29 \\
Desvio Padrão & 0,26 & 0,39 \\
\hline
\end{tabular}

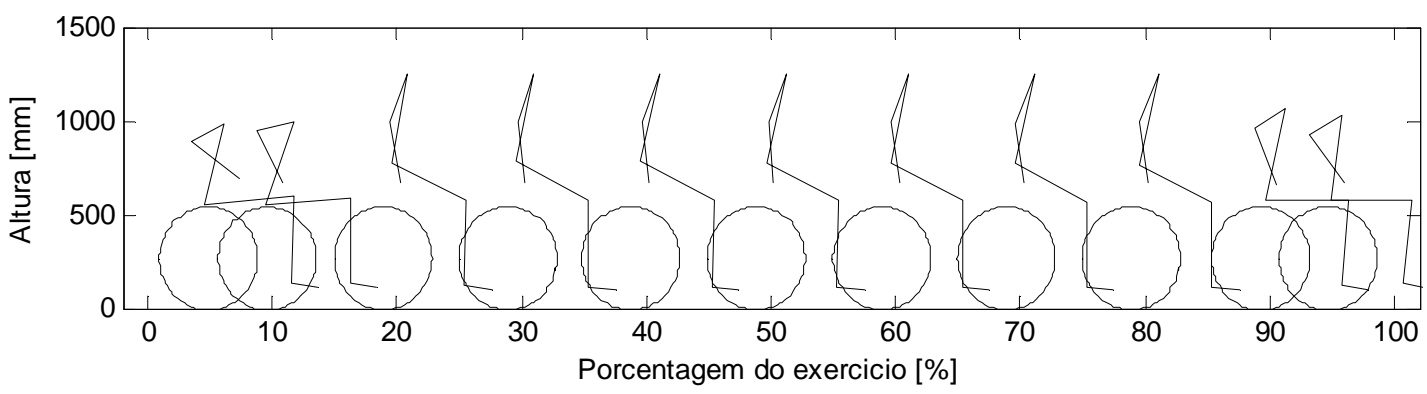

Fig. A13.4 Diagrama do movimento do Paciente 13 durante a Elevação para Alívio da pressão.
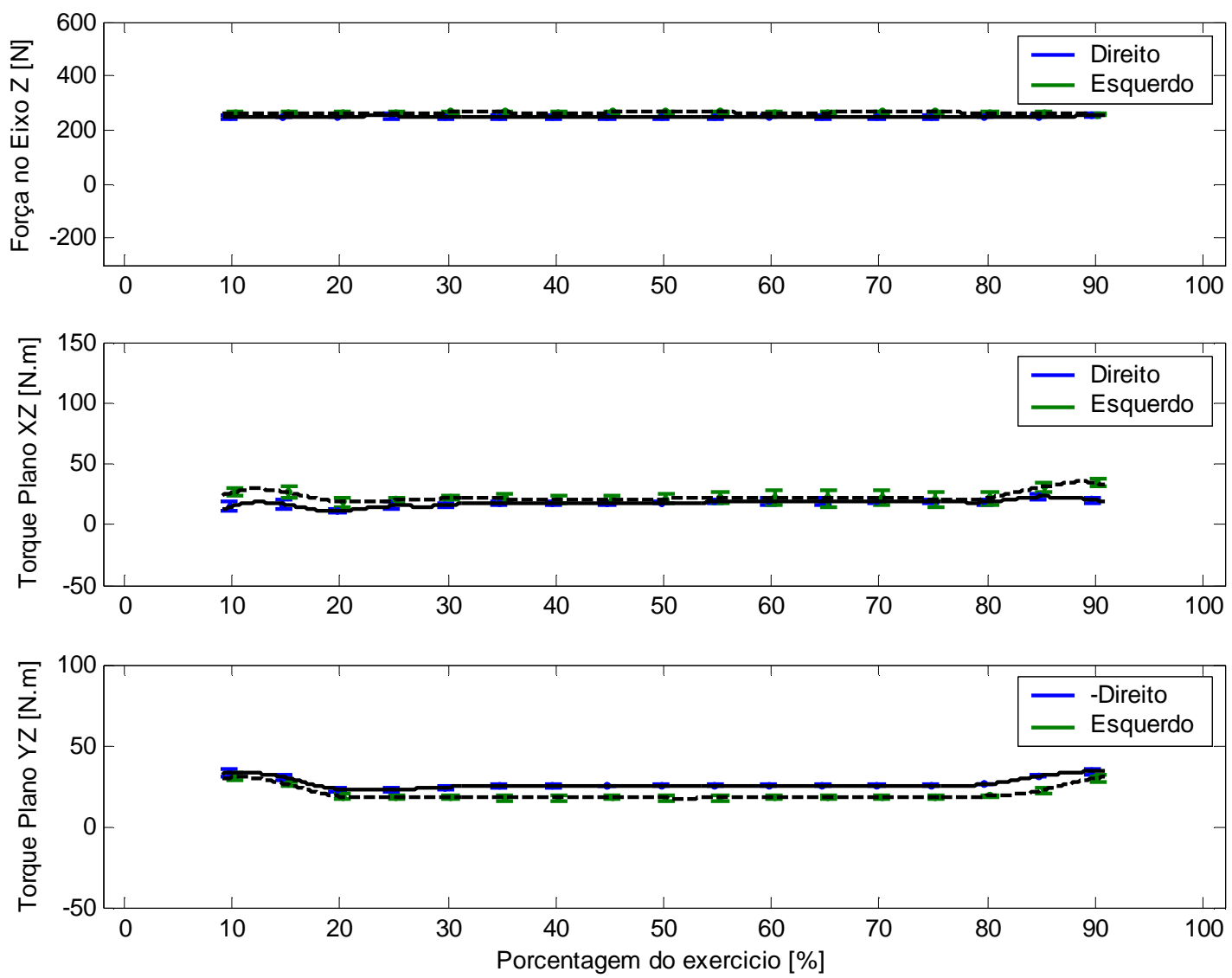

Fig. A13.5 Médias e Desvios Padrões dos Dados Cinéticos do Paciente 13 durante a Elevação para Alívio da pressão. As linhas tracejadas representam as médias do lado esquerdo. 

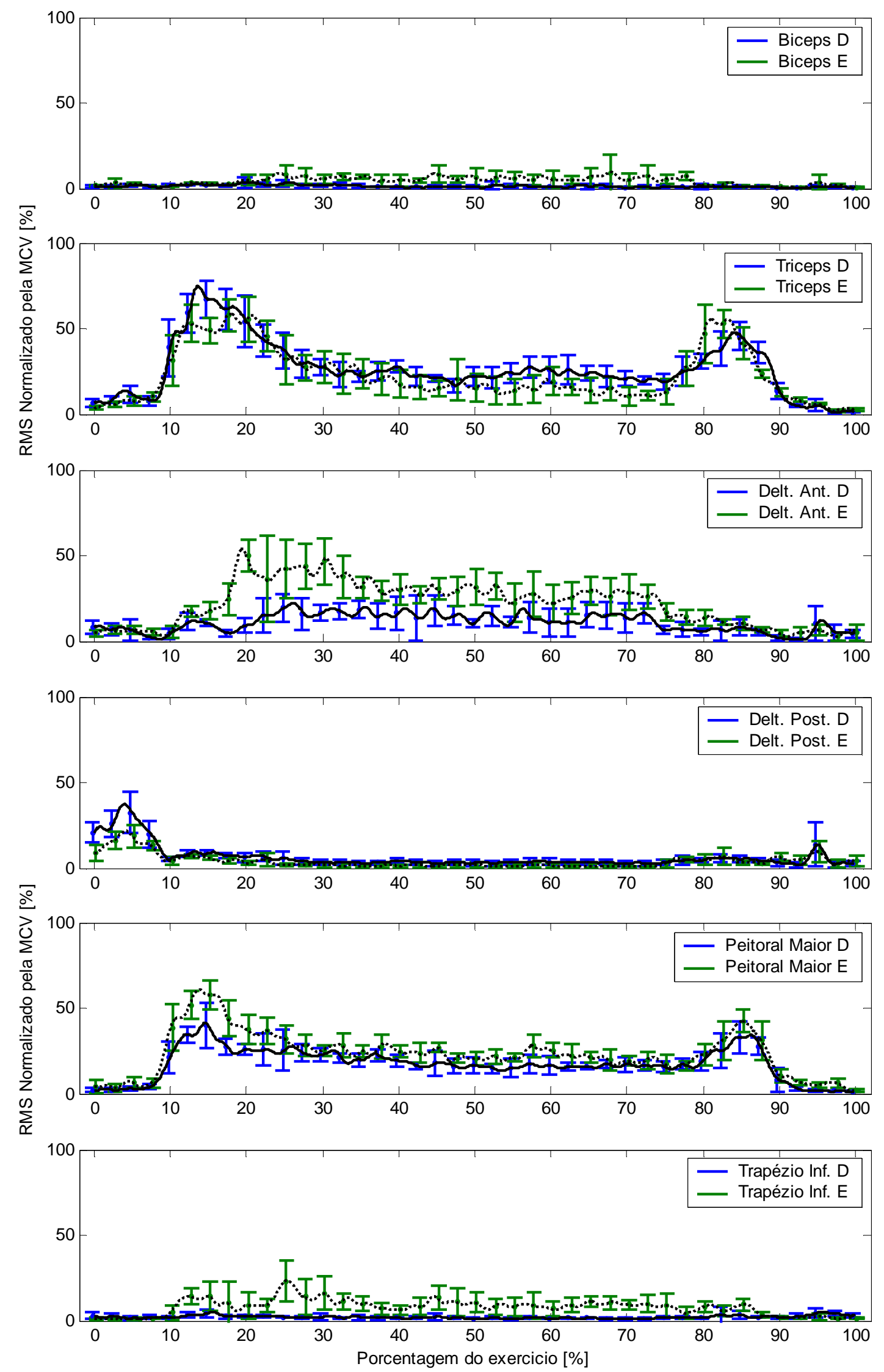

Fig. A13.6 Médias e Desvios Padrões das Atividades Musculares do Paciente 13 durante a Elevação para Alívio da pressão. As linhas tracejadas representam as médias do lado esquerdo. 


\section{A13.3 - MARCHA COM ANDADOR E EENM}

Tab. A13.3 - Características da passada com andador e EENM

\begin{tabular}{lcccc}
\hline & $\begin{array}{c}\text { Tempo } \\
{[\mathrm{s}]}\end{array}$ & $\begin{array}{c}\text { Passada } \\
{[\mathrm{cm}]}\end{array}$ & $\begin{array}{c}\text { Velocidade } \\
{[\mathrm{cm} / \mathrm{s}]}\end{array}$ & $\begin{array}{c}\text { Cadência } \\
\text { [passos/min] }\end{array}$ \\
\hline Média & 4,07 & 54,69 & 13,46 & 29,55 \\
Desvio Padrão & 0,17 & 4,18 & 1,14 & 1,29 \\
\hline
\end{tabular}

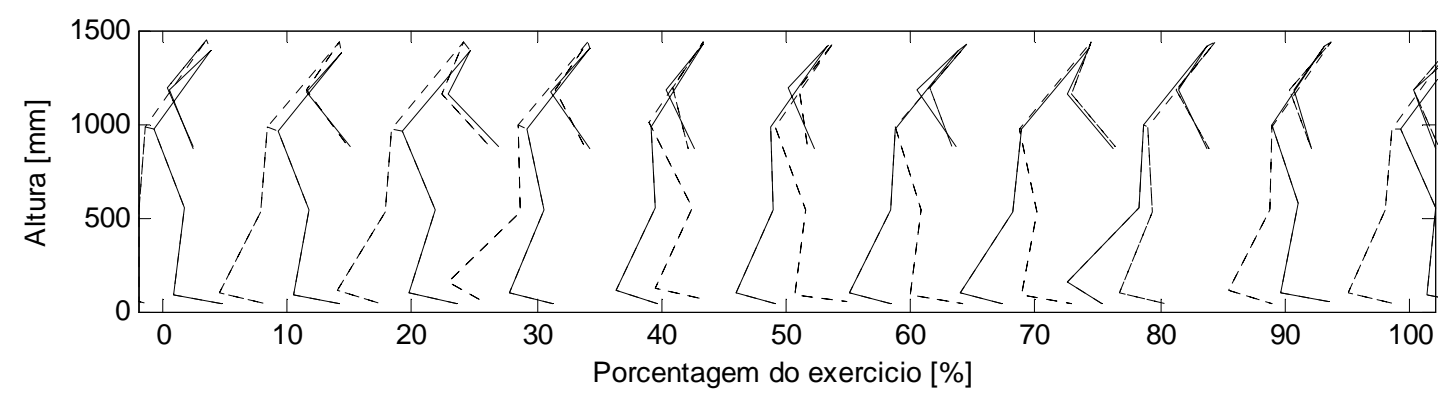

Fig. A13.7 Diagrama do movimento do Paciente 13 durante a Marcha com Andador e EENM.
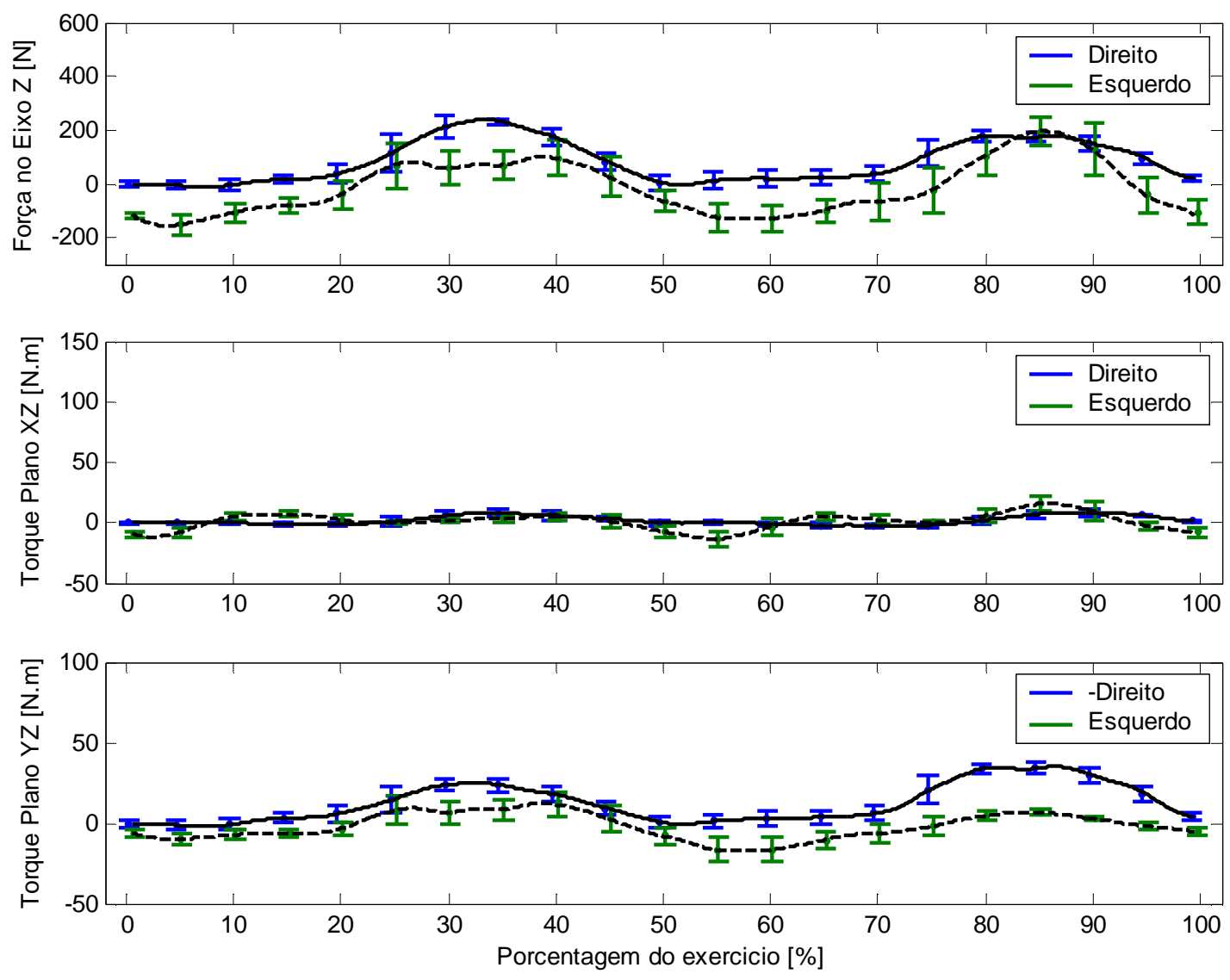

Fig. A13.8 Médias e Desvios Padrões dos Dados Cinéticos do Paciente 13 durante a Marcha com Andador e EENM. As linhas tracejadas representam as médias do lado esquerdo. 

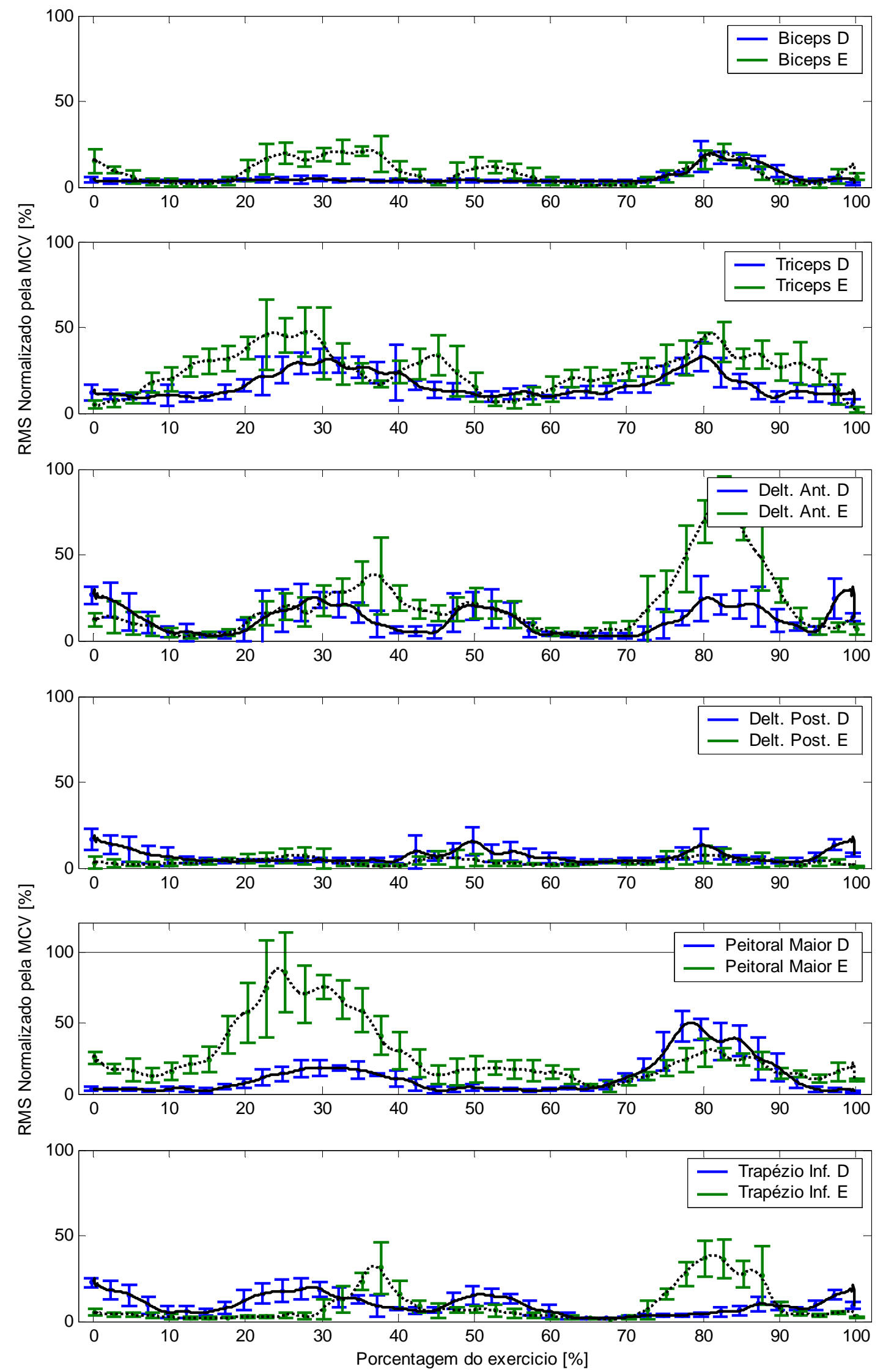

Fig. A13.9 Médias e Desvios Padrões das Atividades Musculares do Paciente 13 durante a Marcha com Andador e EENM. As linhas tracejadas representam as médias do lado esquerdo. 


\section{A14 - Paciente 14}

\section{A14.1 - PRopulsão da CADEIRA de Rodas}

Tab. A14.1 - Características dos 3 ciclos iniciais de propulsão da cadeira de rodas

\begin{tabular}{lccc}
\hline & $\begin{array}{c}\text { Tempo } \\
{[\mathrm{s}]}\end{array}$ & $\begin{array}{c}\text { Distância } \\
{[\mathrm{cm}]}\end{array}$ & $\begin{array}{c}\text { Velocidade } \\
{[\mathrm{cm} / \mathrm{s}]}\end{array}$ \\
\hline Média & 4,51 & 247,83 & 55,60 \\
Desvio Padrão & 0,45 & 29,91 & 9,99 \\
\hline
\end{tabular}

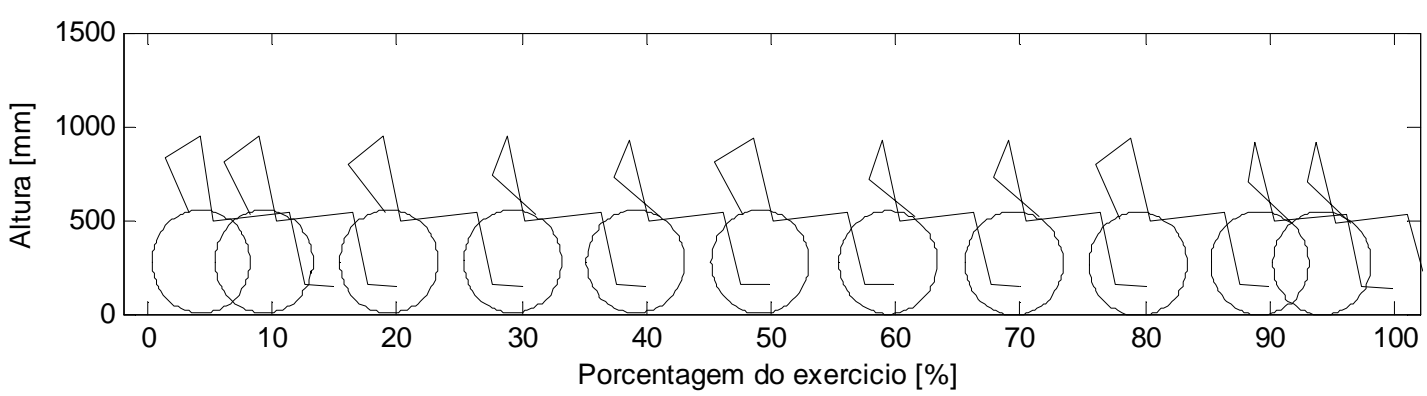

Fig. A14.1 Diagrama do movimento do Paciente 14 durante a Propulsão da Cadeira de Rodas.
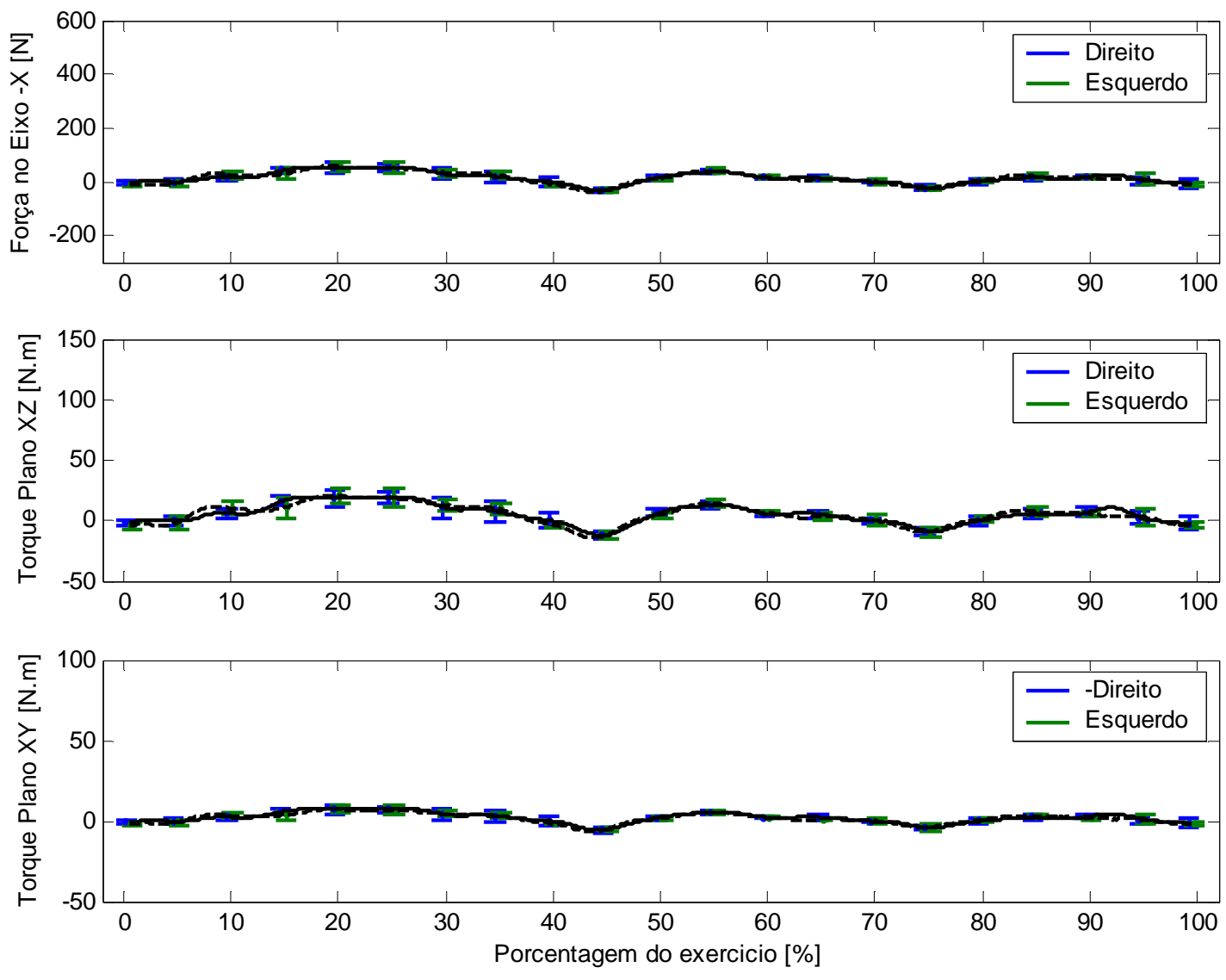

Fig. A14.2 Médias e Desvios Padrões dos Dados Cinéticos do Paciente 14 durante a Propulsão da Cadeira de Rodas. As linhas tracejadas representam as médias do lado esquerdo. 

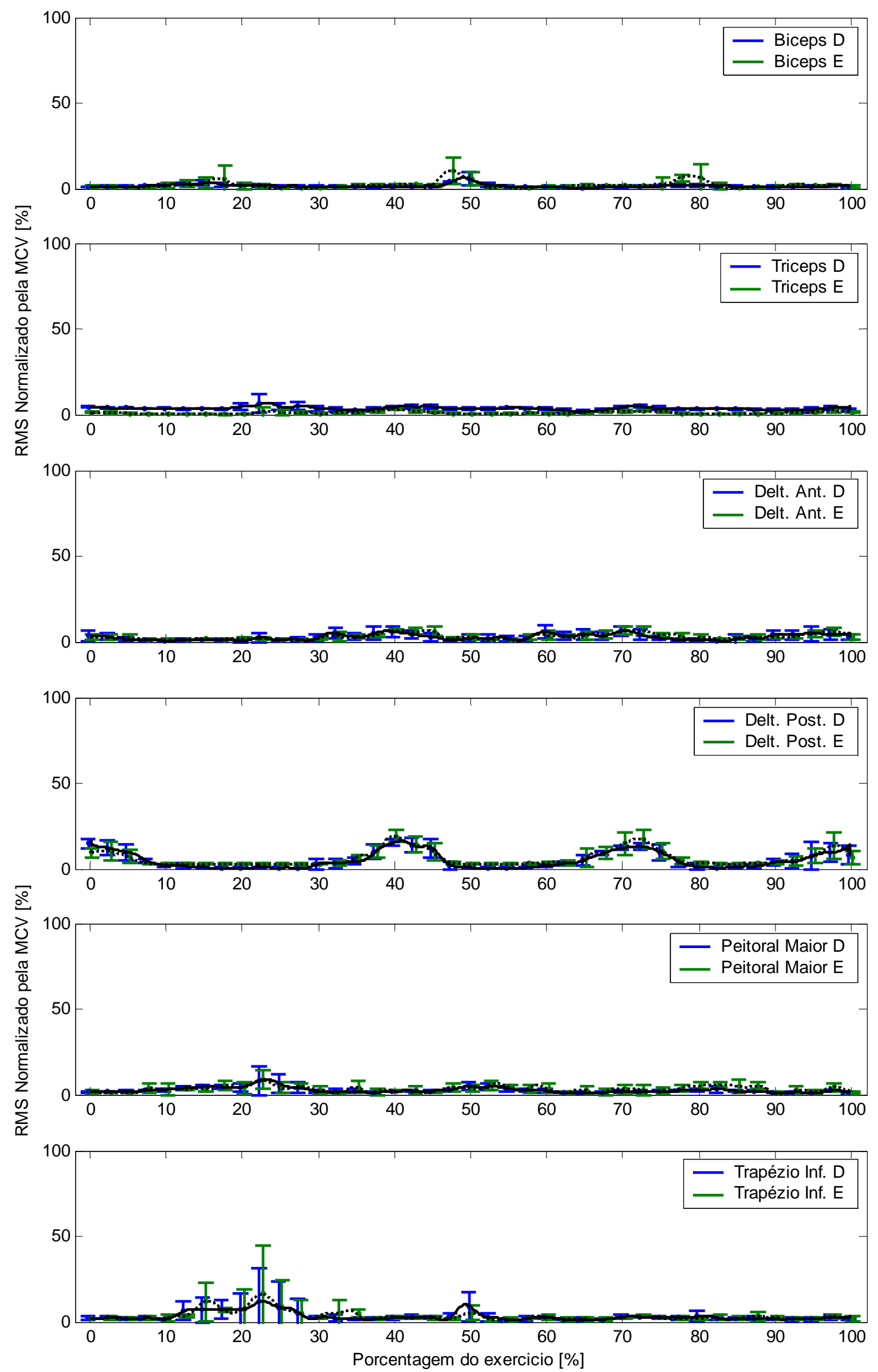

Fig. A14.3 Médias e Desvios Padrões das Atividades Musculares do Paciente 14 durante a Propulsão da Cadeira de Rodas. As linhas tracejadas representam as médias do lado esquerdo. 


\section{A14.2 - Elevação para Alívio da PRESsão}

Tab. A14.2 - Características da elevação para alívio da pressão

\begin{tabular}{lcc}
\hline & $\begin{array}{c}\text { Tempo } \\
{[\mathrm{s}]}\end{array}$ & $\begin{array}{c}\text { Elevação } \\
{[\mathrm{cm}]}\end{array}$ \\
\hline Média & 6,16 & 21,13 \\
Desvio Padrão & 0,45 & 1,34 \\
\hline
\end{tabular}

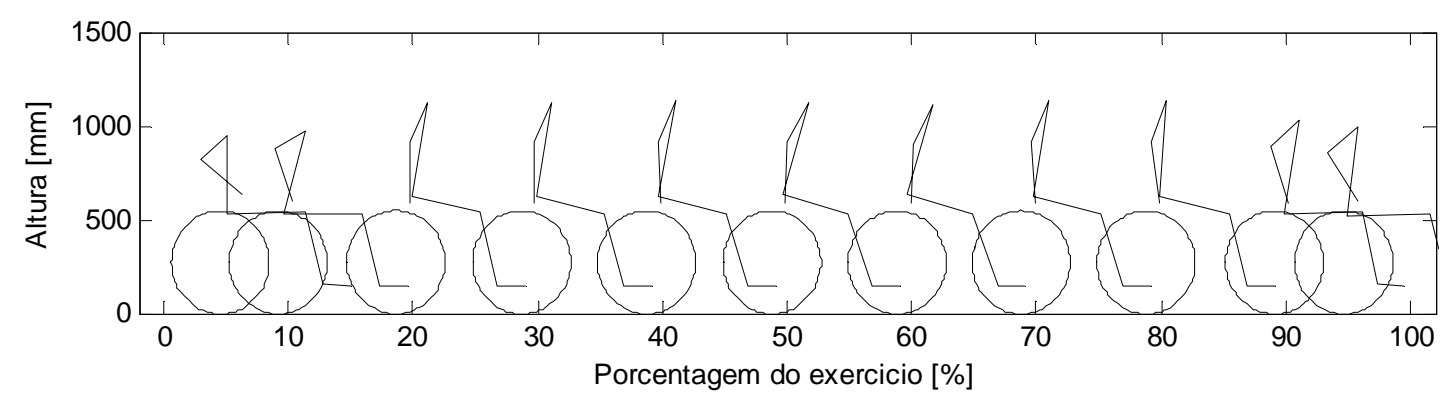

Fig. A14.4 Diagrama do movimento do Paciente 14 durante a Elevação para Alívio da pressão.
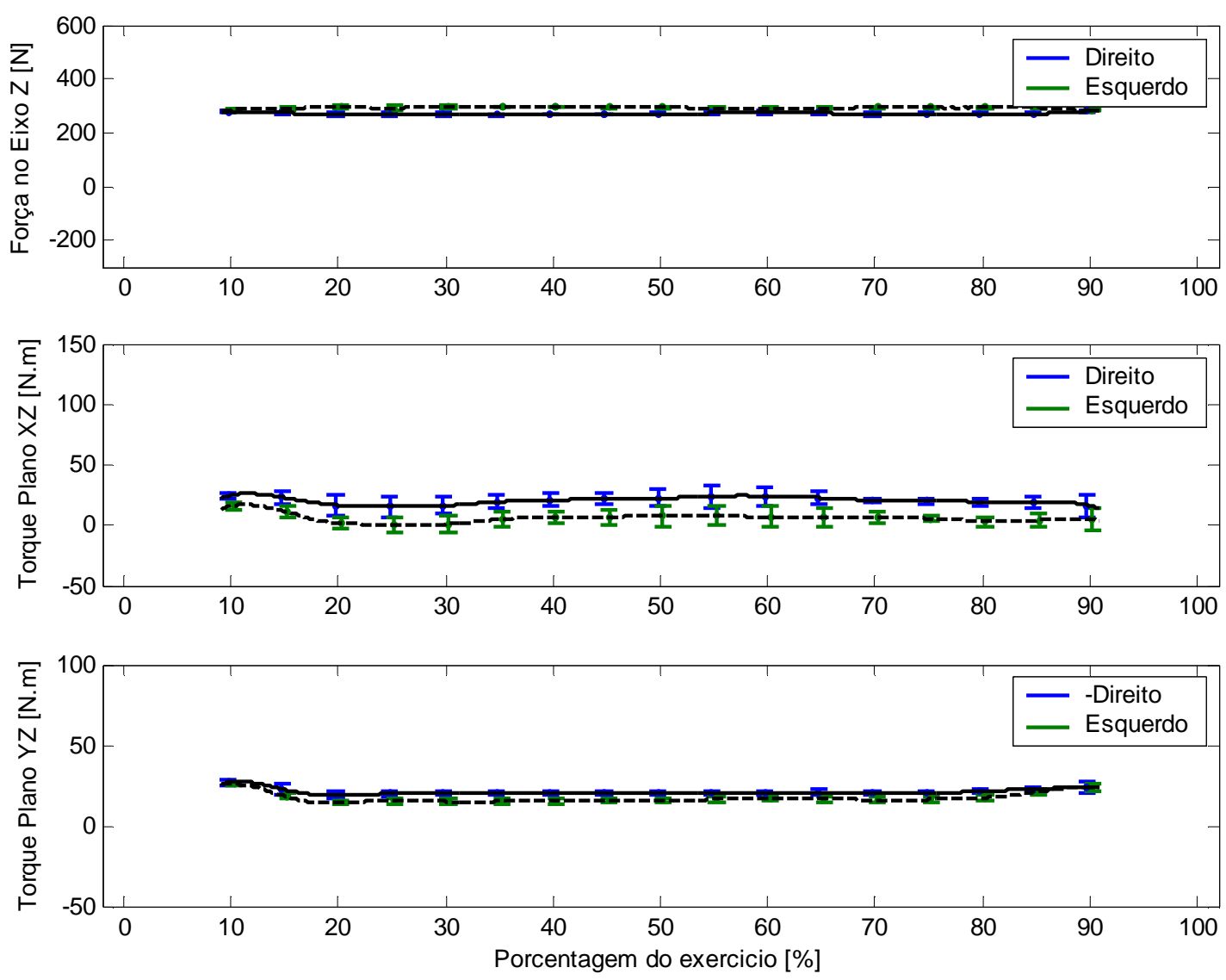

Fig. A14.5 Médias e Desvios Padrões dos Dados Cinéticos do Paciente 14 durante a Elevação para Alívio da pressão. As linhas tracejadas representam as médias do lado esquerdo. 

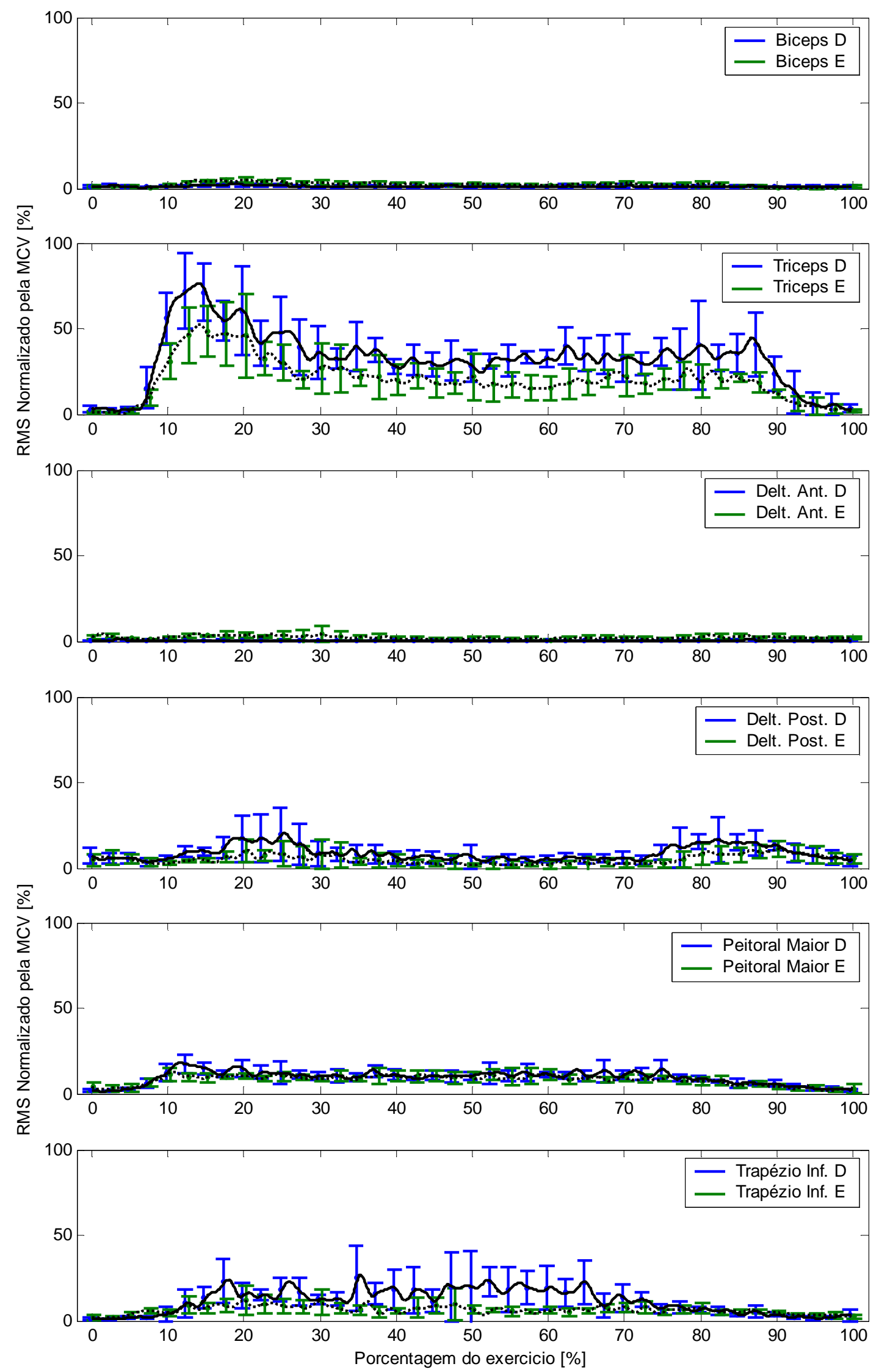

Fig. A14.6 Médias e Desvios Padrões das Atividades Musculares do Paciente 14 durante a Elevação para Alívio da pressão. As linhas tracejadas representam as médias do lado esquerdo. 


\section{A14.3 - MARCHA COM ANDADOR E EENM}

Tab. A14.3 - Características da passada com andador e EENM

\begin{tabular}{lcccc}
\hline & $\begin{array}{c}\text { Tempo } \\
{[\mathrm{s}]}\end{array}$ & $\begin{array}{c}\text { Passada } \\
{[\mathrm{cm}]}\end{array}$ & $\begin{array}{c}\text { Velocidade } \\
{[\mathrm{cm} / \mathrm{s}]}\end{array}$ & $\begin{array}{c}\text { Cadência } \\
\text { [passos/min] }\end{array}$ \\
\hline Média & 5,01 & 68,73 & 13,80 & 24,00 \\
Desvio Padrão & 0,26 & 8,05 & 2,10 & 1,23 \\
\hline
\end{tabular}

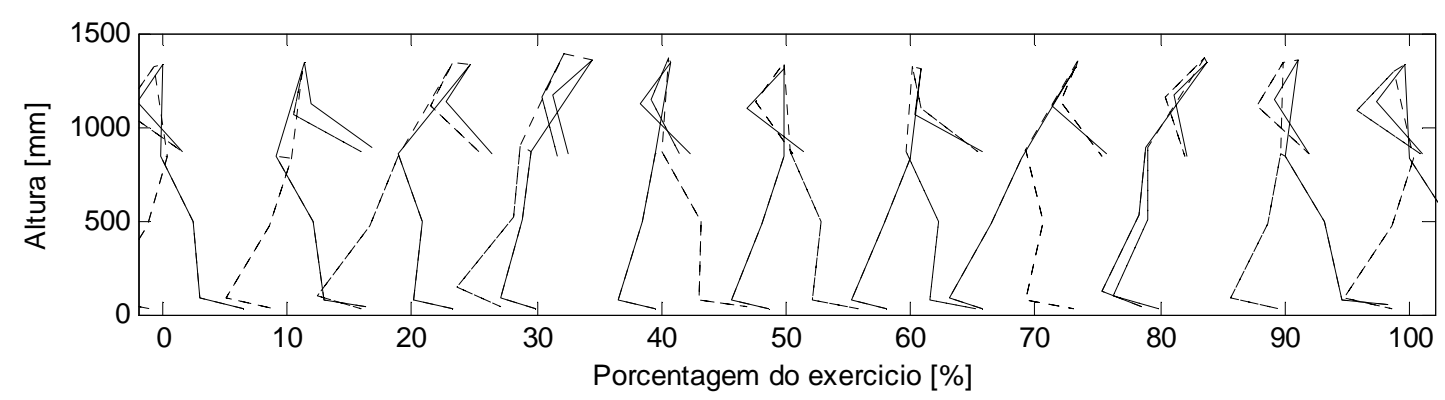

Fig. A14.7 Diagrama do movimento do Paciente 14 durante a Marcha com Andador e EENM.
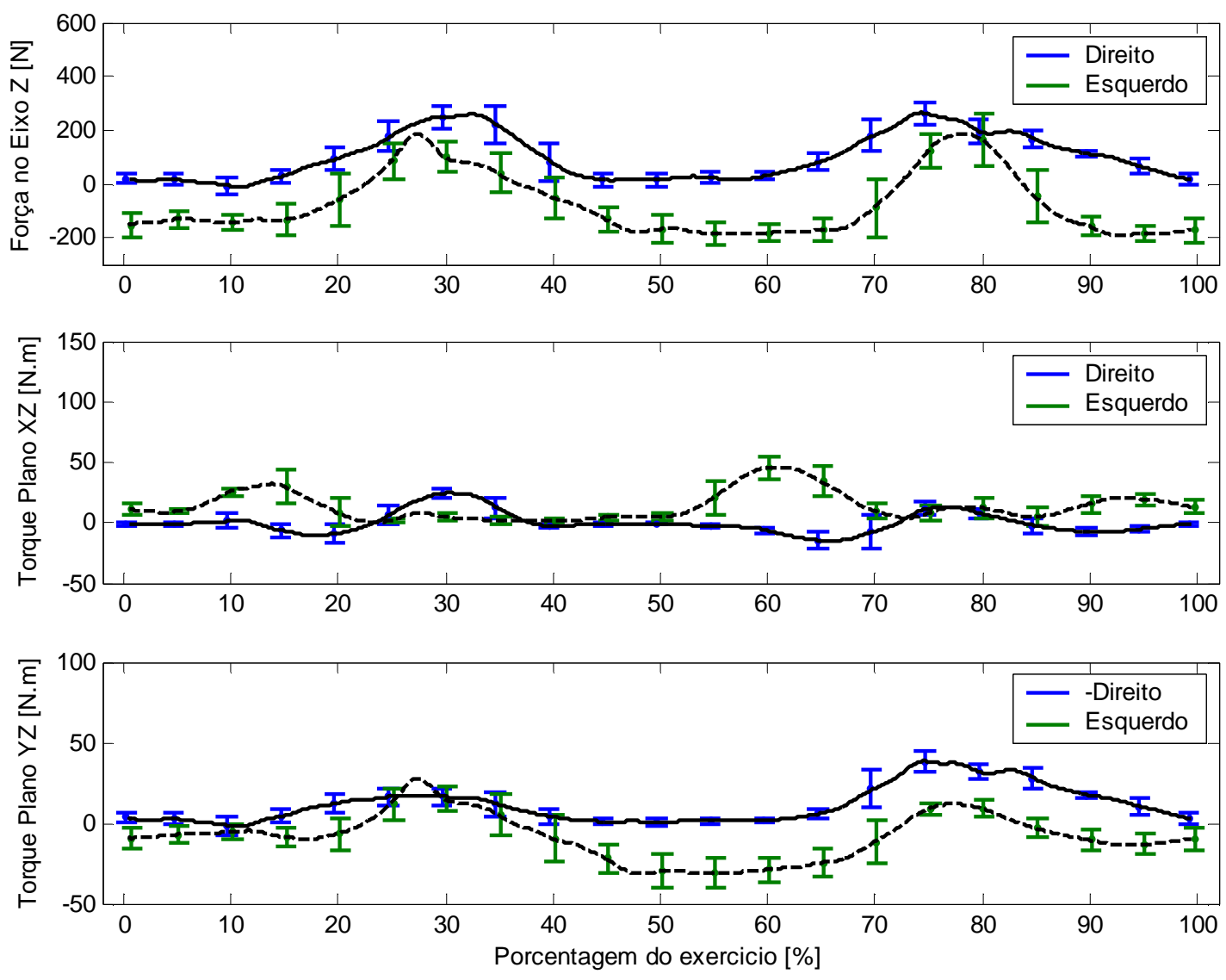

Fig. A14.8 Médias e Desvios Padrões dos Dados Cinéticos do Paciente 14 durante a Marcha com Andador e EENM. As linhas tracejadas representam as médias do lado esquerdo. 

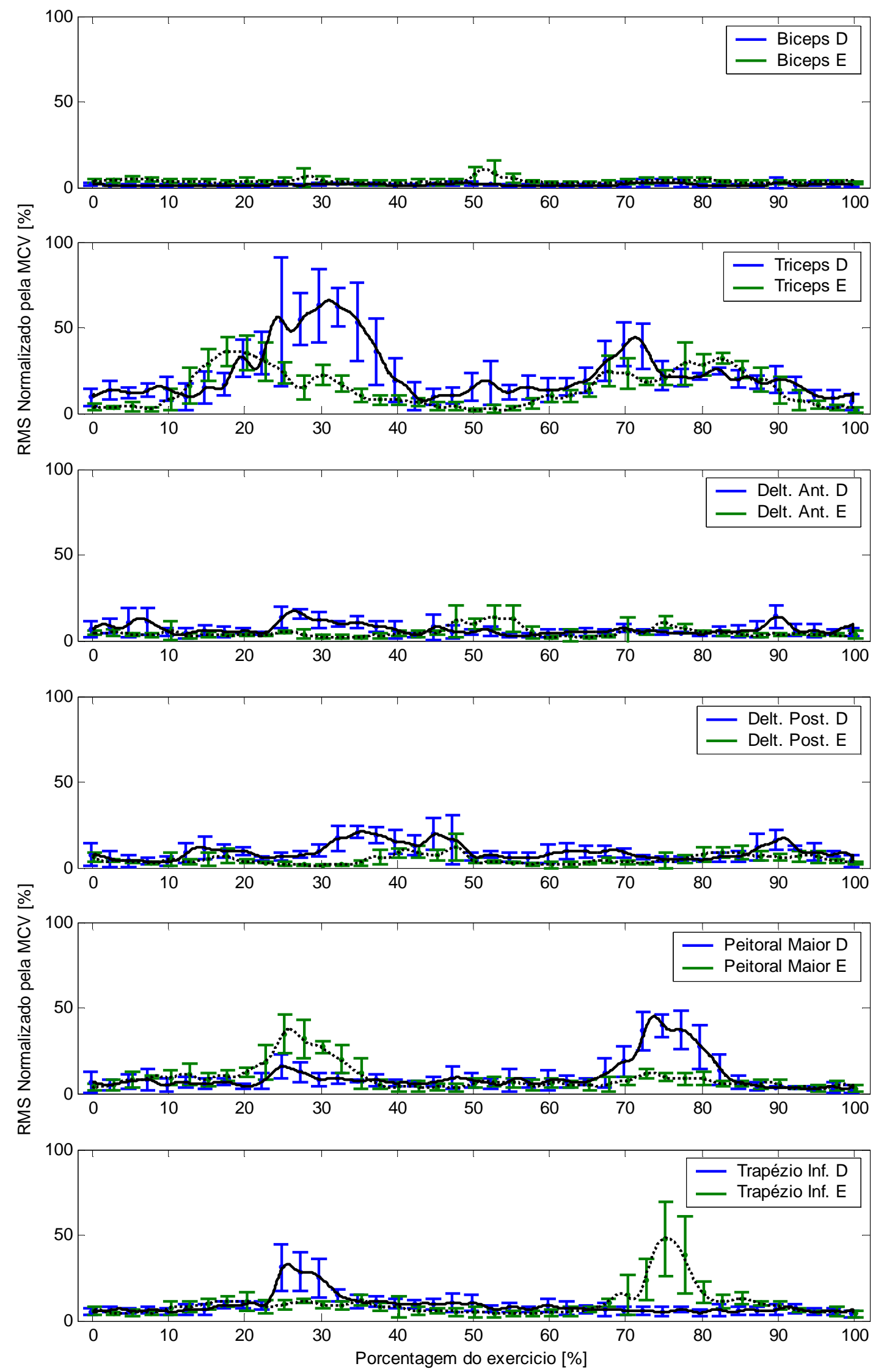

Fig. A14.9 Médias e Desvios Padrões das Atividades Musculares do Paciente 14 durante a Marcha com Andador e EENM. As linhas tracejadas representam as médias do lado esquerdo. 


\section{A15 - Paciente 15}

Exame realizado 03/02/2007

\section{A15.1 - PRopulsão da CADEIRA de RodAs}

Tab. A15.1 - Características dos 3 ciclos iniciais de propulsão da cadeira de rodas

\begin{tabular}{lccc}
\hline & $\begin{array}{c}\text { Tempo } \\
{[\mathrm{s}]}\end{array}$ & $\begin{array}{c}\text { Distância } \\
{[\mathrm{cm}]}\end{array}$ & $\begin{array}{c}\text { Velocidade } \\
{[\mathrm{cm} / \mathrm{s}]}\end{array}$ \\
\hline Média & 3,48 & 205,65 & 59,08 \\
Desvio Padrão & 0,22 & 50,06 & 13,88 \\
\hline
\end{tabular}

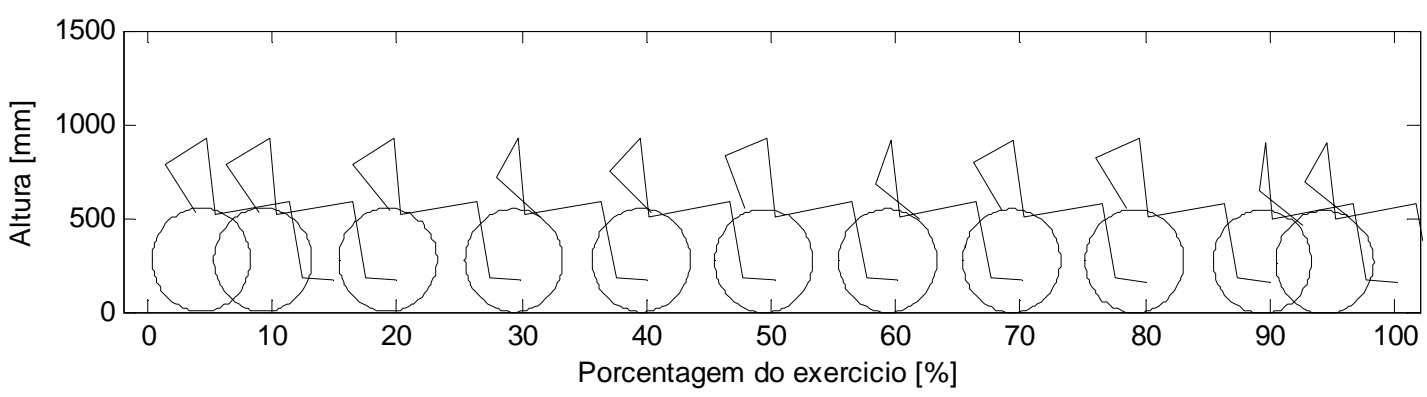

Fig. A15.1 Diagrama do movimento do Paciente 15 durante a Propulsão da Cadeira de Rodas.
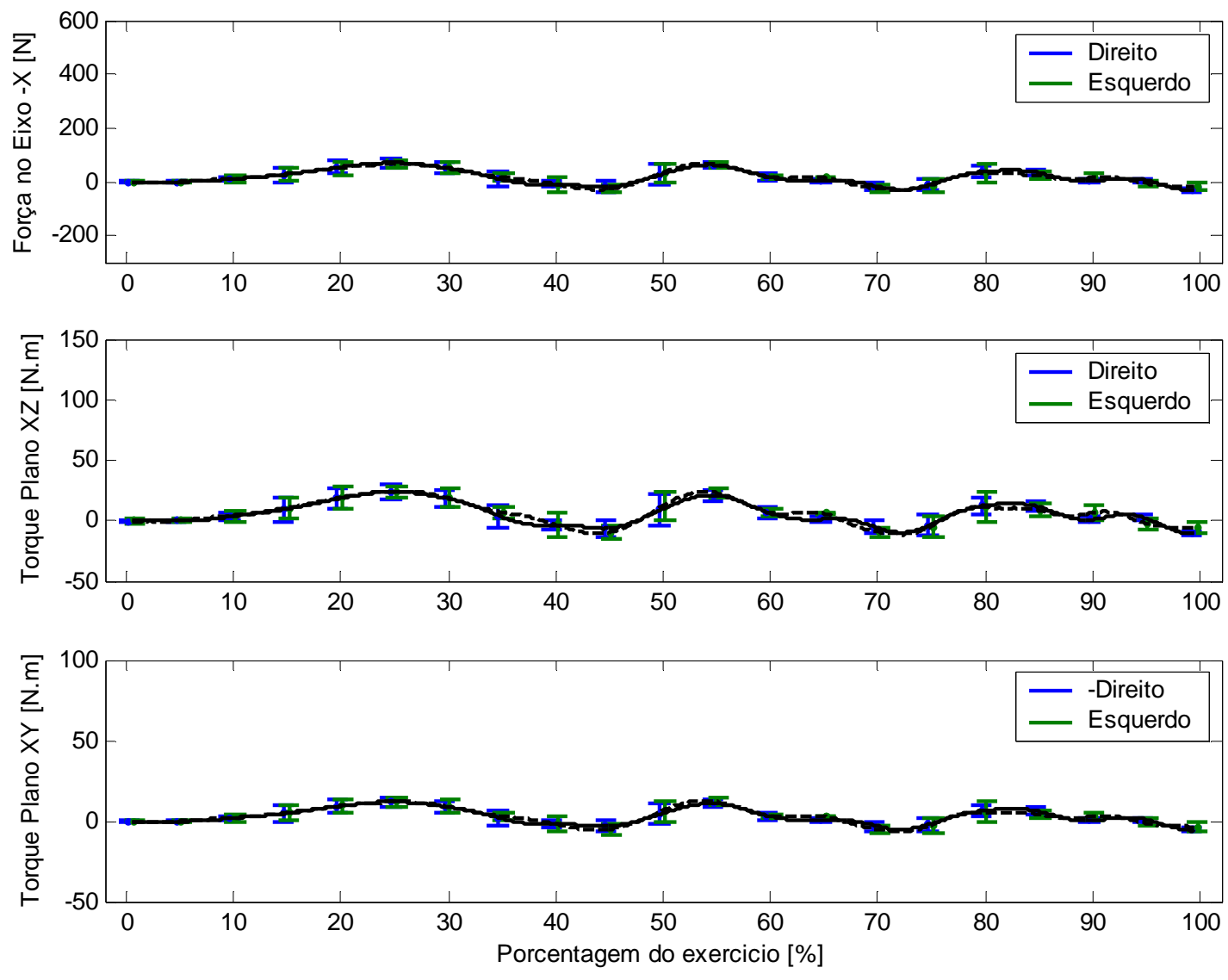

Fig. A15.2 Médias e Desvios Padrões dos Dados Cinéticos do Paciente 15 durante a Propulsão da Cadeira de Rodas. As linhas tracejadas representam as médias do lado esquerdo. 

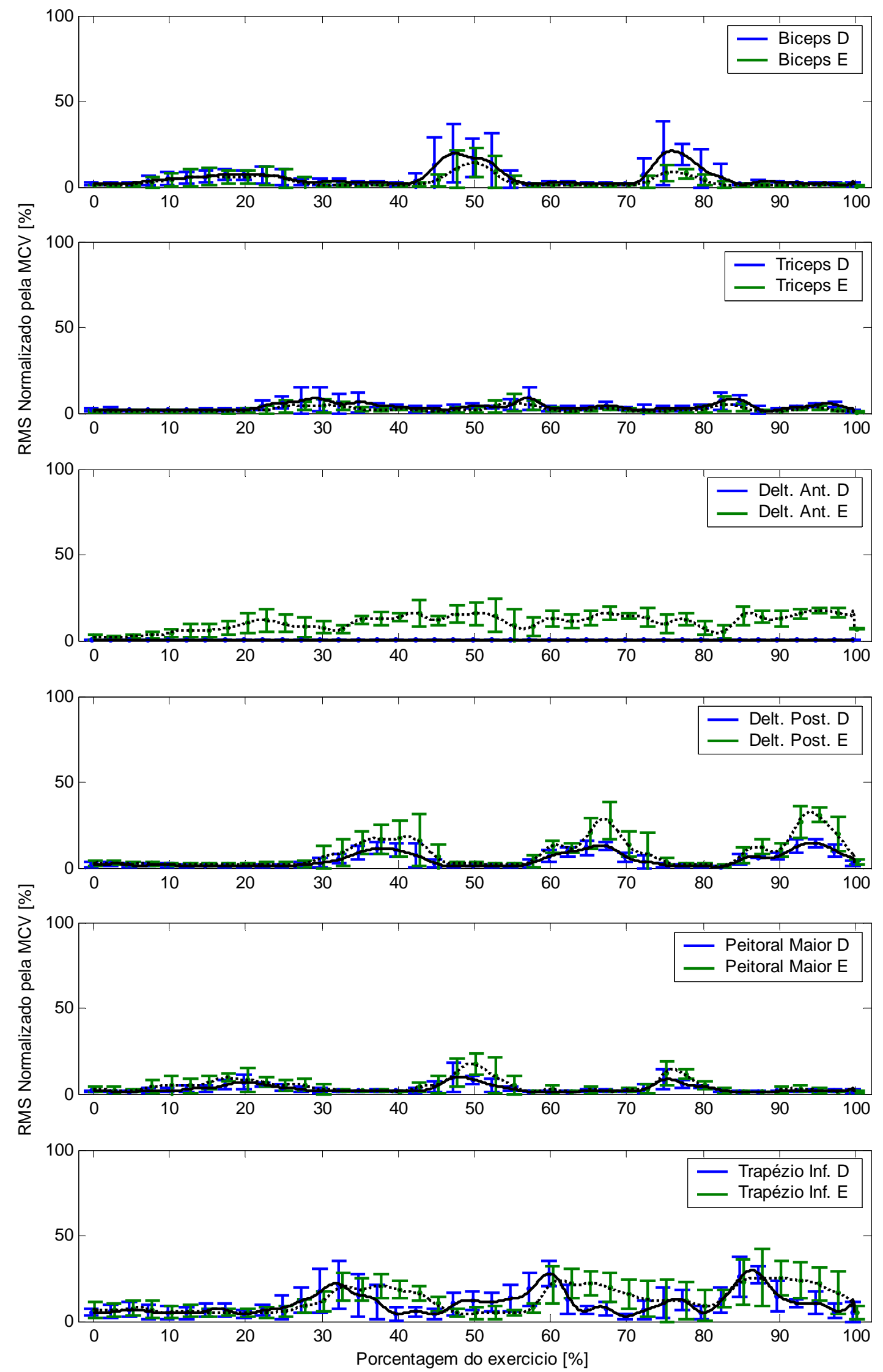

Fig. A15.3 Médias e Desvios Padrões das Atividades Musculares do Paciente 15 durante a Propulsão da Cadeira de Rodas. As linhas tracejadas representam as médias do lado esquerdo. 


\section{A15.2 - Elevação para Alívio da PRESsão}

Tab. A15.2 - Características da elevação para alívio da pressão

\begin{tabular}{lcc}
\hline & $\begin{array}{c}\text { Tempo } \\
{[\mathrm{s}]}\end{array}$ & $\begin{array}{c}\text { Elevação } \\
{[\mathrm{cm}]}\end{array}$ \\
\hline Média & 7,19 & 27,06 \\
Desvio Padrão & 0,34 & 0,93 \\
\hline
\end{tabular}

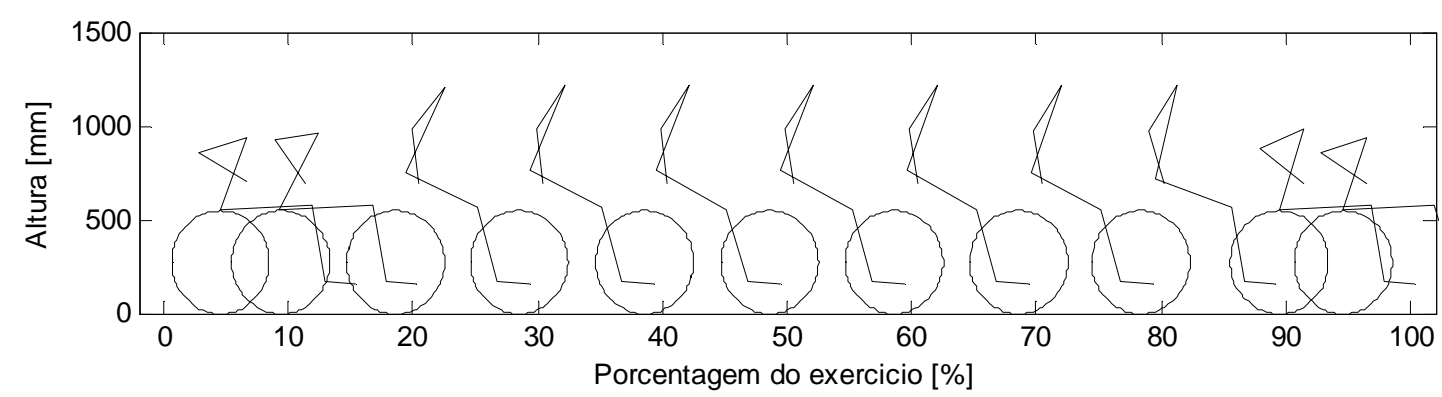

Fig. A15.4 Diagrama do movimento do Paciente 15 durante a Elevação para Alívio da pressão.
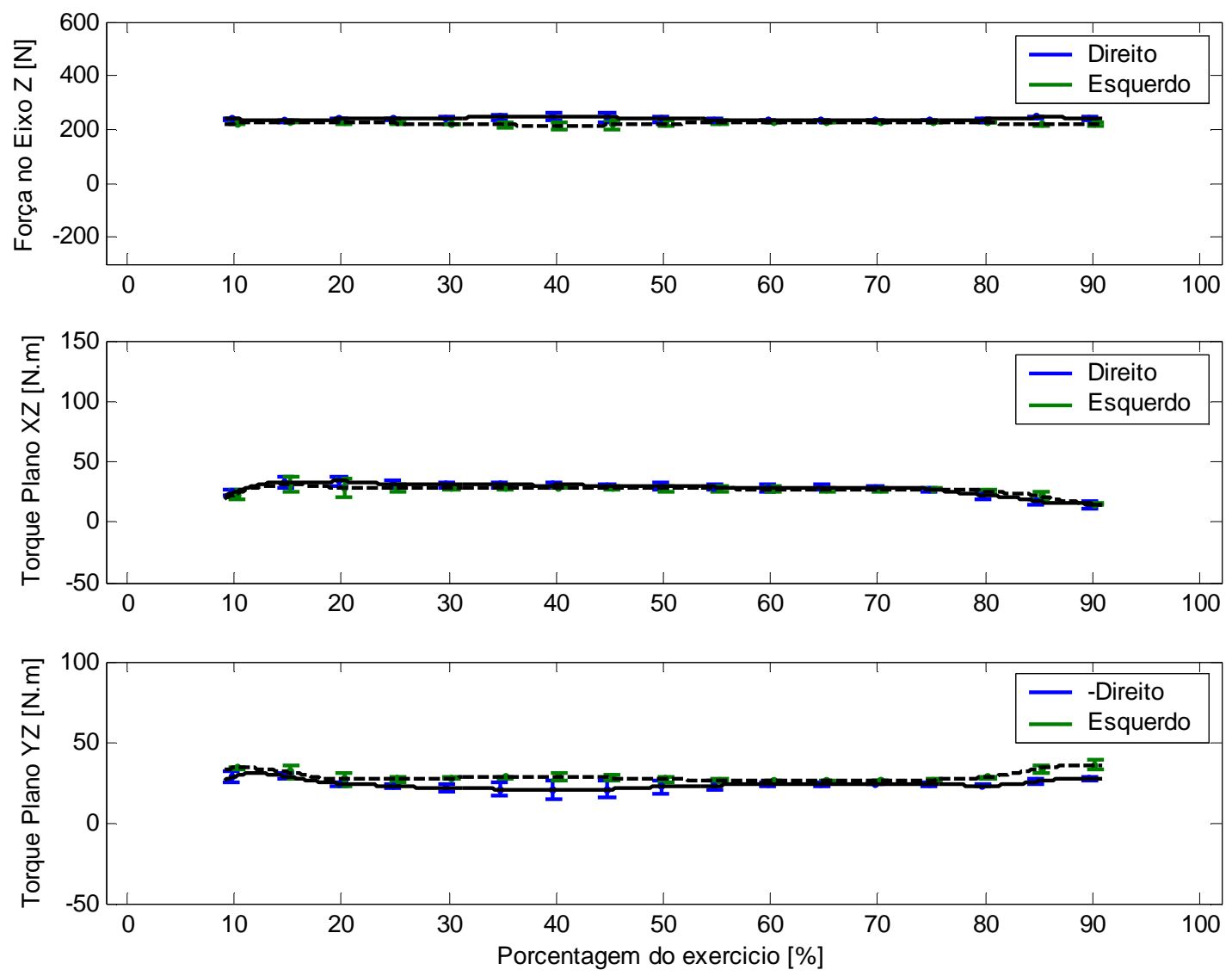

Fig. A15.5 Médias e Desvios Padrões dos Dados Cinéticos do Paciente 15 durante a Elevação para Alívio da pressão. As linhas tracejadas representam as médias do lado esquerdo. 

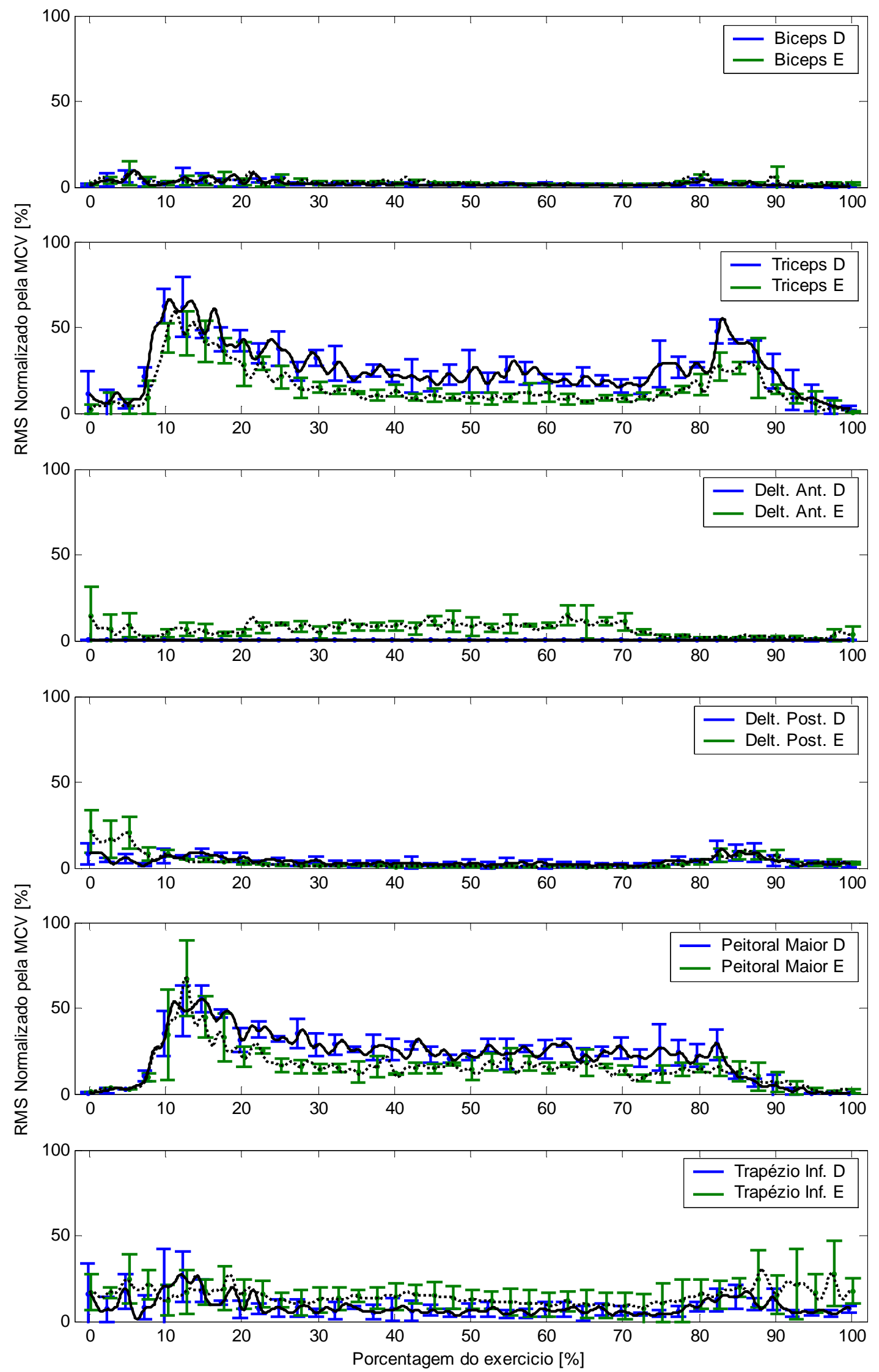

Fig. A15.6 Médias e Desvios Padrões das Atividades Musculares do Paciente 15 durante a Elevação para Alívio da pressão. As linhas tracejadas representam as médias do lado esquerdo. 


\section{Anexo - ASIA}

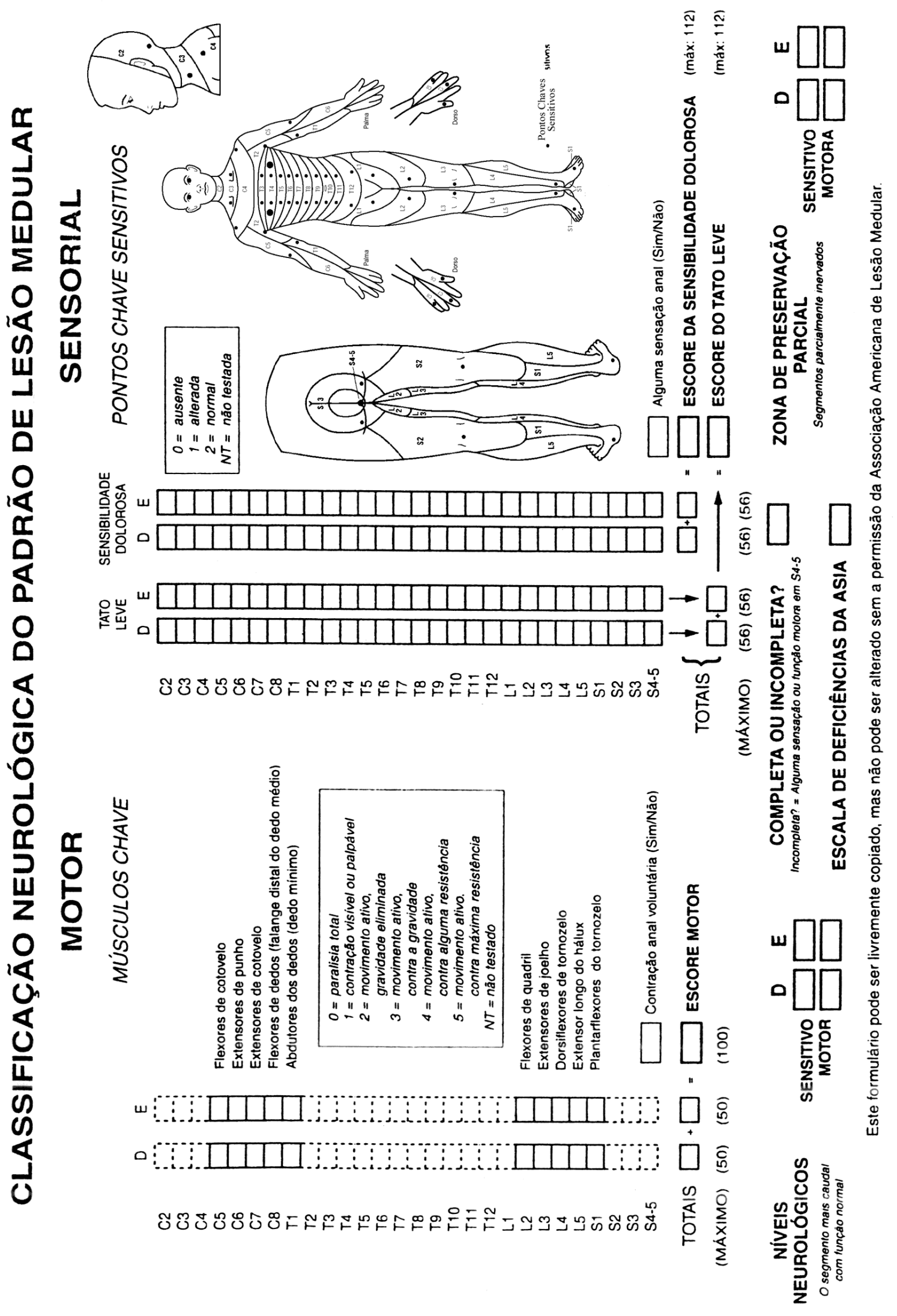

